SAND93-1342

Unlimited Release

Distribution

Printed August 1993

Category UC -132

\title{
Rationale for Finding and Exploiting Fractured Reservoirs, Based on the MWX/SHCT-Piceance Basin Experience
}

\author{
John C. Lorenz \\ Geomechanics Department \\ Norman R. Warpinski \\ Geotechnology Research Department \\ Lawrence W. Teufel \\ Geomechanics Department \\ Sandia National Laboratories \\ Albuquerque, NM 87185
}

\begin{abstract}
The deliverability of a reservoir depends primarily on its permeability, which, in many reservoirs, is controlled by a combination of natural fractures and the in situ stresses. Therefore it is important to be able to predict which parts of a basin are most likely to contain naturally fractured strata, what the characteristics of those fractures might be, and what the most likely in situ stresses are at a given location. This paper presents a set of geologic criteria that can be superimposed onto factors, such as levels of maturation and porosity development, in order to predict whether fractures are present once the likelihood of petroleum presence and reservoir development have been determined. Stress causes fracturing, but stresses are not permanent. A natural-fracture permeability pathway opened by one system of stresses may be held open by those stresses, or narrowed or even closed by changes of the stress to an oblique or normal orientation. The origin of stresses and stress anisotropies in a basin, the potential for stress to create natural fractures, and the causes of stress reorientation are examined in this paper. The appendices to this paper present specific techniques for exploiting and characterizing natural fractures, for measuring the present-day in situ stresses, and for reconstructing a computerized stress history for a basin.
\end{abstract}
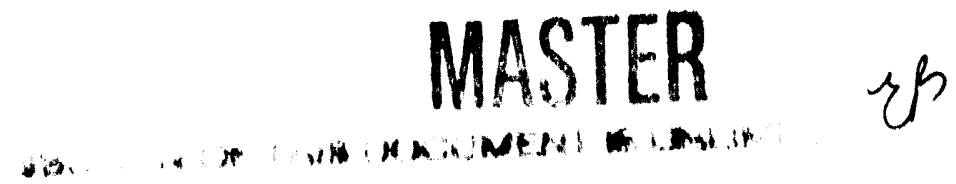


\section{Acknowledgments}

Reviews by James T. Neal and David A. Northrop have improved this manuscript. This work was supported by the U.S. Department of Energy under contract DE-AC04-76DP00789. 


\section{Contents}

Introduction 9

1. Importance of Natural Fractures in Western Basins ................................................. 10

2. Effects of Stresses on Natural Fractures................................................................... 11

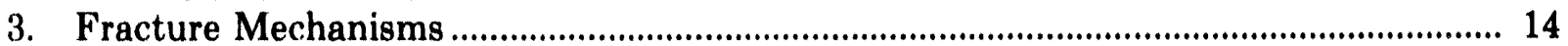

4. Sources of Anisotropic Stress in a Basin ...................................................................... 14

4.1 Horizontal Compression as a Source of Stress ................................................. 16

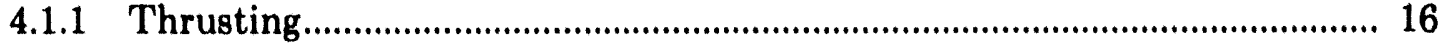

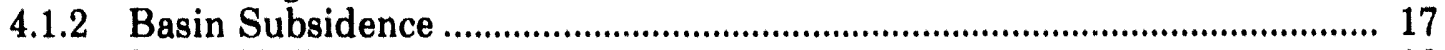

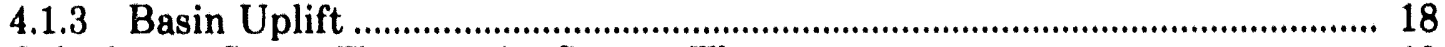

4.2 Calculating Stress Trajectories Due to Thrusts ................................................... 19

4.3 Calculating the Horizontal Stress Due to Basin-Wide Strain............................... 21

5. Local Modifications of Regional Stresses in a Basin................................................. 21

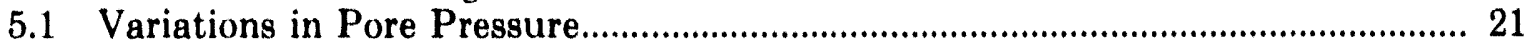

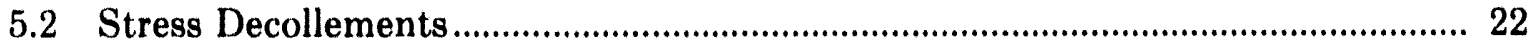

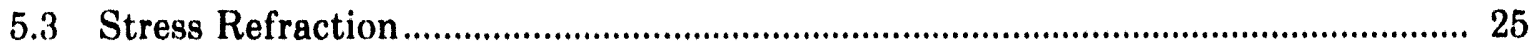

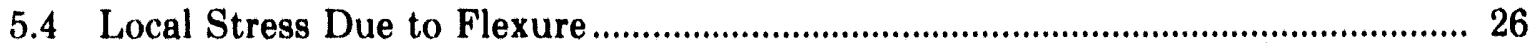

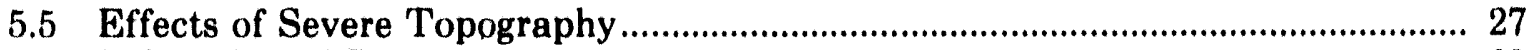

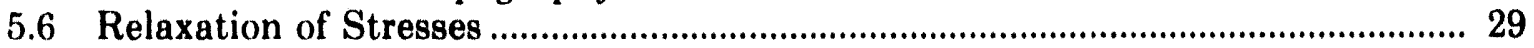

6. Analysis: Reconstructing the Stress/Fracture History of a Basin .............................. 31

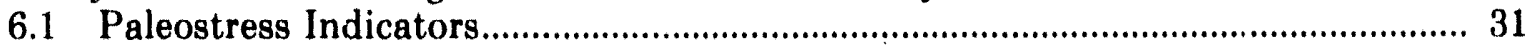

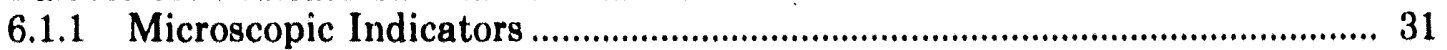

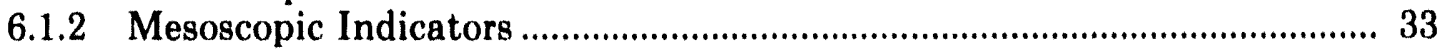

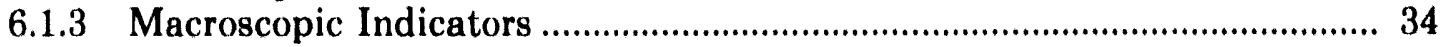

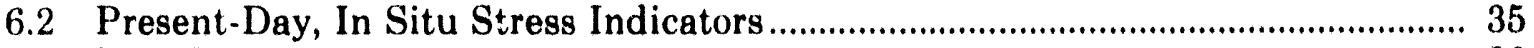

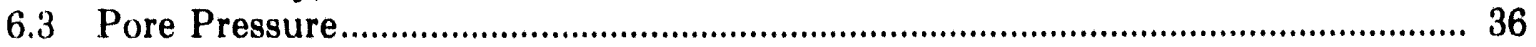

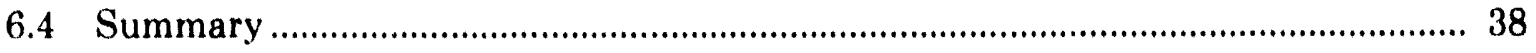

7. Prediction of Fracture and Stress Orientations in a Basin and at a Well Site ........... 39

7.1 Tectonic Stress History.......................................................................... 41

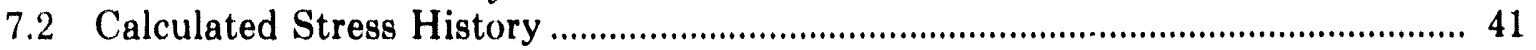

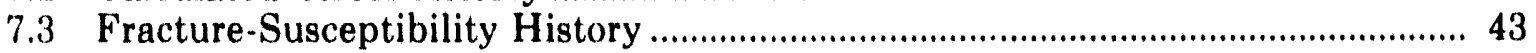

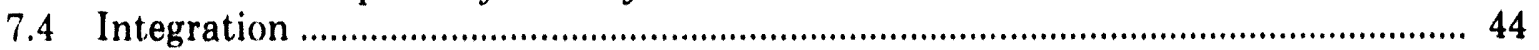

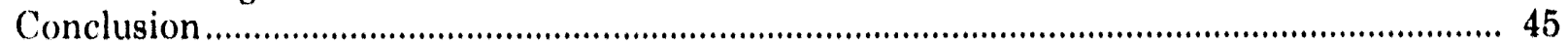

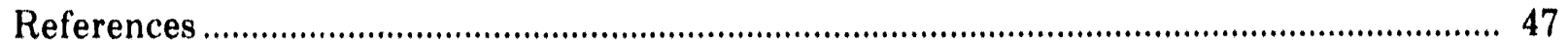

APPENDIX A-Wellbore Geometries for Optimum Fracture Characterization and Drainage ................................................................................... 51

APPENDIX B-Measurement and Analysis of Fractures in Core .................................. 61

APPENDIX C-Eiscoelastic Stress History Equations for Basin Stress Modeling .......... 87

APPENDIX D-Techniques for In Situ Stress Measurement: Anelastic Strain Recovery (ASR), and Circumferential Velocity Anisotropy (CVA) ....... 89

APPENDIX E-Computer Codes for Calculating the Effects of Topography on

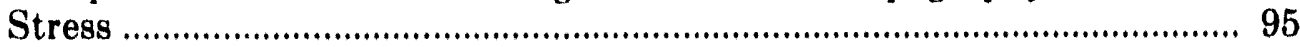

APPENDIX F - Computer Code for Stress-History Calculations ................................... 107 


\section{Figures}

1 Laboratory measurements of the permeabilities through mineralized fractures in sandstones of the MWX reservoirs compared to the matrix permeabilities of adjacent, unfractured samples

2 Laboratory measuremenis of the stress sensitivity of MWX mineralized fractures. Higher conductivity fractures from the Cozzette sandstone have less sensitivity than the lower conductivity fracture from the fluvial interval...

3 Measured permeability anisotropy in the Ekofisk reservoir, relative to the observed fracture orientations and the maximum stress orientation

4 Characteristics of rock failure as a function of confining stress. Rocks show brittle behavior with only small amounts of strain prior to failure if the confining stress is low; they are ductile and accommodate significant strain if confining stresses are high

5 Natural fracture pattern that radiates out from the White River Uplift, created by stress trajectories radiating away from the thrust front during thrusting.

6 Strain due to lengthening of a depositional surface to a hypotenuse during asymmetric subsidence in a narrow, deep basin such as the Late Cretaceous foredeep in southwestern Wyoming....

7 Stresses in strata created by uniform uplift and radial release of confining stresses.....

8 Schematic of the geometry for a constant distributed load applied to a semi-infinite region.

9 Stress trajectories calculated from simple distributed loads as representations of the White Rover thrusts. Line orientations indicate the orientations of the maximum stress; length of the line indicates the relative stress magnitudes.

(Compare to Figure 5.)

10 Measured variation in the minimum horizontal stress, as represented by the fracture gradient, as a function of the pore pressure for the Vicksburg Formation.....23

11 Measured variation in the minimum horizontal stress, as represented by the fracture gradient, as a function of the pore pressure for the MWX site

12 Stress in the Jura Region. (a): Stress variations across a ductile boundary layer in front of the Alpine thrust belt (from Muller et al., 1987); (b): Inferred planview stress trajectories of upper stress array and lower strers array in the same area as (a) (from Becker, 1989)

13 Example of horizontally layered stress domains caused by buttress-induced thrusting (from Kulick and Schmidt, 1988). Measurements of paleostresses within strata with a similar configuration have suggested that the stresses in the upper, unbuttressed lavers had been largely relieved (Genovese and Schmidt, 1989) ............25

14 Stress trajectories deflected by inhomogeneities in strata (from Bell and Lloyd, 1989).

15 The changes in stress orientation and magnitude with depth, due to topographic loading near the MWX site (from Clark, 1983)

16 Schematic of the geometry for a linearly increasing distributed load applied to a semi-infinite region.

17 Calculated stress reorientation due to a mesa and escarpment as a function of the angle of the escarpment relative to the far-field maximum stress orientation. A high mesa can significantly reorient the stress field.

18 Map of the Piceance basin showing the trends and occurrences of paleostress indicators

19 Rapid subsidence in a narrow basin that led to asymmetric stresses and fracturing parallel to the basin axis despite thrust-fault compression normal to the basin axis: Cretaceous foredeep of the Green River basin, southwestern Wyoming 


\section{Figures (continued)}

20 Orientation of the stress field at MWX based on Anelastic Strain Recovery (ASR) data in three wells, Differential Strain Curve Analysis (DSCA) on selected samples, an open-hole hydraulic fracture (impression packer), and four hydraulic fracture experiments where borehole seismic instrumentation was used to map the fracture azimuth.

21 Time/Burial-depth/Surface-elevation diagram for the strata at the MWX site in the Piceance basin

22 Reconstructed stress history for the strata at the MWX site.

23 Stresses (from previous figure) plotted within an empirical failure envelope, indicating the most likely times of fracturing. Outer envelope is failure plane from laboratory data. Inner envelope indicates failure plane corrected for geologic criteria.

24 Calculation of the shear stress, through time, that would have developed at three sites in the southern Piceance basin. Increased shear stress indicates increased potential for fracturing

25 Flow diagram summarizing fracture-assessment techniques and their integration into the procedures described in this paper

\section{Table}

1 Information for Predicting Subsurfaces Stress and Fracture Patterns at a Well Site..... 


\section{Rationale for Finding and Exploiting Fractured Reservoirs, Based on the MWX/SHCT-Piceance Basin Experience}

\section{Introduction}

Insights into naturally fractured reservoirs and in situ stresses were gained through extensive studies and experiments performed at the U.S. Department of Energy's Multiwell Experiment site. This report uses those insights to develop a rationale for the identification and efficient exploitation of naturally fractured, low-permeability, natural gas reservoirs. The lessons of the Multiwell Experiment have a wide range of applications because most reservoirs are fractured, and because in situ stresses commonly control the conductivity of natural fractures. Therefore the efficiency of stimulation and production of such reservoirs often depends on an understanding of the fractures and the stresses present in the strata. Moreover, such an understanding allows for the prediction of areas within a basin where optimum conditions of stress and fracturing may have occurred and thus leads to an exploration methodology.

The Multiwell Experiment (MWX) was a field laboratory designed (1) to characterize low-permeability (tight) natural-gas reservoirs, (2) to assess the existing technologies for the exploitation (stimulation) of this large but generally inaccessible resource, and (3) to develop new stimulation technologies (Northrop and Frohne, 1990). The project consisted of three closely spaced wells located in the Colorado River valley in the east-central Piceance basin of northwestern Colorado near the town of Rifle. The reservoirs of interest were sandstones of the Mesaverde Formation, which occur between the depths of 4000 and $8350 \mathrm{ft}$ at this site. Different depositional zones within the formation contain reservoirs of different character, varying from blanket-shaped marine sandstones to narrow, lenticular sandstones (Lorenz, 1989), but all have low matrix permeabilities (usually less than a microdarcy), all are enclosed in shale or mudstone, and all are extensively fractured despits the absence of major structural deformation of the local strata.

The three MWX wells are arranged in a triangle with interwell spacing varying from about 150-250 ft, depending on depth. A total of $4200 \mathrm{ft}$ of 4 -inch core were taken from the three wells for extensive rock property testing and reservoir characterization. During the eight-year program, six individual reservoir zones were isolated one at a time, and each tested and characterized with extensive reservoir draw-down, build-up, interference tests, in situ stress measurements, and stimulation experiments. Complimentary geologic studies of the core and of nearby outcrops helped to characterize reservoir shapes, sizes, and internal heterogeneity.

Subsequent to the MWX program, a new project was undertaken at the same site, the Slant Hole Completion Test (SHCT), the design of which was based on the MWX findings (Myal and Frohne, 1991). The SHCT project consisted of a deviated well, locally cored, through the Mesaverde reservoirs. The hole azimuth was normal to the subsurface fracture trend. This well and core confirmed (1) that vertical natural fractures are pervasive throughout the formation, (2) that they constitute the primary permeability system in the reservoirs, and (3) that the gas in the formation can be accessed with deviated wellbores.

In addition to the SHCT, DOE has also funded a cooperative program to extrapolate the MWX/SHC'T technology to other parts of the Piceance basin. This program has relied on 
industry wells for which DOE has funded coring, logging, or testing activities. These wells have provided fracture and stress orientation data in other parts of the basin that can then be correlated with the established data base.

Several important understandings came out of these programs: (1) natural fractures are more common in reservoirs than is usually recognized, (2) natural fractures may dominate a reservoir permeability system, especially where the matrix permeability is low, (3) natural fractures may be stress sensitive, in that a) they can be closed when the in situ stresses change during reservoir production, and that b) they may be closed when the maximum horizontal stress is not parallel to fracture trend due to a complex tectonic history of the strata, and (4) natural-fracture permeability systems may be damaged by stress or fluid perturbations of the reservoir during drilling, stimulation, and/or production.

This report will show how these understandings, along with ancillary studies conducted by Sandia, may be used to explore tor naturally fractured reservoirs and to enhance production from them. The sections of this report outline the significance of fractures to the system permeability of reservoirs (section 1), and give the principles and examples of the interactions between stress and natural fractures in a basin, both in terms of the origin of the fractures (section 3), and in terms of the significance of stress and fractures in a reservoir (section 2). The report also outlines a methodology by which these interactions can be documented, studied, and ultimately, predicted for an unknown basin, by discussing the sources of stress (section 4), as well as potential local modifications to regional stresses (section 5). The report then discusses the compilation of these data into a stress history of a basin and how fracturing might be predicted from that history (sections 6,7).

The appendices to the report list specific techniques for fracture studies. 'These include techniques for optimizing the chances for fracture intersection with a wellbore $(A)$ and for characterizing fractures in core (B). Appendix $\mathrm{C}$ presents equations for a stress history model (the computer code for this model is presented in appendix F), while appendix D discusses two of the more reliable techniques for measurement of the present-day in situ stress from core. Finally, a computer code that allows the caluclation of the effects of severe topography on in situ stresses is given in appendix $E$.

This report is intended to provide a fracture analysis toolbox, with instructions and insights for the investigator wishing to find and exploit naturally fractured reservoirs.

\section{Importance of Natural Fractures in Western Basins}

Fractures create quasi-planar breaks in the continuity of a reservoir that may or may not provide an enhancement of the permeability system. Enhancement depends on the ratio of the fracture permeability to the matrix-rock permeability. The permeability of an individual fracture is a function of the width of the fracture, the roughness of the fracture walls, the stress acting on it, and the completeness of cementation (if any).

Fracture system permeability includes the additional factors of fracture interconnectedness, distribution, and trend(s) within a reservoir. Narrow fractures in $\mathrm{a}$ highpermeability reservoir will be of little consequence, but fracture importance increases as reservoir matrix permeability decreases. Even fractures that appear to be completely filled with calcite may offer significant permeability, especially to gas, under high-pressure, in situ reservoir conditions in otherwise "tight" (less than 10 microdarcy) reservoirs. laboratory measurements of the fractures in the MWX sandstone reservoirs (Figure 1) show that permeability even through tight fractures may be several orders of magnitude higher than the sub-microdarcy matrix permeability. Open fractures that are confined to thin beds within laminated reservoirs or that do not connect to adjacent fractures may also be of limited significance to production; each fracture intersected by the wellbore, although individually highly permeable, may not drain enough of the reservoir to be of consecfuence. 'This is because 
the essentially two-dimensional volume of most fracture systems is insignificant compared to the three-dimensional volume of matrix rock, even if it is rock of relatively low-porosity.

Fracture strike is also an important characteristic. If a single set of fractures is present at depth, reservoir system permeability may be highly anisotropic, producing a drainage area that is significantly elongate along the fracture trend. Documented horizontal permeability anisotropy due to unidirectional fracturing at the MWX site ranges from $8: 1$ to 1(0):1 (Branagan et al., 1984), and limits lateral communication between closely spaced wells in the direction orthogonal to the fracture trend. Similar fracture-controlled permeability anisotropies have been measured in other formations (e.g., Kempthorne and Irish, 1981; Elkins and Skov, 1960).

'Tightly cemented fractures within a relatively permeable matrix rock may also produce elongate drainage areas by creating permeability barriers rather than permeability conduits. In this case, reservoir flow would still be directed along the trend of fractures, but would ocur between rather than within the fractures.

Accordingly, it is important to characterize the nature of a reservoir fracture system in order to be able to predict and understand the effects of natural fractures on production and drainage patterns.

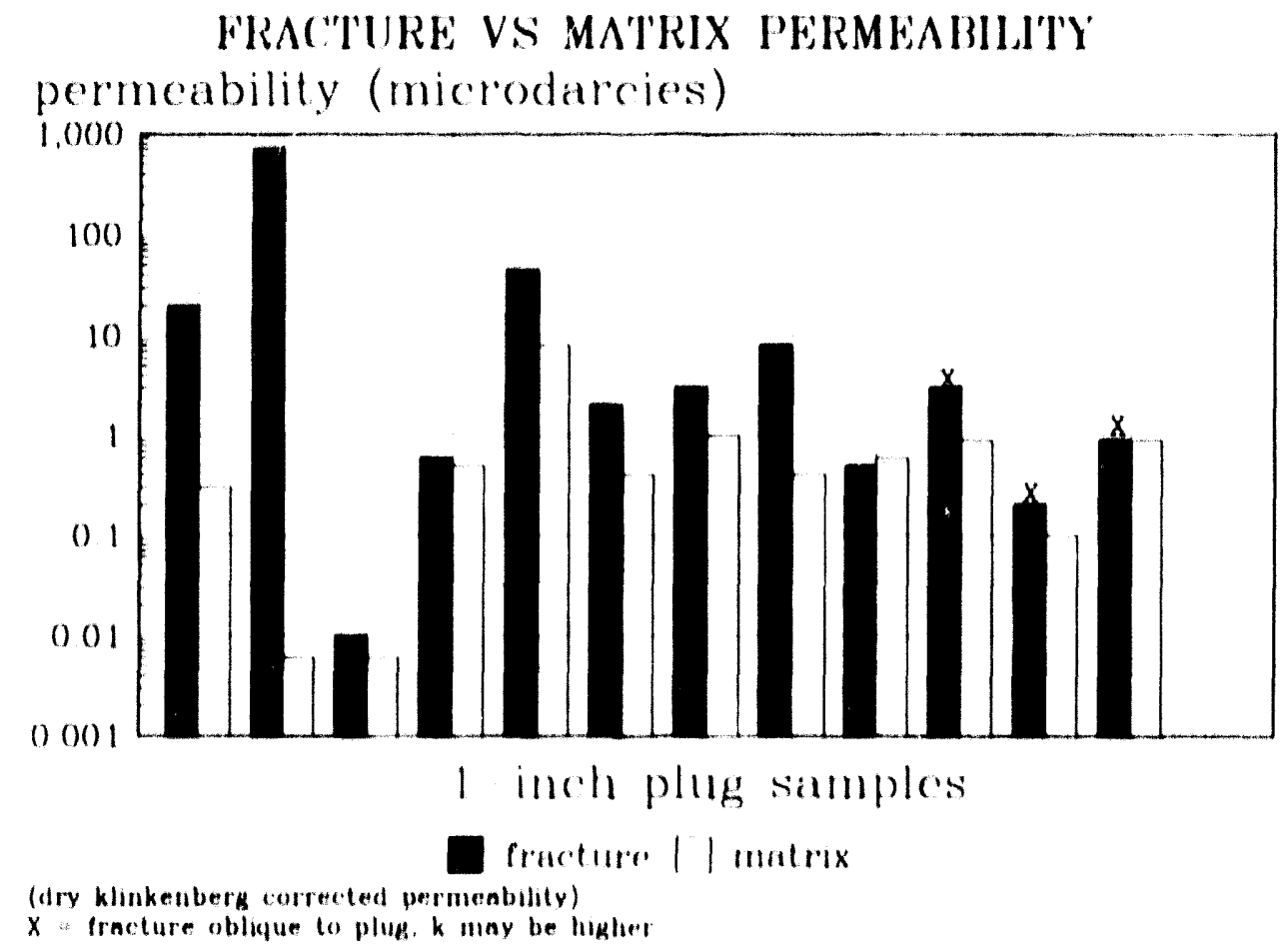

Figure 1. Iaboratory mensurements of the permeabilities through mineralized fractures in sandstones of the MWX reservoirs compared to the matrix permeabilities of adjacent, unf ractured samples.

\section{Effect of Stresses on Natural Fractures}

Fracturing of struta results from the unisotropic stresses that build up in formations during tectonic movements of the earth. Fructures generally form parallel to a plane defined by the maximum and intermediate principal stresses, and open in the direction of the least principal stress. 'Thus, where the lectomic history of the strata is not complicated, fractures commonly have a st rike that is purallel to the maximum horizontal principal st ress, and there may be few or no cross fractures to provide the interommedions. In such cones, the in silu 
stresses act to keep fractures open and permeable. However, hydraulic stimulation fractures, which also parallel the maximum horizontal stress, will not efficiently access such a reservoir permeability system because the stimulation fracture will parallel the natural fractures. This was apparent in the results of most of the MWX stimulation experiments (Branagan et al., 1985) where the hydraulic fractures did not produce the expected production enhancement (although formation damage was also an important factor).

Where tectonic activity has continued to evolve after fracturing of the strata, the subsurface stresses may have changed orientation and may no longer be aligned with the fractures that were formed at an earlier stage of basin evolution. In some wells near the MWX site, severe topography has resulted in locally reoriented stresses such that stimulation fractures may be directed across the natural fracture trend, enhancing stimulation potential.

Existing fractures may also act as planes of weakness that were reactivated during later tectonic stages. However, if the existing fractures were either well-cemented or highly oblique to the reoriented stresses, entirely new fractures may form if stresses are sufficient. The Ekofisk field in the North Sea is an example of radial fractures caused by doming of the strata being superimposed on regional northeast trending fractures (Teufel and Farrell, 1990).

Whether or not new fractures form, reoriented stresses will act to press fractures of the initial set closed, limiting permeability. Moreover, the conductivity of many fractures is sensitive to changes in the in situ stress magnitudes, regardless of whether the stress orientation has changed. For example, the permeability of the natural fractures in the Cozzette sandstone at the MWX site was degraded when the well was allowed unrestricted flow (formation pressure was reduced, higher effective stresses were created, and the fractures were forced to close), whereas enhanced fracture permeability was created when formation pressures were increased during injection tests (Warpinski, 1991).

Fluid flow along mineralized natural fractures has been documented in the laboratory, although flow through completely mineralized fractures is limited (e.g., Morrow, 1990). Tests were performed at Sandia on two fractures from the SHC'T Cozzette core that, although mineralized, are considerably more conductive than previous samples, having visible remnant apertures within the mineralization. The results (Figure 2) show that even the highly conductive samples have some stress sensitivity, although the planar fractures typical of MWX samples were much more stress sensitive. 'The two Cozzette fractures were both about 60 ) 80 " filled with cement, but the available porosity was vuggy in nature. 'The highest conductivity sample has a fracture permeability of several darcys.

Thus it is important to reconstruct the geologic/tectonic history that strata have been subjecied to, and to characterize in detail both the stresses and the fractures within the strata in order to predict (1) the behavior of a reservoir permeability system, and (2) the locations for the optimum development of fractures and stresses. For example, a set of numerous fractures, if it is oriented at a high angle to the maximum or intermediate principal stresses, may not be as important to the permeability of a reservoir as a set of less numerous or narrower fractures that are oriented normal to the least principal stress. As noted, the Ekofisk reservoir provides an example of this behavior (Figure 3). 'The maximum permeabil. ity orientation was found to be aligned with the maximum stress orientation rather than with the maximum fracture orientation ('Teufel and Farrell, 1992). 


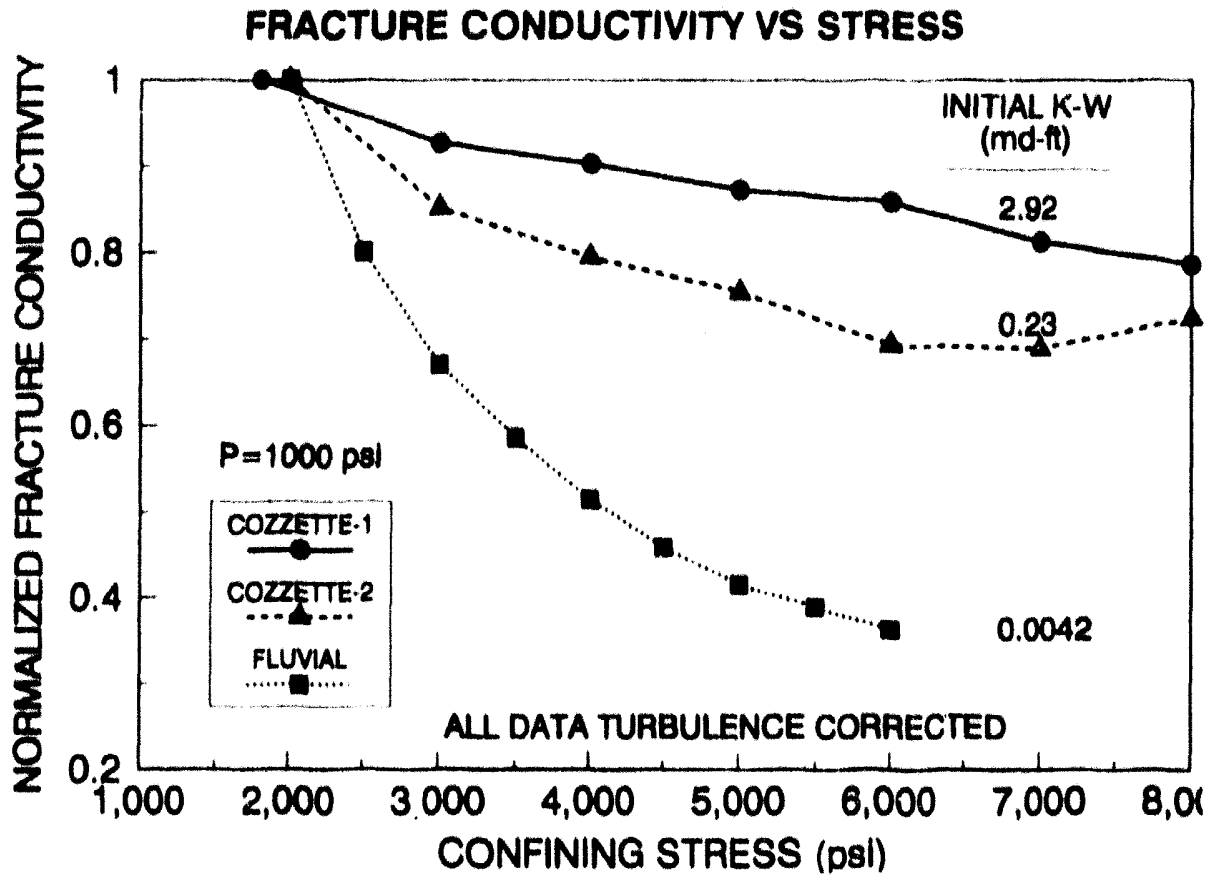

Figure 2. Laboratory measurements of the stress sensitivity of MWX mineralized fractures. Higher conductivity fractures from the Cozzette sandstone have less sensitivity than the lower conductivity fracture from the fluvial interval.

Effect of in Situ Stress on Permeablilty Anlsotropy

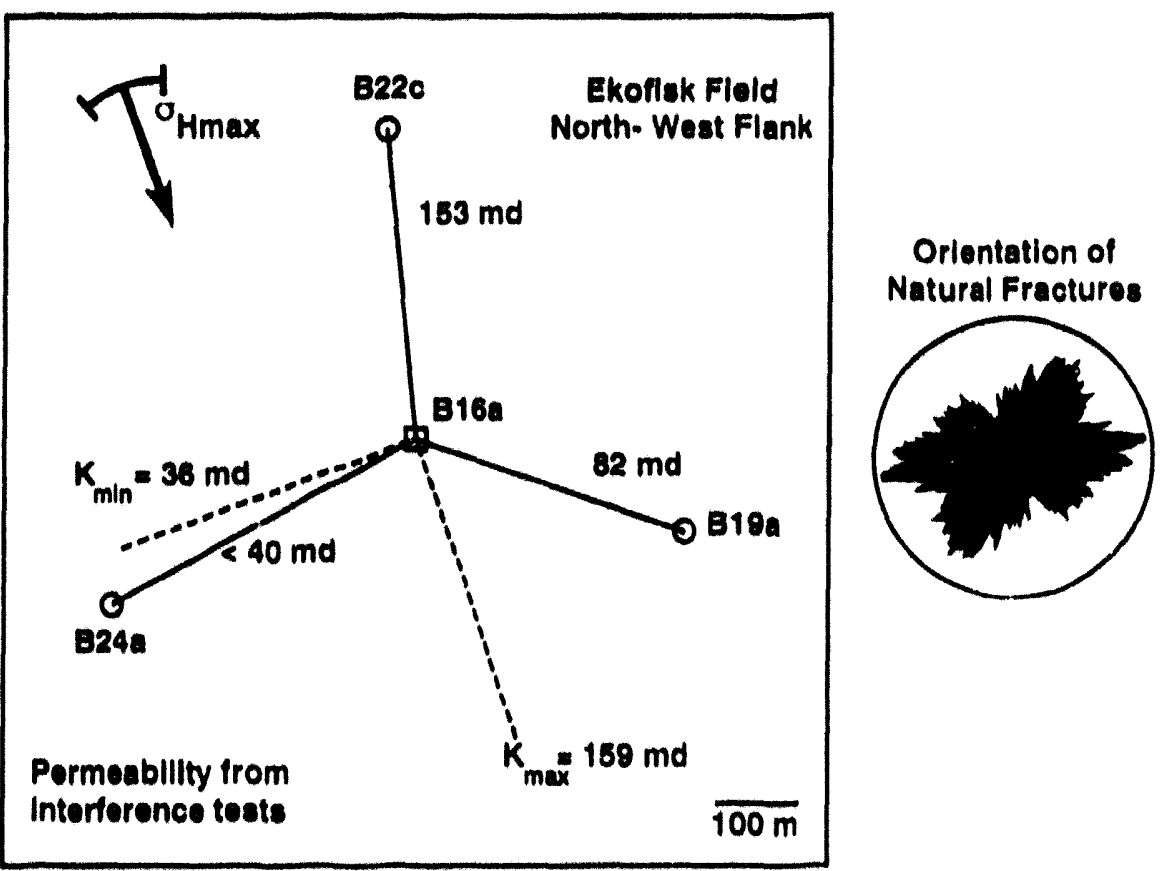

Figure 3. Measured permeability anisotropy in the Ekofisk reservoir, relative to the observed fracture orientations and the maximum stress orientation. 


\section{Fracture Mechanisms}

Regional fracture systems are the primary concern in reservoirs of the western tight-gas basins. Therefore, regional fractures are the focus of this section, but it should be recognized that structurally induced fractures can provide additional fracture sets that significantly enhance the "system" permeability.

Regional natural fractures are often attributed to natural hydraulic fracturing, but this is a mistaken belief that was formulated without a thorough understanding of the mechanics, poro- mechanics, and failure properties of sedimentary rocks. Most regional natural fractures are likely due to load-parallel extensional failure of the rocks. Such a failure mechanism is well-known in the rock mechanics literature (Figure 4), and the characteristics of the type of fracturing match the characteristics of the observed regional natural fractures.

The basic mechanism of regional fracturing has two criteria that must be met in order to achieve load-parallel extensional failure (Lorenz, et al., 1991). First, there must be a horizontal stress anisotropy, as due to tectonics or basinal subsidence behavior. Second, the net confining stress on the rocks must be low, as would occur in overpressured regions. 'The first requirement is the mechanism that causes extensional fuilure of the rock anl vreferentially aligns the natural fractures. 'The second requirement allows the fractures to be created under relatively small amounts of horizontal stress anisotropy. If the net confining stress is not low, then large stress anisotropies are needed, and the characteristics of the fracturing (if it occurs) become shear in nature, oblique to the stress. Such fracturing is more typical of more intensely deformed, folded, and faulted areas.

Regional fractures created under such conditions have characteristics that make them particularly suitable as flow conduits. Since they are induced by compression in the direction of the fracture strike, there is a dilatancy associated with the process that opens the fractures and holds them open as long as the stress anisotropy exists. This persistent dilatancy allows for the fractures to be mineralized and, commonly, propped open.

'The drawback of regional natural fractures is that they tend to be unidirectional, as there is no mechanism to create cross fracture sets. As a result, the interconnectivity of these systems is poor, and any hydrocarbon drainage will be highly elliptical.

Structurally induced fractures, on the other hand, may have conjugate or other multiple sets, and these are superposed on the regional fractures if the structure post-dates the regional-fracturing episode. 'Therefore, structure is important in these tight-gas reservoirs for its contribution to the fracture system rather than for its usefulness as a trapping mechanism (although trapping is obviously important for conventional oil and gas reservoirs).

\section{Sources of Anisotropic Horizontal Stress in a Basin}

Because stresses both cause and control fracture permeability, they are an important part of a fractured reservoir permeability system and must be understood before fracture location and behavior can be predicted.

Under ideal conditions, both horizontal stresses in a formation are equal and are the result of lateral expansion of the strata due to the weight of the overburden. 'The magnitudes of the horizontal stresses are primarily a function of the weight of the overburden as modified by the Poisson's ratio of the strata (Jaeger and Cook, 1976). Pore pressure and elevated temperatures, attained by strata as they are buried, also contribute an isotropic stress component to the total stress system (Warpinski, 1989). However, the ideal situation of isotropic horizontal stress is rarely obtained under actual geologic conditions, and horizontal stresses are most commonly unequal due to tectonic movements. Worldwide measurements have shown that horizontal stress anisotropy exists even in quiescent basins, far from active orogenic regions (e.g., Zoback and Zoback, 1980). 


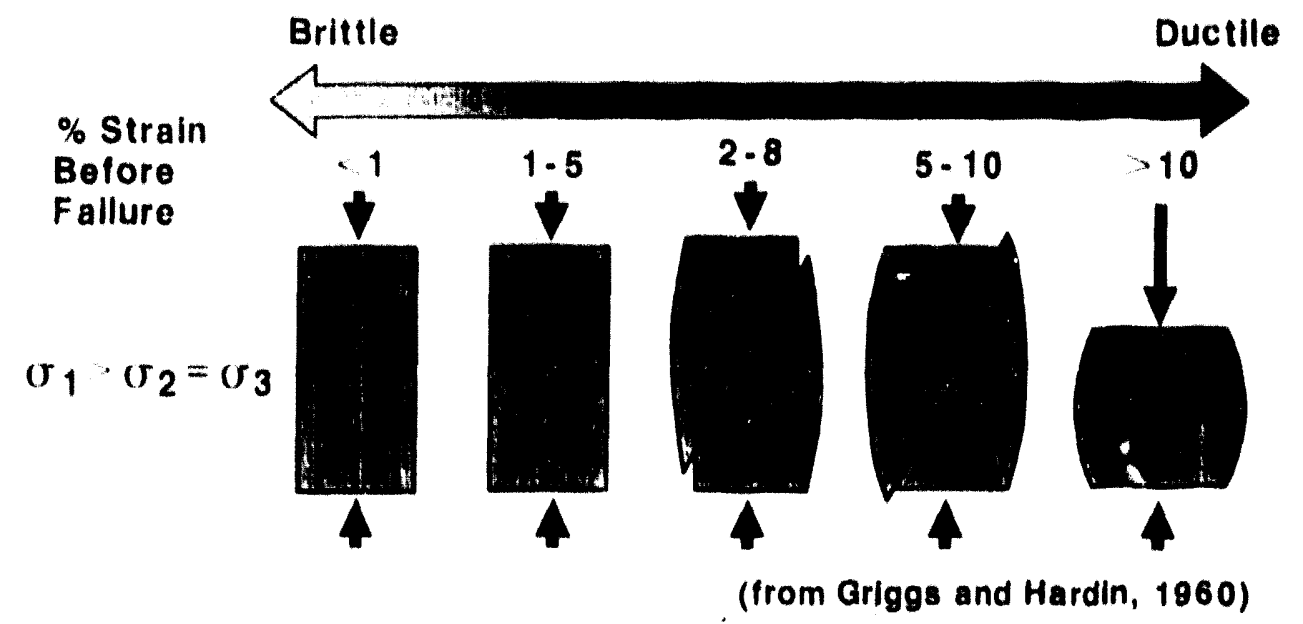

Figure 4. Characteristics of rock failure as a function of confining stress. Rocks show brittle behavior with only small amounts of strain prior to failure if the confining stress is low; they are ductile and accommodate significant strain if confining stresses are high.

The equation for the effect of the overburden stress on the horizontal stresses is simply derived. First, however, the calculations must be performed in effective-stress space because the effective stresses are the only component of the total stress that contribute to deformation. Defining the total stresses as $S_{v}$, the overburden stress, $S_{h}$, the minimum horizontal stress, and $S_{H}$, the maximum horizontal stress, the effective stresses are then given as

$$
\begin{aligned}
& \sigma_{v}=S_{v}-{ }^{2} P, \\
& \sigma_{h}=S_{h}-{ }_{\alpha} P \text {, and } \\
& \sigma_{H}=S_{H}{ }_{\alpha P} \text {, }
\end{aligned}
$$

where or is the poroelastic parameter (often called Biot's modulus) and $\mathrm{P}$ is the pore pressure. linear elasticity requires that

$$
\begin{aligned}
& W_{h}-\sigma_{h} \quad "\left(\sigma_{H}+\sigma_{v}\right), \\
& E_{H}=\sigma_{H} \quad \mu\left(\sigma_{h}+\sigma_{v}\right), \text { and } \\
& \left.E_{v}-\sigma_{v} \quad \sigma_{H}+\sigma_{h}\right),
\end{aligned}
$$

where " is Poisson's ratio, $F$ is Young's modulus, and the various are the strains in the three principal directions. If it is stipulated that there is no strain in any horizontal direction (uniaxiai strain), then $c_{h} c_{H} \quad 0$ and $\sigma_{h} \quad \sigma_{H}$. These equations can then be solved to yield

$$
\sigma_{h}-\sigma_{H}=\omega /(1-\cdots) \sigma_{v} .
$$

In terms of the total stresses, this becomes

$$
S_{11} \quad S_{11} \quad \mu /(1-\cdots)\left(S_{v} \quad(r P)+(\alpha P .\right.
$$

'This equation is used indiscriminately by most modelers, even when there is no justification for this severe assumption. 
The effect of temperature is isotropic if the material is isotropic, and is given by

$$
\Delta S_{\mathbf{h}}=\Delta S_{\mathbf{H}}=\alpha_{\mathrm{T}} \mathrm{E} \Delta \mathrm{T} /(1-\nu),
$$

where $\alpha_{\mathrm{T}}$ is the coefficient of linear thermal expansion, $\mathrm{E}$ is Young's modulus, and $\Delta \mathrm{T}$ is the temperature change causing the thermal stresses. For typical values of $\alpha_{\mathrm{T}}\left(6 \times 10^{-6}\right.$ in/in $\left./{ }^{\circ} \mathrm{F}\right)$ and $\mathrm{E}\left(5 \times 10^{6} \mathrm{psi}\right)$, a $10^{\circ} \mathrm{F}$ change in temperature will induce a 300 psi change in stress, a significant amount for any engineering calculations. (See also Appendix F.)

Many authors have suggested that stress anisotropies measured in undeformed/platformarea strata are due to continental-scale plate tectonics, i.e., to drag at the base of the lithosphere, several tens of kilometers deep, by convection currents in the ductile aesthenosphere (e.g., Zoback et al., 1989,), or to distant ridge-push forces at the edges of global plates (e.g., Bott, 1991). Hydrocarbon reservoirs and most of the subsurface stress measurements that have been made occur in the shallowest parts of the lithosphere. Stresses derived from base-of-crust drag or ridge-push are likely to be secondary effects at best within the shallow strata of interest to petroleum geologists.

Rather, the stresses of interest for this report are those that have been imposed laterally on strata in a basin from nearby tectonism, from local structure and topography, and from volume constraints during basin subsidence and uplift. Stress from two or more sources may be superimposed, and there are a number of local phenomena such as high topographic relief that can alter local stresses. The following section outlines common sources of horizontal stress anisotropy in sedimentary basins where hydrocarbon reservoirs occur and notes causes for the superposition of stresses that complicate exploration for, and production from, fractured reservoirs.

\subsection{Horizontal Compression as a Source of Stress}

\subsubsection{Thrusting}

Numerous linear thrust belts around the world have been produced by horizontal compression at plate margins. Some of this compression is often transmitted through the thrust belt into the stable platform area beyond, where it combines with horizontal compression due to the impingement of the thrust belt itself into the strata of the adjacent foredeep. Several good examples exist of measured maximum horizontal stresses and regional fractures trending normal to thrust fronts, although the relationship between thrusting and stress in adjacent strata is not universally accepted (e.g., Bell and Adams, 1990). Where significant plan-view curvature of a thrust belt is present, the stress trajectory and/or fracture strikes commonly change regionally to maintain an angular relationship that is essentially normal to the thrust front.

Such thrust-front-normal stresses are apparently effective for a few hundreds of kilometers in front of the source of stress (e.g., Europe in front of the Alps, the Arabian platform in front of the Zagros Mountains; Hancock and Bevan, 1987), although the stress magnitude diminishes with distance (e.g., in front of the Canadian Rockies; Woodland and Bell, 1988). At present, there is no reliable way to predict magnitudes of stresses based on amount of thrusting because of the complexities inherent in geologic systems. However, although the magnitudes must be measured directly, the stress orientations in many cases can be predicted in the absence of structural complexity (discussed below) simply by drawing stress trajectories normal to thrust fronts.

More localized thrusts, such as the thick-skinned Laramide block uplifts of the Rocky Mountain foreland province, produce stresses in adjacent strata in the same manner. However, because they impinge on relatively small areas, the stress trajectories commonly radiate out from the thrust front as if it were a point source once a sufficient distance from the thrust front is reached. For example, a fan-shaped pattern of natural fractures radiates across part of the Piceance basin directly in front of the White River Uplift (Figure 5). This 
pattern has been duplicated by a stress trajectory array modeled from an indenter stress superimposed on a regional stress (Lorenz et al., 1991).

The depths at which these thrust-derived stresses are present depends on an number of factors, including the depths at which the thrust fronts indent the adjacent strata (Hafner, 1951). Horizons of weaker strata may also dissipate stresses similar to thrust decollements, such that stresses below the weaker strata may not reflect nearby indentation of the thrust whereas stresses in overlying strata will. This is discussed further below.

\section{FRACTURES IN CRETACEOUS AND TERTIARY STRATA IN FRONT OF THE WHITE RIVER UPLIFT}

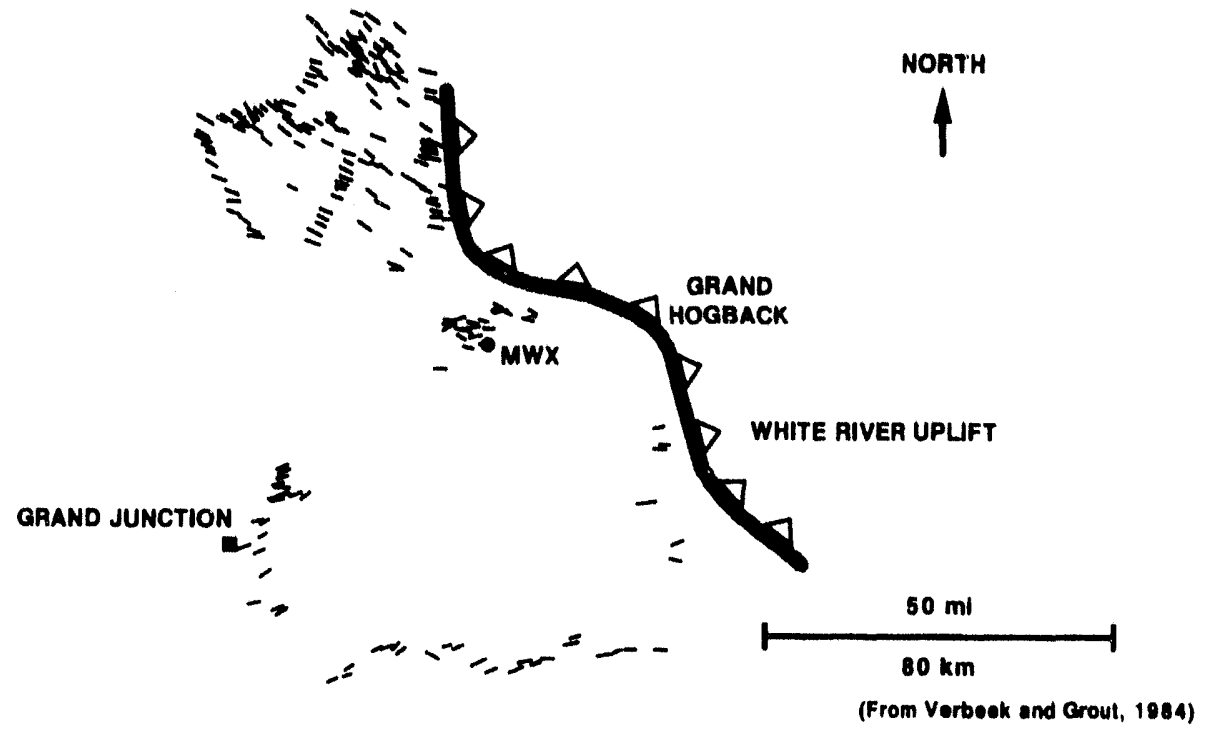

Figure 5. Natural fracture pattern that radiates out from the White River Uplift, created by stress trajectories radiating away from the thrust front during thrusting.

\subsubsection{Basin Subsidence}

Few if any basins subside at equal rates in all parts of the basin, as this would require vertical, parallel basin margins and a nonspherical earth. Rather, subsidence is commonly greatest in certain parts of the basin (a faulted margin, the center of a basin, etc). The strata must accommodate strain as volume constraints are met during subsidence within the basin boundaries into a sphere of diminishing radius. Because most basins are wider than they are deep by orders of magnitude, and because the radius of the earth is so large relative to the common depths of basin subsidence, this mechanism rarely adds significant strains to the strata in a basin.

However, significant strain can result during subsidence in especially narrow, deep basins. For instance, Upper Cretaceous strata in the foredeep adjacent to the Idah?/ Wyoming thrust belt are about $6000 \mathrm{~m}$ thick, whereas they are less than $2000 \mathrm{~m}$ thick over the Moxa Arch $55 \mathrm{~km}$ to the east (Weimer, 1961). In order to lengthen the $55 \mathrm{~km}$ line along the original depositional surface to its position as the hypotenuse of a triangle after deposition and burial, about $0.2 \%$ strain must be accommodated (Figure 6). Moreover, because the hypotenuse is not a straight line but is convex upward due to lithospheric elasticity, an additional strain of $0.06 \%$ is imposed for a total strain of nearly $0.3 \%$, which is sufficient to fracture in situ strata over geologic time. Thus the strain (which produces stress) across the short axis of a narrow, deep basin exceeds the strain/stress along its long axis, and 
anisotropic stresses result. If the stresses are of sufficient magnitude, they may produce fractures aligned parallel to the long basin axis.

\section{Strain from Lengthening Line to Hypotenuse}

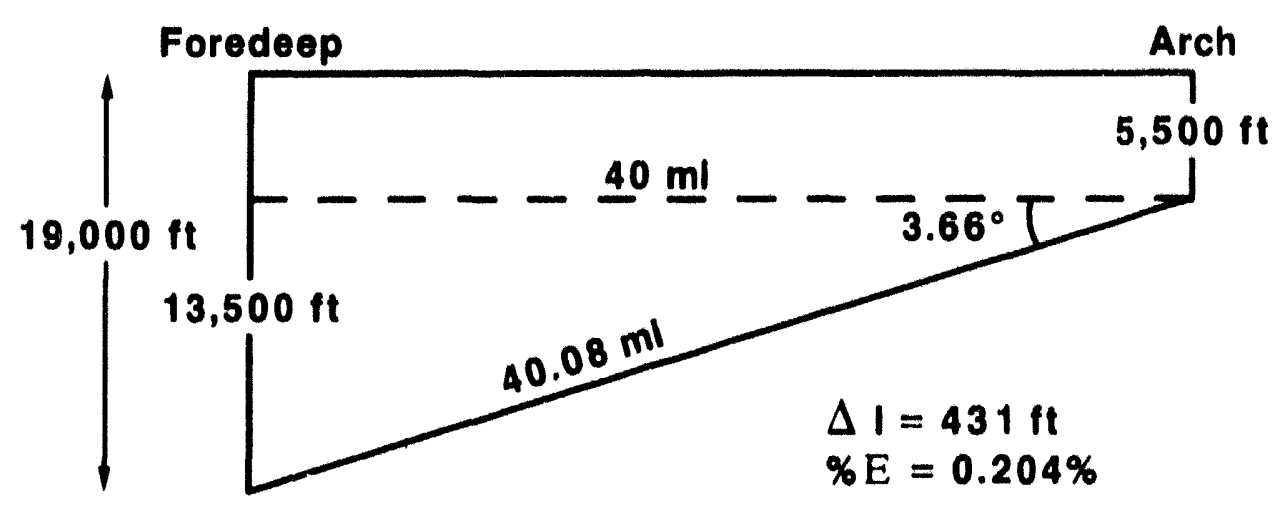

Figure 6. Strain due to lengthening of a depositional surface to a hypotenuse during asymmetric subsidence in a narrow, deep basin such as the Late Cretaceous foredeep in southwestern Wyoming.

Price (1974) recognized a variant of this phenomenon that involves consideration of the curvature of the earth's surface. Ideally, as the strata in a basin subside, they are subjected initially to lateral compression as their length, measured along the curved surface of the earth, is shortened to the length of the line measured across the chord of the earth between the edges of the basin. This assumes that there is no subsidence at the basin margins.

The magnitudes of the stresses and strains set up by the compression will be a function of the width of the basin, i.e., how far the strata must subside, and therefore how much shortening there will be before the originally curved surface line is concordant with the straight chord line. Less subsidence will be required in a narrow basin than in a wide basin to achieve this condition, and if a basin has a long and a short axis, the stress set up across its short axis will be less than that across its wide axis, leading to asymmetric horizontal stresses. Chord-line depth is actually relatively shallow. For instance, for the Piceance basin, the two main axes are 100 and $250 \mathrm{~km}$ across, and depths to chord lines at the middle of the basin are less than $100 \mathrm{~m}$ and $600 \mathrm{~m}$ for each axis respectively.

Stress anisotropy remains as subsidence continues beyond a chord line, but for the opposite reason: extensional strain results as the reference line, theoretically pinned at the basin edges, is lengthened in an arc during continued subsidence. Extension across the narrow axis of the basin will always be greater because the radius of the theoretical circle is smaller, and short-axis-parallel extension would be initiated at shallower depths than that across the greater dimension of the basin. This again would cause asymmetric horizontal stresses that could lead to fracturing. (Note that the extensional strain referred to does not lead to true tension, but rather merely decreases the subsurface compressional stress in that direction.)

\subsubsection{Basin Uplift}

As strata in a basin are uplifted, an opposite effect to that just described may occur if the basin edges are pinned. However, this is rarely the case. It is more likely, since uplift takes the strata out of the realm of lateral constraints, that the basin margins will have little effect 
on the strata. As the strata are uplifted, however, they will be subtending an arc of a sphere of slightly larger radius and will be subject to a release of some percentage of the previous horizontal stresses, equally in all horizontal directions if uplift is uniform (Figure 7).

If the previous horizontal stresses were asymmetric, as is most likely, then an equilateral stress release will still leave a remnant stress anisotropy, which will govern the orientation of any stress-release fracturing. 'Thus, stress-release fractures will form parallel to the previous minimum horizontal stress, as the locked-in elastic stresses rebound against the direction of the previous maximum horizontal stress (see experimental results of Gallagher et al., 1974; Rathore et al., 1989).

\subsection{Calculating Stress Trajectories Due to Thrusts}

'There are simple analytical solutions that can be adapted for estimating the stress trajectories induced by a thrust fault, such as the White River thrust which is found on the east side of the Piceance basin. Given the geometry of a distributed load (Figure 8), the stresses can be calculated (Jaeger and Cook, 1976) as

$$
\begin{aligned}
& \sigma_{x}=X / \pi\left\{\theta_{1}-\theta_{2}-\sin \left(\theta_{1}-\theta_{2}\right) \cos \left(\theta_{1}+\theta_{2}\right)\right\}, \\
& \sigma_{y}=X / \pi\left\{\theta_{1}-\theta_{2}-\sin \left(\theta_{1}-\theta_{2}\right) \cos \left(\theta_{1}+\theta_{2}\right)\right\}, \text { and } \\
& \tau_{x y}=X / \pi\left\{\sin \left(\theta_{1}-\theta_{2}\right) \sin \left(\theta_{1}+\theta_{2}\right)\right\},
\end{aligned}
$$

where $\theta_{1}=\tan ^{-1}(x /(y-a))$ and $\theta_{2}=\tan ^{-1}(x /(y+a))$, and $X$ is the load per unit length.

Such simple solutions can be superposed to yield more complicated thrust geometries. For example, a calculation of the effect of the White River thrust in the Piceance basin (Figure 9) is obtained by superposing two separate thrust plates located in offset positions. The stress trajeciories fan out from the source of the load, giving a radial pattern. It should be noted that these calculations assume plane strain behavior, so they may not be appropriate right at the surface. At depth, they should provide good estimates of the stress trajectories.

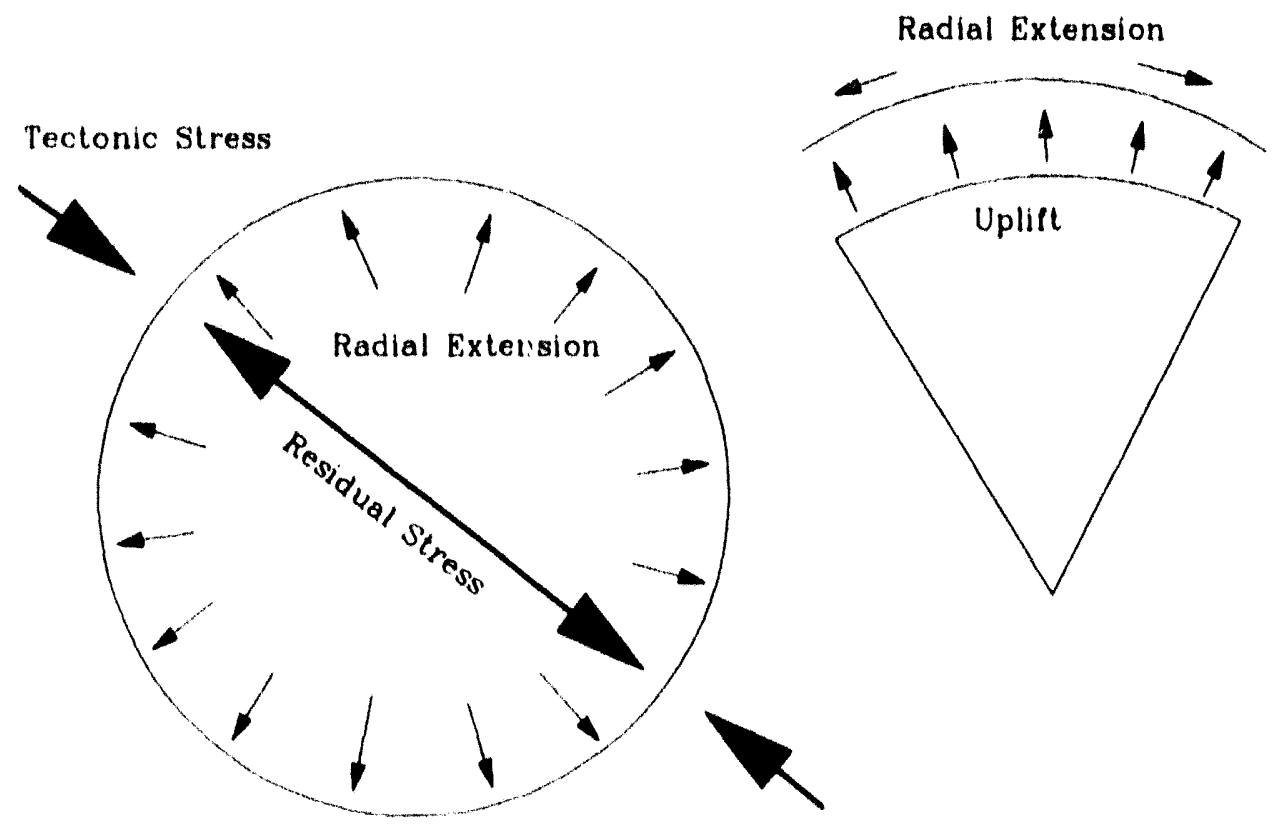

Figure 7. Stresses in strata created by uniform uplift and radial release of confining stresses. 


\section{GEOMETRY FOR DISTRIBUTED LINE LOAD}
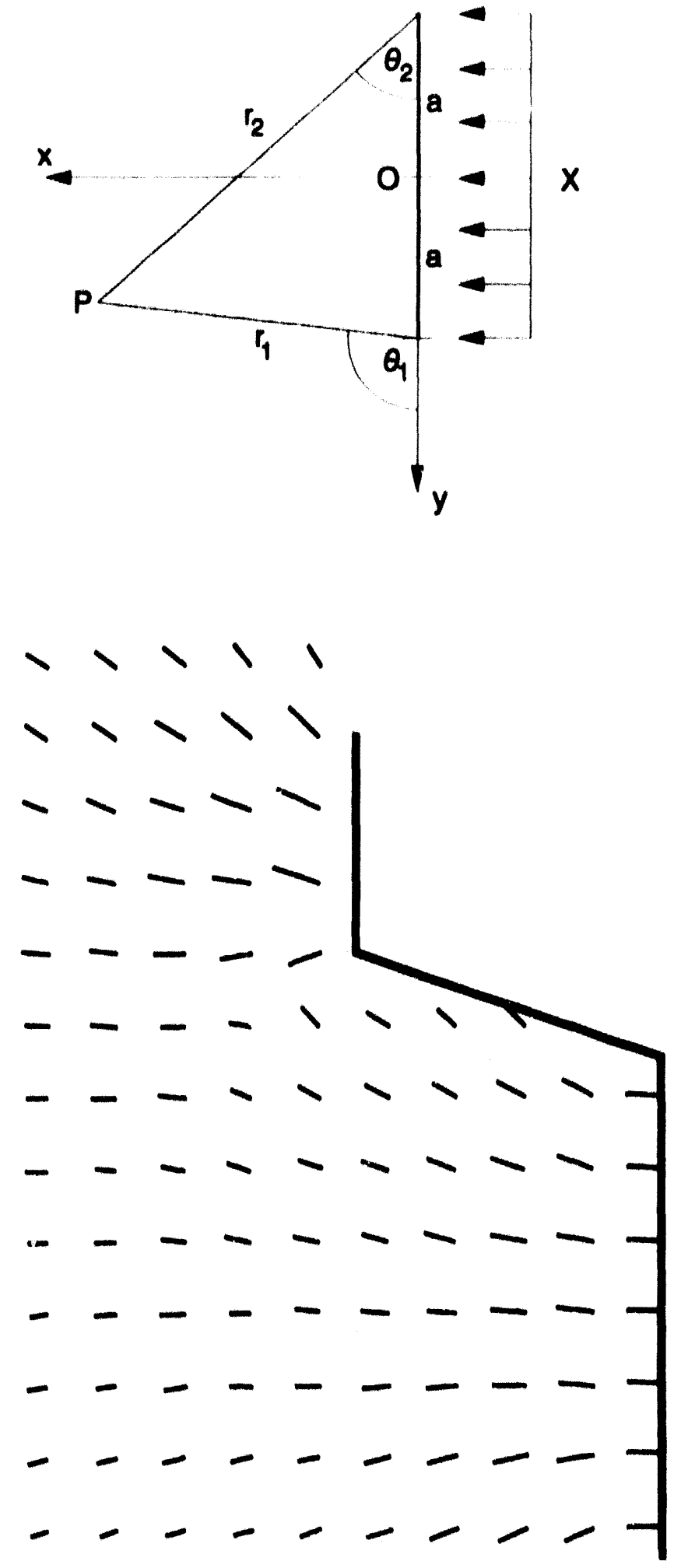

Figure 8. Schematic of the geometry for a constant distributed load applied to a semi-infinite region.
Figure 9. Stress trajectories calcu. lated from simple distributed loads as representations of the White Rover thrusts. Line orientations indicate the orientations of the maximum stress: length of the line indicates the relative stress magnitudes. (Compare to Figure 5.) 


\subsection{Calculating the Horizontal Stress Due to Basin-Wide Strain}

'The component of the horizontal stresses due to the horizontal strains imposed on a basin can be calculated in a straightforward manner. Assuming that there are tectonic strains, $c_{h}$ and ${ }_{H}$ (also, since $t_{H}$ is defined as the maximum stress direction, $c_{H}>c_{h}$ ), then the stress components due to tectonics, $S_{h t}$ and $S_{H t}$, are

$$
\begin{aligned}
& S_{h t}=E_{t_{h}} /\left(1-\nu^{2}\right)+\nu E_{t_{H}} /\left(1-\nu^{2}\right) \text { and } \\
& S_{H l}=E_{t_{h}} /\left(1-\nu^{2}\right)+\nu E_{t_{h}} /\left(1-\nu^{2}\right)
\end{aligned}
$$

Thus the stress in each of the horizontal directions depends on the strain in its direction and the strain in the orthogonal horizontal direction.

\section{Local Modifications of Regional Stresses in a Basin}

In the absence of heterogeneity, stresses will be uniform or will at least change uniformly over large areas. This ideal condition is rare. Among other effects, formation properties change laterally and vertically, stresses change with time or may be superimposed, geologic structures may provide significant "free" surfaces within a formation that may alter the local stress array, and strata may be warped by flexure to create local, structurally produced stresses. 'These effects and others are examined below.

\subsection{Variations in Pore Pressure}

Pore pressure is an important factor in determining whether strata are susceptible to being fractured. Formations containing high pore pressure are more likely to fracture under otherwise similar conditions of anisotropic stress and rock properties than formations with normal pore pressure. 'Therefore, if conditions of concurrent high pressure and anisotropic stress are reconstructed for some time within the geologic history of a formation, natural fracturing can be expected. Moreover, if parts of a formation were more highly pressured than others, the high-pressure areas are more promising targets for fractured-reservoir exploration.

Pore pressure varies through both time and space as a function of mechanisms such as relative rates of sedimentation, burial, dewatering, compaction (e.g., Fertl, 1976; Dickey, 1979), and the onset of hydrocarbon maturation and the resultant generation of gas. Overpressured conditions may be reversed over time due to pressure leak-off. Underpressured conditions may be present where rapid uplift and erosion has occurred. Reconstructing the geologic history of a formation in order to decide whether overpressured conditions once existed is not overly difficult, although the magnitude of such conditions can rarely be quantified or dated precisely.

Spatial variation in pore pressure within a formation is just as important. Some parts of formations are often buried more deeply and/or more rapidly so that they may be more highly pressured than shallower areas of the same formation. Similarly, if hydrocarbons capable of generating gas are only present locally in a formation, that area may become more highly pressured than other areas despite otherwise similar conditions.

The Mesaverde Formation provides an example of present-day lateral variation in pore pressure (ranging from normal pressures in reservoirs at the western margins of the basin to significant overpressuring in the deeply buried reservoirs near the MWX site). 'The formation also contains evidence to suggest that paleo-pore pressure varied. 'The latter condition is 
suggested by a set of fractures that is apparently limited to the deeply buried, central parts of the basin. These are dominantly west-northwest trending fractures that formed between about 36-40 m.y. ago under conditions of high pore pressure and regional anisotropic horizontal stress. The less deeply buried, less pressurized parts of the formation along the western edges of the basin were subjected to the same stresses, yet did not fracture at this time. Fracturing of these zones of the formation did not occur until several million years later under conditions of stress anisotropy that were slightly different in origin and orientation (Lorenz and Finley, 1991). 'Thus the fracture domains in the strata of the Mesaverde (iroup) are vertically and laterally separated, depending on ariations in the magnitude of the formation pore pressure. Fracture domains are not zoned parallel to formation boundaries.

Pore pressure variations also affect the total stress in strata, as crP is one component of the total horizontal stress. Data from the Vicksburg formation (Salz, 1977) provide the classic example of how pore pressures influence horizontal stress (Figure 10). Data from MWX (Figure 11), while more limited, show the same trend of increasing horizontal stress with increasing pore pressure.

\subsection{Stress Decollements}

Vertical zonation of stresses and fractures may also be caused by layers of weaker strata that allowed physical, lateral motion of rock, as in a thrust decollement. An example of this is given by Becker et al. (1987) for the Jura Mountains area in front of the Alpine thrust belt of Europe. In this locality, a zone of relatively ductile anhydrites and halites separates a lower domain of regional northwest-trending stress from an upper domain of stresses which radiate from north-northeast to west (Figure 12 a and b). 'The upper, radiating pattern is due to the indentation of the Jura Mountain block into the European craton, which was in turn a result of the regional northwest compressive stress.

Thus the ductile strata allowed thin-skinned thrusting, and the thrusting imposed a secondary stress on the strata in front of the thrusting, but only at the shallower levels above the ductile zone. Whether the shallow strata also contain a secondary fracture pattern is not reported, but would be a function of their fracture susceptibility and the magnitude of the secondary stress. Regardless, if fractures had been formed by the northwest regional stress in these strata prior to thrusting, the present oblique stress orientation would act to close most. of the fractures.

This type of vertical stress zonation may occur within as well as in front of thrust sheets, resulting from several structural configurations. If a thrust impinges on a basement high or other structural "buttress," a secondary thrust plane may form. Strata below this plane will remain highly stressed (unless strain is accommodated by folding or other deformation), whereas stress within the strata above the plane may be partially released during the relatively unopposed motion of the strata above the buttress (Figure 133).

Conversely, in an unbuttressed situation, the stresses within the strata below a new thrust plane may be the ones relieved by the formation of the new thrust. 'Thus once a thrust plane forms within a previously uniformly stressed section of strata, the stress below the plane is relieved as strain along the fault plane, whereas the stress above the fuult plane is maintained by the force needed to move the thrust sheet. 'This assumes that the regional stress no longer acts on the lower strata, but rather is directed only against the moving strata of the upper plate, as is probably the case in the Piceance hasin. In this instance, the relatively ductile Mancos Shale provides a stress and motion decollement much as does the anhydrite laver in the Alpine foreland, and blind thrusts die out within a tectomically thickened section of Mancos Shale over the Divide ('reek anticline (Cirout et al., 1991). 
MINIMUM STRESS INCREASES AS PORE

PRESSURE INCREASES

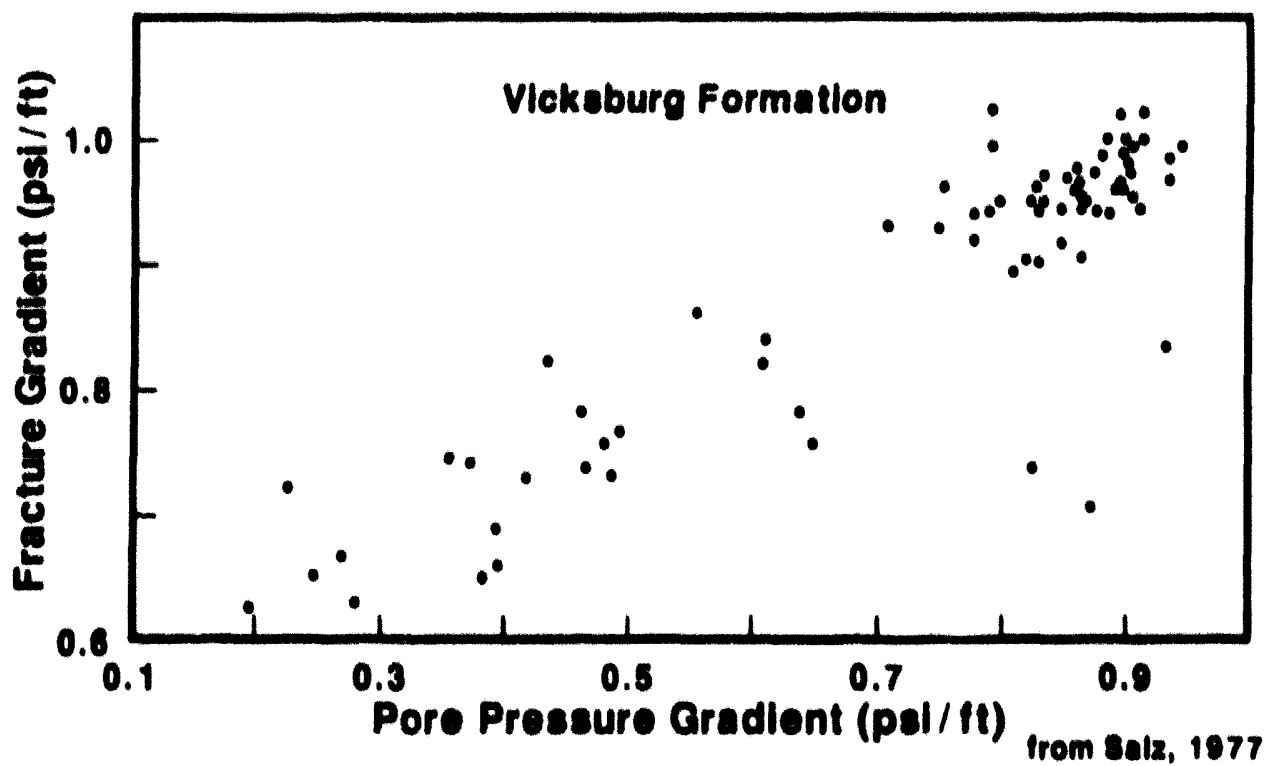

Figure 10. Messured variation in the minimum horizontal stress, as represented hy the fracture gradient, as a function of the pore pressure for the Vicksburg Formation.

MWX - MINIMUM STRESS VS POAE PRESSURE

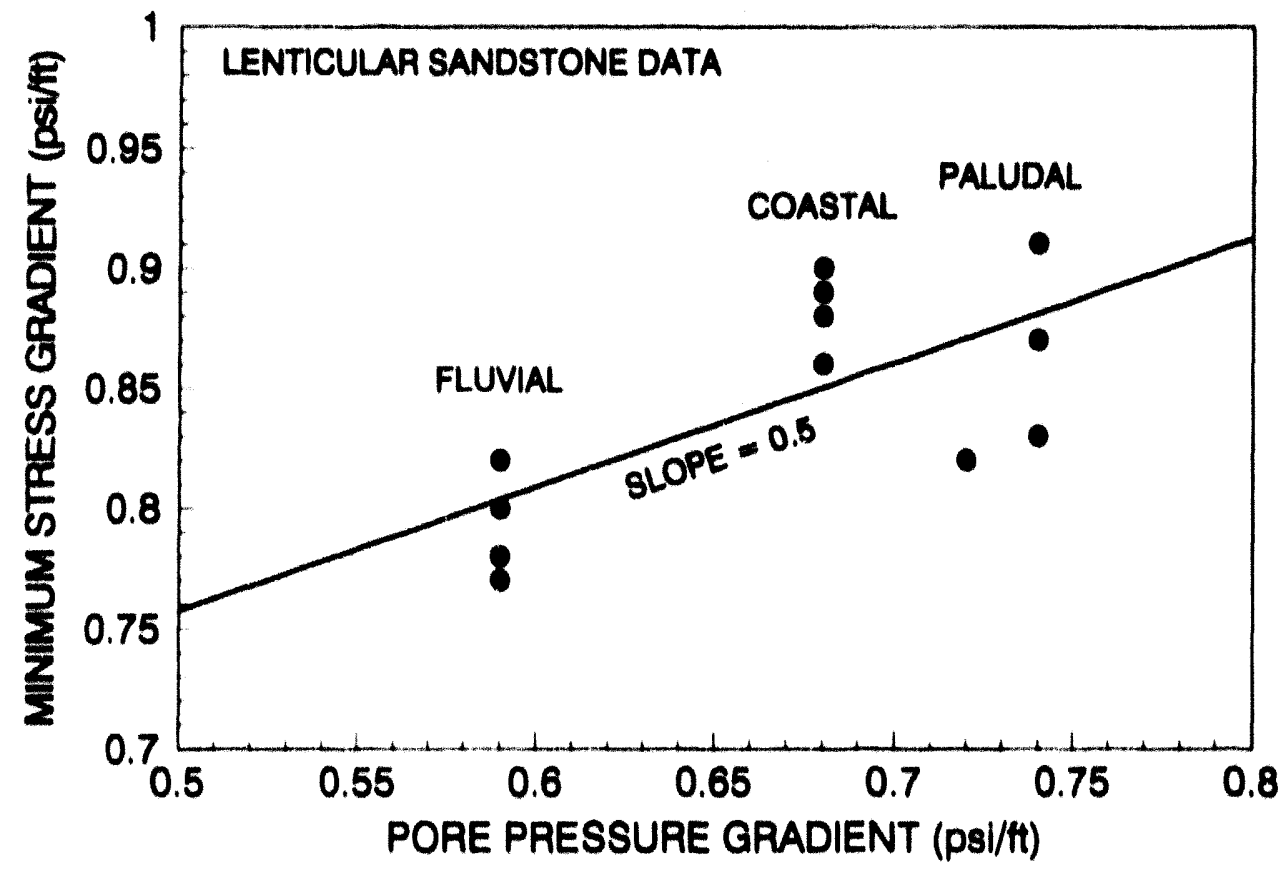

Figure 11. Measured variation in the minimum horizontal stress, as represented by the fracture aradient, as a function of the pore pressure for the MWX site. 
60. CHANOE IN STAESS VECTOR ACROSS DECOLLEMENT, JUAA RECION

Wollbore

Depth (m) Lltholory

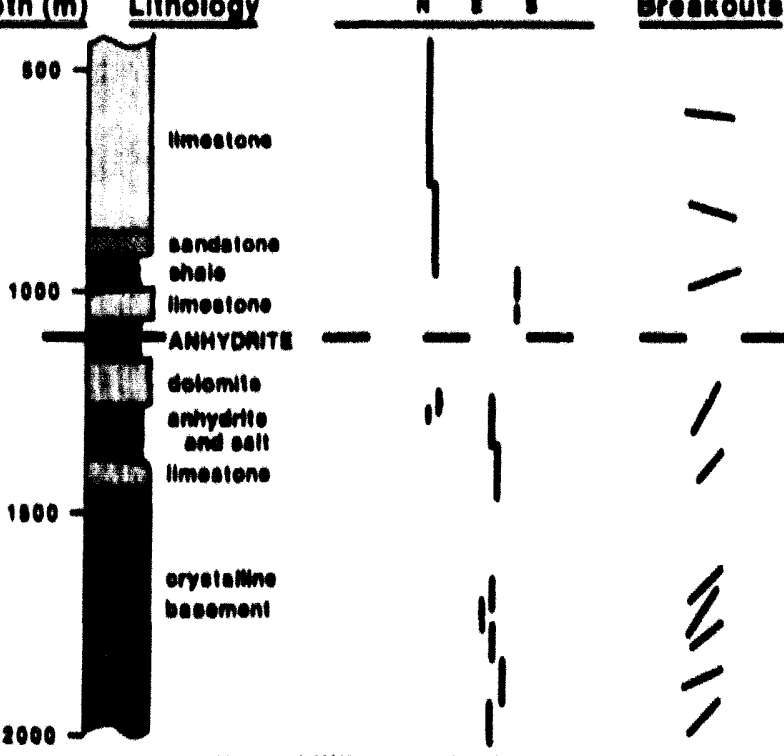

From Muller of al., 1987

(a) Stress variations across a ductile boundary layer in front of the Alpine thrust belt (from Mueller et al., 1987).

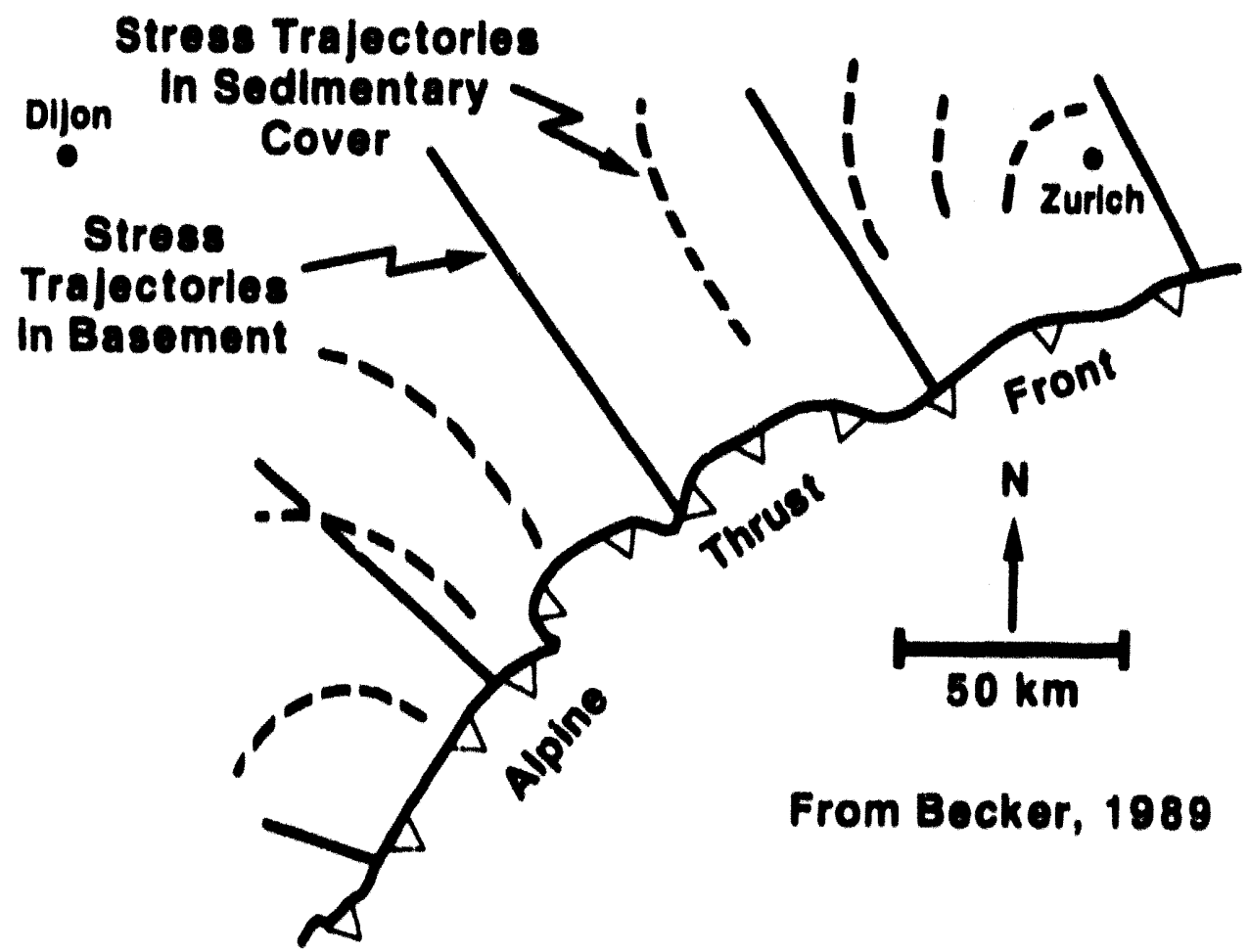

(b) Inferred planview stress trajectories of upper stress array and lower stress array in the same area as (a) (from Becker, 1989).

Figure 12. Stress in the Jura Region 


\section{DIFFERENT LAYERS WILL BE SUBJECT \\ TO DIFFERENT STRESSES}

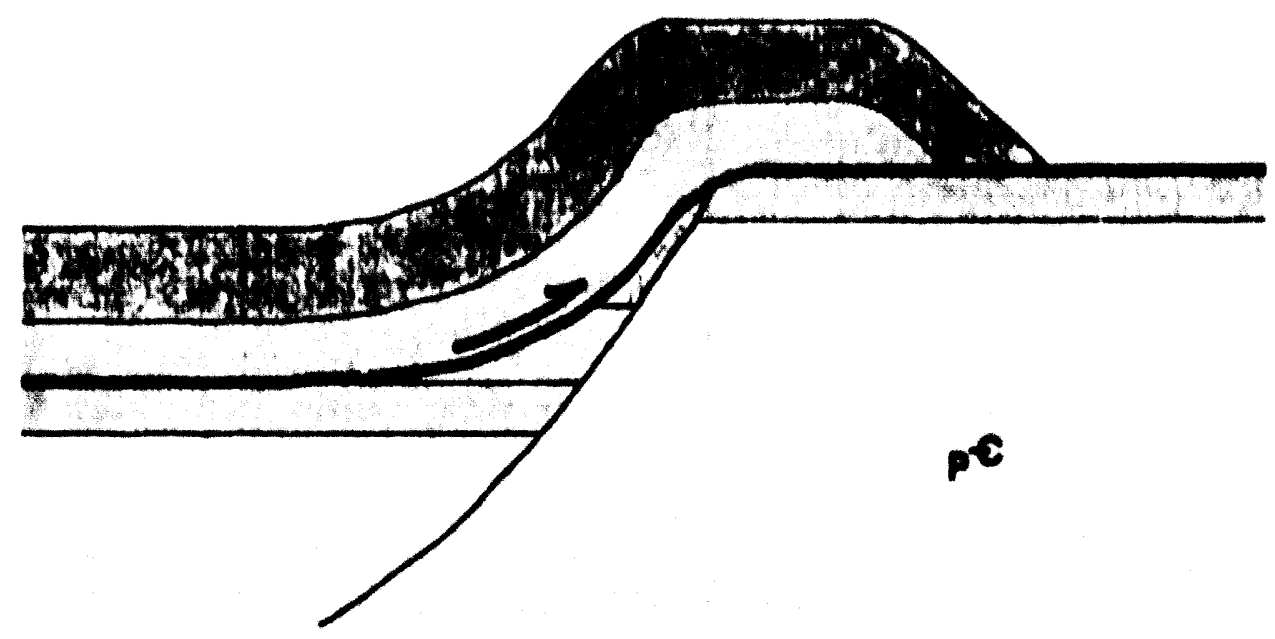

From Kullek and 8chmldt, 1988

Figure 13. Example of horizontally layered stress domains caused by buttress-induced thrusting (from Kulick and Schmidt, 1988). Measure. ments of paleostresses within strata with a similar configuration have sukgested that the stresses in the upper. unbuttrasked layers had been larkely relieved ((ienovese and Schmidt, 1989).

\subsection{Stress Refraction}

(hanges in stress orientation due to inhomogeneities in strata have heen hypothesized and can be demonstrated at the laboratory scale, but have not yet been proven at the basin scale. However, there is every reason fo believe that stress refraction at this acale can be real, and the concept has been used to explain observations of otherwise anomalous stress trajecturies. Bell and l.luyd (1989) have sukgested that un observed change in stress orientation across the l'eace River Arch in western ('anada is due to the refraction of regional stresses. Refraction is inferred to be the result of stress propagation through the higher modulus granitic/basement rock brought up by the uplift (Figure 14). It in conceivable that stress orientations within lenticular reservoirs could be oblique to stresses in the oncasing strata if the rock properties of the two strata are different. In fact, it is not uncommon for adjacent layers of strata in outcrop to display a $10^{\circ} 20^{\circ}$ divergence in strike between fractures of the same set.

On a somewhat smaller scale, normal faults may provide a sufficiently "free" surface so that the local stress trajectories are reoriented to curve away from the rexional trend and abut the fault at a right angle. 'This requires that the mochanical continuity of the formation be broken at the fault (1) by changes in rock properties such as filling of the fault by gouge, (2) by fluid pressure in the fault or fault asperity offuets so that the fault walls are not in solid contact, or (3) by the juxtaposition of strata with differing rock properties due to large displacement along the fault.

If a free-surface fault juxtaposes two different formations, the trajectories may merely refract across the surfice. However, if the original st resses are normal or parallel to the fault, little change in orientation would he expected across it.

Regional stress trajectorios oblique to a shear fault will also be affected by the local inhomogeneity. As shown by Anderson (1942), where shear creates local tension along the 
fault, trajectorien will reorient to trend normal to the funlt, an with a nurmal findt. However, where the shear creates compression along the funlt, the regional anjectories will reorient to become parallel to the fault. Such a mechanism probubly explains the various patterms of secondary fracturing in the Arches National Monument aren described by loyer (1988): lowally the secondary fractures curve to become normal to the primary irnctures, but elaewhere they curve to become parallel.

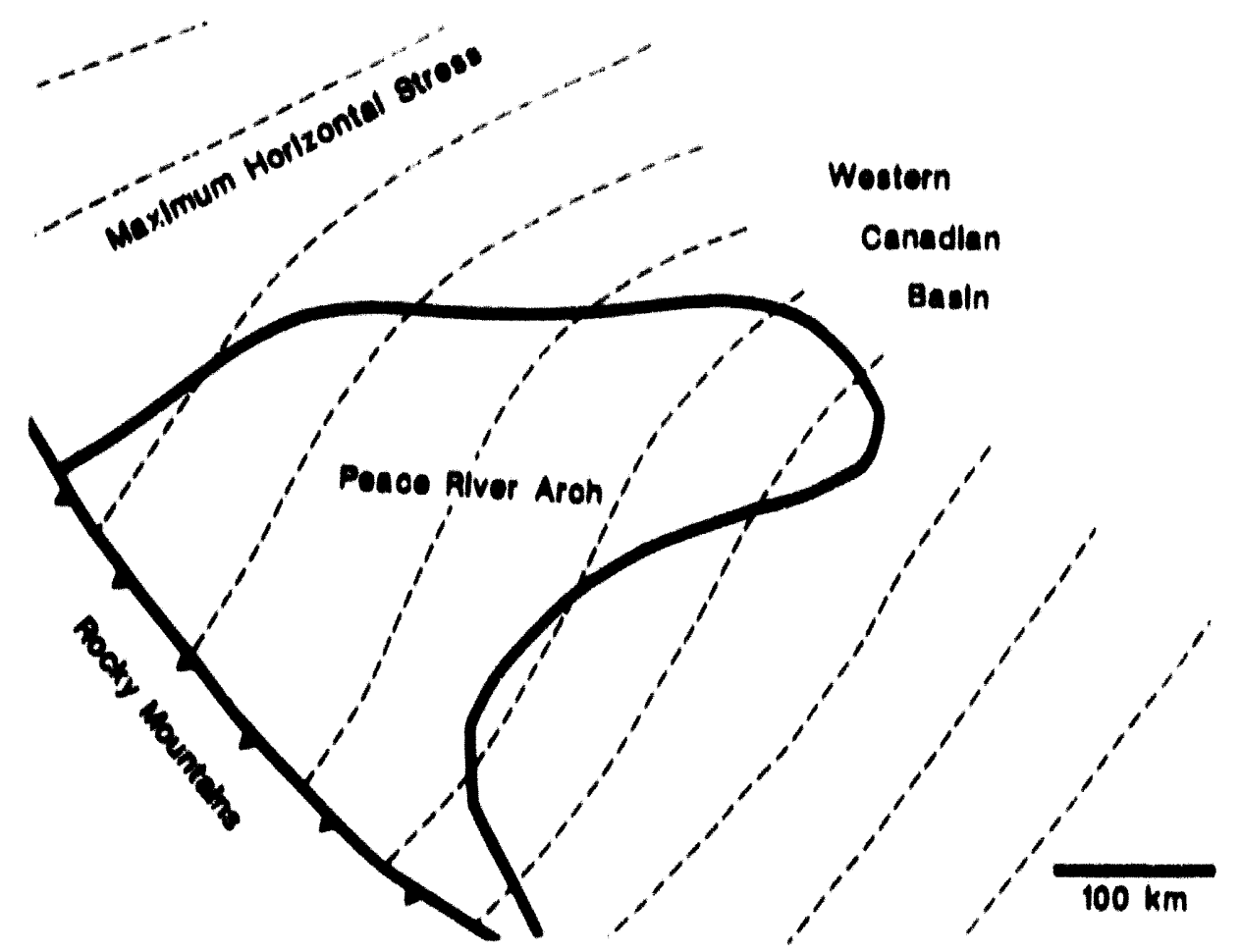

Figure 14. Stress trajectorien deflected by inhomogeneities in struta (from Bell and I,lovd, I9s:)).

\subsection{Local Stress Due to Flexure}

Fracturing is often one of the ourliest structural responsen of a formalion to anisotropic atresses. Stresses may continue to huild denpite fracturing, however, and the ultimate response of the strata may be monifest as folds or funlts. Flexure imposes a secondary set of localized stressen on the formation, strensen that may locully be quite high and that may result in the development of locul fracture sets (Stearns and Friedman, 1972). If the rocks within the fold have not fractured previously. several sets of 'iractures may develon with a geometrically predictable relationship to the trend of the fold hecouse of the flexural stresses. However, if regional froctures are prenent in the formalion prior fo folding, they may act as planes of weakness and accommodate most of the llexural strain hy reactivation. 'The angular relationship between the enrly fractures (if any), the llexural fractures, and the stresses imposed by flexure will vary from place to place on the fold: thus the permenbility of the fracture system and the producibility of a reservoir will vary. 'The system of stresses, radial fractures, and regionul iructures in chalks on the domal st ructure of the Wikofink Field is a good example of this internction ('Teufel and Furrell, 19!6)). 


\subsection{Effects of Severe Topography}

The weight of the mass of rock present in a mountuin range will add a component of stress with predictable orientation and magnitude to the regional st ress system in adjacent areas if the load is supracrustal and not isostatically compensated. The greater the relief and the more abrupt the relief, the greater the stress it imposes and the deeper it will be significant.

This phenomenon is present at the MWX site, where a topographic ress is imposed on the regional west-northwest stress. 'The topographic stress derives from the $4(0)(0)$ to $60(0)$ fit of relief between the valley floor and adjacent highlands located only a few miles immediately to the north and south (('lark. 198:3). 'The topographic stress component trends north-south at the MWX site, and ifs effect is to rotute the fotal st ress trajectory a maximum of about $15^{\circ}$ to a more enst - west orientation in the shallower parts of the MWX holes (Figure 15). 'T'his effect diminishes with depth.

Another probable example of topographic effects occurs in reservoirs in the DOE and Barrelt wells that are locuted immediutely to the south of the Anvil Points escarpment, north of the MWX site. The fractures in these reservoirs formed at the same time as those at the MWX site and therefore trend west-northwest, yet these wells responded favorably to hydraulic stimulation fractures, whereas the MWX wells, for the most part, did not. At $M W X$. the principal horizontal in situ stress trends nearly parallel to the fractures; thus the stimulation fractures did not intersect many natural fractures. Nenr the excarpment, however, the superimposed topongraphic strosm is strong and is inferred to have rotated the trend of the maximum compressive stress sufficiently to direct the hydraulic stimulation Iractures transverse to the natural fracture permeability trend. Data from one of the Barrett wells sugkests that the stresses are rotated 2()$^{\circ} 400^{\circ}$ from that found at MWX.

A colculation of the stresses due to topoxruphy can be simply made (a finite element solution will be more accurate. but also much more difficult) using the same stress solutions as for the thrust induced strens trajoctories given earlier. Given the solutions (Jaeger and ('ook, 1976) for a constant dist ributed lond.

$$
\begin{aligned}
& \theta_{2} X / \pi\left|\theta_{1} \quad \theta_{2} \sin \left(\theta_{1} \quad \theta_{2}\right) \cos \left(\theta_{1}+\theta_{2}\right)\right|, \\
& \theta_{1} X / \pi\left|\theta_{1} \quad \theta_{2}+\sin \left(\theta_{1} \quad \theta_{2}\right) \cos \left(\theta_{1}+\theta_{2}\right)\right| \text {, and } \\
& r_{2 y} X / \pi\left|\sin \left(\theta_{1} \quad \theta_{2}\right) \sin \left(\theta_{1}+\theta_{2}\right)\right| .
\end{aligned}
$$

and those for a limearly increasing lond (Figure (6),

$$
\begin{aligned}
& \text { n. }(X / 2 \pi) \| 1+(y / n) \mid\left(\theta_{1} \quad\left(n_{2}\right) \quad \sin 2 \theta_{1}\right) . \\
& \text { n. }(X / 2 \pi) \| 1+(y / a) \mid\left(\theta_{1} \quad\left(\theta_{2}\right)+\sin 2 \theta_{1} \quad(x / a)|n|\left(r_{2} / r_{1}\right)^{2} \|\right. \text {, and } \\
& \text { tay } \left.(\|) / 2 \pi) \| \quad(x / n)\left(\theta_{1} \quad \theta_{2}\right) \quad \cos 2 \theta_{1}\right) \text {. }
\end{aligned}
$$

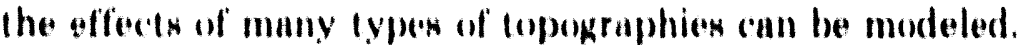

An example c'nlculation (Figure 17) is shown for Anvil Points in the vicinity of MWX and the Barrell wells (See also Appendix W). Ising stress data for struta at 600 ) ft depth and adding in the effeces of the hish Anvil Points mesn, the reorientation of the stress field was calculated as a function of the ungle of the mesa excarpment relative to the maximum primcipal stress, with the distane from the escorpment as a parameter. It can be clearly seen that the topography can significantly reorient the stress field, even at a distunce of three milen. 


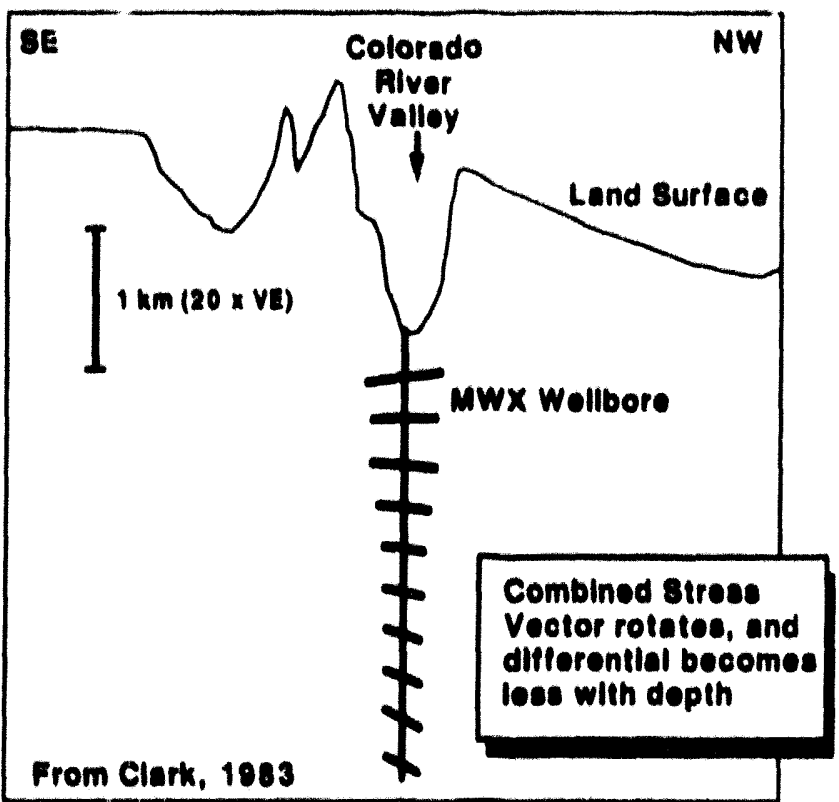

Figure 15. The changes in stress orientation and magnitude with depth, due to topographic loading near the MWX site (from Clark, 1983).

\section{GEOMETRY FOR DISTRIBUTED LINE LOAD}

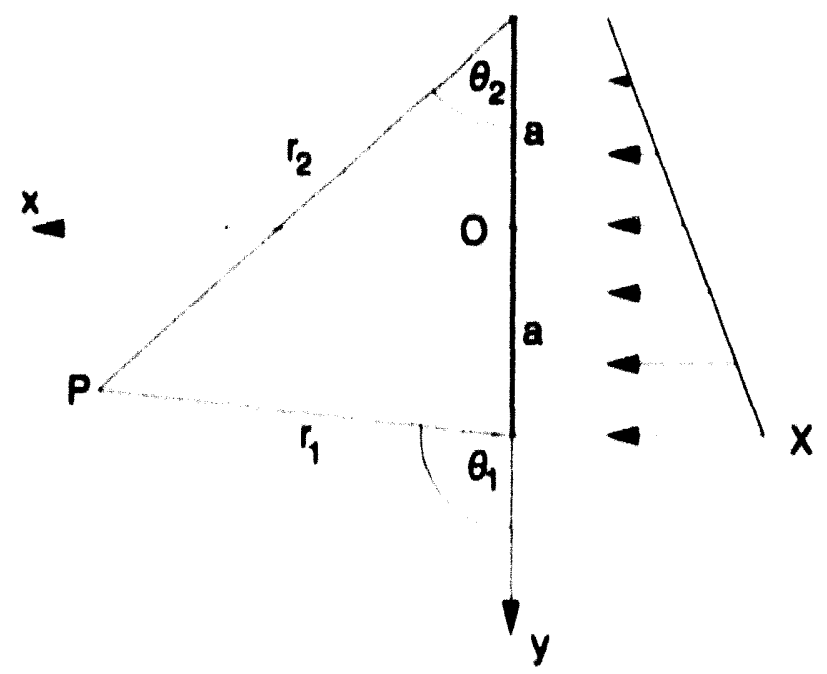

Figure 16. Schematic of the geometry for a linearly increasing distributed load applied to a semi-infinite region. 


\section{EFFECT OF TOPOGRAPHY ON STRESS AZIMUTH}

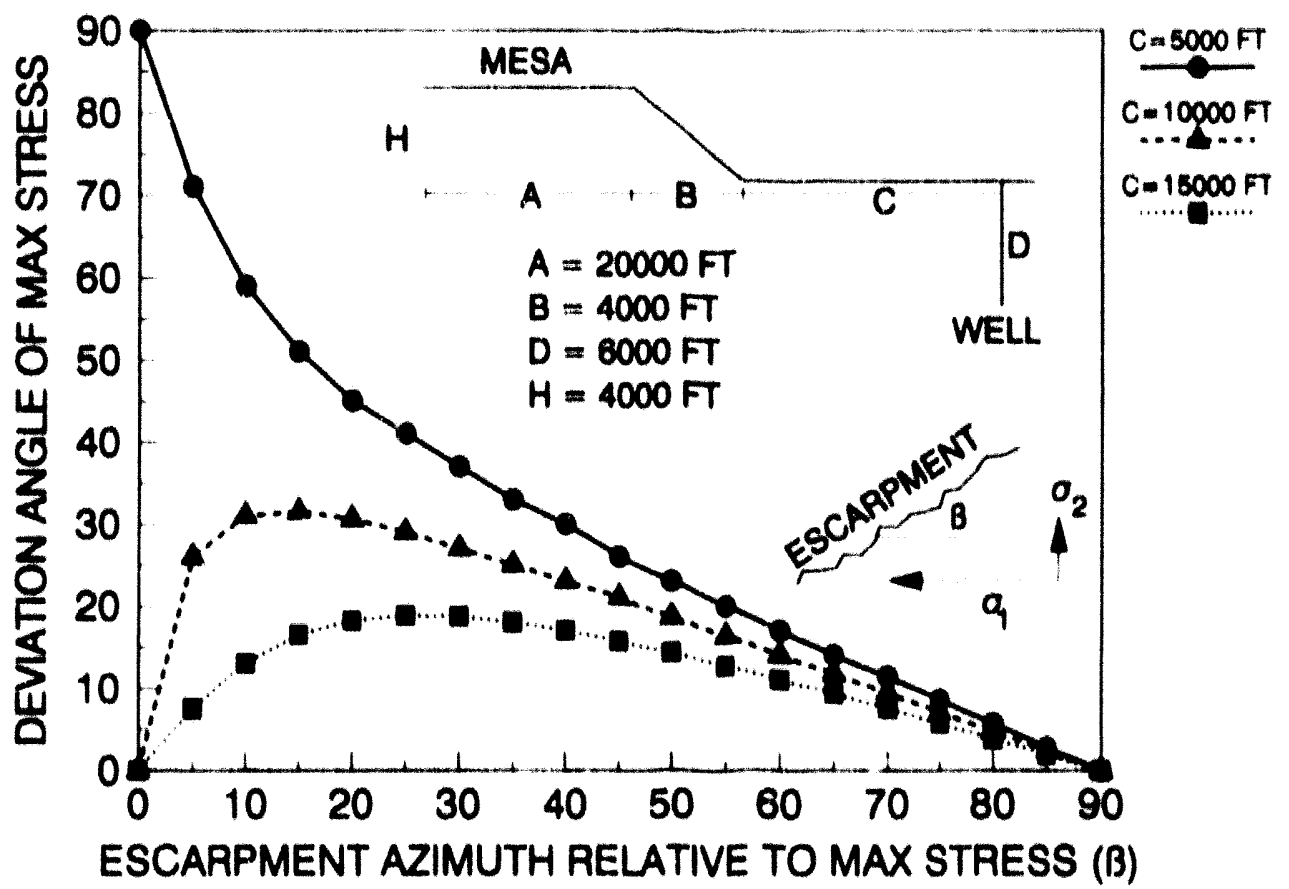

Figure 17. Calculated stress reorientation due to a mesh and escarpment as a function of the angle of the escarpment relative to the far field maximum stress orientation. A high mesa can significantly reorient the stress ficld.

\subsection{Relaxation of Stresses}

When a confining stress is removed from strata, as during uplift, erosion, or regional change of tectonic regime to extension, the response of the strata varies according to the petrophysical properties and history of the rock. Some rocks, such as sandstones, commonly display a remnant, locked in stress even after all external confining stress is removed. 'This stress originates when the component grains of the rock are cemented together by diagenesis while they are elastically deformed by external stress. Some of the elastic deformation of each grain may be "locked in" by cementation, such that when the external stress on such a rock is released, the cementation prevents the relaxation of this struin, which sets up secondary, internal stresses in the rock between the grains and the cement (Gallagher et al., 1974; Rathore et al., 1989).

If the grains were originally deformed anisotropically, the remnunt/locked in stress will be anisotropic. 'This internal stress will, in fact, hehave similarly to an active tectonic stress in affecting the behavior of hydraulic fractures or stress-sensitive reservoirs (Figur. 7). 'I'hus a reservoir may be located in a currently inactive tectonic area, yet may display anisotropic stress behavior.

Stress-release fracturing is another effect of locked.in stress. If external confining stress is released, the strength of the locked-in elastic stresses may be sufficient to break the rock, producing fractures that trend normal to the maximum confining stress at the time the stress was locked in. If fractures parallel to that stress had also formed prior to stress release, a reticulate fracture pattern may develop. 'This is a common occurrence in surficial rocks where stresses are released during quarrying activities and where preferred cleavage directions are apparent in rock without visible fabric. It also is probably responsible for the formation of 
many of the short, orthogonal, connecting fractures between throughgoing fractures in strata exposed by erosion at the surface.

In the Piceance basin, the $\mathrm{F}_{4}$ fracture set mapped by Verbeek and Grout (1983) may have such an origin. These fractures maintain an abutting and orthogonal relationship to a radiating, regional $\left(F_{2}\right)$ fracture set. $A$ related phenomenon is documented in core from the MWX site in the numerous Anelastic Strain Recovery (ASR) measurements made. When rock samples were released from the confining stress at depth during coring, some of the locked-in stress was relieved by the development of microcracks oriented normal to the in situ maximum horizontal compressive stress. Microcrack development over the course of several hours was measured as microstrains on strain gauges (Warpinski and Teufel, 1989).

Stress-release fractures would not be expected to be present in the subsurface in most instances, as significant stress release at depth is not common. Therefore such fractures mapped on outcrops should not be extrapolated indiscriminantly into reservoirs at depth.

If stress is not locked in (poor cementation or no cementation at all), the rocks would relax elastically, and no fracturing would be expected on stress release. Alternatively, if the components of the rock are ductile, remnant locked-in stress anisotropy would not be posaible, and stress-release fracturing would not occur.

The ductility of some strata, notably of clay-rich shales, commonly allows much of the stress in a rock to dissipate over time and distance when the stress is removed, or even under conditions of constant stress. Ductile strata typically are not fractured. Many "shales" contain fractures, commonly those with high percentages of carbonate and/or silica components, and not all "shales" are ductile. Moreover, high pore pressure may make otherwise ductile strata relatively brittle; shales with a high organic content may, under conditions of organic maturation and high local pore pressure, become more susceptible to fracturing than adjacent strata that would be more brittle under atmospheric conditions.

Some of these phenomena are illustrated at the MWX site by measurements of the different in situ stresses in the shales and sandstones of the Mesaverde Formation. The minimum stress in the shales has relaxed since the last tectonic stress episode and now is (1) horizontally isotropic and (2) has a magnitude which reflects only the weight of the overburden strata (Warpinski et al., 1985, Warpinski and Teufel, 1989). The horizontal stresses in the sandstones, however, are anisotropic. They are less than that which would be generated by the weight of the overburden because of a degree of strength inherent in the sandstone rock structure that helps to support this weight. Since the surrounding shales are horizontally isotropic, they are not presently transmitting a horizontal tectonic stress. However, they must have transmitted enough stress at some point in their history to have caused the sandstones to fracture. Therefore the stress anisotropy in the sandstone reservoirs must be a remnant one, transmitted through the shales before they relaxed.

Another example of locked-in stress is documented by McLellan (1988) in describing the foredeep basin of Alberta. The situation is essentially that found at the MWX site, with horizontally isotropic, relaxed shales at overburden stress and horizontally anisotropic stresses in the sandstones. In Alberta, however, the stresses in the sandstones are higher than the overburden stress, arguing for a significant horizontal tectonic stress during cementation (which is entirely likely given the adjacent thrust belt) and/or the erosional removal of a significant thickness of overburden strata (also likely in this area).

Theoretically, limestones would be less likely than siliciclastic sandstones to retain a locked-in stress because their ductility under high confining pressure and elevated temperature commonly exceeds that of shale (e.g., Handin, et al., 1963). Moreover, carbonates are typically soluble under these conditions, especially when nonuniformly stressed, and strain in limestones may therefore also be accommodated through pressure solution and recrystallization. The ductility of dolomite, however, is nearly as low as that of clean, quartzitic sandstone.

There are good examples of anisotropic stresses measured in chalk reservoirs (e.g., Ekofisk field), and many of these rocks behave elastically in the laboratory on a short time 
scale. 'Thus carbonates may exhibit not only the record of an active tectonic stress anisotropy, but they also seem to have the potential for preserving a remnant stress anisotropy. If so, stress-release fractures may develop in limestones under the right conditions.

The difference in behavior between an elastic rock, such as a well-cemented sandstone, or a more ductile one such as clay-rich shale, probably represents the extremes of a spectrum. Shales have a short relaxation time constant (the MWX shales fit a 5 million year time constant; Warpinski, 1989), whereas sandstones seem to have vastly longer relaxation time constants, probably on the order of tens to hundreds of millions of years. Accordingly, sandstones are essentially elastic during the time scales of interest.

Stress may dissipate laterally as it is "diluted" radially from a point source and/or as it is accommodated by strain in the rocks. This is not a stress release, but it may limit the size of an area that is subject to sufficient stress to cause fracturing.

\section{Analysis: Reconstructing the Stress/Fracture History of a Basin}

In reconstructing the tectonic history and ultimately the stress/fracture history of a potentially fractured reservoir, it is necessary to be able to read the fossilized record of stress in the rocks. It is also useful to be able to measure the present-day in situ stresses. Such stress records may include but are not limited to the kinematic indicators used by structural geologists. Many stress records do not record actual motion of the rocks, only the orientation of the contemporaneous stress.

Some measurement techniques can be used to calculate present-day stress magnitudes, but there are few if any reliable ways to measure paleostress magnitudes.

\subsection{Paleostress Indicators}

Paleostress records range in size from microscopic crystal deformation to the trends of mountain ranges. The reliability of each indicator can vary with local circumstances, and each should be evaluated accordingly. A suite of mutually supporting indicators of different categories and magnitudes offers the most reliable evidence. Such a suite has been documented within the Piceance basin (Figure 18), and this will be used as the primary example in the discussions below.

\subsubsection{Microscopic Indicators}

Calcite is subject to crystallographic twinning when stressed anisotropically. 'This produces characteristic deformation lamellae that can (laboriously) be measured in thin section with a petrographic microscope and universal stage in order to determine the stress orientation (e.g., Groshong et al., 1984; Teufel, 1980)). Several samples of calcite cement in sandstone core from the MWX wells were analyzed in this manner, yielding maximum horizontal paleostress orientations of northwest to west-northwest.

Quartz also deforms under stress, but instead of twinning, crystallographic shear planes are produced (Mclaren et al., 1970). These shear planes can also be measured under the microscope and analyzed for the maximum compressive stress. Dula (1981) analyzed quartz deformation planes in the White River Uplift (the mountainous Laramide uplift just east of the Piceance Basin), concluding that the recorded maximum paleostress was horizontal and that it trended west-northwest.

These measurements of the paleostress in the vicinity of the MWX site are consistent and suggest that the horizontal stress locally exceeded the vertical, overburden stress. This fits well with the concept of the White River Uplift as a thick-skinned, overthrust indenter into the basin. The direction of thrusting indicated by the crystallographic evidence is westnorthwest, which fits with evidence from the microscale configuration of the Grand Hogback (the boundary between the basin and the uplift). 'This will be discussed below. 


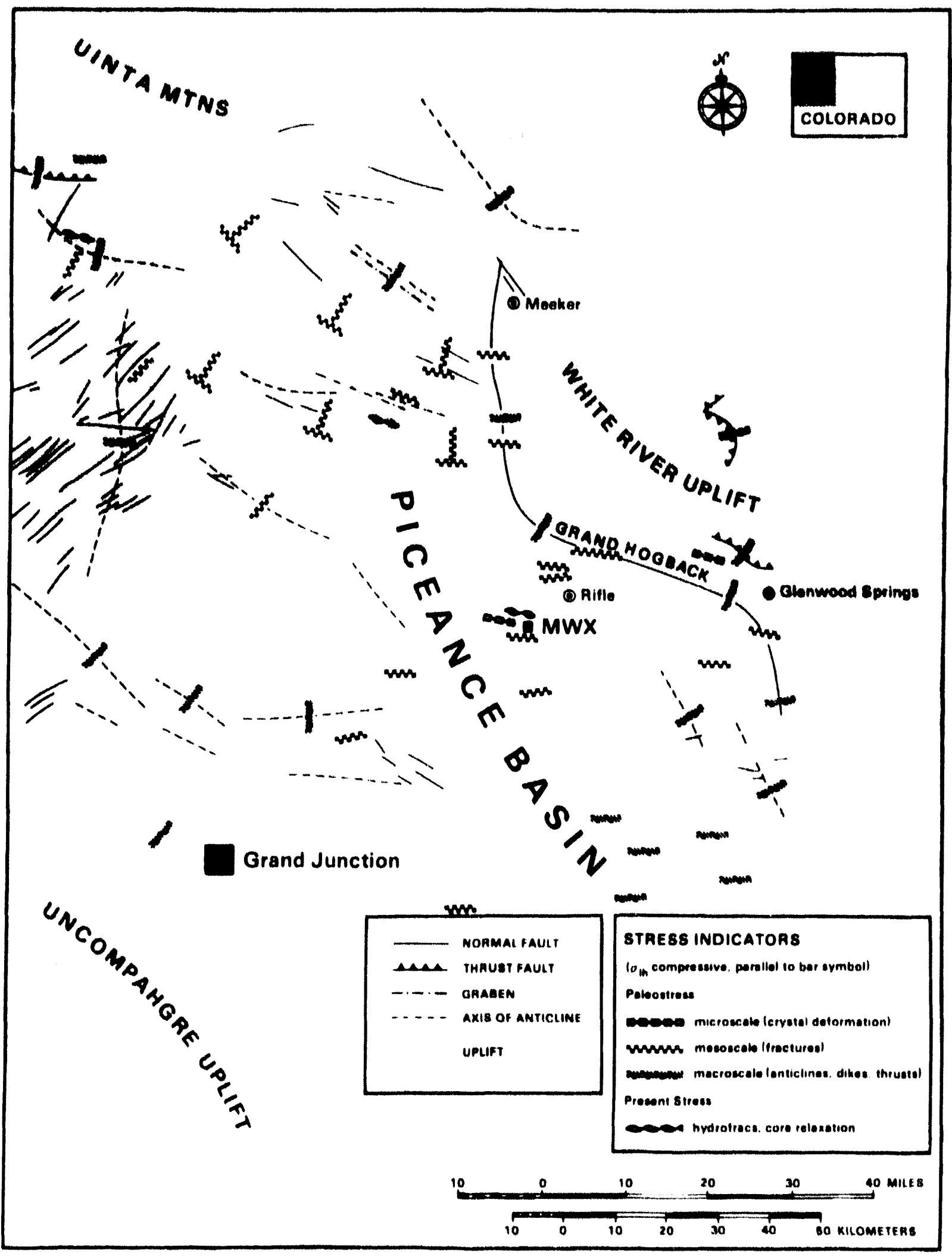

Figure 18. Map of the Piceance basin showing the trends and occurrences of paleostress indicators. 
Stress domains may vary rapidly both laterally and vertically, and isolated microscopic stress indicators should not be relied on for the reconstruction of stress trajectories across entire basins. Nevertheless, they do offer important information ou stresses at local sites and corroborating evidence for more regional stress history reconstructions. For calcite twin lamellae, estimates of the differential stress at the time of formation can be made, and a threshold of at least 100 bars must be achieved before twins are formed (Jamison and Spang, 1976). However, the actual stress magnitudes cannot be derived.

\subsubsection{Mesoscopic Indicators}

The intermediate scale of stress records includes most of what are usually measured as "kinematic indicators" (e.g., slickensides, veins/gashes, conjugate shears, etc., e.g., Arthaud and Choukroune, 1973) by structural geologists when reconstructing the relative motion between great masses of rock. However, since relatively few hydrocarbon reservoirs are located under mountain ranges, we will concentrate here on the more subtle indicators that occur in less-deformed, sedimentary strata, i.e., vertical extension fractures. (See also Appendices A, B.)

Vertical extension fractures are present in almost all sedimentary strata, despite the absence of other evidence of deformation. Such fractures form as a result of horizontal stress anisotropy in the strata acting on rocks that fail in a brittle mode despite high confining stresses; pore pressure partially negates the confining stresses, creating brittle strata. Stress anisotropy not only creates fractures, but it also dictates fracture orientation and maintains fracture aperture. Fxtension fractures will be oriented in the plane of the maximum and intermediate compressive stresses and will be normal to the least confining stress. Since the overburden stress is most commonly the maximum stress, most extension fractures are vertical. Even if one of the horizontal stresses is the maximum stress, extension fractures will be vertical as long as the overburden stress remains at least the intermediate stress.

Thus vertical extension fractures may be used to determine the orientation of the horizontal stress anisotropy. Because horizontal stresses will be isotropic in the absence of tectonic influence, fracture orientations may often be used to infer the presence, type, and location of tectonic activity at the time of fracturing.

At the MWX site and in the Piceance basin, several sets of fractures have been documented by numerous authors. (See summary in Lorenz and Finley, 1991.) Westnorthwest fracture orientations suggest a west-northwest maximum horizontal compressive stress in strata throughout most of the basin. 'These are interpreted to reflect the stresses derived from the Sevier overthrust belt to the west and locally from the incipient thrusting of the White River Uplift.

Several exceptions to this west-northwest trend occur, most notably (1) in fractures that form an array spreading westward across the basin in the Tertiary strata and (2) in fractures that are younger than and orthogonal to other fractures. 'The former are interpreted as having followed an arcuate stress trajectory formed by the point stress source as the White River Uplift was thrust into the basin. (See Figures 5 and 9.) The latter are inferred to be stress-release fractures, as discussed above, formed during uplift and erosion.

Vertical extension fractures may also form where no obvious source of compressional tectonism exists, or may even be normal to an expected trend if extension in another direction exceeds that from an obvious but superficial source of compression. An example of this is the Cretaceous strata of southwestern Wyoming, where asymmetric subsidence in a narrow, deep basin produced significant extension transverse to the narrow axis of the basin. 'This strain exceeded the extension due to compression froin the adjacent thrust belt; thus the fractures were formed parallel to the axis of the basin and parallel to the thrust belt (Laubach and lorenz) (Figure 19). 

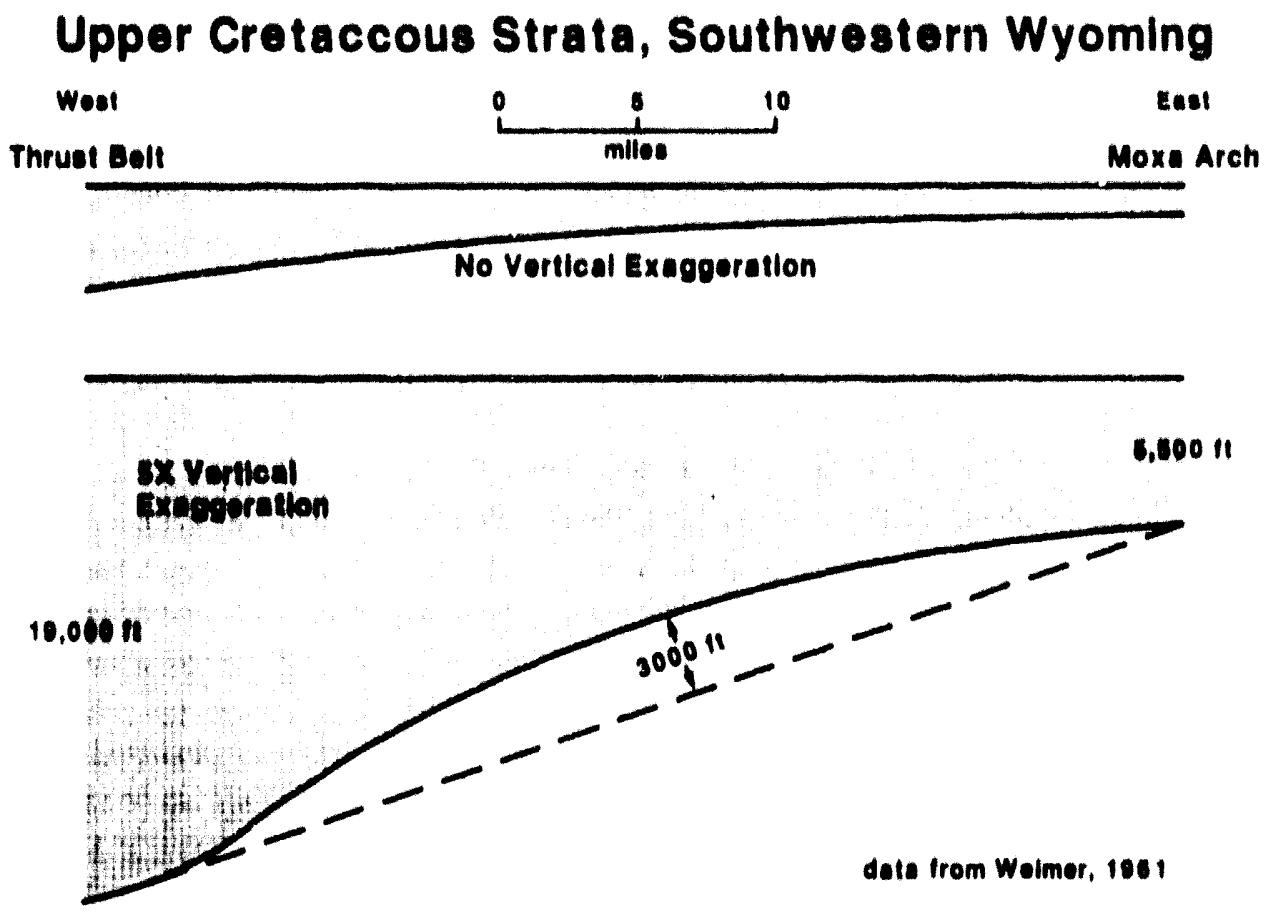

Figure 19. Rapid subsidence in a narrow basin that led to asymmetric stresses and fracturing parallel to the basin axis despite thrust-fault compression normal to the basin axis: Cretaceous foredeep of the Green River basin, southwestern Wyoming.

\subsubsection{Macroscopic Indicators}

Large-scale stress records are perhaps the easiest to see and measure, yet are also potentially the most deceptive. Examples of mesoscopic stress indicators that occur in the Piceance basin include normal faults and thrust faults, anticlines, graben, and igneous dikes. There have also been remote-sensing studies of various "lineaments" in the basin, but the significance of lineaments is highly questionable when their origin is unknown, and they will not be discussed further here.

The least ambiguous of these indicators are igneous dikes. Several 'Tertiary dikes have been mapped in the south-central part of the basin, and others exist in the central basin, all of which trend east-west. A dike is a natural hydraulic fracture and will be oriented normal to the least compressive stress; therefore, the maximum horizontal stress in the basin at the time of intrusion was east - west. The dikes are up to 5 miles long and reflect a consistent stress orientation in the strata to a depth of at least this magnitude. Stress rotation with depth would be apparent as an en echelon segmenting of the dikes, which does not occur. 'Thus the dikes are good paleostress records, and their orientation is consistent with other stress indicators discussed thus far because the strikes of extension fractures in this part of the basin rotate to become east-west or even slightly west-southwest.

Faults must be interpreted more carefully. Ideally, normal faults and graben form in extension normal to the least compressive stress while thrust faults form normal to the maximum compressive stress. However, there may be a component of strike-slip motion in addition to the dip-slip motion in either type of fault. 'The magnitude of this oblique motion can be considerable and is the result of stresses that are not entirely at right angles to the fault plane. A pre-existing weakness in the rock may also dictate the location and trend of the fault, whereupon the stresses only activate that weakness, do not control the fault orienta. tion, and cannot be directly inferred from fault orientation. 
Normal faults and the one gruben within the Piceance basin trend primarily northweat, consistent with the dominant northwest maximum compressive stress suggested by other indicators. 'There is some scatter, which probably reflects basement heterogeneity, but no evidence for strike-slip motion has been reported from these faults.

A major thrust fault is present at the eastern margin of the basin, forming the (irand Hogback and creating the White River Uplift. Smaller thrusts are buried below the Divide Creek and Wolf ('reek Anticlines in the southeastern part of the basin (Cirout et al., 1991). 'The edge of the Uncompahgre Uplift at the southwestern markin of the basin may also be located at a thrust fault, but this has not been documented.

The smaller, buried thrusts apparently record east-west thrusting. Although they are complex, they may be interpreted in a relatively straightforward manner once suitable subsurface/seismic data is available. 'The (irand Hogback thrust, however, displays an ambiguous dogleg in the middle sector that has been interpreted to indicate a thrust event directed toward the south or southwest (Perry et al., 1988). Southwest thruating would be in addition to (and at a different time from) the eastward-directed thruating suggested by the north-south trending segments of the hogback. Strata along the dogleg are rotated more nearly vertical than strata on other parts of the hogback, and an overhang has been demonstrated near the center by industry drilling.

Study of this zone is incomplete, but none of the fracture patterns directly south of the dogleg support local north-south compression. Alternatively, the dogleg may an artifact of basement heterogeneity, and the true structure may be a tear-fault discontinuity in the north-south thrust that is obscured by blind, eastward-directed thrusting beneath the Mesczoic cover. In any case, the major thrust fault in the Piceance basin is an ambiguous stress indicator despite its large size and large-scale movement.

Anticlines within the Piceance basin are the least reliable of all of the local stress indicators. An anticline is typically interpreted as the result of horizontal compression normal to its axis, especially where numerous en echelon anticlines are present as in the Appalachian fold belt. However, most of the examples of antiform strata in the Piceance basin are out of phase. Most also trend west-northwest, suggestive of a north-northeast compressive stress that is nearly normal to any other stress record present in the basin. 'These "anticlines" seem to have been draped passively over faulted basement blocks. Each block was uplifted by stresses that were only loosely related to folding of the overlying atrata, and the fold axes were commonly oblique to the stresses that uplifted the fault blocks. In such cases, the trend of the antiform reflects primarily the heterogeneity of the faulted basement, not a dominant stress orientation.

\subsection{Present-Day, In Situ Stress Indicators}

Several techniques can be used to measure the modern in situ stress orientation, and some also provide a measure of the stress magnitudes. Most of the methods provide only site-specific information.

Core and wellbore analysis were used to measure site-specific stresses at the MWX site. Among the techniques used to measure stress from core samples were Anelastic Strain Recovery (ASR), Differential Strain Curve Analysis (DSCA), Circumferential Velocity Anisotropy (('VA) (see Appendix 1)), and the measurement of coring-induced petal/petal. centerline, scribe-line, and disc fractures (see Kulander et al., 1990; lorenz et al., 1990; Strickland and Ren, 1980); Teufel, 1983). 'The first three techniques measure the orientation of microscopic stress release fractures that develop in the rock normal to the maximum in situ horizontal stress when the confining stress is released. Coring induced fractures form with a strike (petal, petal-centerline, and scribe-line fractures) or plume axis (disc fractures) that usually parallels the in situ maximum horizontal stress. All of these methods provide information on the maximum horizontal stress direction only if the core is or can be oriented.

Stress magnitudes may also be calculated from the ASR technique in ideal cases (Warpinski and 'Teufel, 1989). Another procedure that measures the magnitude of the minimum in situ stress is the mini-or micro-frac technique, where small volumes of fluid are 
injected into the formation from the welloore while the injection pressure is monitored (Warpinski, 1986). Pressure continues to be monitored after injection is stopped, giving a measure of the stress the formation exerts on the fluid as the induced fracture is forced closed.

Analysis of the breakouts in a borehole, using caliper, borehole images, or other downhole tools will also indicate the local maximum horizontal stress direction (e.g., Fordjor et al., 1983; Plumb and Cox, 1987). A borehole commonly becomes elliptical as breakouts develop preferentially on the borehole walls that are aligned with the minimum horizontal compres. sive stress.

Finally, the direction of propagation of a hydraulic fracture may be monitored seismically (Hart et al., 1984) or by the use of instruments such as tiltmeters. 'The direction of propagation is controlled by and will parallel the maximum horizontal in situ stress. All of these methods (except tiltmeters) have been used successfully at the MWX site, and they consistently indicate a west-northwest maximum horizontal compressive stress.

There have been reports of success in determining the local subsurface stress direction by measuring seismic shear wave anisotropy (e.g.. Crampin, 1985). In theory, since horizontal stress anisotropy preferentially holds open those natural microcracks in the rock that are aligned with the maximum compressive stress, shear waves will be impeded in the direction transverse to the open microcracks. A unidirectional set of macrofractures will have the same effect, whether they are aligned with the present maximum stress or not. Although fractures and stresses are commonly so alikned, care must be taken to be sure that stress is being measured with this technique and not an oblique fracture orientation.

Barthquake fochl mechanisms have been used to determine the direction of stress orientations in large tectonically active areas (liang and Wyss, 1991). Although such measurements are valid, they commonly measure the stresses at much greater depthe than most reservoirs, and they are not sensitive to the local variations in stress that structures and topogruphy can couse.

In the l'iceance basin, the orientation of the stress field has been successfully measured at several sites. 'The orientation of the stress field at MWX (Figure 20) has been measured using several technigues, all of them showing a stress orientation that is slightly north of west with a possible rotation with depth. Measurements further north (Bredehoeft et al., 1976) showed a similar stress orientution (Figure 18), as did velocity anisot ropy measurements on a Fuelco well about if $\mathrm{mi}$ to the southwest of $\mathrm{MWX}$. 'The only data in disagreement are velocity anisotropy and coring-induced fracture results from the Barrett MV8.4 well in (irand Valley. However, this well is under the severe topography of Anvil Points and probably suffers a rotation due to the additional lond.

ASR results at the MWX site suggest that differences in the two horizontal stresses in the Mesaverde vary from about 6(0) 1200 psi, depending upon the depth and the zone.

\subsection{Pore Pressure}

One of the major uncertainties in reconstructing the fracture history of a basin is the fracture susceptibility of the struta through time. This is largely dependant on formation pore pressure, though other factors such as changing rock properties fa function of cementation, compaction, diagenesis, etc.) are also important. Pore pressure will change as the organic material in a formation matures and produces gas, as burial/compaction ratios evolve, as the strata are compressed laterally by tectonism, and/or as temperature gradients change. Reconstruction of pore pressure histories is difficult. Uncertainties include the gross estimates that must be made of organic volumes contained by formations and the percentages of the gasses produced that may have heen lost or adsorbed.

Nevertheless, geologically reasonable estimates can often be made at least of the probable timing of elevated pore pressures, if not of their magnitude, and of how the pressure history interacted with the tectonic/stress history of a formation. Such estimates were made for the Piceance basin at the MWX site, where it can be demonstrated that elevated pressure produced by gas generation in the formation (Spencer, 1987) coincided with enhanced 
tectonic compression to create natural fractures (Lorenz and Finley, 1991). An important piece of corroborative data for this interpretation came from fluid-inclusion analyses, which provided an indication of the in situ temperatures and pressures during fracturing.

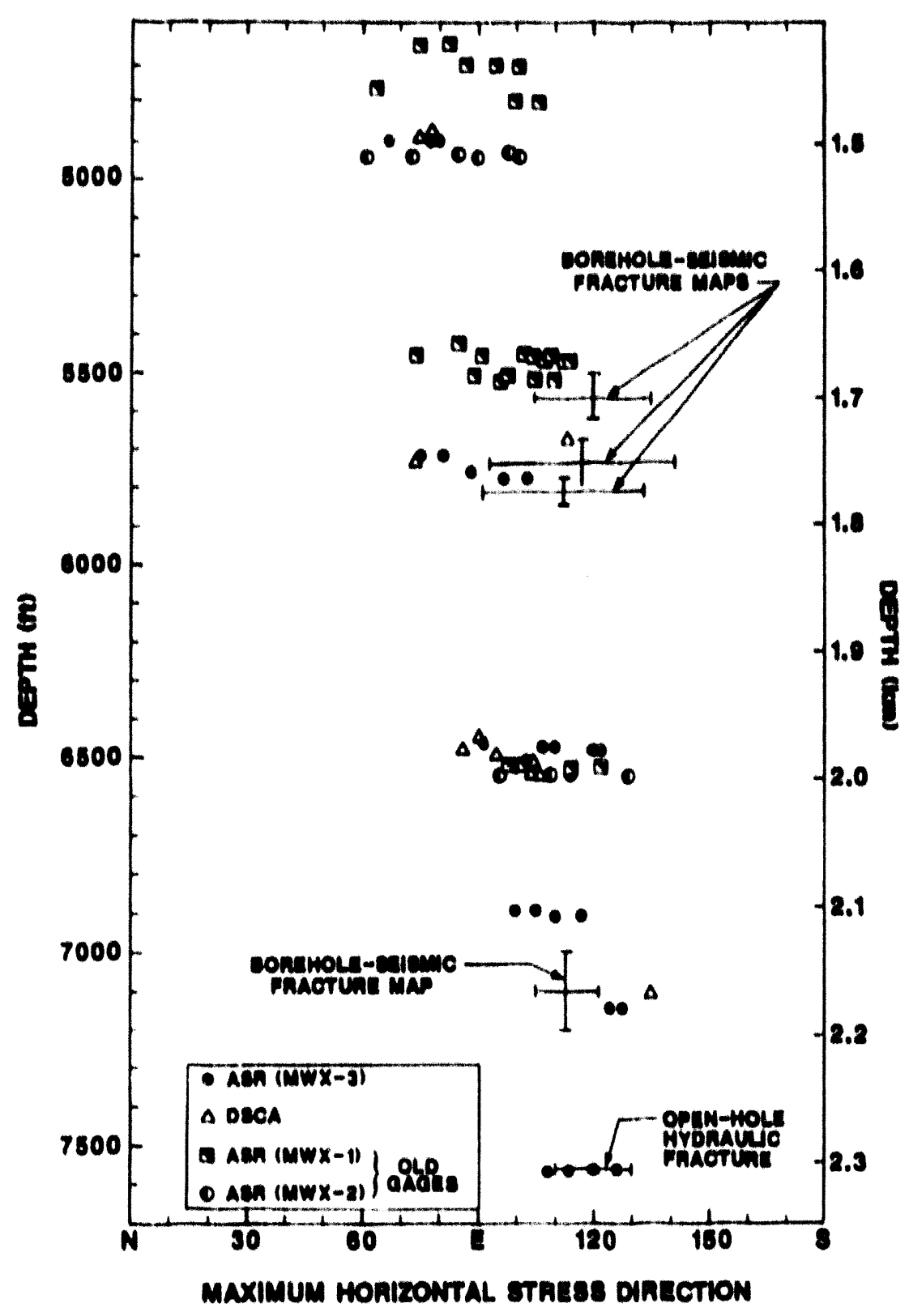

Figure 20. Orientation of the stress field at MWX based on Anelastic Strain Recovery (ASR) data in three wells, Differential Strain Curve Analysis (DSCA) on selected samples, an open-hole hydraulic fracture (impression packer), and four hydraulic fracture experiments where borehole seismic instru. mentation was used to map the fracture azimuth. 


\subsection{Summary}

Paleostress indicators should be uned in conjunction with tectonic reconstructions to create a conceptual strens-history model of the stratn in cuention. An integrnted numerical model is within the capabilitien of computer programs (e.g. Warpinski, 1989), but is only un accurate as the geologic data available. Any model must use or correctly predict the measured paleo-stress indicators and the known prenent - day stresses as known tio points.

A tectonic and atreas history model was constructed for the Mesaverde atrata it the MWX site (lorenz, 1086; Warpinaki, 1989; lorenz and Finley, 1991) that incorporatex mont of the factors discussed above. 'The principal components of the model include (1) " curve depicting the depth of burial relative to the changing-elevation land surface through time (Figure 21), (2) an analywis of the timing and probuble effects of the different tectonic ovents in and around the basin (regional uplift, volcanimm, hasin-margin thruating, etc.), (i3) " conceptual model of the pore pressure in the formation through lime, (4) basement heterogeneities, (5) empirical evidence of the natural fracture characteriatics and dist ribution throughout the basin, and (B) measurements of the modern in situ strenнes.

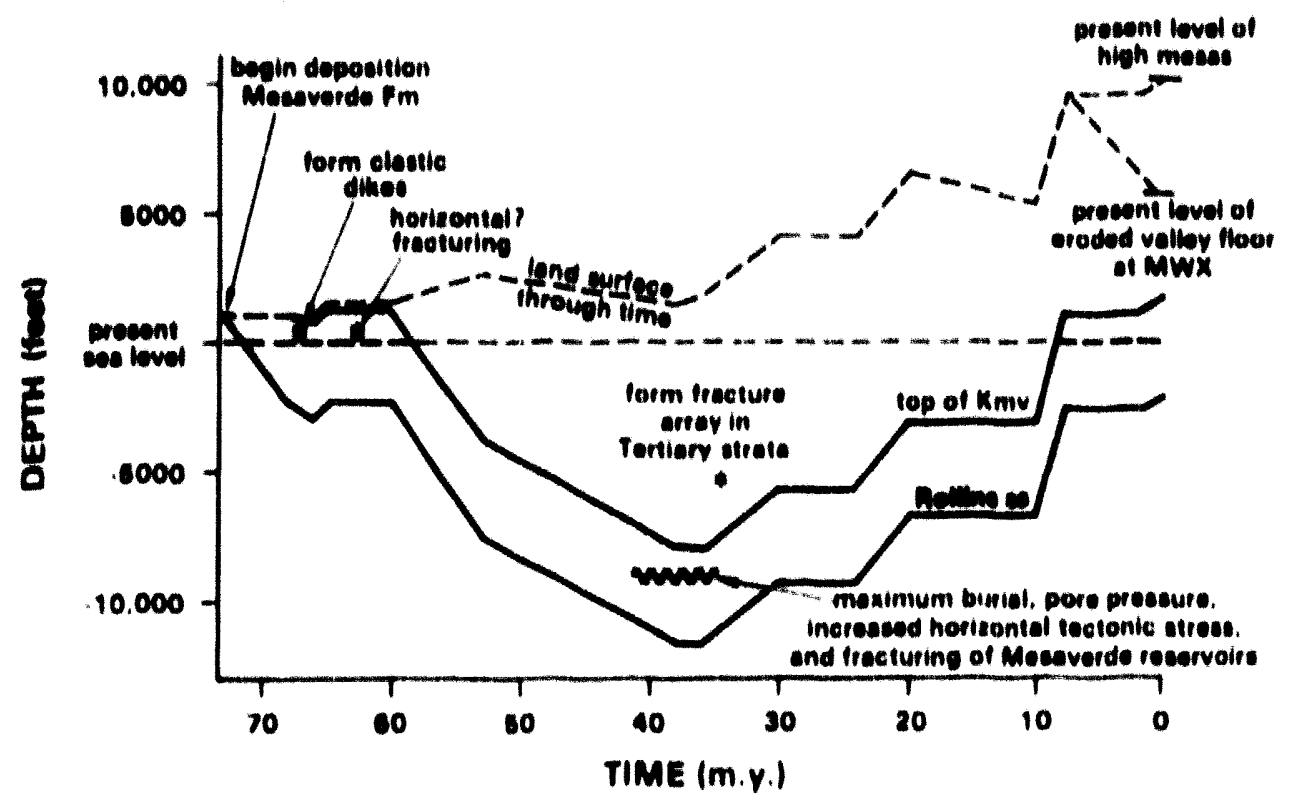

Figure 21. 'Time/Burial depth/Surfuce-elevation diakrum for the struta at the MWX site in the Piceance basin.

'These data and the synthesis suggest that natural fracturing occorred during a time of elevated pore pressure, at maximum depth of burial, and under conditions of enhanced compressive stress due to basin-markin tectonic compression about 36 . 41 million years nko. Significantly, the shales that surround the sandstones are in a relayed state and reflect the overburden stress. Therefore. the present stresses in the reservoir sandstones must be locked in/remnant stresses because no horizontal tectonic compression is boing transmitled to the sandstones through the shales. 'The maximum horizontal stresses (both puleo and present) caused fracturing and are therefore parallel to the natural fructures. Accordingly, most of the fractures comprise a single, west-northwest trending, regional set. However, the local high-relief topography may rotate the present shallow stress orientations by $10^{\circ} 16^{\circ}$. 


\title{
7. Prediction of Fracture and Stress Orientations in a Basin and at a Well Site
}

The above criterin can be used to infer paleo and present stress patterns in a basin and thus to predict (1) the potential for fructuring in a kiven set of reservoir atrata and (2) the probable relative orientations of iractures and the in situ stresses. With thin information, the effects of the stresenes on renervoi deliverability may be inferred.

As with any prediclions, the larger the data base, the befler the prediction. Moreover, once a well is drilled based on predictions, new data become nvalable, allowink for the incremental refinement (or sometimex the drastic modificution) of original predictions until the prediction eventually matches reality when all factors are known. 'The goal, of course, in to make as accurate a prodiction an ponsible an early an ponsible. Infortunately, time and money often dictate that the initial prediction will be baned on a limited data net. (iven the complexity of geoloxic systems, which usually contain hidden factors that are revealed only at inopportune times, one should be propared to modify predictions.

A nummary list of the data desirable for predicting utrensen and fractures in the neneric basin is siven in Thable I. T'his is 1 short table, but, as shown above, each catenory admits numerous possible sources of data and contains numerous potential ambiguitien.

\section{Table 1. Information for Predicting Subsurface Stress and Fracture Patterna at a Woll Blte}

\author{
Prenent rexional strens orientutions \\ Present regional stress magnituden \\ Surface fracture palteriss \\ Time depth history of the strata \\ Regional structural patterns and timing \\ Formution pronsures, past and prenent \\ 'Topokraphic profiles of the site
}

There are two parallel studies that must be made and then interrated in order to reconstruct the fracturing events and to predict fracture orientation. One in to entimate the fracture susceptibility of the stratn through time, and the other in to reconstruct the stress-anisotropy (tectonic) history of the basin. 'Time intervals where high susceptibility coincides with high anisotropy are the mont likely limes of fracturing, and the stress orientations at these times will control fracture trends.

A numerical example if this approach has been constructed for the Piceance basin (Warpinski, 1989). Stresses were culculated through time hased on geologic extimates of compressive tectonic stress and depth of hurial (Figure 22), and fracture susceptibility was calculated based on varying rork properties (derived from geologic estimates of the pore pressure, temperature, und dingenenis histories). In this study, the likelihood of fracture was based on a romparianon of the stress conditions with a laboratory-derived failure envelope for samples of the reservoir sundstones (Figure 2:3). ('alculated end-result stresses correlated best with those measured in the strata when a visco elastic model of the strata was used.

All alternative, empirical, and complementary approach to modeling the same basin is presented by lorenz. and Finley (1991). In this analysis it was noted that the limink of maximum compreskion due to husin margin thrusting coincided with maximum burial and with maximum organic malurution (therefore with maximum formation pore pressure). 'Therefore, maximum fracture susceptibility was contomporaneous with maximum stress anisotropy, and fracturing was inferred to have cocurred at this time. 'The orientation of the fractures is compatible with the compressive stress trajectories produced by thrusting. 


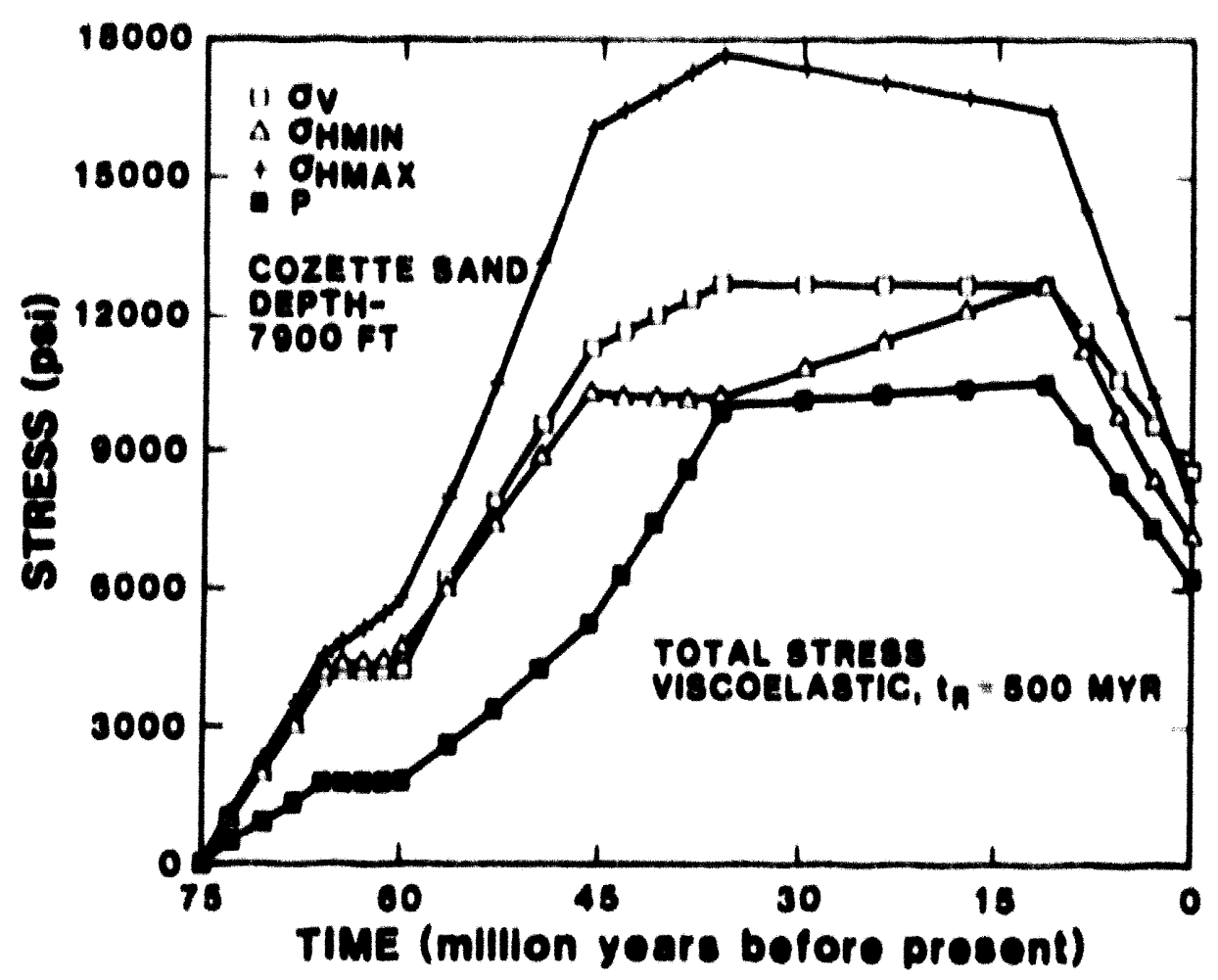

Figure 22. Recometructed atrens hintory for the atrata at the MWX nite

\section{CALCULATED 8TAE88 hIBTORY FOR COZZETTE BANDSTONE}

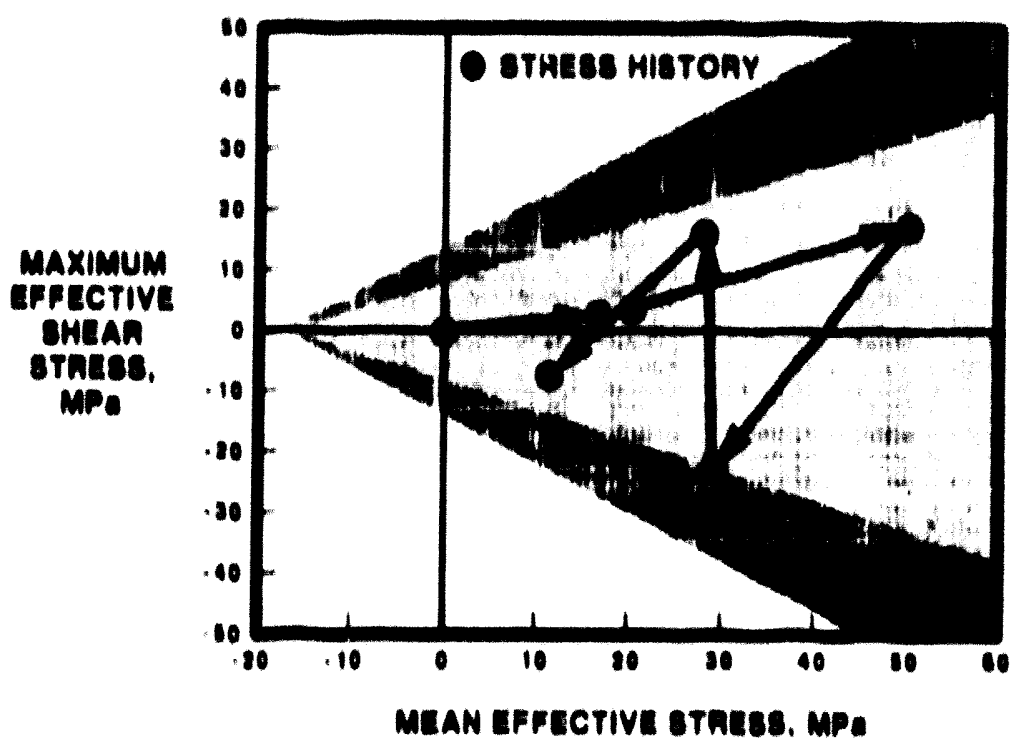

Figure 23. Stressen (from previous figure) plotted within an empir. ical failure envelope, indicating the most likely times of fraciuring. Outer envelope is failure plane from laboratory data. Inner envelope indicates failure plane corrected for geolonece criteria. 
Similar approaches may be taken to predict fracturink and fracture/streas orientations without foreknowledge of the fracture character or of the present stress state at depth. However, there will be fewer definitive tie pointa between the model and reality, and the reconatruction will be commenaurately less reliable.

\subsection{Tectonic Stress Hiatory}

1. The tectonic hiatory of a basin muat first be understood. All potential sourcen of anisotropic streas in the basin (asymmetric basin subuidence, thrusting. flexure, topography, etc., as diacumaed earlier) must be identified and mapped, and the probable orientations of trajectorien of the stresses produced by each source plotted. Differentiate between regional stressen and local stresu-modifying features.

2. The time intervala during which each stress was a factor muat be determined as closely an posnible. Stratigraphic dating and radiometric dating are essential in this exercise, but, unfortunately, the two time ncales do not always coincide, and they rarely offer the deaired precision.

3. The maknituden of ntrensen should be estimated if possible. This may be approached by measuring indentation diatances, radii of curvature, amountw of uplift, or the amounts of strain that resulted from each mource. Une geologic principles and inventivenews.

4. A time-depth curve (e.R., Figure 21) mhould be conntructed for the specific wite of intereat. Azain, dating may be lesw precine than desirable. Mont timo-depth curves do not account for more than the position of the struta rolative to the land surface, but more inmight may be kained by (a) plottink the strata relative to nea level, which allown uplift ovents to be meen in context, and (b) plotting the local land surface relative to men level in order to retain a plot of total burial dopth. Morecover, the thicknewen of strata removed by eromion should be entimated and included in the plot.

5. All paleontress indicators should be identified and plotted along with any constraints on their time of urigin in map form or even on a serien of time-nlice maps. These maps may be the same ones on which the structures/atress sourcen are located, where corrolations between the two often become apparent.

6. Note potential vertical dincontinuition in strewsen wuch an depthe of indentation or ductile atratigraphic layern.

7. 'The result should be a A-dimensional concept of stressen in the hasin (vertically, 2.dimenuional laterally, and time) that in as quantitative as possible. 'This will commonly be more quantitative than the geolopist in comfortable with, yet lean so than an engineer would like.

\subsection{Calculated Stress History}

Stresn-strain relationships for a linear-elastic, homoneneous, and isotropic material are well known and can be written an

$$
\begin{aligned}
& \text { Edtz }-d \sigma_{z}-u\left(d a_{y}+d a_{z}\right) \quad \text { aEd'T } \\
& \text { Edey }=d a_{y}-u\left(d a_{z}+d a_{a}\right) \quad \text { aEd'l' }
\end{aligned}
$$

for the horizontal directions, where $F$ is Young's modulus, $"$ is Poisonn's ratio, a is the coefficient of thermal expansion, $d$ is a differential strain, do is an effective differential ntress, and d'l' in a difforential temperature change. 'The stresses, strains, and temperature are written as differentials because they will need to be integrated later to account for changes in material properties. In addition, a will always denote an effective atreas. Alan, compreasion 
is positive; thus increasing d'T results in expansion, and a minus sign precedes the thermal strain term.

These equations can be solved for the stresses as

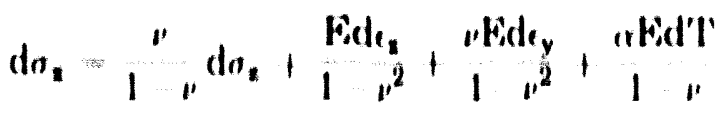

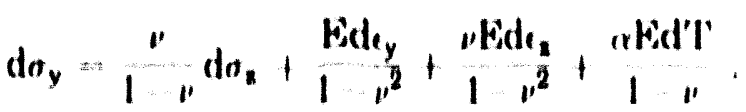

Each of these components was separately discunsed earlier. In this form, o, is recognized as the offective differential overburden atress caused by a change in depth, pore pressure or propertien. It is given by

$$
\left.d o_{a} d|(\rho k-\lambda)|\right) \mid \text {, }
$$

where $p$ is the rock bulk density, $g$ is the kravitational constant, $\lambda$ is the pore pressure gradient ( $p s i / f t$ or $\mathrm{kPa} / \mathrm{m})$, and $\mathrm{D}$ is the depth. Throughout the unalysis, $a_{n}$ will be the minimum compresaive atress and $a_{y}$ the maximum compressive stress. Without more information, it is tacitly assumed that Biot's modulus is unity.

These equations are the basis for both elastic and viscoelastic analyses. 'The simplest solution is for elastic behavior with constant rock propertien and pore pressure gradient. 'This renults in

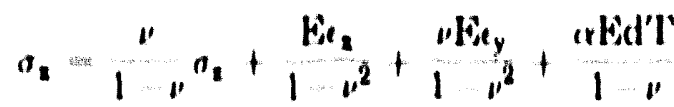

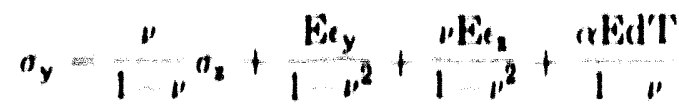

$$
\begin{aligned}
& \left.n_{2}=(p k-\lambda) I\right),
\end{aligned}
$$

with the obvious implication that the stresses at depth can be calculated at any lime if the properties, strains, pressure, and temperature are known. There are many limitations to this approach (Voight, 1974: Prats, 1981), and these equations will not provide accurate strens calculations for most applications. 'The strains are nssumed to be tectonic or geometric and are applied at the edge of the basin.

In general, rocks in a sedimentary basin have time-varying properties: strains, temperature, and pore pressure, with "locked in" or cumulative st resses. 'The solution now requires an integration as

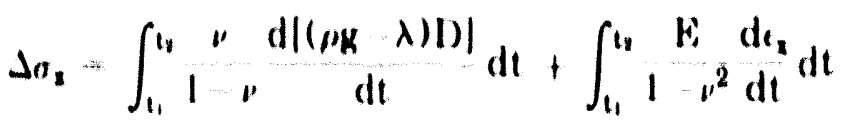

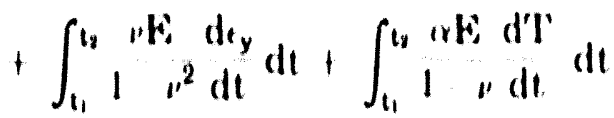




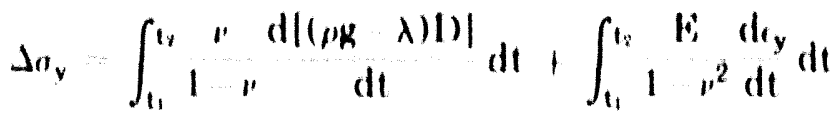

$$
\begin{aligned}
& 1 \int_{1}^{12} 1 t^{2} d t d t+\int_{1}^{1} \frac{1}{1} 1 t d t d t d t
\end{aligned}
$$

with

$$
\sigma,(1)=\ln (1) \mathrm{n}-\lambda(1) \mid 1)
$$

The overburden stress is assumed to instantaneously reflect any changing values and can thus always be calculated if the properties, pore pressure, and depth are known at any instant. 'The horizontal stresses must he integrated through history to arrive at a reasonable estimate of the horizontal stresses at depth. 'The integrals have been taken with respect to time because it is always possible fo make some simple assumptions about the way properties and other parameters will vary through time (assuming the burial, tectonic, and diagenetic history are known). 'These equations can now be used to include the effect of lithification and changes in load parumeters.

A comparable analysis can be performed for viscoelastic behavior of the rocks, and the equations are given in Appendix ( $\therefore$. For the viscoelastic case, it is also necessary to entimate a relaxation time for the rocks. It is generally expected that sandstones will behave elastically over reasonable geologic time periods (- 1 $1(2)$ million years) while shales probably behave viscoelastically over very short time periods, 5 million years).

An example calculation for the stress history of three wells in the Piceance basin (Figure 24) shows that large st ress anisotropies are expected at the time of muximum burial, but pore pressure is also high at this time. Thus conditions are conducive to the formation of regional Practures. (See also) Appendix (C)

\subsection{Fracture-Susceptibility History}

1. Estimate the rate of lithification of the strata. 'This will be a function of diagenesis, burial (compaction), cementation, etc., and will be qualitative since no standard or universal rate exists. However, the more a sediment turns into a rock, the higher the modulus it will have, and the more it will be prone to fracture.

2. Create a pore-pressure history for the strata. 'This is another difficult and qualitative exercise, but is important becnuse pore pressure acts to negate confining pressure, and a less confined rock is brittle and prone to fracture. Oranac maturation, rate of compaction, ease of formation dewatering, and lateral compression of struta are all factors to consider. It may also be important to note the lateral distributions of certain pore pressure domains (i.e., if certain parts of a formation contain coal, organic maturation may generate formation pressures higher than in zones without coal). Since pore pressure will also cont ribute to the total st ress of a system, its effects should also be considered when constructing the stress history above.

3. Determine thermal and overburden stress histories. 'Thermal strains can be very high, and a large component of the lateral stresses comes from the overburden stress. Isotropic stresses from these two factors will add to the total stress of a system, and deep burial and/or a high geothermal gradient will increase the fracture susceptibility of' struta. 
The result should again be a 4-dimensional concept of lateral and vertical pore pressure variation through time, although this will in all probability be more qualitative than the stress-history model.

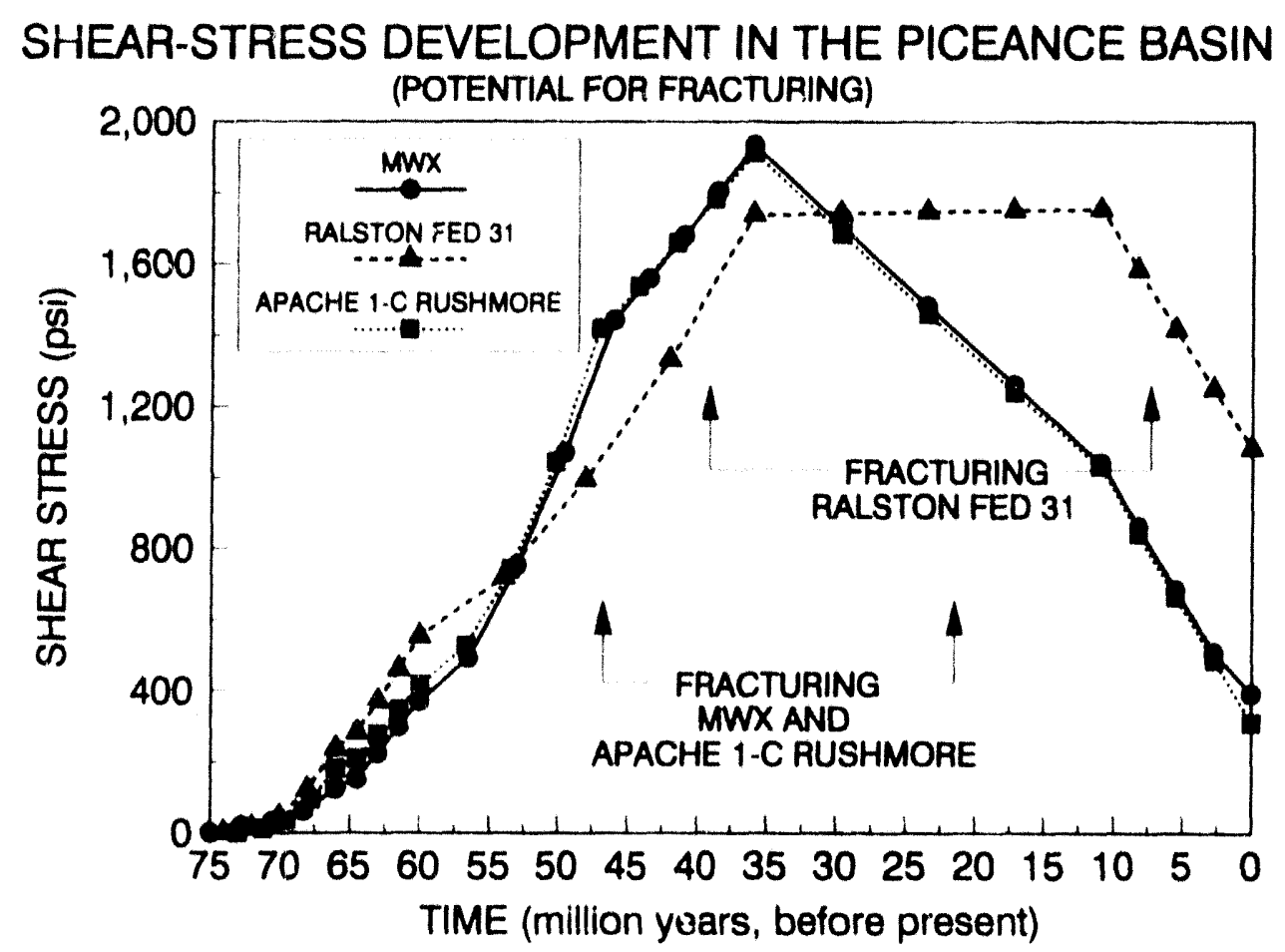

Figure 24. Calculation of the shear stress, through time, that would have developed at three sites in the southern Piceance basin. Increased shear stress indicates increased potential for fracturing.

\subsection{Integration}

The optimum condition: ior fracturing, and therefore the most probable times of fracturing, occur at the intersections of maximum stress anisotropy and maximum fracture susceptibility. This may not always be the case, for if earlier, less ideal conditions allowed fracturing, subsequent ideal conditions may only reactivate existing fractures. Moreover, there may be more than one fracturing event in a basin, and fracture sets may be superimposed Thus the interpretation of fracturing in a basin must be made carefully and with full knowledge of the geological history of the basin.

Regardless of when the fracturing actually occurs, fracture planes should be aligned with the maximum and intermediate compressive stresses at the time of fracturing. 'These orientations are derived from the stress trajectories created by the combined stress sources in the basin. 'Thus the maps of stress sources and of stress indicators provide the basis for predicting fracture orientations in a given set of strata in a given area. These maps can also be used to predict the present-day in situ stress orientations (which commonly, but not always, parallel the paleo-stress orientation).

Once regional fracture and regional stress orientations are known, the probable details of specific well sites can be predicted, and specific exploration prospects may be generated. The latter may consist of searching for anomalies where the regional stress has been altered due to local structure or radical topography, providing a mechanism to direct hydraulic stimulation fractures across the natural fracture trend for enhanced efficiency. They may also consist of areas of the hasin where the reconstructed tectonic stresses or fracture susceptibility of the strata were maximized, increasing the likelihood of fractured reservoirs. 


\section{Conclusion}

The multi-discipline processes described above for assessing the fracture history of a basin, a specific site within it, and the probable effects of the fractures on the reservoir in question can be summarized in a flow diagram (Figure 25). 'This figure lists, as the "Fracture Analysis Toolbox," the techniques that can be used to measure current stresses and to reconstruct paleostresses, as well as the methodologies used to infer probable fracture types and their effects on a reservoir. Application of as many of these techniques as possible to a given problem, although expensive and time consuming, is desirable in order to constrain the modeling and inferences that follow at the ensuing interpretive-level procedures.

Use of these techniques allows for a scientifically-based evaluation of the potential for fractures to be present in the subsurface, and if present, their probable importance to permeability and thus to the recovery of hydrocarbons from the reservoirs in the system. 


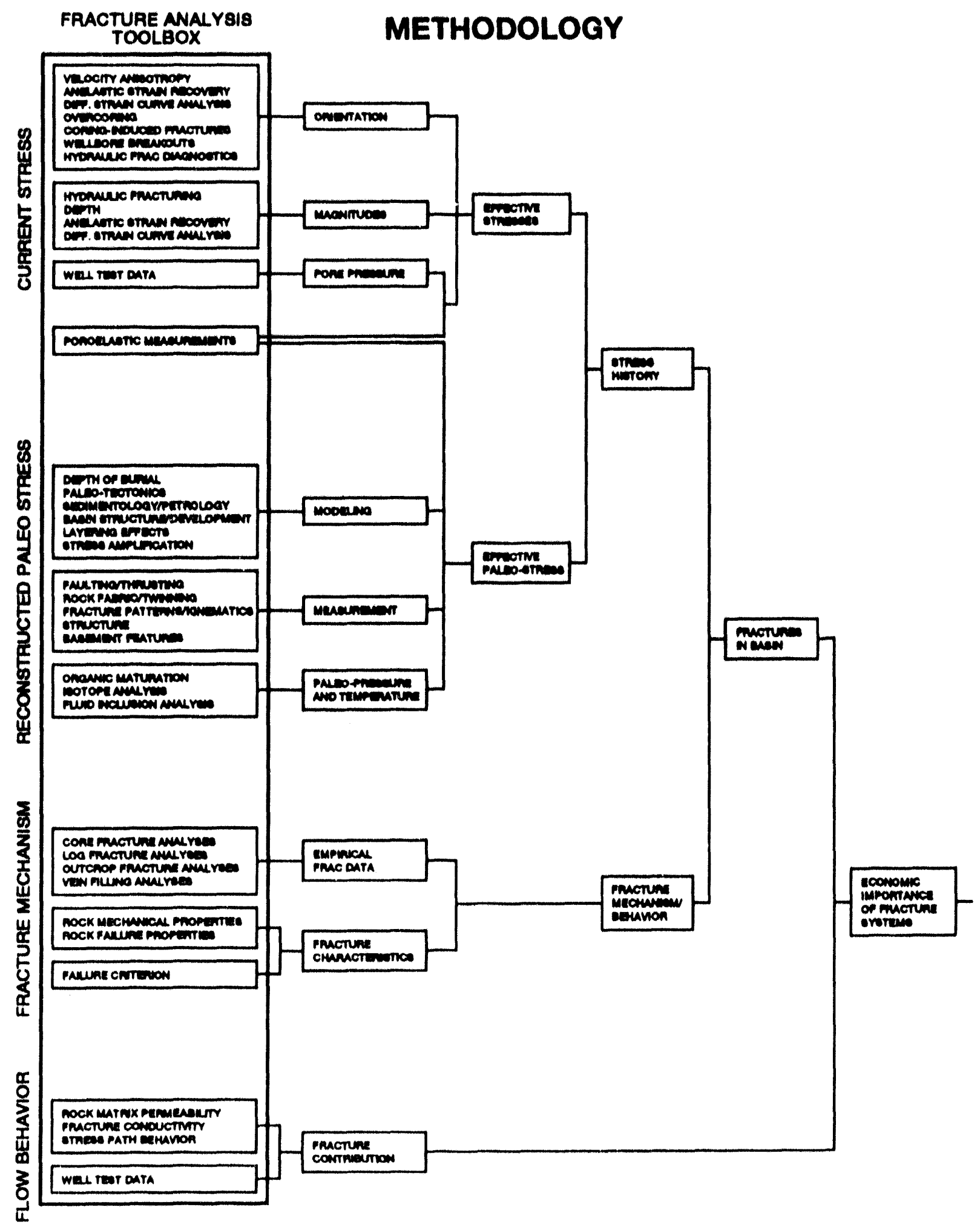

Figure 25. Flow diagram summarizing fracture-assessment techniques and their integration into the procedures described in this paper. 


\section{References}

Anderson, E.M., 1942, The Dynamics of Faulting: Oliver and Boyd, Iondon. $183 \mathrm{p.}$

Arthaud, F., and Choukroune, P., 1973, Method d'analyse de la tectonique cassante a l'aide des microstructures dans les zones peu deformees: exemple de la plate-forme Nord-Aquitaine: Revue de l'Inatitute Francais du Petrole, v. 27, p. 175.732.

Becker, A., 1989, Detached neotectonic streas field in the northern Jura Mountains, Switzerland: Geologiache Rundachau, v. 78, p. 459476.

Becker, A., Blumling, P., and Muller, W.H., 1989, Recent stress field and neotectonics in the eastern Jura Mountains, Switzerland: 'Tectonophysics, v. 135, p. 277-288.

Bell, J.S., and Lloyd, P.F., 1989, Modelling of atress refraction in sediments around the Peace River Arch, western Canada: Current Research, Part D, (ieological Survey of Canada, Paper 89-1D, p. 49-54.

Bell, J.S., and Adams, J., 1990, Do the rocks remember? How contemporary are the regional stresses in Canada?, in Herget, (.., Arjang. B., Betournay, M., Gyenge, M., Vongpaisal, S., and Yu, Y.S., eds., Proceedings of Specialty Conference: Stresses in Underground Structures: Mining Research Laboratories, Canada Centre for Mineral and Energy Technology, EMR, p. 13-22.

Bott, M.H.P., 1991, Ridge push and associated plate interior stress in normal and hot spot regions: Tectonophysics, v. 200, p. $17-32$.

Branagan, P.T., 1984, Interference testing of the naturally fractured Cozzette sandatone: a case atudy at the DOE MWX site: Society of Petroleum Fingineers paper number 12868, SPE Unconventional Gas Recovery Symposium, Pittaburgh, p. 359 .366.

Branagan, P. T., Cipolla, C. L., Lee, S. J. and Wilmer, R. H., 1985, Comprehensive well testing and modeling of pre- and post-fracture well performance of the MWX lenticular tight gas sands: Society of Petroleum Engineers paper number 13867, Proceedings, 1985 SPE Symposium on L,ow Permeability Reservoirs, Denver, CO, p. $191 \cdots 202$.

Bredehoeft, J.D., Wolff, R.G., Keys, W.S. and Shuter, E., 1976, Hydraulic fracturing to determine the regional in situ stress field: Geologic Society of America Bulletin, Vol. 87, p. 250-258.

Clark, J.A., 1983, The prediction of hydraulic fracture azimuth through geological, core, and analytical studies: Society of Petroleum Engineers paper number 11611, SPE/1)OE Joint Symposium on Low Permeability Reservoirs, Denver, CO, p. 107-114.

Crampin, S., 1985, Evaluation of anisotropy by shear-wave splitting: Geophysics, v. 6048, p. 142-152.

Dickey, P.A., 1979, Petroleum development geology: PPC Books, Tulaa, Oklahoma.

Dula, W.F.J J., 1981, Correlation between deformation lamellae, microfractures, macrofractures, and in situ stress measurements, White River Uplift, Colorado: Geological Society of America Bulletin, v. 92, p. 37-46.

Elkins, L.F., and Skov, A.M., 1960, Determination of fracture orientation from pressure interference: Petroleum Transactions, AIME, v.219, p. $301 \cdot 304$.

Fertl, W.H., 1976, Global occurrence and evaluation of abnormal formation pressures, in Abnormal Formation Pressures: Elsevier, New York, p, 325 347.

Fordjor, C.K., Bell, J.S., and Gough, D.I., 1983, Breakouts in Alberta and stress in the North American plate: Canadian Journal of Earth Sciences, v. 20, p. 14451455.

Gallagher, J.J., Friedman, M., Handin, J., and Sowerg, G.M., 1974, Experimental studies relating to microf racture in sandstone: 'Tectonophysics, v. 21, p. 203-247.

Genovese, P.W., and Schmidt, C..J., 1989, A calcite twin-strain analysis of thrust sheets, southwestern Montana: evidence for stress field concentration by Rocky Mountain foreland anticlines.

Griggs, D. and Handin, J., 1960, Observations on fracture and a hypothesis of earthquakes: (Geological Society of America Memoir 79, p. $347 \cdots 364$.

Groshong, R.H.Jr., 'Teufel, L.W., and (iasteiger, C., 1984, Precision and accuracy of the calcite strain-gage technique: Ceulogical Society of America Bulletin, v.95, p. 357 363.

Grout, M.A., Abrams, C.A., Tang, R.I., Hainsworth, 'T.J., and Verbeek, E.K., 1991, Late Laramide thrust-relatt.J and evaporite-domed anticlines in the southern Piceance basin, Northeastern Colorado plateau: American Association of Petroleum (ieologists Bulletin, v. 75, p. 205218. 
Hafner, W., 1961, Stress distribution and faulting: Cieological Society of America Hulletin, v. 62, 19. 37:1 398.

Hancock, P.I., and Hevan, 'Y.(B., I987, Brittle moder of foreland extension, in M.P. ('oward, J.F. I)ewey, and P'I. Hancock, eds., Continental Extenuional 'Tectonica: Ceological Society Special Publication no. 28, p. 127 1:37.

Handin, J., Hager, R.V., Friedman, M., and Feather, J.N., 1963, Fxperimental deformation of sedimentary rocks

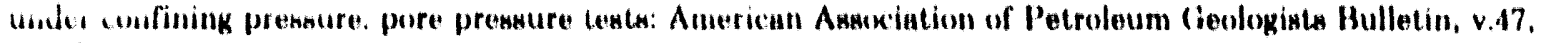
p.717 755 .

Hart, C.M., Fingi, D., Floming, K.P. and Morris, H.F., 1984, Fracture diegnonticen reanlten for the Multiwell Experiment's paludal zone stimulation: Society of Petroleum Fingineers paper number 12862, Proceedings, SPF/LOE: Unconventional (ian Recovery Symponium, Pittuburgh, PA, p. 221 228.

Jaeger, J.C. and Cook, N.G.W, 1976, Fundamentals of Kock Mochanics, Halated Press, New York.

Jamian, W.R., and Spang, J.H., 1876, Une of calcite twin lamellae to infer differential streas: (ieological Socioty of America Bulletin, v. 87, p. 868 872.

Kempthorne, K.H., and Irish. I.P.K., IG8I. Norman wells a new lesk at one of Canada's largent oil fiolds: Journal of Petroleum 'Technology, v. 33, p. 985991.

Kulander, B.R., Dean, S.L., and Ward, B.t.Ir., 1991, Fractured core analysis: interpretation, lokging, and use of natural and induced fractures in core: American Asmociation of Petroleum cieologiats, Methexda in Fxplora. tion Series, No. $8,88 \mathrm{p}$.

Kulick, D.M. and Schmidt, (., , 1988, Region of overlap and atyles of interaction of Cordilleran thruat belt and Rocky Mountain foreland: (ieological Society of Amorica Memoir 171, p. 7598.

Laubach, S.F., and Lorenz, I.C., 1992, Preliminary aseessment of natural fracture pattorns of Frontier Formation sandstones, southwestern Wyoming, in Mullen, C.F. (ed.), Rediecover the Rockien; Wyoming (ieological Amaciation, 4:3rd Field Conference Ciuidebook, 1). 87 96.

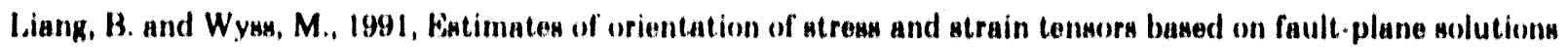
in the epicontral area of the great Hawaian earthejuake of 1868: Bulletin of the Seismological Society of America, Vol. HI, p. 2izo 2:134.

l.orenz, J.6, 1989, Renervoir sedimentology of rocks of the Mesaverde (iroup at the Multiwell Fixperiment site and east central Piceance hasin, in B. F. Law and C.W. Spencer, eds., Cieology of tight gas renervoirs in the Pinedale anticline area, Wyomink, and at the Multiwell Experiment nite, Colorado: (I.S. Cieological Survey Bulletin 1886, p. K1 K24.

Lorenz, J,C., 1985, Tectonic and atress histories of the Piceance Creek busin and the MWX site, from 75 million years ago to the prement: Sandia National laboratories Report SANI)84 2603, $55 \mathrm{p}$.

Lorenz, I.C., and Finley, S.I., I99I, Kexional fractures II: fracturing of Mesnverde renervoirs in the Piceance basin, Colorado: American Association of Petroleum Cieologists Bulletin, v. 76, p. 1738 1757.

Iorenz, J.C., 'Teufel, I.W., and Warpinaki, N.R., I991, Regional fractures I: a mechanimm for the formation of regional fractures at depth in flat lyink reservoirs: American Association of Petroleum Cieologista Bulletin, v. 75, p. 17141737.

Lorenz, J.C., Finley, S.J., and Warpinski, N.K., 1990), Significance of coring induced fractures in Mesaverde core, northwestern Colorado: American Association of Potroleum Cieologists Bulletin, v. 74, p. 1017 1029.

Mclaren, A.C., Turner, R.(i., Boland, J.N., and Hobbs, B.W., 1970, Dislocation structure of the deformation lamellae in synthetic quartz; a study by electron and optical microscopy: Contributions to Mineralogy and Petrology, v. 29, p. 104115.

Mclellan, P., 1988, In situ stress prediction and measurement hy hydraulic fracturing. Wapiti, Alberta: Journal of Canadian Petroleum 'Technology, v. 27, p. 85095.

Morrow, N.R., Brower, K.R., Ma, S. and Buckley, I.S., 1990, fluid flow in healed tectonic fractures: Journal of l'otroleum 'lechnology, p. 13110 1318.

Muller, M., Niuberding, F., and Wanninger, M., 1988, 'Tectunic style and pressure distribution at the northern margin of the Alps between I,ake ('onstance and the River Inn: (ieologische Rundschau, v. 77, 1). 787796.

Myal, F.K., and Frohne, K. H., 1991, I)rilling the SHC'I' well in the Picenuce ('reek basin, Colorado: Society of Petroleum Fingineers paper number 21866 , Society of Petroleum Fingineors doint Rocky Mountain Regional Meeting and low Permeability Keservoir Symposium, Denver, p. fill fi22.

Northrop, 1).A., and Frohne, K. H., 1990, Insights and contributions from the Multiwell Fxperiment: a field laboratory in tight sundstone rearervirs: Journal of Potroleum 'lochnology, v. 42, p. 772779. 
Perry, W.J. Jr., Cirout, M.A., Tang, R.L., and Hainenworth, T.J., 1988, Wedge model for late laramide basement involved thrusting. Cirand Hobghack Monocline and White Rivor uplift, western Colorado [abatract): Cieological Society of America, Abatracta with Programs, v. 20, p. 384385.

Plumb. R.A., and Cox, J.W., 1987, Streas directions in eastern North America determined to $4.5 \mathrm{~km}$ from borehole elongation measurements: Journal of Geophysical Research, v. 82, p. 4806-4816.

Prats, M., 1981, Effect of burial history on the subsurface horizontal stresses of formations having different material properties: Society of Patroleum Engineery Journal, Vol 21, p. 668 662.

Price, N.J., 1974, 'The development of stress systems and fracture patterns in undeformed sedimenta: Proceedinga of the 3rd Congress of the International Society of Rock Mechanics, v. 1.A, p. $487-496$.

Rathore, J.S., Holt. R.M., and Fjaer, E., 1989, Effects of atress history on petrophysical properties of granular rocks; Proceedings of the 30th U.S. Symposium on Rock Mechanice, p. 765-772.

Salz, B., 1877, Relationahipa between fracture propagation presaure and pore pressure: Soclety of Petroleum Engineers paper 6870, Proceedings, 62nd Annual SPE Annual Technical Conference.

Spencer, C.W., 1987, Hydrocarbon generation as a mechaniam for overpresauring in the Rocky Mountain region: American Association of Petroleum Ceologista Bulletin, v. 71, p. 368-388.

Stearns, D.W., and Friedman, M., 1972, Renervoirs in fractured rock: American Association of Petroleum Geologiats Memoir 16, p. $82-106$.

Strickland, F.G., and Ren, N.-K., 1980, Prediction the in-situ streas for deep wells using differential strain curve analysir: Society of Petroleum Engineers paper no. 8954, SPE/DOE Symposium on Unconventional Gan Recovery, Pittuburgh, p. 251-258.

Teufel, 1.W., 1983, Determination of in-situ stress from anelastic strain recovery measurements of oriented core: Society of Petroleum Engineers paper no. 11649, SPE/DOE Symposium on Low-Permeability Gas Reser* voirs, Denver, p. $421-\mathbf{4 3 0}$.

Toufel, L.W., 1980, Strain analyais of experimental superposed deformation using calcite twin lamellae: 'Tectonophysics, v.65, p. $291-309$.

Toufel, L.W., and Farrell, 1900, In situ streas and natural fracture distribution in the Fkofisk Fiold, North Sea, in 3rd North Sea Chalk Symposium. Copenhagen, Denmark, June 11-12: Norwegian Petroleum Directorate and Danish Energy Agency, Joint Chalk Research Program, 33 p.

Teufel, L.W. and Farrell, 1992, Interrelationship between in situ stress, natural fractures, and reservoir permeability anisotropy, a case study of the Ekofisk field, North Sea: Proceedings, Fractured and Jointed Rock Mass Conference, Lake Tahoe, CA, 9 p.

Voight, B., 1974, Stress History and Rock Stress, Proceedings, Third International Congress of Society for Rock Mechanics, Vol.2, pt A, p. $580-582$.

Warpinski, N.R., Branagan, P.T. and Wilmer, R., 1985, In situ stress measurements at U.S. DOE's Multiwell Experiment site, Mesaverde, group, Rifle, Colorado: Journal of Petroloum Technology, Vol. 37, p. 627 -636.

Warpinski, N.R., 1989, Elastic and viscrelastic calculations of stresses in sedimentary hasins: SPE Formation Evaluation, v. 4, p. 622-530.

Warpinski, N.R. and Teufel, L.W., 1989, A viscoolastic constitutive model for determining in situ stress magnitudes from anelastic strain recovery of core: Society of Petroleum Engineers Production Engineering, Vol. 3, p. 272-280.

Warpinski, N.R. and Teufel, L.W., 1989, In situ stresses in low-permeability rocks: Journal of Petroleum Technology, Vol. 41, p. 405-414.

Warpinski, N. R., 1991, Hydraulic fracturing in tight, fissured media: Journal of Petroloum Technology, p. 146-152, 208-209.

Weimer, R.J., 1961, Uppermost Cretaceous rocks in central and southern Wyoming, and northwest Colorado: Wyoming (ieological Association, 16th Annual Field Conference Guidebook, p. 17 28.

Woodland, D.C., and Bell, J.S., 1988, In-situ stress magnitudes from mini-frac records in western Canada: Petroleum Society of CIM, paper no. 88-39-67, 39th Annual Technical Meeting, Calgary, p. 67-1 to 67-27.

Zoback, M.L., and Zoback, M.D., 1980, State of stress in the coterminous United States: Journal of Geophysical Research, v. 85, p. 6113 6156.

Zoback, M.L., and 29 co-authors, 1989, Global patterns of tectonic stress: Nature, v. 341, p. 291298. 


\title{
APPENDIX A \\ Wellbore Geometries for Optimum Fracture Characterization and Drainage
}

(From: Lorenz, J.C., 1992, paper in West 'Texas Geological Society Bulletin, v. 32, p. 5 8).

\begin{abstract}
There are two problems that are rarely considered when drilling a deviated well for the purpose of draining naturally fractured reservoirs: (1) how to intersect enough fractures with the pilot hole to accurately characterize the fracture population; and (2), does reservoir heterogeneity limit vertical permeability, despite fractures, such that a horizontal well provides little benefit in enhanced drainage volume?

The first problem can be addressed with slightly deviated wellbores. A 30-degree deviation from vertical will enhance the probability of intersecting a vertical fracture in a 35 .ft thick reservoir by up to 6200 ". The optimum $6200^{\prime \prime}$ " occurs if the wellbore azimuth is oriented normal to fracture strike. However, even if fracture strike is unknown, there is a two-thirds chance of intersecting at least half of this percentage with a randomly oriented wellbore azimuth.

The second problem becomes severe in horizontally laminated reservoirs where fractures are bounded by bedding and where lateral wellbore lengths are limited due to lease lines or small reservoir sizes. In these reservoirs, there is a quantifiable advantage to drilling slant holes ivith deviations of less than 80 degrees. Increases in reservoir heterogeneity increase the drainage-volume advantage of the short slant hole over that of the horizontal hole. 'Thus, there is still a need for sedimentary characterization of fractured reservoirs.
\end{abstract}

\section{Fracture Characterization}

\section{The Problem}

Vertical to near-vertical fractures do not have a high probability of being intersected by vertical wells. 'Therefore, the absence of fractures in vertical core does not constrain the possible occurrence of fractures and fracture-dominated production in a reservoir. Conversely, the presence of any fractures in core should be cause to consider the probability that the reservoir contains significant fracture porosity (Figure Al).

An example of this problem is presented by Lorenz and Hill (1991), where $85 \mathrm{ft}$ of ve:tical core from the Cozzette Sandstone (Upper Cretaceous Mesaverde Croup) at the MWX site, Garfield County, Colorado, contains no fractures. However, core from the deviated hole at the same site shows that natural fractures in this reservoir are abundant, with an average spacing of only three $\mathrm{ft}$ (Figure A2). 'The fractures in this reservoir create an increase in permeability of two orders of magnitude, and cause a horizontal permeability anisotropy of between $10: 1$ and 100:1.

Therefore, if the objective of a pilot well is to characterize natural fractures for the purpose of designing horizontal holes, the probability of intersecting natural fractures in the well must be enhanced. 


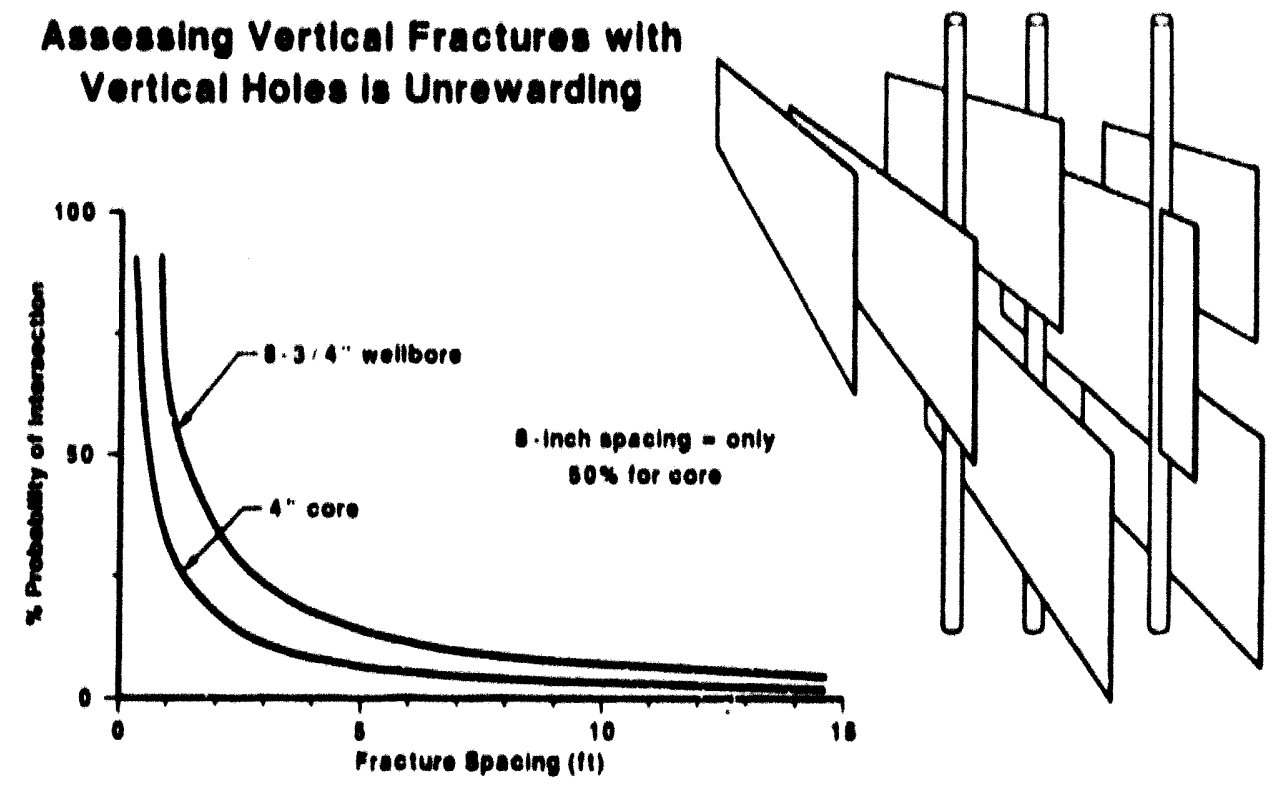

Figure A1. Relationship between lracture spacing and the probability of intersecting a fracture with a vertical hole/core.

$M W X \cdot 1 \quad M W X \cdot 2$
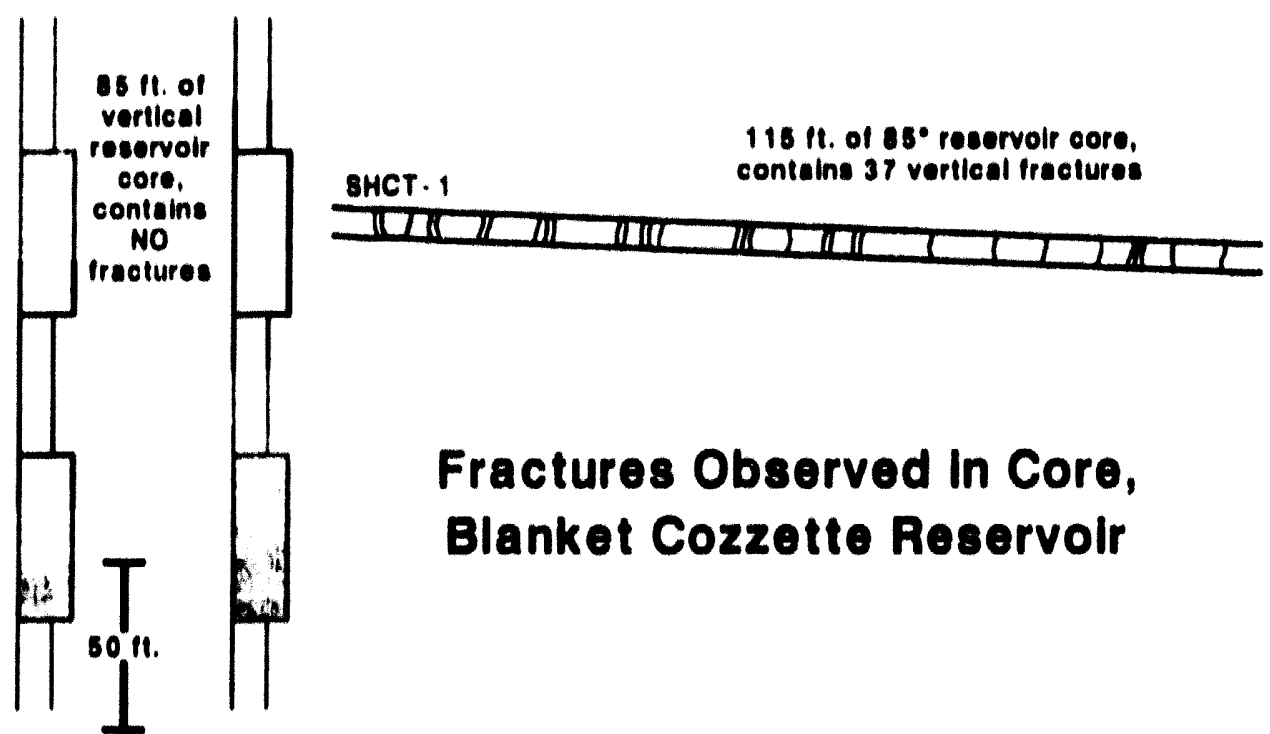

\section{Fractures Observed In Core,} Blanket Cozzette Reservolr

Figure A2. Fractures observed in vertical vs deviated core from the same reservoir at the same site: Cozzette Sandstone Member (Upper Cretaceous Mesaverde Group), Garfield County, Colorado.

\section{One Solution}

Relatively small deviations of a wellbore will dramatically increase the chances of fracture intersection. Whereas vertical core typically spans only four inches of reservoir width, the width interrogated by a deviated hole is a function of the tangent of the deviation angle and the reservoir thickness (Figure A3). For example, a hole deviated by 30 degrees in a $35-\mathrm{ft}$ thick reservoir samples more than $20 \mathrm{ft}$ of the reservoir width, for a lateral-interrogation advantage over vertical core of 6200 " $\mathrm{i}$. 
Advantage of Deviated Woll For Fracture Intereection

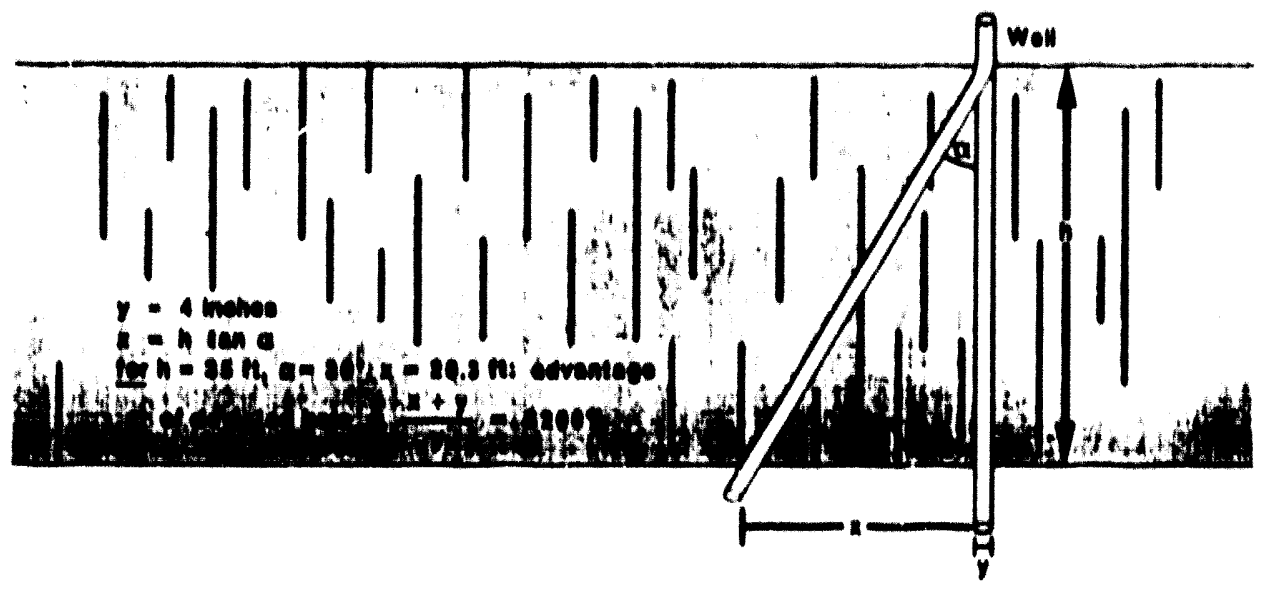

Figure A3. Advantage of a deviated well for fracture intersection.

The advantage of a 30-degree wellbore can also be viewed in terms of how it would compare to the optimum sampling allowed by a 90 -degree (horizontal) wellbore. Because the horizontal distance sampled is a function of the sine of the deviation angle, the 90 .degree wellbore yields a sampled width of only twice that of the more easily drilled and maintained 30-degree wellbore of the same length (Figure A4).

$A$ bonus in coring a deviated hole is that, in many cases, the expense of a core orientation survey need not be incurred (Lorenz and Hill, 1992). The geometric relationships are such that if the uphole direction and top-hole side of the core can be determined (usually apparent if bedding is present and arguably horizontal), the orientation of fractures can be derived using the standard wellbore survey, which gives wellbore inclination and azimuth (Figure A5). Moreover, there is commonly less ambiguity in distinguishing between natural and coring-induced fractures in deviated core. (Note that Figure 5 shows core from a hole deviated by 60 degrees, but that the same principle works for deviations between about 20 and 85 degrees).

It has been assumed, until this point, that the deviated wellbore azimuth is oriented normal to a known fracture trend (strike). However, if the fracture strike is poorly constrained or even unknown, a deviated wellbore still may offer a considerable advantage over the vertical wellbore. This is because the planview number of fractures hit, expressed as a percentage of the optimum of those that would be hit if the wellbore azimuth was exactly normal to fractures, is a simple sine function of the angle between fracture strike and wellbore azimuth (Figure A6). The distance normal to fracture strike traversed by the wellbore is computed by multiplying the horizontal length of the wellbore by the sine of the angle between is azimuth and the fracture strike. Thus, as the angle decreases from 90 degrees, the rate of fracture intersection efficiency drops off slowly for the first plus or minus 30 degrees. In fact, this efficiency is at least $50 \%$ for a sweep of plus or minus 60 degrees, which encompasses two-thirds of the possible directions of drilling. If fracture orientation is known, the azimuth of well deviation should be normal to the fractures. If strike is not known, even a random azimuth is api to be useful, as shown in Figure A7. Preliminary geologic studies can usually narrow the range of uncertainty.

The percentage of fractures hit by a wellbore will be a function of both the angle between fractures and the wellbore azimuth in the horizontal plane, and the angle of deviation in the vertical plane. It can be quite high even where the angular relationships are not optimum. (If the strata are not horizontal, or the fractures are not vertical, there will be a third geometric factor to consider.) In horizontal strata with vertical fractures, the fracture intersection efficiency is the sine of the angle between wellbore azimuth and fracture strike, times the sine of the angle by which the wellbore is deviated from vertical. 


\section{A $30^{\circ}$ Wollbore WIII HII Hall As Many Fractures}

As semo-Length Horizontal Wollbore

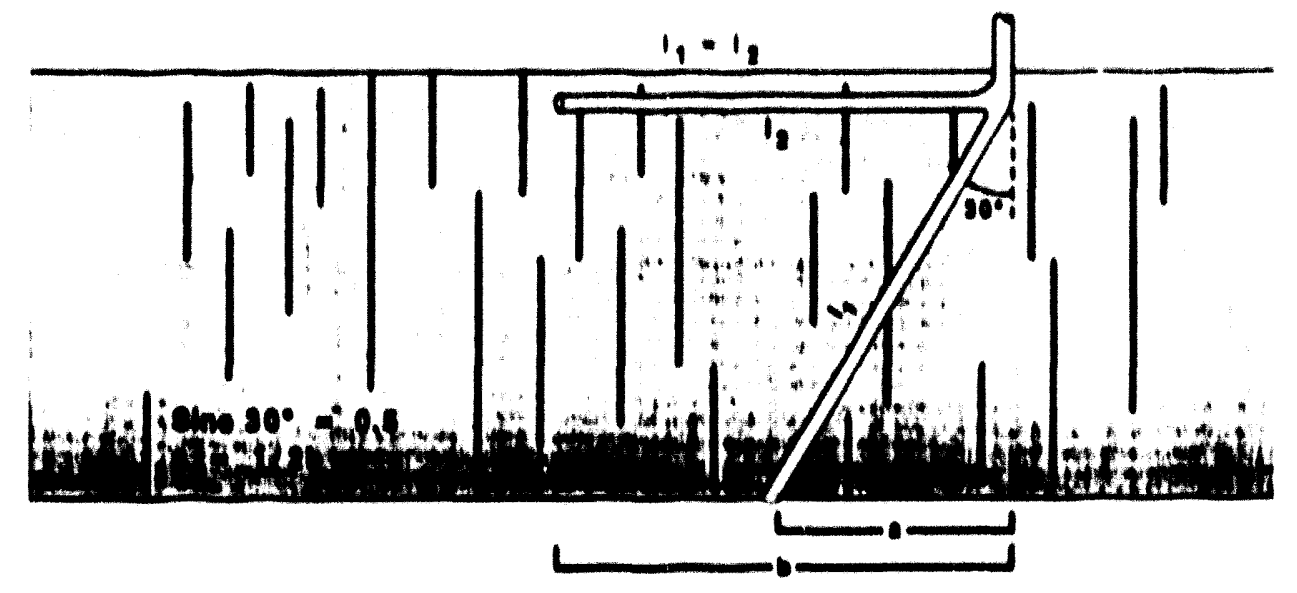

Figure A4. A 30-degree wellbore will hit half as many fractures as a horizontal hole of the same length.

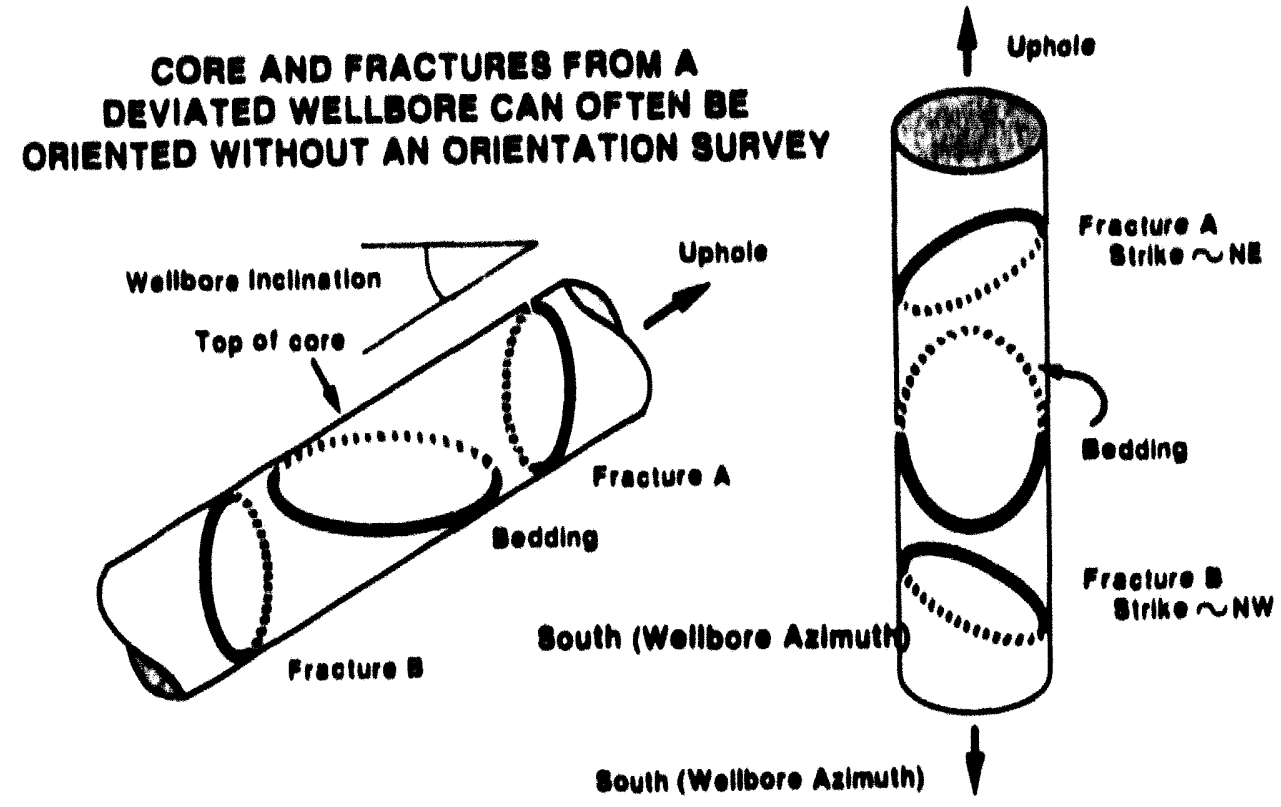

Figure AB. Core and fractures from a deviated wellbore can often be oriented without an orientation survey. 


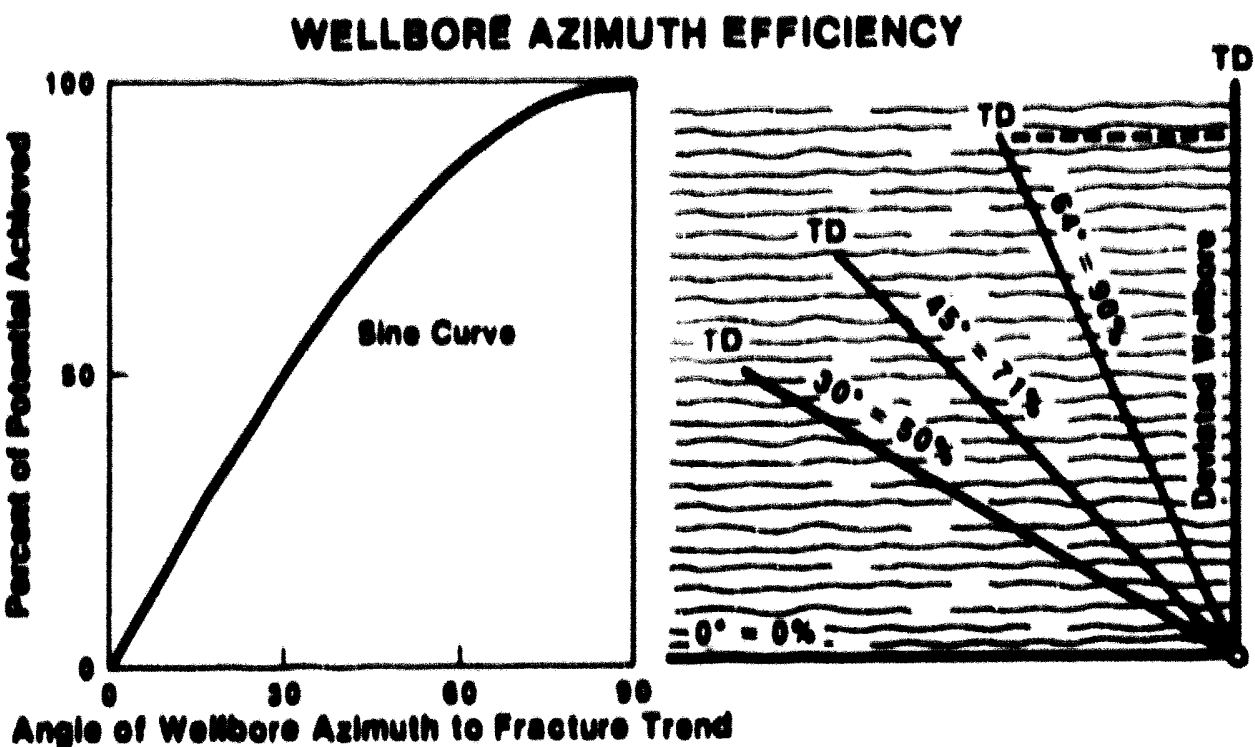

Pleure A6. Relationship between a wellbore aximuth and itw efficiency in fracture intersection.

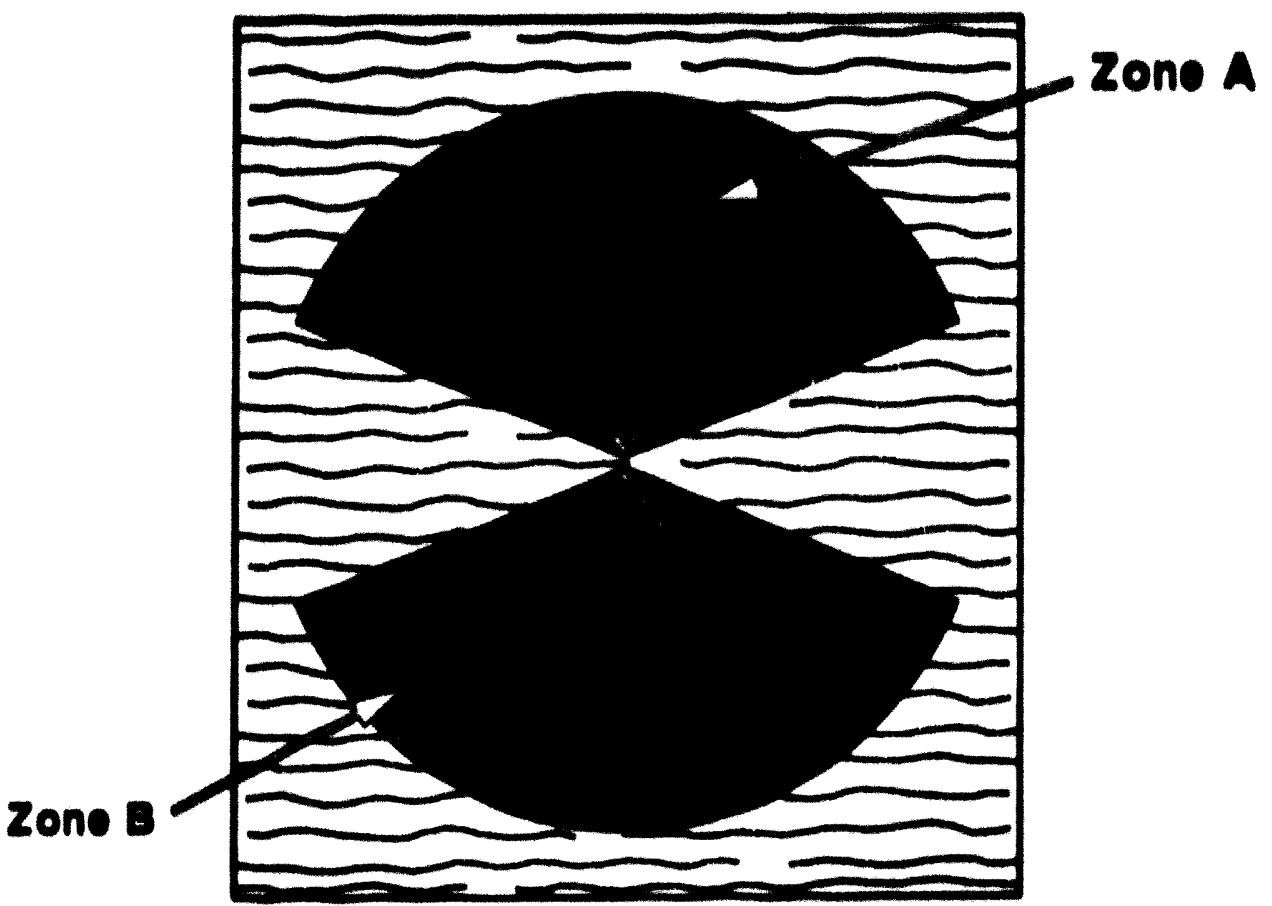

Figure A7. Horizontal wellbore azimuth efficiency (planview). Any wellbore azimuth drilled within zone $A$ (within 30 degrees of normal to the (racture trend) will encounter at least $87 \%$ of the fractures that a fracture-normal wellbore would have hit. Similarly, a wellbore drilled anywhere within plus or minus 60 degrees of fracture-normal (zone B) will have at least a 50"' fracture-intersection efficiency. A randomly oriented horizontal wellbore azimuth will have a two-thirds chance of having at least a 50 "' efficiency. 
This relationahip is advantageous for any devinted welliore. High percentagen of fractures are eany to hit with deviated holew. Where fracture ntrike in uncertain or unknown. there in an excellent chance of internecting, and thus characterizing, a larke 11 umber of fractures with deviated holes. This in a cont effective approach to obtaining vital information ciol the denigli of horianital welle.

\section{Drainage Efficiency of Deviated Holes in Heterogeneous Reservoirs}

Once a reservoir fracture system has been characterized, production considerationa may dictate an optimum wellbore geometry. If the fractured reservoir is otherwise homoxeneous, with unlimited verfical drainake, increasing deviations from vertical access more and more of the renervoir, with an unlimited length horizontal wollbore being the mont desirable (Jowhi. 1988). However, reservoir heterogeneity commonly rentricts vertical communication, oven in fractured strata, and drainage efficiency wuffers accordinxly.

For a vertical well in a homogeneosus but fractured reservoir, the drainage volume is limited only by the lateral permeability and radius of drainage. For simplicity, this is considered inly in two dimensions, and the "area" of drainage ("A") will be uned an the atandard of comparinon: l.e., drainage from hypothotical renervoirs described here will be premented as a percentage of " $A$ " (Figure $A 8$ ). For example, a deviation of 4 th dexrees allows drainage from in similar radius on either side of the well, but also accesses the area within the renervoir that in truverned by the well, and the drainage area in 226 ", of "A." (Addition of the third dimension will change the resulte by a constant figure that in the length of the drainake radius in that third dimension, alonk the natural fracture trend).

Once barriers to vertical permeability are inserted into this idealized, hypothetical renervoir. the improvement in drainaze area created by a deviated hole is diminished, becaune there are now areas (compurtements) ubove and below the wellbore that are no longer ansily

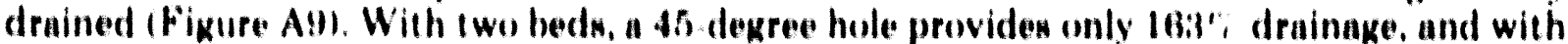
five beda, drainuse in diminished lo l:26\%.

Increasing the well bore deviation increasen drainage efficiency, the addition of bedding discontinuities olfsets this advantage at a rapid rate (Figure Alo).

Unfortunately, more numeroun permeability barriers/litholonic dincontinuitien also de crease the efficiency of a horizontal hole. A single bed binecting the reservoir decreases the immediate drainake by half. If there are live beds and only one is accessed by the horizontal hole. drainake as a percent of "A" still increanen dramatically with the length of hole in the reservoir, but the area inot drained increases four timen as last (Figure Ali). If there are 10 beds, the situation is that much worse.

For limited length wollbores in hoterogeneous reservoirs, slant holes offer an advantake in drainaze aren over horizontal holen (Figure A12). With five beds, $4(0)^{\prime 2}$, of " $A$ " in achieved with a 610 ft, 85 degree slant hole. 'The sume length horizontal hole in this reservoir yields only about :3(x)", of "A." 'Io achieve $4(x)$ ', with a horizontal hole, the hole must be 760 fit lonk. The more heterokeneous the reservoir, the longer a horizontal wollbore must be to equal the drainage efficiency of a wlant hole. 


\section{Additional Drainage from Slant Hole In Homogeneous Reservlor}
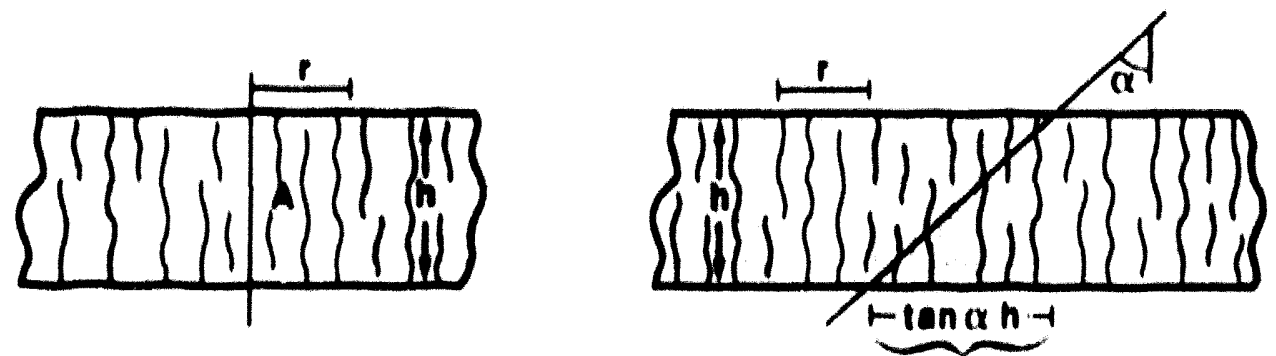

Verlioal Well:

Dralnage $=2 r h=A$

$=$ 8tandard, or $100 \%$

Devialed Woll:

Dralnage $=2 r h+\tan \alpha h \cdot h$

Figure A8. Additional volume can be drained from a slant hole in a homokeneous reservoir.

Reservolr Heterogenelty Reduces Advantage of Slant Hole
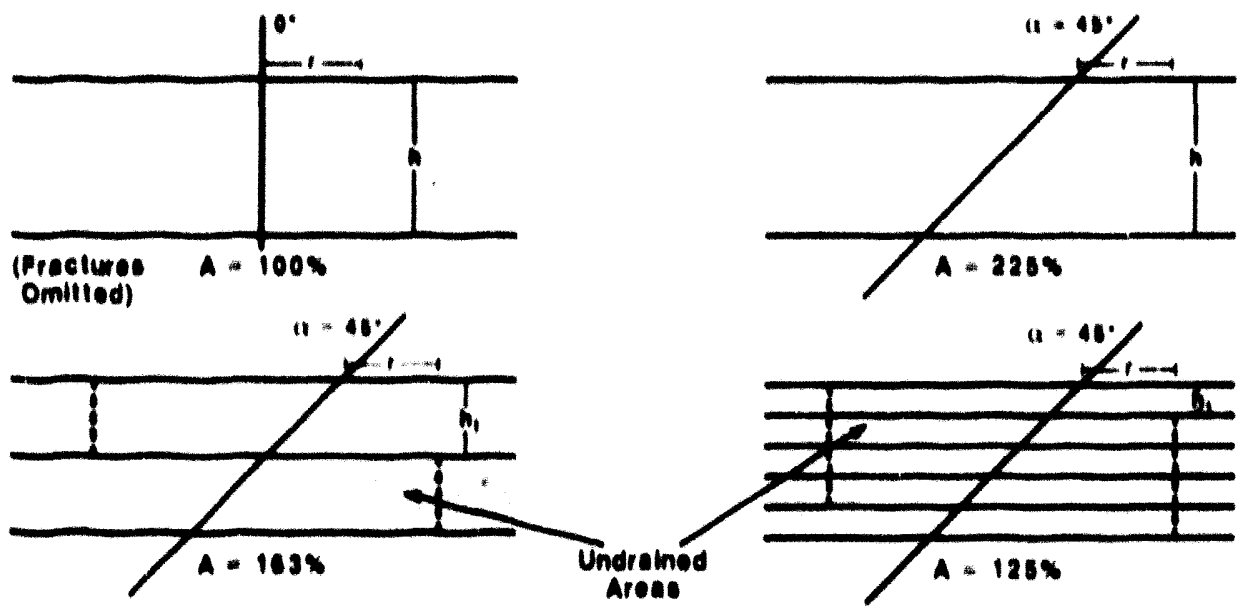

$$
\left(x \text { or } A=\frac{(2 m)+\left(\tan a n_{1} \cdot n_{1}\right)\left(N_{0} . \text { Bodo }\right)}{2 m} \cdot 100\right)
$$

Figure Ag. Renervoir heterogeneity reduces the advantage of a slant hole. 


\section{Effecte of Hetorogenelty and Degree of Deviation on Dralnage Efflclenoy}

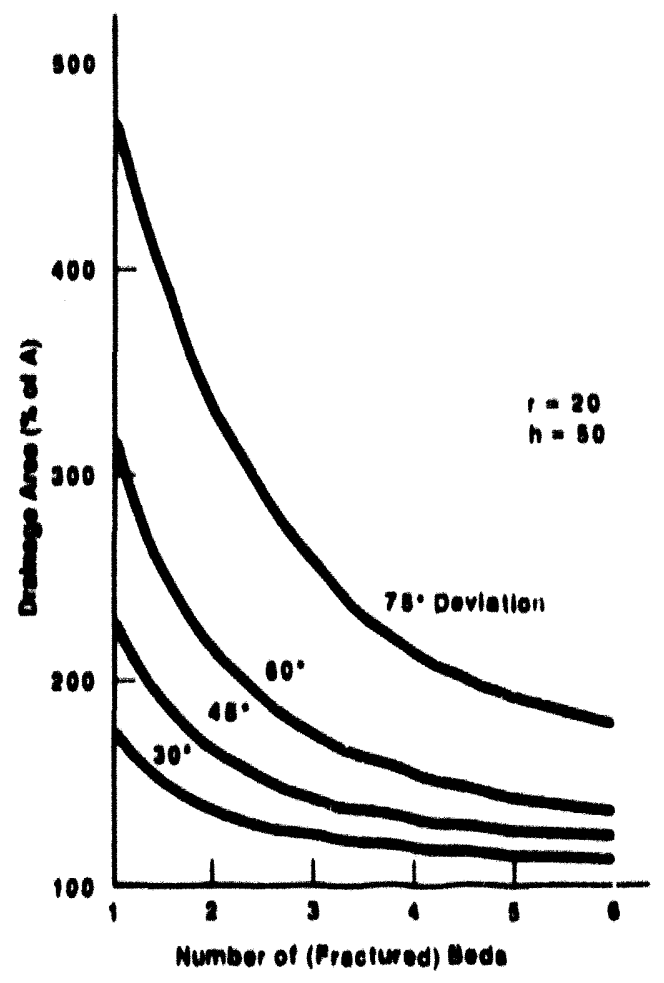

Figure A 10. Relationship of reservoir heterogeneity and wellbore deviation to drain. age efficiency.

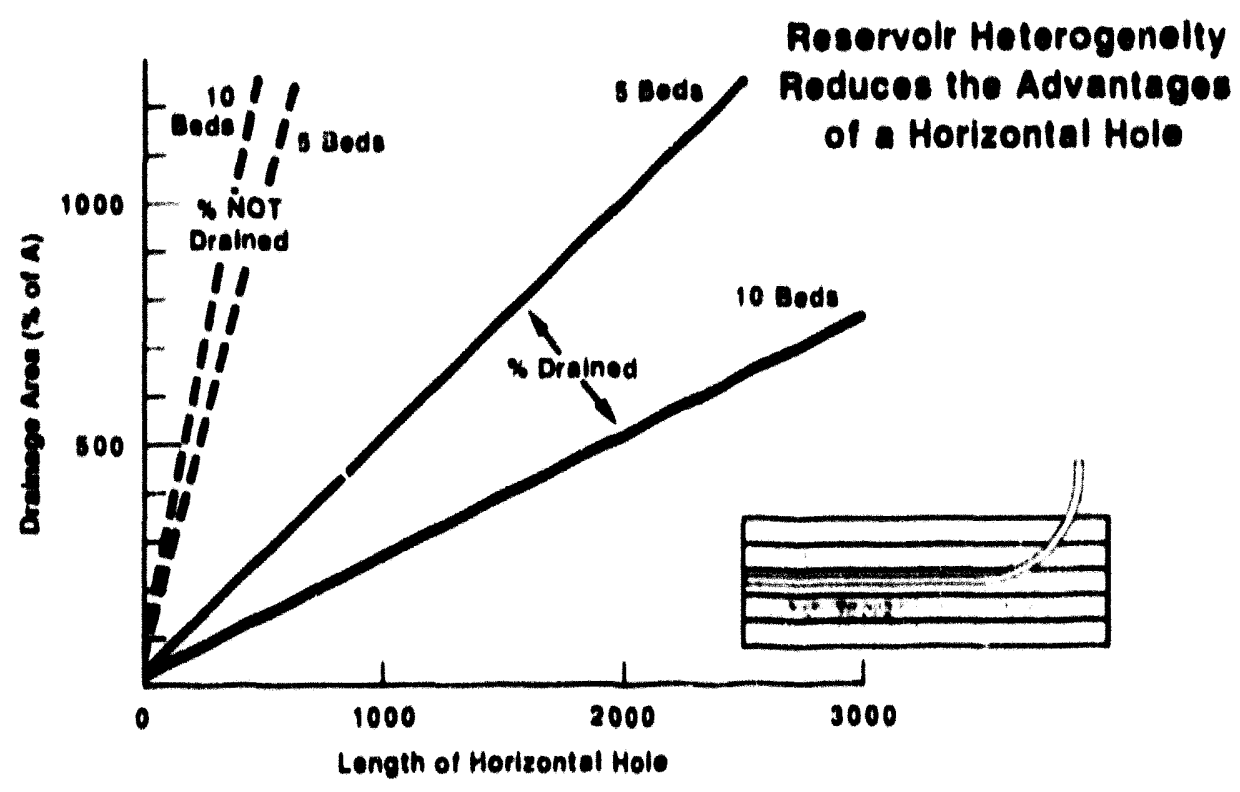

Figure A11. Relationship of reservoir heterogeneity to drainage efficiency for a horizontal hole. 


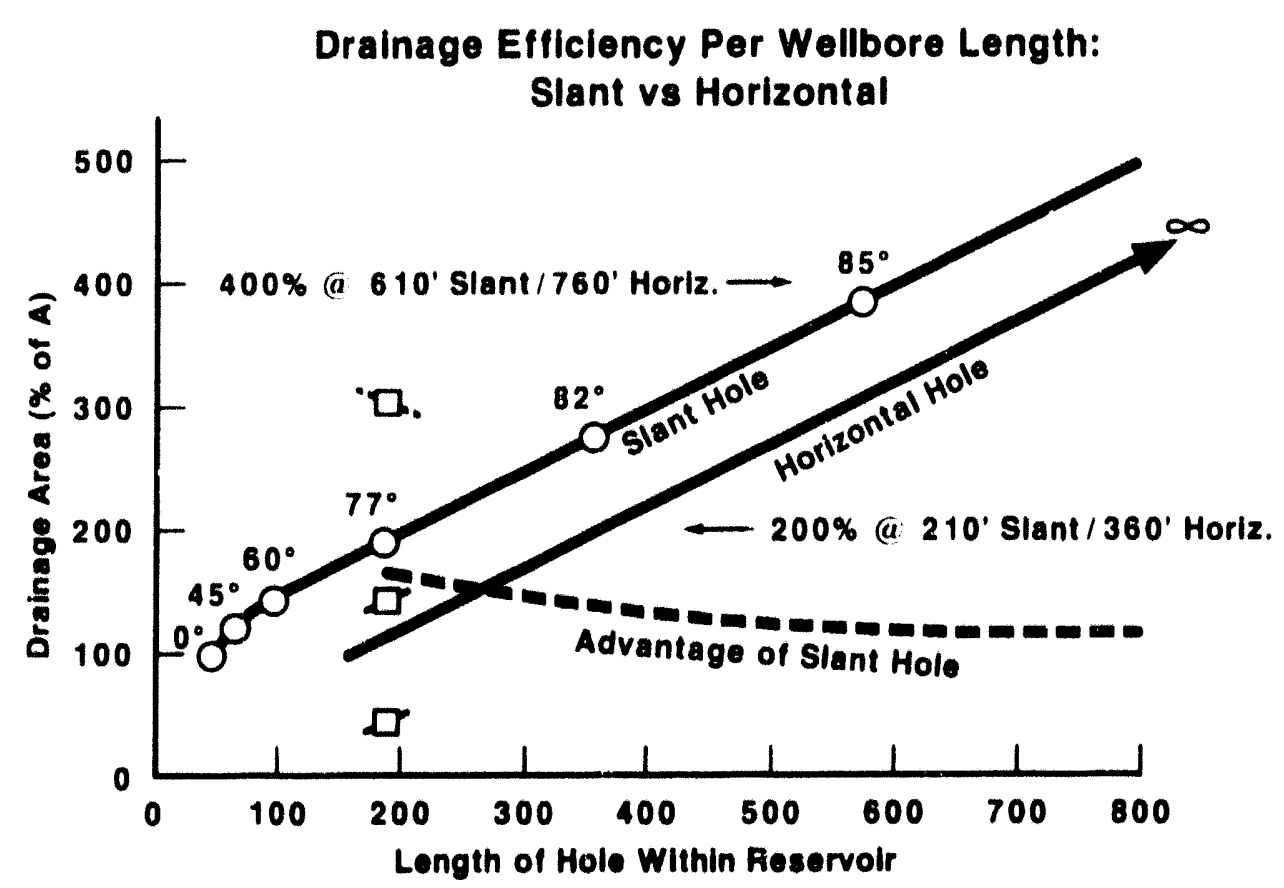

Figure A12. Comparison of the drainage efficiency per wellbore length for slant and horizontal wells in a reservoir with five hypothetical permeability discontinuities. Note that the difference between slant and horizontal hole efficiency is significantly greater for a ten-bed configuration (boxes).

\section{Conclusions}

Slightly deviated pilot holes will significantly increase the chances of intersecting and characterizing vertical and near-vertical natural fractures, thereby improving the data base for a horizontal well design. Although initially it may be more costly to deviate a pilot hole, it would be a waste of money to drill a vertical hole that does not intersect fractures if that is the purpose of the hole.

Slant wellbores should be considered when fractured reservoirs are heterogeneous, especially where the length of a horizontal lateral is limited due to lease or reservoir size. A slant well may also offer a greater probability that, given time, the relatively inaccessible compartments of a reservoir will be drained through lateral permeability restrictions, because they are commonly more permeable than vertical restrictions.

\section{References}

Joshi, S.D., 1988, Augmentation of well productivity with slant and horizontal wells: Journal of Petroleum Technology, v. 44, p. 729-739.

Lorenz, J.C., and Hill, R.E., 1991, Subsurface fracture spacing: Comparison of inferences from slant/horizontal core and vertical core in Mesaverde reservoirs: Society of Petroleum Engineers, paper number 21877, Proceedings of the Rocky Mountain Regional Meeting and Low-Permeability Reservoirs Symposium, Denver, CO, April 15-17, 1991, p. 705-716.

Lorenz, J.C., and Hill, R.E., 1992, Measurement and analysis of fractures in core; in Schmoker, J.W., Coalson, E.B., and Brown, C.A. (eds.), Geological studies relevant to horizontal drilling: Examples from western North America: Rocky Mountain Association of Geologists, p. 47 59 (see appendix B of this report). 


\title{
APPENDIX B
}

\section{Measurement and Analysis of Fracture in Core}

(From: Lorenz, J.C., and Hill, R.E., 1992, paper in Geological Studies Relevant to Horizontal Drilling: Examples from Western North America, J.W. Schmoker, E.B. Coalson, and C.A. Brown, eds.; Rocky Mountain Association of Geologists, p. 47-59).

\begin{abstract}
Optimum analysis of natural fracture characteristics and distributions in reservoirs requires conscientious supervision of coring operations, on-site core processing, careful layout and marking of the core, and detailed messurement of fracture characteristics. Natural fractures provide information on the in situ permeability system, and coring-induced fractures provide data on the in situ stresses. Fracture data derived from vertical core should include fracture height, type and location of fracture terminations with respect to lithologic heterogeneity, fracture planarity and roughness, and distribution with depth. Fractures in oriented core from either a vertical or a deviated well yield information on dip, dip azimuth, strike, mineralization, and the orientation of fractures relative to in situ stresses. Only measurements of fractures in core from a deviated/ horizontal well will provide estimates of fracture spacing and fracture porosity. These data can be graphed and cross-plotted to yield semiquantitative fracture characteristics for reservoir models. Data on the orientations of fractures relative to each other in unoriented core can be nearly as useful as the absolute orientations of fractures.
\end{abstract}

\section{Introduction}

Published detailed characterizations of fractures in core are not common, since nonproprietary data bases that are large enough to allow a reasonable characterization of a 3-D, in-situ fracture network are rare. When data are available, important parameters have often been left unmeasured, and analyses often omit important relationships such as fracture orientations with respect to each other in unoriented core, and fracture distribution with respect to sedimentary heterogeneity. We offer here a set of descriptions and measurements of fractures in cores that illustrate different "nuts and bolts" techniques for relatively complete measurements of fractures from vertical and deviated wells. We further suggest how the data derived from these techniques may be analyzed for the characterization of a fracture system.

Several prominent references precede this paper: Kulander et. al. $(1979,1990)$, and Norman and Garrett (1988) list criteria for making the critical distinction between natural fractures and fractures that are artificially induced by the coring and handling processes, and offer excellent descriptions of the types of fractures in core. Skopec et. al. (1990); in press), and Nelson et. al. (1987) describe core handling procedures, and the process for correlating oriented core with an orientation survey. In this paper, we recommend several additional steps for processing core for fracture analysis. 
Several methods have been offered for converting fracture measurements in vertical core to fracture spacing (Lerche and Narr, 1986; Aguilera, 1988; Narr, 1991). These techniques assume a relatively regular fracture distribution in evenly bedded strata, whereas fractures commonly occur in irregular swarms (e.g., Laubach, 1991), and are irregularly distributed within heterogeneous reservoirs (Lorenz and Hill, 1991). Other references, such as Van Golf-Racht (1982), approach fractured reservoirs from the petroleum engineer's point of view, and build fractured reservoir models around idealized fracture characteristics. More often than not an engineer can and does take the mere fact that fractures are present, modified perhaps by data on fracture orientation, to model reservoir production. It may not be possible to quantify heterogeneous fracture distributions into absolute terms usable by a reservoir engineer, but a useful, working, semi-quantitative characterization of fractures can be constructed if enough core is available.

Much of the fracture-characterization problem derives from the fact that core data are one-dimensional and usually vertical. Moreover, vertical fractures are hard to intersect, and therefore hard to characterize, with vertical core. However, data from one- dimensional core can be analyzed, and, within limits, turned into a concept of the three-dimensional fracture distribution. We present examples of fractures in core from vertical, horizontal, and moderately deviated wells, that show which types of fracture information and measurements can and cannot be derived from each type of core, and compare their value for fracture characterization.

Our most complete example is from the Piceance basin, northwestern Colorado. At this site, $4200 \mathrm{ft}(1280 \mathrm{~m})$ of vertical core containing 275 vertical-extension fractures, $236 \mathrm{ft}$ of $60^{\circ}$-from-vertical core containing 28 fractures, and $115 \mathrm{ft}$ of near-horizontal core containing 37 fractures were taken from the Upper Cretaceous Mesaverde Formation from the U.S. Department of Energy's Multiwell Experiment (MWX) and Slant Hole Completion Test (SHCT) wells (Lorenz and Hill, 1991). These projects were designed to assess and develop technologies for recovery of natural gas from low-permeability reservoirs (Northrop and Frohne, 1990; Myal and Frohne, 1991). The sandstone reservoirs in this formation at this site would have sub-microdarcy in situ permeabilities, and would be unproducible, without the pervasive natural fracture system that is present in the sandstones (Lorenz et. al., 1989). The fractures at this site are irregularly spaced, unidirectional, regional fractures, created by basin-wide dilatancy of the strata during horizontal compression rather than by flexure (Lorenz and Finley, 1991). The abundance of core from wells of different deviations at this site has allowed a greater degree of subsurface fracture characterization than would normally be possible, but this example points the way toward analysis of fractures in wells where less core is available.

\section{Coring, Processing, and Preliminary Measurements}

\section{Monitoring Coring Operations}

Significant information on core condition and fracture character can be obtained by on-site monitoring of coring operations. If this is not possible, such information (though without as much detail), can sometimes be gleaned from the coring engineer's report, the geolograph, and the mud log. High or erratic torque is often used as evidence of fractured formations, but may also indicate points of correlation between rubbleized sections of the core and breaks in the orientation survey record. Abrupt increases in pump pressure or weight-on-bit may induce fractures in the core, and knowing the exact depths of such increases may help determine whether an otherwise ambiguous fracture in the core is natural or induced. At the very least, the depth at which the drill-pipe connections were made during coring should be noted, as these are often associated with spinoffs in the core and abrupt scribe rotations, and are therefore useful in determining whether the orientation of a fracture 
in one piece of core can be compared with that in another piece, or whether a discontinuity exists in the core between them.

\section{Core Processing Procedures}

Core processing can be divided into four different activities: 1) recovery, 2) layout, reassembly, and marking, 3) description and measurement, and 4) packaging. Aspects of the procedures for layout, and for recovery and packaging have been discussed by Skopec et al. (in press) and description and measurement are described by Kulander et al. (1990). We suggest several additions to these procedures, and emphasize that steps 2 and 3 can and should be performed, at least in a preliminary fashion, at or near the wellsite. The benefits of so doing usually outweigh the logistical difficulties of field processing. The cost of a coring operation begs for maximized data acquisition.

\section{Importance of Field Processing}

There is a trend toward the use of liners in core barrels, especially in formations that are prone to jam the barrel during coring. While this may improve core recovery, it also removes the geologist one step from the raw data since the geologist usually does not examinc the core until it is shipped to the laboratory and therefore is rarely on site during coring. The locations of incipient jamming, increased bit weight or revolutions per minute, or other events that can affect the condition of the core are rarely recorded by on-site personnel.

A significant loss of data also occurs with each successive manipulation of the core, as pieces of rubble are discarded, pieces of core become inverted, samples (and souvenirs) are removed, and additional breakage of the core, especially across fractures, occurs. Thus, logging of core for fractures is increasingly difficult after each handling procedure, and is especially frustrating if the core has been extensively sampled for other analyses. This is because all of the core is significant for fracture logging: lengths of unfractured intervals are important to measurements of fracture spacing, and even rock chips with fracture-face mineralization in rubble zones yield data on the presence and location of fractures.

When core is slabbed, some of the smaller fractures are often revealed, but the advantage of waiting to $\log$ fractures until after slabbing is usually outweighed by the loss of information during slabbing. Information is lost due to (1) additional breakage and removal of core, destroying core continuity and decreasing the potential for comparison of the relative orientation of fractures, and (2) the significantly smaller volume of rock that is left for examination in the slabs. However, the logging of fractures in unslabbed core requires that the entire core surface be carefully inspected.

The location and nature of fracture terminations are also important, but cannot be determined if critical pieces of core have been lost or sampled. Fracture width cannot be measured in horizontal core if a core sample with a fracture face on one end has been removed. Unfortunately, horizontal core often breaks at fractures, and these end pieces are commonly the ones taken for samples. Unless stringent operating procedures are followed, under strict wellsite supervision, core data will be lost. To minimize this, core should be cut in an unlined, standard core barrel if possible (not likely if the strata are highly fractured) or else the core from core-barrel liners should be processed in the field before significant data loss occurs.

Another advantage of field processing is that it allows problems with orientation and coring equipment to be corrected between core runs. Murphy's Law tends to be especially applicable to most wellsite operations, and the value of field processing and monitoring cannot be overemphasized. 
Further checks on orientation quality can be made after the fracture orientation data have been collected. For cxample, a plot of fructure strike with depth can be used to cross check the orientation survey: if fractures have consistent orientations within each core run, but the trend varies from run to run, one or more of the orientation surveys may be suspect.

\section{Core Recovery, Layout, and Marking Procedures}

Fracture measurement cannot begin until the core has been removed from the core barrel, laid out, the core pieces reassembled as accurately as possible, and the appropriate markings made for footage, orientation, and uphole direction.

1. Core Recovery: Core damage can be avoided when using a conventional (unlined) barrel by laying the barrel down on the wellsite pipe rack and pumping the core out hydraulically with a high-pressure, low-volume pump. A rubber plug should be inserted in the barrel to prevent water from contacting the core. Except where the core is highly fractured and wedges itself in the barrel, it can be slowly pumped out into numbered trays. This procedure avoids the damage to the core that is commonly associated with the sledge-hammer/gravity-feed removal method on the rig floor, and preserves the smaller pieces of core, along with their orientation, allowing long intervals of continuously-fit core to be reassembled.

2. Core Layout: Layout and reassembly of the core pieces as much as possible are critical steps in orienting any core, since the strength of a data set is proportional to the length of the intervals of continuous fit. Even if core is not oriented, it should be processed as though it were, because cores can often be oriented after they have been cut and because the relative orientations of fractures to each other are useful.

3. Marking for Orientation: The basic procedures for orienting core have been published (e.g., Bleakly et. al., 1985; Nelson et. al., 1987; Skopec et. al., 1990). We elaborate here on the technique for deriving fracture orientations from oriented core. Oriented core has three grooves scribed into the core surface as it is cut, with two lines close together and an isolated line on the opposite side of the core. 'The isolated scribe is called the Principal Scribe Line (PSL); its orientation relative to true north is recorded by the core orientation survey.

Because of the rotation of the bit, the scribe lines commonly drift clockwise downhole, despite the bearing assembly designed to decouple the inner core barrel from the rotation of the outer core barrel. For this reason, a straight, artificial Master Orientation Line (the $\mathrm{MOL}_{\text {, }}$ is useful (1) for comparing the relative orientations of features in the core, and (2) as an oriented reference point (with respect to the oriented PSL, and thus to true north) for calculations of true fracture orientations. 'The MOL is marked on the core, after the core is laid out and fit together, as follows: at the uphole end of each continuous-fit section of core pieces, the core is rotated so that the PSI, is at the "top" of the core. A pipe-welder's level helps to position this line at the exact top. A chalk line is snapped along the top of the core, and is then scribed by hand and marked in blue. Red and black lines are marked on either side of the MOL, with the red on the right side of the MOL looking uphole, to prevent pieces of core from becoming inverted.

Thus the core is marked with both a rotating PSI, (usually green) and a straight, blue MOL. The MOL is most useful for comparing relative orientations of fractures within each continuous-fit interval and for absolute fracture orientation. The MOL, is re-set to coincide with the PSI, at each rubble zone, spinoff, or other core discontinuity. Knowledge of where the connections and bit rotation-speed changes were made during coring, and the continuity of the orientation survey, can aid in determining whether the PSL and MOL were continuous through these discontinuities, and whether a feature to be oriented correlates to an orientation-survey data point located above or below the discontinuity. 
Once the core is marked, the first measurement to make is the angular deviation of the PSL from the MOL with depth. The deviation of the PSL from the MOL should correlate with the changes in magnetic toolface orientation reported by the orientation survey (Bleakly et. al., 1985, Skopec et. al., 1990). If a significant discrepancy exists between the two, or if the PSL rotates more than $10-15 \% / \mathrm{ft}$ (so that the common plus-or-minus one-foot depth correlation uncertainties between core and the survey cause significant orientation uncertainties), then absolute-orientation calculations for fractures may be worthless.

\section{Measurement of Fracture Dip and Strike}

Fracture dip and strike in core can be most accurately measured with an electromagnetic goniometer, but adequate preliminary results may be obtained with a dime-store protractor, or, preferably, with a $0-360^{\circ}$ annular protractor with an inside diameter equal to the core diameter. To measure the relative orientation of fractures, the MOL is used as a $0^{\circ}$ reference point, with the true azimuth of the MOL added to the measured orientations later to obtain true fracture orientation.

Dip angle may be approximated with a protractor aligned with the core axis. If the fracture extends diagonally through the core, dip angle may be also obtained from the arc tangent of the height of the fracture along the core axis divided by the core diameter. Apparent dip angle must be corrected for hole deviation in non-vertical wells, which requires oriented core. Where fractures are not vertical, measuring dip azimuth resolves a possible $180^{\circ}$ ambiguity in dip direction that is present if only fracture strike is measured, and which would mask the difference between a set of parallel inclined fractures, and two sets of opposite-dipping inclined fractures with the same strike.

The strike of fractures in core can be calculated several ways:

1. In vertical core, obtain the angle from the MOL to each intersection of the fracture with the core surface $(\alpha 1$ and $\alpha 2$, Figure B1), measured counter-clockwise looking down-core. If the fracture dips, these angles must be measured at two different depths along the core axis, and the distance between the measurement points recorded (Figure B2). With these 5 measurements, the relative strike and dip of the fracture can be calculated using the equations shown on Figure B2. True strike is obtained by correcting for deviation of the MOL from the PSL and for the true orientation of the PSL.

2. For vertical core, the relative fracture strike may also be taken as $90^{\circ}$ to the line estimated normal to the fracture plane and bisecting it midcore, with the position of that line measured clockwise from the MOL with a protractor. Degrees on the protractor must increase clockwise looking down-core. (If the fracture dips with respect to the core axis, strike is $90^{\circ}$ to the uppermost or lowermost intersection of the fracture with the core surface). True fracture orientation is then derived by adding the MOL and PSL deviation components. Alternately, the PSL can be aligned directly against its true orientation value on the circular protractor, and the true orientation of the line $90^{\circ}$ to the fracture can be read directly (Figure B3), provided that the core depth can be accurately correlated to the orientation survey depth.

3. The orientation of a fracture relative to the core axis in deviated core is measured in the same manner, but the orientation must then be reoriented by means of a stereonet (e.g., Ragan, 1973), or a computer program. In core from a deviated hole, the orientation survey gives the position of the PSL in degrees clockwise (looking downhole) from the "high side" or roof of the hole, not its position relative to true north. This position must be geometrically combined with the true azimuth and dip of the core axis provided by the wellbore survey to provide a 3-D framework for reorienting the fractures. 
Geometric relationships useful for this process include: (1) An originally horizontal reference plane (pre-coring/in situ orientation) may be demarcated on the core by bedding if the strata nre horizontally laminated (Figure B4) but otherwise must be reconstructed from the PSL orientation survey and the wellbore deviation survey. This plane will cut the deviated core with an apparent angle of dip, measured relative to the core axis, equal to the deviation of the well from vertical. (2) The apparent dip azimuth of this plane (relative to the core axis) will be parallel to the wellbore azimuth, and the downhole end of the plane terminates on the high side of the core. (3) The strike of this plane relative to the core axis is the horizontal axis for rotating the core back to its in situ position.

4. For a rough, field estimation, fracture orientations in deviated core can be estimated with a protractor if the core is held in the appropriate in situ position with sand bags. The core position is based on the wellbore orientation survey, and bedding or the PSL orientation. The geometry of this method may be visualized in Figure B4: bedding and/or the core orientation survey define the top of the core and its uphole direction, while the wellbore survey provides core axis dip angle and azimuth.

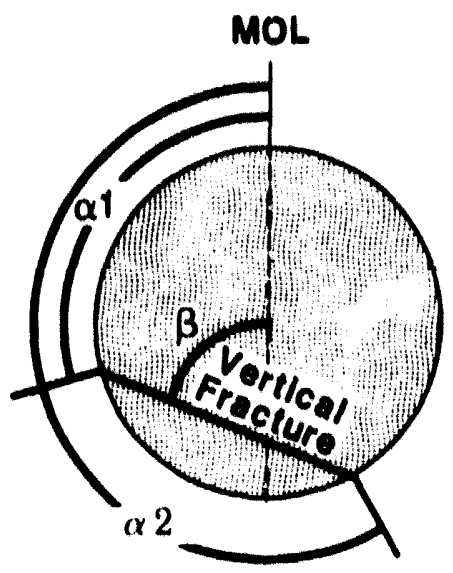

The strlke $(\beta)$ can be calculated:

$$
\beta=\tan ^{-1}\left(\frac{\sin \alpha_{2} \cdot \sin \alpha_{1}}{\cos \alpha_{1} \cdot \cos \alpha_{2}}\right)
$$

\section{Viow is looking down on core}

Figure B1. Schematic of core cross-section, showing the angles to be measured, and the formula for converting the angles into strike relative to the MOL, for fractures in vertical core. MOL is the Master Orientation Line, $\beta$ is the strike angle relative to the MOL, $\alpha 1$ and $\alpha 2$ are the angles between the MOL and the two edges of the fracture on the core surface. 
ene1

$$
\begin{aligned}
& D i p=80 \cdot \Phi \text { where } \\
& \Phi=\tan ^{-1}\left[\frac{\frac{d}{2}\left\{1 \cdot \cos \left(\frac{\alpha 1}{2}\right)\right\}}{L}\right]
\end{aligned}
$$

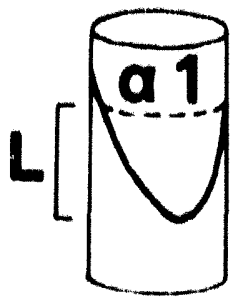

$d=$ core diameter and must be in the same untis as $L$

\section{cane}

$$
\Phi=\tan ^{-1}\left[\frac{\left.\frac{d}{2}\left\{\cos \left(\frac{\alpha 2}{2}\right)-\cos \left(\frac{\alpha 1}{2}\right)\right\}\right]}{L}\right] L
$$

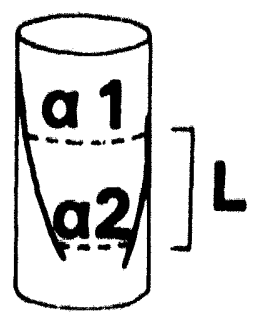

Figure B2. Diagrams of fractures in core, showing the angles to be measured between the intersections of a fracture on a core surface ( $\alpha 1$ and $(x 2)$, and the formula for converting the angles into fracture dip angle with respect to the core axis for two cases: Case 1: The dip can be calculated with one strike measurement and the distance from the angle to the apex of the fracture trace $(\mathrm{L})$ if the fracture exits the core; Case 2: Dip can be calculated by measuring two angles and the vertical distance between them ( $L$ ). 


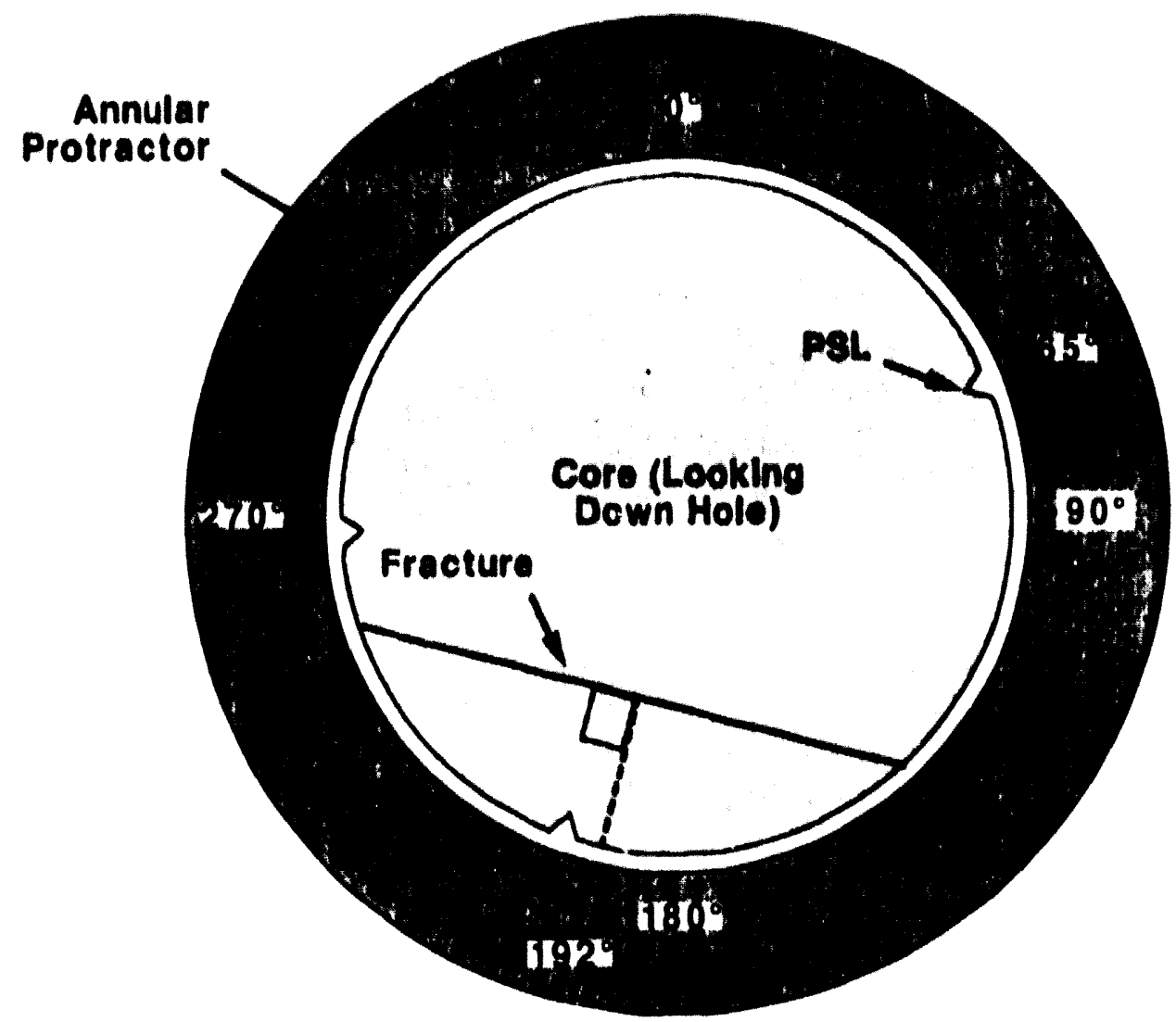

Figure B3. Schematic of core cross section and annular protractor: Fracture strike in the core can be read directly, if the orientation survey is good and if the scribe rotation is minimal, as follows: (1) the principal scribe-line groove (PSL) is aligned on the protractor with its true orientation at that depth, provided by the orientation survey, of $65^{\circ},(2)$ an imaginary line normal to the midpoint of the fracture at that horizon is measured at $192^{\circ}$, and (3) true fracture strike is calculated as $90^{\circ}$ from the imaginary line, at $102^{\circ}$. Fracture strike can be read from its direct intersection with the protractor only if it exactly bisects the core.

However, if scribe rotation is a significant lactor, more precise measurements are obtained as follows: zero on the protractor is aligned with the PSL, and relative fracture strike read from the imaginary $90^{\circ}$ line to the fracture; thus $127^{\circ}$ minus $90^{\circ}$ equals $37^{\circ}$. The true PSI orientation is then added to the relative strike to give true strike: $37^{\circ}$ plus $65^{\circ}$ equals $102^{\circ}$. This becomes slightly cumbersome whenever sums exceed $360^{\circ}$, and this method requires that the depths of the orientation survey be correlated exactly with equivalent depths of the core, for which a PSL-deviation-from-MOL. diagram must be made (see skopec et al., 1990), and compared to the orientation-survey deviation. 


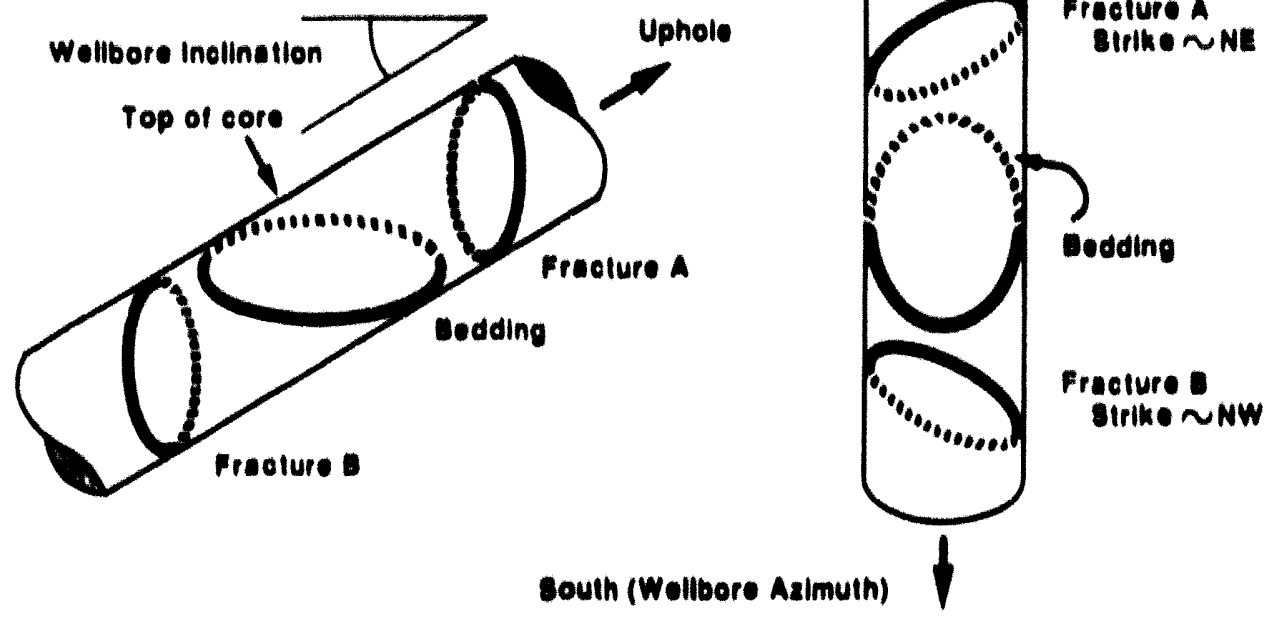

Figure B4. Diagram showirg two views of fractures in the same piece of core, and portraying (1) how a rough, field measurement of fracture orientation may be obtained, and (2) how core from a deviated well may sometimes be oriented without an orientation survey. The latter tech. nique requires that bedding is sufficiently planar and horizontal to indicate the top of the core, that the uphole direction of the core is known (an anymmetric ncribe shoe is valuable here), and that the wellbore azimuth and deviation for the cored interval are available from a wellbore survey.

\section{Orienting Unoriented Core}

Unoriented core can be oriented after the fact in some cases, by comparing features indicative of the in situ stress orientation that may be present in both the unoriented core and in oriented downhole logs. If an oriented four-arm caliper log has been run in the hole, and if it shows definitive breakouts indicating anisotropic horizontal stresses, the borehole elongation will commonly trend normal to the strike of stress-controlled, coring-induced scribe-line, petal, and petal-centerline fractures. If no petal fractures are present, other stress-identification techniques may apply. Anelastic Strain Recovery (ASR) or Differential Strain Curve Analysis (DSCA) measurements must be made on the core immediately after it is removed from the core barrel, but laboratory measurements of acoustic velocity anisotropy may be made on core years after it was cut (e.g., Strickland and Ren, 1980; Teufel, 1983). All of these tests are designed to indicate the orientation of the principal horizontal stress, and thus the core can be oriented relative to the stress directions indicated by breakouts. Similarly, features recognized in both core and oriented wellbore-image logs may correlated and used to orient core, as discussed later.

Paleomagnetic core orientation may be used to orient small segments of core where fractures occur, long after the core has been collected (Van Alstine et. al., 1991). A disadvantage is that numerous plugs must often be taken from a short interval of core. 


\section{Descriptions of Fractures in Core from Vertical Wells}

Vertical core provides the moat commonly available data base for characterizing fractures. In fact, it is common to attempt to asseas the fractures in a formation by drilling and coring a vertical pilot hole prior to drillink a horizontal well (Skopec, 199i). When fractures are intersected in this way, significant data are obtained. A liat of fracture parameters that can and should be measured in core in order to characterize fracture permeability ayatems in given in Table BI.

\section{Table B1. Fracture Parametern that Bhould Bo Measured In Core}

- Host Lithology: type and thickness number and type of sedimentary heterogeneitien

- Depth of Fracture and Powition within Bed:

- Vertical Fracture Terminations: location and character relationship to nedimentary heterogeneity relationship to core surface

- Fracture Hoight in Core: note if minimum due to fracture exiting core note if minimum due to misaing core

- Cieneral Fracture Character: uingle, en echelon, anastamosed, etc.

- Type of Fracture: direction of separation/offuet

- Strike and Dip (Dip Azimuth): absolute (if possible) relative to other fractures and strens indicators (if not)

- Spacing between Fractures:

- Mineralization:

type character (crystal size, amorphous, slickencryats, etc.) percent of fracture filled

- Total and Remnant Fracture Width: character of remnant porouity

- Surface Ornamentation Beneath Mineralization: slickensides, plumose ntructure, etc. planarity orientation of linear features orientation relative to fracture plane

- Number of Fracture Seta:

relationship to nearby fractures (abutting, crossing, otc.)

Unfortunately, the probability of intersecting vertical fractures with vertical core is not high. In the simplest case, where one set of evenly apaced fractures is present, the probability of encountering a fracture is the ratio of the core diameter (or borehole diamoter when using loge) to fracture spacing. 'Thus, even if fractures are only oight inches apart, the probability of coring a fracture with a four-inch diameter core is only $50 \%$. 'This probability decreases rapidly as fracture spacing increases (Figure B5). 
Drilling-induced fractures are common in vertical core, and the strike of induced petal and petal.centerline fractures supplies an important measure of the in situ stresn orientation (Kulander ot. al., 1990); Lorenz et. al., 1990). This type of fracture must be distinguished from natural fractures, and the petal fracture strike should always be measured, if only relative to the strike of adjacent natural fractures. This relationship in important because hydraulic stimulation fractures will parallel the principal horizontal atress, and therefore the angular relationship between stimulation fractures and natural fractures, as well an the probability of a natural fracture aet being upen or clomed at depth, may be predicted.

\section{Characteristics Measurable Only in Vertical Core}

Fracture planes that parallel the axin of the core (vertical fractures and vertical wella) provide nome types of information that are important, but that are not available from horizontal wells. Specifically, vertical core allows for the measurement of fracture heights (Figure B6a, b, and c), and for the locations and typen of fracture terminations (Figure B7). For regional fractures, such as those in the heterogeneous Mesaverde reservoirs in the Piceance Basin, fracture heights are commonly less than grows bed thicknews becaune they are limited by the numerous internal sedimentary heterogeneitien. Fractures are alao commonly limited by ductile reservoir bounding strata. 


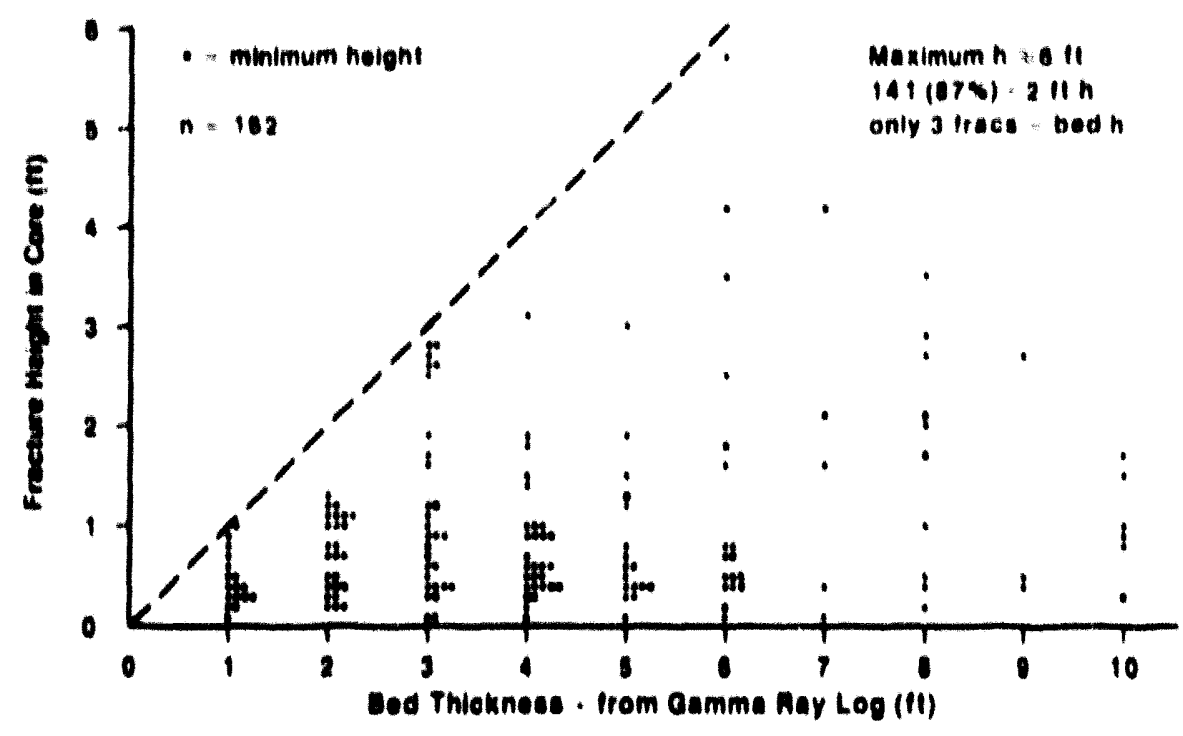

a. Individual fracture height in core an a function of bed thickness for sandatone beds no more than $10 \mathrm{ft}$ thick. "Minimum height" indicutes that the total fracture height in unknown due to missing core or wher factor. Dashed line indicates the 1:1 bed thickness to fracture height rutio that is rarely attained.

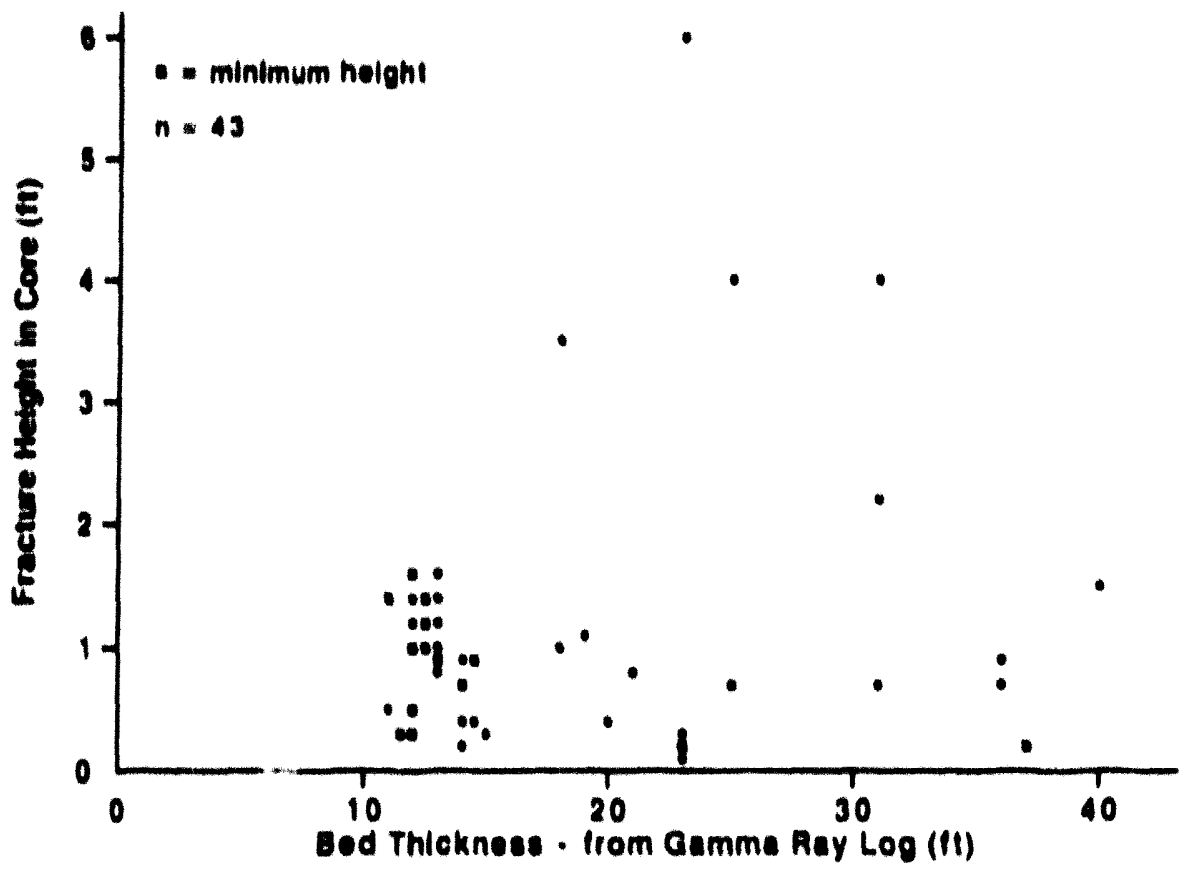

b. Individual fructure height as a function of gross hed thickness for sandstone beds greater than $10 \mathrm{ft}$ thick. A horizontally compressed version of Figure $6 \mathrm{~A}$ would fit into the space at the left of this graph, showing that most of the fractures cored are in the thinner sandstone and siltstone beds.

Figure B6. (cimtinted on next page) 


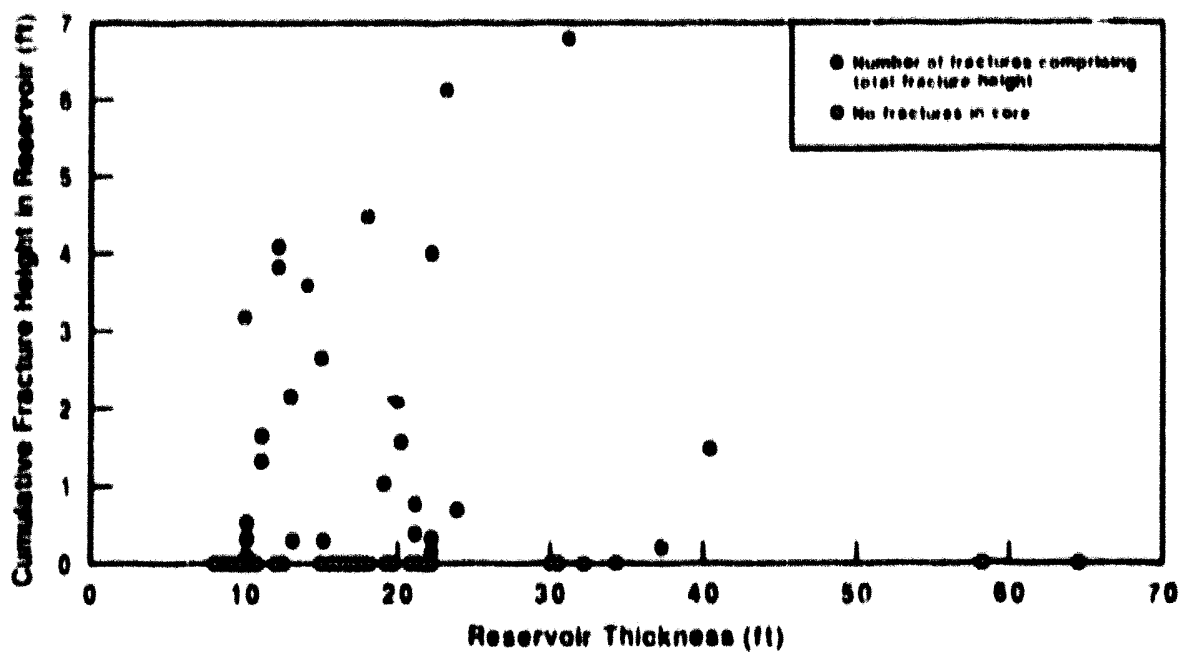

c. ('umulative fracture height in core in sandstones that are ut leant ten feet thick. Note that core from over half (52") of the reservoirs, including the thickest ones, displayed no fractures, yet deviated core shows that these same andatones are in fact highly fractured.

Figure 136. Plots of fracture height data from vertical core, that highlight the irregular fracture distribution within heterogeneous Muvial sandatone reservoirs of the Mesaverde Formation in the Piceance Basin, (olorado. (1)ata are from the MWX wells.)

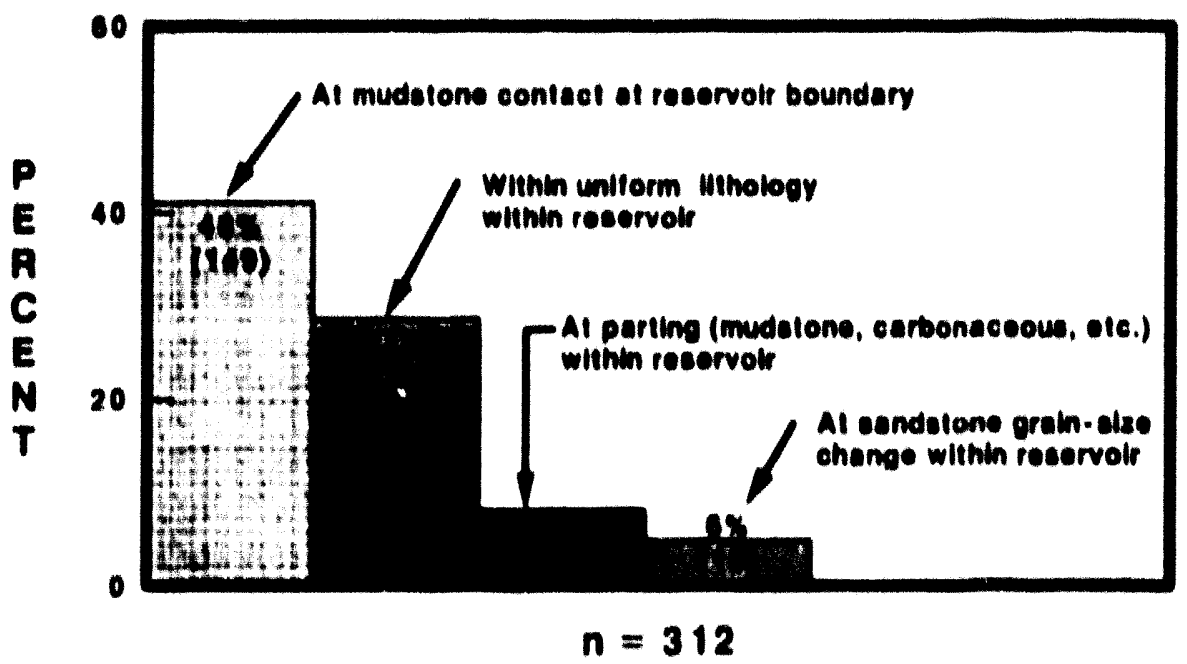

Figure B7. Histogram showing the locations of fracture termina. tions in vertical core from heterogeneous, fluvial sandstone reser voirs in the Mesaverde Formation in the Piceance Basin, Colorado. (1)ata are from the MWX wells.) 'The percentage of fracture termi nations at bounding mudatone lithologies is high in this plot because many of the fractures occur in relatively thin beds. 'These data sugkest that froctures that extend the full thickness of unv reservoir are rare to uhaent. 
Core lithology and fractures should be described together, because the distribution of fractures relative to lithology is important. Thus if measurements show (1) that the fractures are limited to the reservoir strata, and (2) that fracture heights are significantly less than bed thickness, then vertical fracture permeability between and within reservoirs will be severely limited, and both horizontal drilling and cubic-block reservoir-engineering models may be inappropriate. Fracture planarity and surface roughness (due to mineralization and/or fracture-surface ornamentation) are also more readily measured in vertical core simply because larger samples of the fracture planes are obtained, if fractures are intersected, than in horizontal core. Estimates of these parameters can be used by the reservoir engineer to determine flow rates and turbulence, and by the geologist as clues to the origin of the fractures.

Finally, vertical core can provide a measurement of fracture distribution with depth (Figure B8), and of the variation in fracture characteristics as different formations are penetrated by a well. As noted in Figure B8, however, such vertical distributions should be used with caution, as changes may be facies controlled and more apparent than real.

Vertical core in heterogeneous reservoirs will not provide definitive data on the presence or absence of vertical fractures, much less on fracture spacing and fracture porosity, but it will allow the measurement of dip, strike, and permeability. These will be discussed below, together with dimensions tha0t can be measured from either vertical or deviated core.

\section{Descriptions of Fractures in Core from Deviated Wells}

The chances of intersecting vertical to near-vertical fractures increase dramatically when wells are deviated. The ratio of the horizontal distances within the reservoir sampled by (1) a deviated well, and (2) vertical four-inch diameter core, varies as the thickness of the reservoir times the tangent of the deviation angle (Figure B9). Thus a well with a $30^{\circ}$ deviation in a $35-\mathrm{ft}$ bed will sample $20.3 \mathrm{ft}$ of horizontal distance, or $6200 \%$ more than vertical four-inch core. If the deviated wellbore azimuth is normal to the fracture strike, chances of intersecting vertical fractures are increased by $6200 \%$. Therefore deviated pilot holes should be considered when planning horizontal wells.

Even though fractures are not difficult to intersect with a deviated well, an irregular fracture distribution and the resulting limited vertical fracture permeability will significantly decrease the production advantage of such a well. Therefore it is important to characterize the nature of the fractures and fracture-permeability system in the reservoir in order to properly design wells, and fracture analysis beyond notations of fracture dip, strike, and depth is needed. 


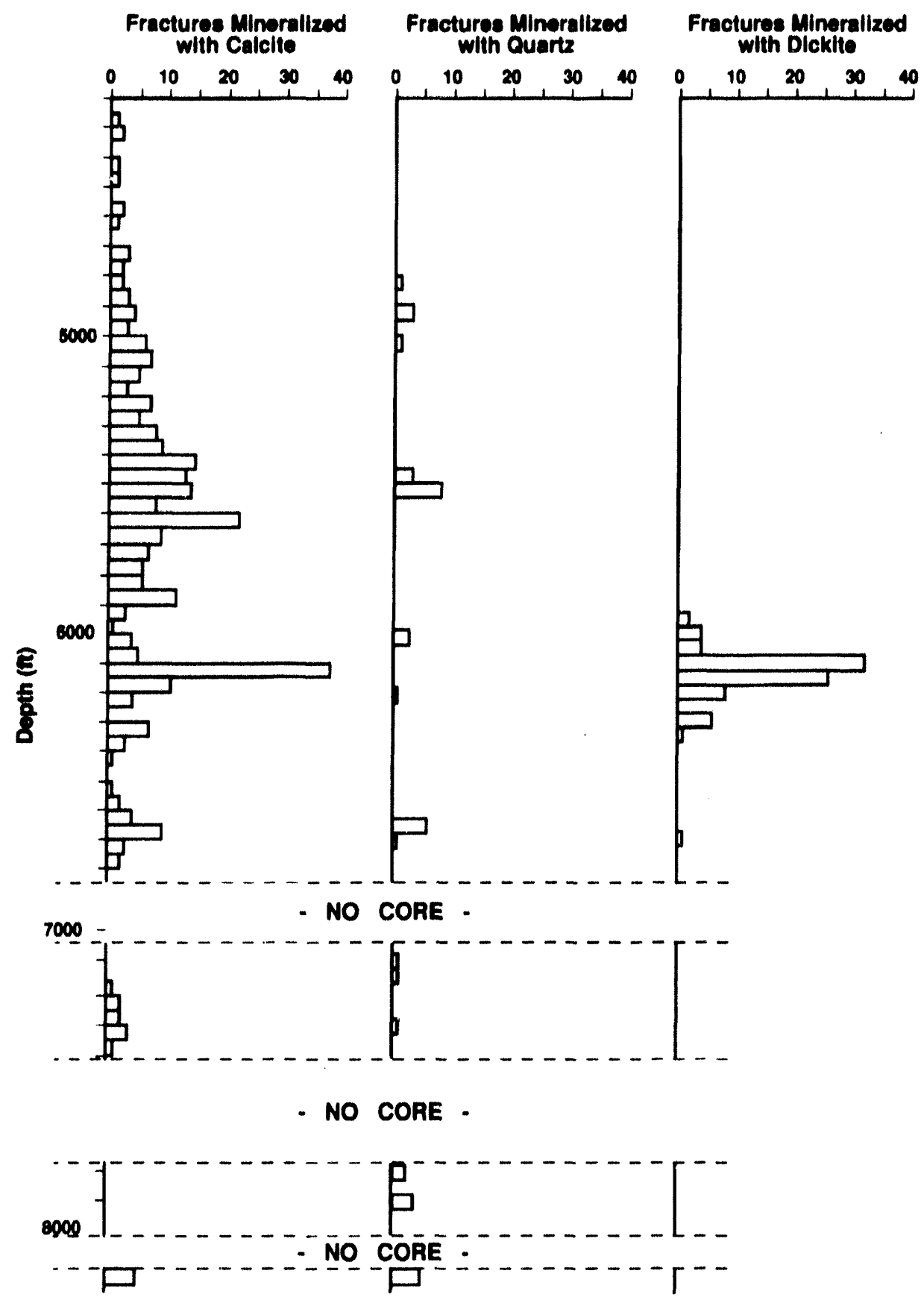

Figure B8. Histogram showing fracture frequency in vertical wells as a function of depth in the Mesaverde Formation in the MWX wells in the Piceance Basin of Colorado. These wells are relatively straight, but apparent high frequencies could be caused in other wells by deviated segments of a wellbore. New data from the deviated SHCT-1 well (Lorenz and Hill, 1991) show the measured paucity of fractures in the lower intervals to be misleading, as deviated core contains numerous closely spaced fractures in these same zones. The apparent decrease in fracture frequency is a function of a decrease in the number of highly fractured, interbedded thin sandstones in the lower zones, caused by changing depositional facies. Fracture spacing within the actual reservoirs of these lower strata is not significantly less than spacing in the higher reservoirs. 
Advantage Of Deviated Well For Fracture Intersection

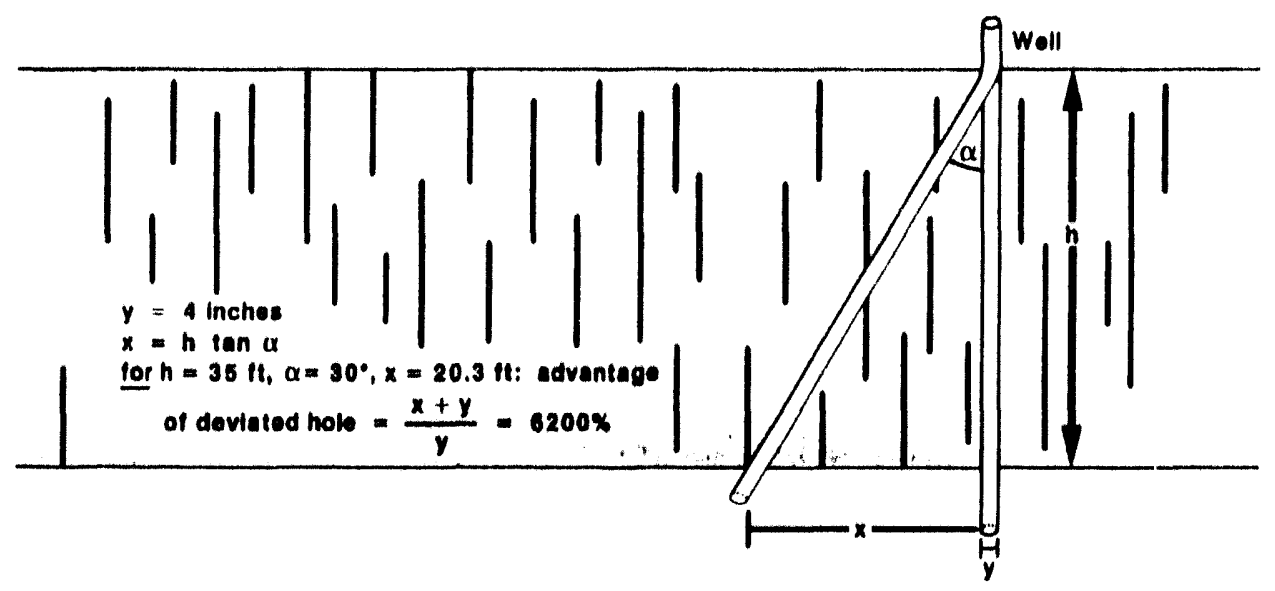

Figure B9. Schematic drawing showing the increased chance of encountering vertical fractures in a deviated well, as a ratio between the lateral distance crossed by the deviated hole, and the four inches "traversed" laterally by four-inch core. For the purpose of fracture characterization, a slant hole offers a significant advantage over vertical holes. $h$ is bed thickness, $\alpha$ is the angle the hole is deviated from vertical, $y$ is the core diameter, and the heavy vertical lines are fractures.

\section{Characteristics Measurable Only in Deviated Core}

The principal characteristic of fractures measurable only in core from deviated holes is fracture spacing. However, although an absolute spacing can be measured in the core, the data are still one-dirrensional, measured along the core axis. Measured spacing along the core axis must be converted into true horizontal spacing by accounting for the geometric relationships between hole deviation, hole azimuth, and fracture strike. Once this is done, the distribution of spacings can be analyzed.

The extrapolation of measured fracture spacing in core to the rest of the reservoir, based on the principle that extensional strain should be constant throughout the reservoir, may or may not be valid depending on reservoir heterogeneity. However, the precise number derived from core for the average or the range of fracture spacings is rarely applicable to reservoir engineering models. For the horizontal SHCT-1 core in the relatively homogeneous, marine Cozzette sandstone, fracture spacing varies between a minimum of less than one inch to a maximum of $17 \mathrm{ft}$ with an average of $3 \mathrm{ft}$ (Lorenz and Hill, 1991). The "average fracture spacing" value in this case is of little use as a direct input parameter to reservoir engineering models because it ignores the wide range of spacings. It may, in fact, be misleading, because it includes the spacings of isolated fractures as well as the spacings within fracture swarms, even though swarms are effectively single fractures in an engineering sense (P.T. Branagan, personal communication, 1991), while single, isolated fractures may contribute little to the system.

For comparison, 17 distinct gas shows in the mud log from a side-track of the SHCT-1 well have spacings of 2 to $35 \mathrm{ft}$. Such spacing compares more favorably to the $2.5-17.6 \mathrm{ft}$ range of swarm and isolated fracture spacings than to individual fracture spacings seen in the correlative core (Figure B10). Swarms of closely spaced fractures appear on the mud $\log$ as single gas shows. If some of the isolated fractures are deleted from the core spacing computation on the assumption that they may not show on the mud log, the upper limit of the fracture spacing range for core approaches the observed upper spacing limit of the mud log gas shows. 

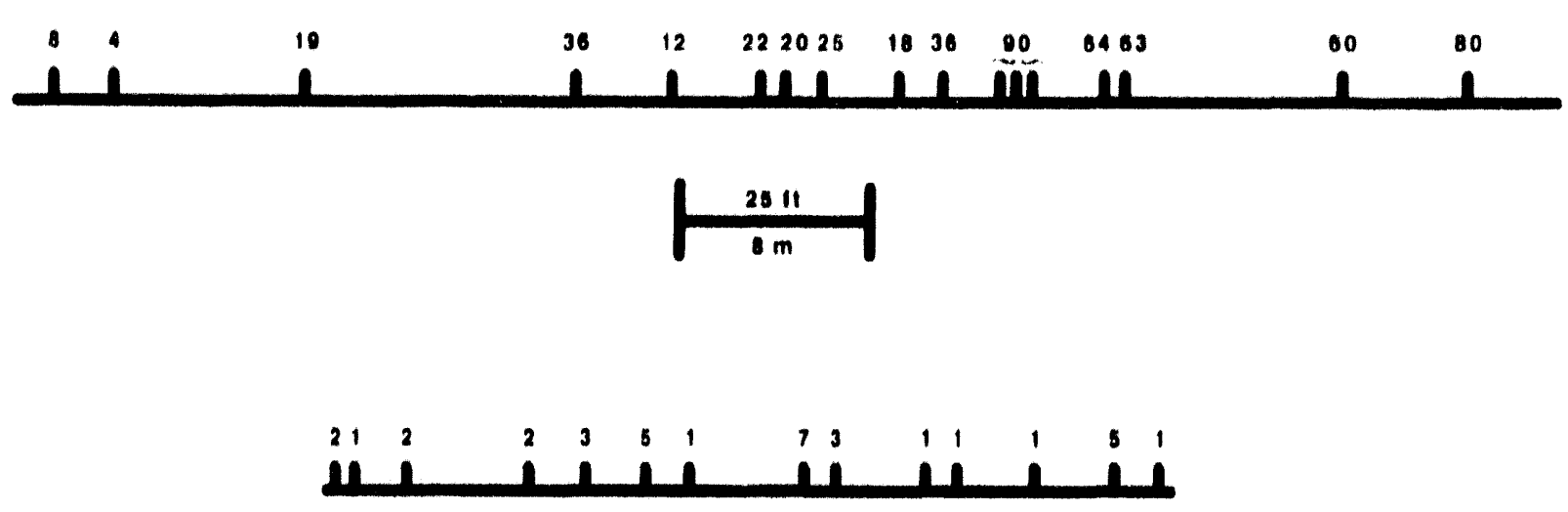

Figure B10. A comparison between the location and volume of gas shows in the horizontal portion of the SHCT-1 sidetrack (top line; volume of gas in gas units X 10 indicated above line), and the spacings of isolated fractures and fracture swarms in horizontal SHC'T-1 core (bottom line; numbers of fractures per location indicated above line) in the same reservoir at the same depth. The two traces are from parallel holes, so there is no direct correlation, but swarm spacing is comparable to gas show spacing, whereas the average spacing of all fractures is considerably less than the spacings of gas shows. Data from the Mesaverde Formation, Piceance Basin, Colorado.

If the average spacing of fracture swarms is more useful to the engineer, then the spacing populations must be characterized so that this figure can be determined. Fractal analysis is one approach to fracture characterization (e.g., LaPoint, 1988; Nelson, 1991), but for the limited data set commonly available in core, a somewhat simpler statistical approach based on cumulative probability distribution plots of fracture spacings may be equally useful. An example of such plots of fracture spacings in the SHC'T-I core (Figure B11a) highlights the difference between two sub-populations of spacings. 'The closely spaced swarm population can be removed to leave the spacings of probable engineering significance, and compares favorably to the spacings of gas shows (Figure Bllb).

Fracture spacing is significantly less than gross reservoir thickness in the heterogeneous Mesaverde reservoirs at the MWX/SHC'T site. This holds true for both the narrow, lenticular, 25 to $35-\mathrm{ft}$ thick channel sandstones and the 60-ft thick, blanket, marine sandstones (bed-thickness to fracture-spacing ratios of 10-15 and 20 respectively).

Once the spacing of fractures has been measured, an estimate of fracture porosity can be made using average fracture open width and average fracture spacing, and can be compared to the rock matrix porosity. A quantitative estimate of fracture porosity can be made with core from a deviated hole, whereas only a qualitative estimate can be derived from vertical core. 


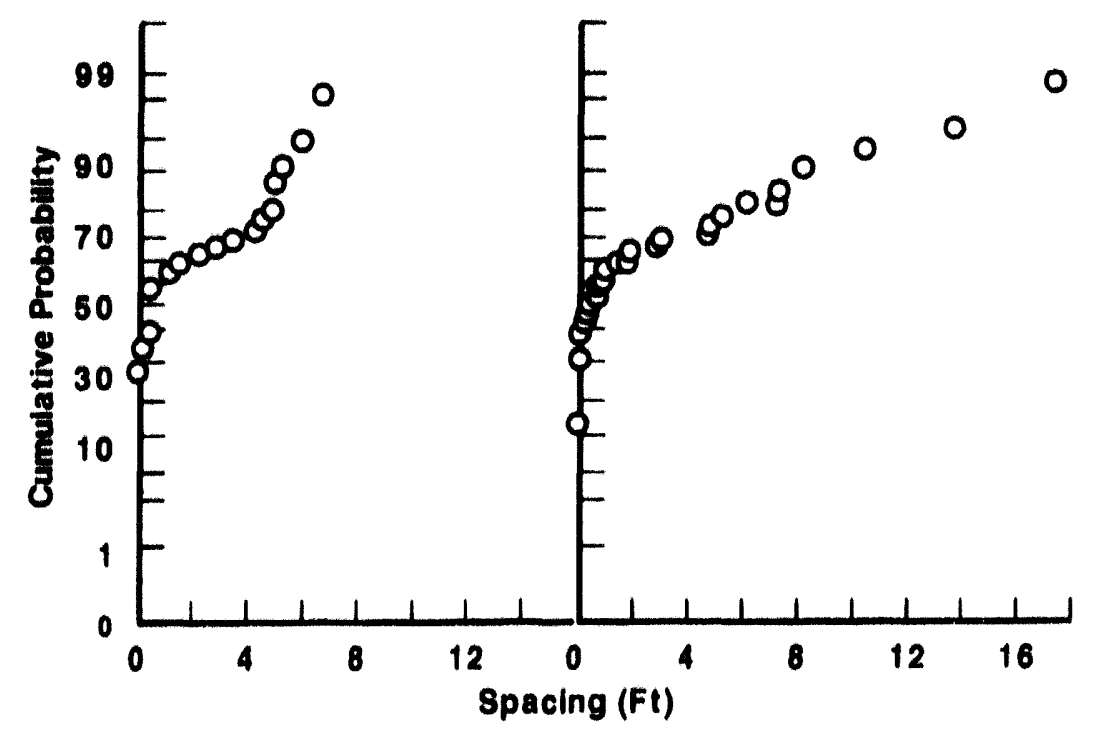

a. Cumulative probability plots of fracture spacings in the SHCT-1 core. These data show (1) populations that are not normally distributed, and (2) sub-populations of spacings, as defined by different slopes. The steep slopes of closely spaced fractures represent fracture swarms (left: plot for lenticular channel sandstones 25-35 ft thick; right: plot for blanketshaped marine sandstone $60 \mathrm{ft}$ thick).

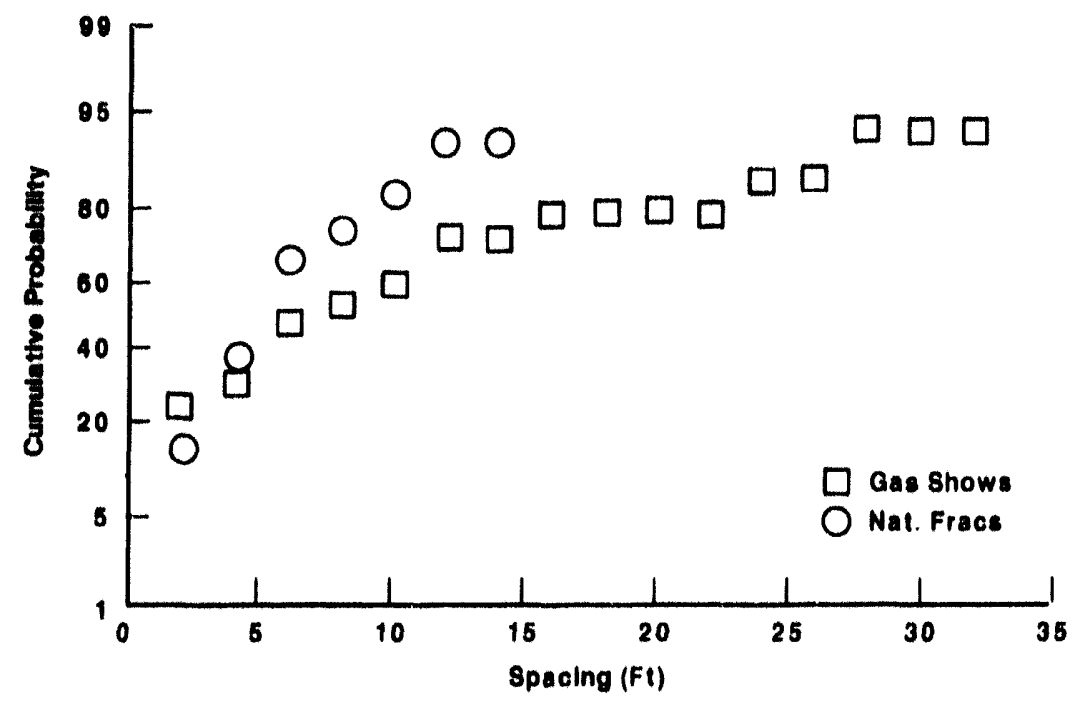

b. Cumulative probability plots of the spacings of gas shows (data from Figure B10), and the Cozzette core fracture spacings greater than $2 \mathrm{ft}$. This figure suggests that the widely spaced fractures are those that influence production. (Data are from the SHCT-1 well, Mesaverde Formation, Piceance Basin, Colorado. Cumulative probability plots are described by D'Agostino and Stephens, 1986.)

Figure B11. Characterization of fracture spacing in horizontal wells. 


\section{Fracture Characteristics Measurable in Both Vertical and Deviated Core}

Fracture dip and strike can be obtained from either deviated or vertical core if the core is oriented. Even if core is not oriented, the fracture orientations relative to each other and relative to any stress indicators such as petal fractures should be made, and referenced to an arbitrary orientation line (the MOL described above) if sufficient lengths of continuous-fit core are available for study. Fractures that are consistently parallel to each other argue for a single set of sub-parallel fractures, and thus for significant permeability anisotropy in the subsurface (Figure B12). Parallel or oblique strike relationships between fracture sets and the principal horizontal stress can also be determined from consistent angular relationships between petal fractures and natural fractures. This relationship is important to (1) prediction and understanding the effects of hydraulic stimulation fractures, (2) determining which of multiple fracture sets is most important to permeability, and (3) determining the sensitivity of fracture permeability to changes in stress during production-induced pore pressure changes.

Many natural fractures are mineralized, which reduces the permeability along the fracture (Figure B13). Smaller fractures may appear to be completely mineralized and to have little or no permeability, although many apparently mineraiized fractures provide significant permeability under in situ conditions. Moreover, such fractures may parallel more open fractures that have not been cored, and thus should be measured as an indication of fracture trend.
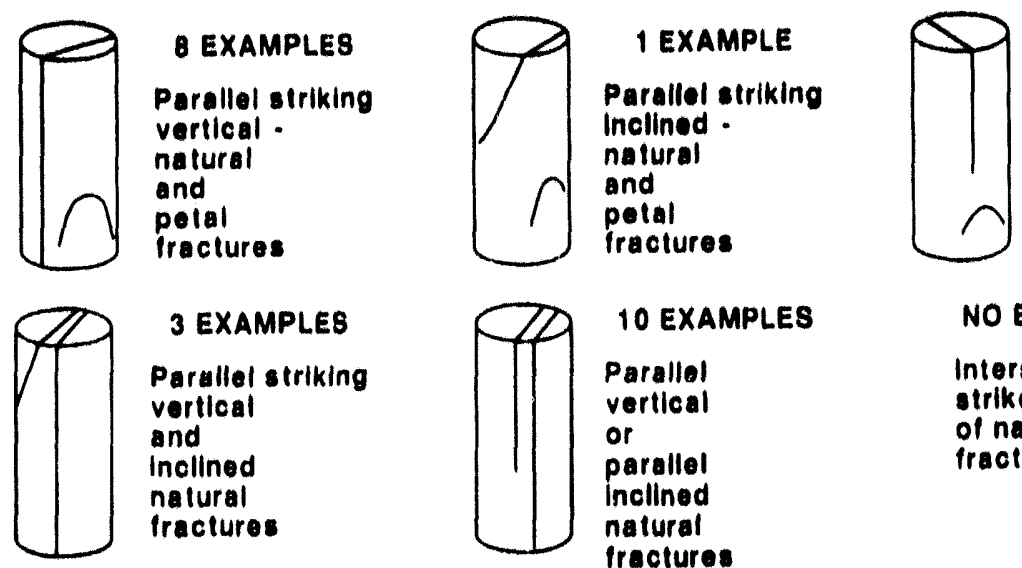

1 EXAMPLE

Oblique - striking

vertical.

natural

and

petal

fractures

Praclures

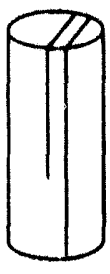

10 EXAMPLES

NO EXAMPLE8

Parallal

vertical

or

parallel

inclined

natural

iractures

Figure B12. An example of fractures in a core that can be demonstrated to be parallel to each other, and to the maximum horizontal stress, by measuring fractures relative to an arbitrary orientation line (MOL-see text) over several short, continuous-core intervals. This was possible despite the breakdown of the core orientation survey and badly rubbleized core. (Data are from the Austin-Mississippian limestone at 13,000)- $\mathrm{ft}$ depth, in the Heyco Duncan Unit 3 well in the Tatum basin, NM, courtesy of Larry Brooks and the Harvey E. Yates Co.) The fracture trend is still unknown, but the data suggest that the fractures will create anisotropic horizontal permeability, and that a hydraulic stimulation would be relatively ineffective. 
Direct measurement of fracture permeability is a tricky operation. (cutting a plug that contains the fracture is difficult, as only fractures that are well cemented will hold together during the plugging process (e.g., Morrow et. al., 1990). Unfortunately, the tightly cemented fractures may not contribute as much to the system permeability as less easily plugged, open fractures. Whole-core measurements of permeability can give more realistic, and commonly much higher, values for system permeability (e.g., Lamb and Ferguson, 1988). Poorly cemented fractures may sometimes be artificially cemented, plugged, the artificial glue dissolved, and the plug then tested.

Table B2 compares the types of fracture data that can be obtained from core from vertical and deviated wells. Both types of data are desirable for optimum characterization of subsurface fracture systems. Only a limited number of fracture measurements are exclusive to horizontal core, but these parameters, spacing and porosity, are important.

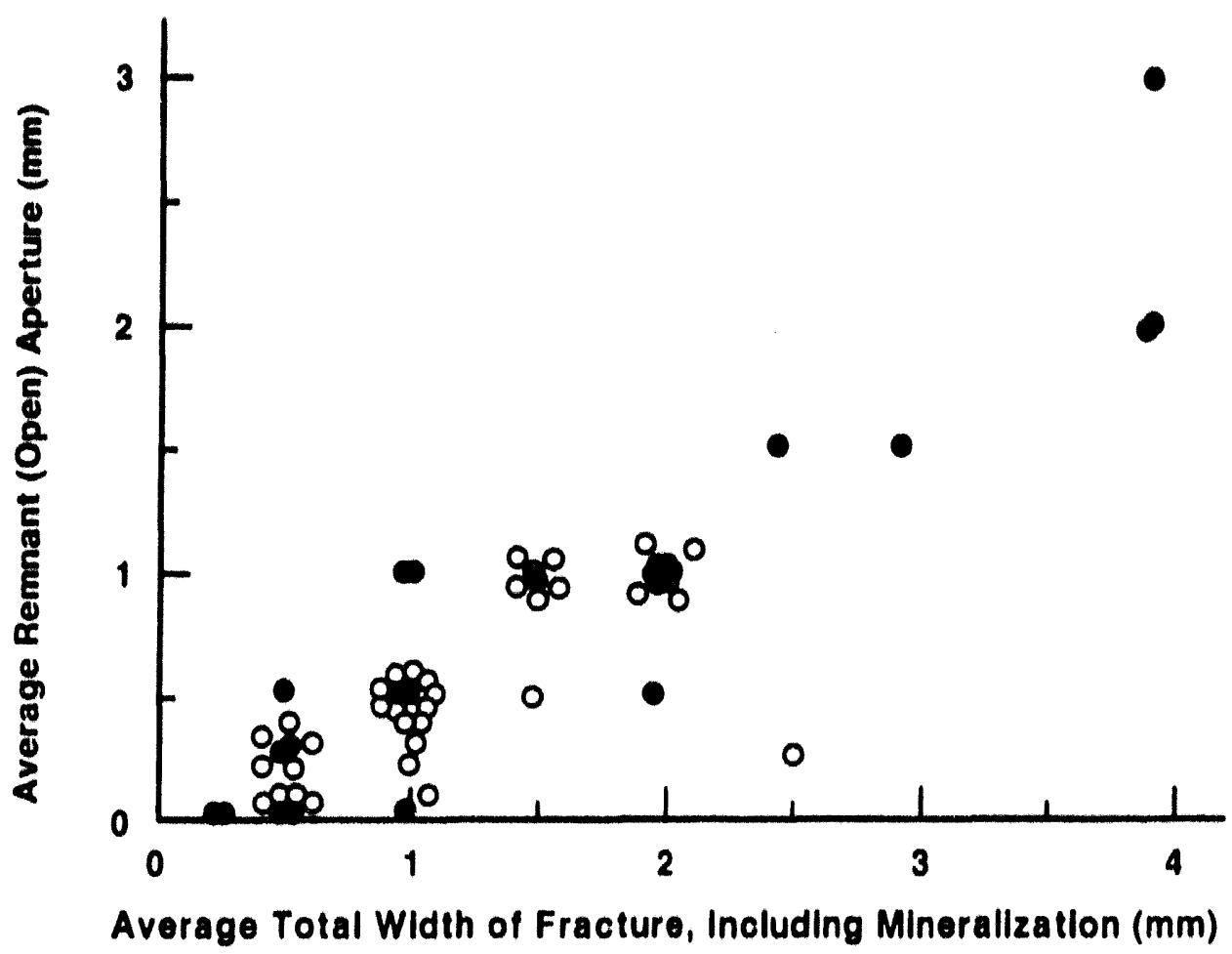

Figure B13. 'Total fracture width plotted against remnant (unmineralized) fracture aperture of the same fracture. The smaller fractures tend to be more completely mineralized. Solid circles from lenticular channel sandstones; open circles from marine sandstones. (Data are from core from the SHC'I'-1 well, Mesaverde Formation, Piceance Basin, (Colorado.) 
Table B2. Comparison of Types of Data Measurable in Core from Vertical and Deviated Wells

\begin{tabular}{lcc}
\multicolumn{1}{r}{ Measurable Characteristic } & $\begin{array}{c}\text { Vertical } \\
\text { Core }\end{array}$ & $\begin{array}{c}\text { Deviated } \\
\text { Core }\end{array}$ \\
\hline Spacing & - & $\mathbf{x}$ \\
Total Width & $\mathbf{x}$ & $\mathbf{x}$ \\
Remnant Aperture/Mineralization & $\mathbf{x}$ & $\mathbf{x}$ \\
Formation Fracture Porosity & -1 & $\mathbf{x}$ \\
Fracture Permeability & $\mathbf{x}$ & $\mathbf{x}$ \\
Strike and Dip & $\mathbf{x}$ & $\mathbf{x}^{2}$ \\
Number of Fracture Sets & $\mathbf{x}$ & $\mathbf{x}$ \\
Vertical Termination Locations & $\mathbf{x}^{3}$ & - \\
Height & $\mathbf{x}^{3}$ & - \\
Preferred Host Rock & $\mathbf{x}^{3}$ & - \\
Surface Morphology & $\mathbf{x}$ & - \\
Fracture Type & $\mathbf{x}$ & $\mathbf{x}^{3}$
\end{tabular}

Comments: 1. Qualitative estimate may be possible

2. May not require oriented core

3. Requires sufficient core

Note that if fractures are intersected, vertical core will provide more attributes than deviated core, but not the important factors of spacing and porosity.

\section{Fracture-Identification Logs}

Fractures in fracture-identification logs can be analyzed in much the same fashion as fractures in core (e.g., Emmendorfer, 1989). Unfortunately, no fracture-identification logs were run in the SHCT-1 well or its side track, and other wells will be used to illustrate this section.

\section{Comparison With Core Data}

Fracture-identification logs can provide a check on the fracture orientations obtained from oriented cores. Figure B14a and b shows an example of agreement between fracture orientations derived from image-log analysis and from correlative core. Although agreement in fracture orientation is common, in most cases it is difficult to correlate specific individual fractures between core and image logs. It is always desirable to have core to calibrate the images seen on logs, as apparent fractures on logs, especially in horizontal holes, can be the products of tool malfunction.

In some cases, natural fractures can be distinguished from induced fractures on image logs. In such cases, the different orientations of the two types of fractures, seen in the log and corroborated by core observations, may allow the initial distinction to be made. Once this criterion is established, other characteristic image differences such as width and brightness of the fracture image may become apparent. Image logs can identify open fractures which are commonly filled with drilling mud near the wellbore and therefore of fer a resistivity and density contrast. Mineral-filled fractures can only be seen if there is a significant resistivity or density contrast between the mineralization and the rock matrix. 
A

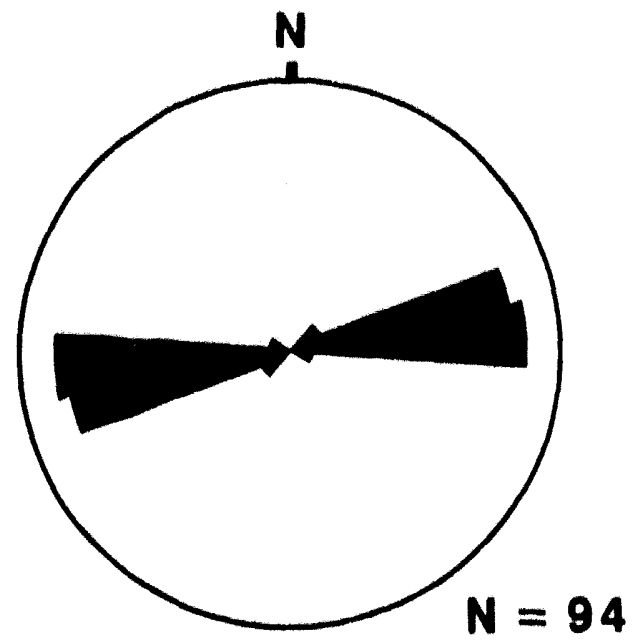

a. Pass through $1740 \mathrm{ft}$ of the Mesaverde Formation, Piceance Basin, Colorado, by Schlumberger's FMS log
B

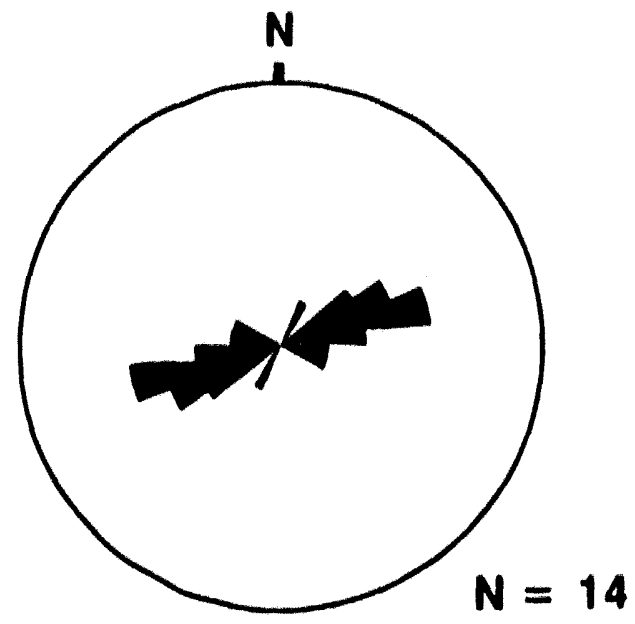

b. Strikes from $109 \mathrm{ft}$ of oriented core within the same section. (Data are from the Barrett MV 8-4 well in the central Piceance basin, $\mathrm{CO}$, courtesy of Kurt Reinecke and Barrett Resources Corp.)

Figure B14. Rose diagrams showing the strikes of coring-and drilling-induced fractures in a vertical well.

\section{Orienting Core Using Fracture Identification Logs}

Image logs can be used to orient vertical and deviated cores. The unoriented core is processed as though it was oriented, as described above, and measurements of fracture orientations are made relative to an $\mathrm{MOL}$. Orientation is achieved by correlation of an orientable feature such as inclined bedding on the log to the same structure in the core. 'The log orientation of the feature is then used to determine the true orientation of the MOL. for that section of core. Crossbeds and large fractures are commonly good features for correlation purposes. By orienting the MOL in this manner, it is possible to orient other fractures visible in the core but not in the log. Caution should be used as some types of coring-induced fractures do not extend from the core into the wellbore wall, and vertical natural fractures seen in a vertical wellbore image log need not intersect the smaller-diameter core.

\section{Interpretation Without Core Data}

When core data are not available, fractures on image logs must be interpreted carefully, especially as to their origin (induced vs natural) and therefore their significance. Experience with the common orientations and unique log signatures of different types of fractures in an area may allow classification of fractures (e.g., Standen, 1991).

Most classifications of fractures using logs alone are somewhat subjective, and conclusions from such classifications should be made with caution. It is possible to analyze the orientations of fractures from image logs on stereoplots or rose diagrams, and to attempt to isolate different populations. For instance, drilling-induced fractures commonly have high dips, and a population of fractures with average dips of less than $70^{\circ}$ is likely to be one of natural fractures. However, if a formation has not previously been well characterized, core is essential for reliable interpretation of borehole image logs. 


\section{Discussion and Summary}

'The more core that is available from wellbores of different orientations, and the more fracture identification loge that are run, the more complete will be the resulting character. ization of the subsurface fracture system. For the Mesaverde reservoirs at the MWX/SHC'T site, core measurements of fractures demonstrated the existence of a dominant fracture trend. 'This trend creates a pronounced horizontal permeability anisotropy (up to $1(0): 1$ as indicated by well tests), and results in highly elliptical drainage patterns in the reservoirs (Lorenz et. al., 1989). However, unulysis of the fractures and lithologies together suggested that the fractures are irregularly distributed within the heterogeneous fluvial reservoirs, and commonly terminate within the reservoirs at minor lithologic discontinuities. Few, if any, fractures extend the full thickness of the reservoirs. 'Thus the vertical fracture permeability in the reservoirs is limited. Fxcept in the more homogeneous marine sandatones, even horizontal wells may not drain the gas with optimum efficiency.

Moreover, the relative inefficiency of the hydraulic stimulation fracture experiments at this site could have been predicted from the parallelism between natural and induced fractures in the core. Hydraulic fractures parallel the principal horizontal stress (as do the strikes of the induced fractures), and therefore propagate parallel to, rather than across, the high-permeability trend created by the natural fractures.

Fractures that are normal to the maximum horizontal in situ stress, even if numerous, may not be as important to the system permeability as a set of less numerous fractures that are parallel to this stress ('T'eufel, and Farrell, 1992). Most of the stress-normal fractures would be closed, whereas the less numerous, stress-purallel fractures would be open and relatively permeable if they are not completely mineralized. 'The induced fractures that commonly record stress orientation should be measured as well as the natural fractures.

Measurements of parameters such as spacing, width, and vertical distribution of fractures cannot be put directly into a numerical reservoir model. Even when abundant data are available as from the MWX/SH('I' projects, once the measurements described above have been made, the task of further refining the fracture model devolves into the realm of assumptions, extrapolations, and alchemy. Moreover, the significance of the precision of the measurements is questionable when core samples such a limited area of the reservoir. 'The measurements may be most useful as relative indications of degree of fracturing of the reservoir and degree of heterogeneity of fracture distribution. Other important dimensions, such as horizontal fracture length, interconnectedness of fractures, and variations in remnant aperture along individual fractures cannot be measured in core, and remain to be inferred intuitively or from filtered outcrop data.

Nevertheless, attention to detail during the logging of a core for fractures will yield significantly more insight into the characteristics of a fracture system. In order to optimize the amount of information that can be derived from fractures in core, procedures such as on-site core processing, measuring fractures before slabbing, monitoring coring operations, and deviating pilot wells should be seriously considered. Thought should also be given to using the relative orientations of fractures even in core that is not oriented and to the possibility of orienting cores after they have been cut. 


\section{References}

Aguilera, K., І988, Determination of aubaurface distance between vertical parallel natural fractures baned un core data: American Ansociation of Petroleum (ieolowints Bulletin, v. 72, p. 8458 85.

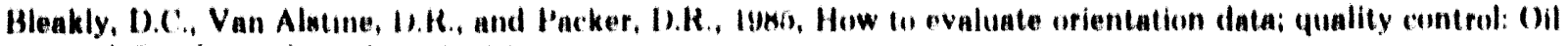
and (ian Journal, v 86, p. 46 64.

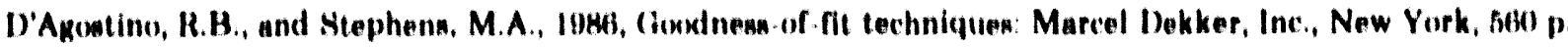

Emmendorfer, A., 1989, Fracture orientation: une of the dipmeter type fracture log: 'The Mountain Coulogiat, v 26, p. 6il 67.

Kulander, H.R., Harton C.C., and Dean, 8.I., 1979, 'The application of fractozraphy to core and outcrop fracture

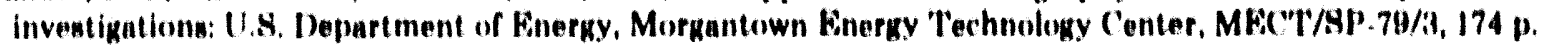

Kulander, B.K.. Dean, S.L., anci Ward, B.J. Ir., IGG), Fractured core analymia: Interpretation, logeing, and une of natural and induced fracturen in core: American Asmociation of Potroleum Genlonintn, Mothoxdn in Fxplora tion Serien, No.K, $88 \mathrm{p}$.

Lamb, C.F., and Fergumon, D.(i., 1988, The role of core analyain in fractured reanervoir evaluation: Canadian Institute of Mining and Metallurky, paper number 88-39-86, 39th Annual Technical Meeting. Calkary, June 12 16, p. 86. 1 to 84. 10 .

LaPoint, P.R., I9A8, A method to characterize fracture density and connectivity through fractal neometry: International Journal of Rock Mechanice and (Beomechanicy Abatractu, v, 26, p. 421.424.

Laubach, S.K., 1991, Fracture patterns in low porsnoahility nandatone gan roservoir rockn in the Kocky Mountain rexion: Hociety of Hetroleum Bngineern paper number $2185 \%$, in Society of Potrolecin Kngineern doint Kocky Mountain Section Mooting and Low Permeability Reservoir Symposiom, April 16 17, 1901, Denver, 10. p. B01 610 .

Lerche, I., and Narr, W. 1986, Eatimating subsurface fracture density in core: Erfecte resulting from variable fracture spacins: Slik Formation Fvaluation, v. 2, p. 249 265.

lorenz, J.C, and Hill, R.E., I891, Subsurface fracture spacing: Comparinon of inferencen from alant/horizontal core and vertical core in Mesaverde renurvolrm: Society of Petroleum Ensineern paper number 21877, in Socioty of' Potroleum Fngineers Rocky Mountain Rexional Mooting and Low Pormentillity Remervoirs Symposium, April is 17, 1941, Ienver, ('0, 1). 706 716.

Lorenz, J.C., and Finley, S.I., I89I, Regional fractures II: Fracturing of Menaverde reservoirs in the Piceance Basin, Colorado: Americun Asanciation of Potroloum Cieologinten Bullotin, v. 75, p. 1736 1757.

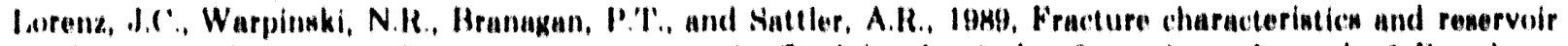

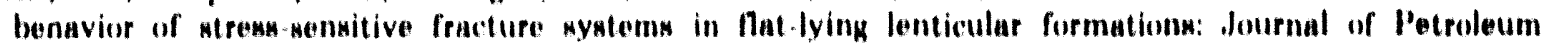
'Technoluky, v, A1, p. H15) (222.

Lorenz. J.C., 'Teufel, I. W., and Warpinaki, N.K., I09), Regional fracturen I: A mechaniam for the formation of

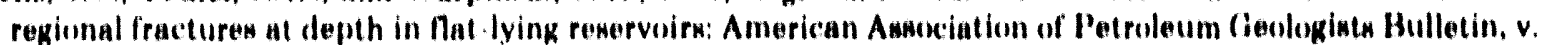
76, p. $171417: 17$

lorenz, J.C., Finley, S.J., and Warpinxki, N.R., IG90, Significance of coring induced fracturen in Mesaverde coro, northwestern Colorado: American Asmociation of Potroleum Cieologinta Bullotin, v. 74, p. 1017 1029.

Morrow, N.K., Hrower, K.K., Shouxiank, M., and Buckloy, J.S., 199), Fluid fow in healed tectonic fractures: Journal of Potroleum 'Tochnology, v. 42, p. 1:110 1:318.

Myal, F.K., and Frohne, K. H. Ig9I, Slant Hole Completion 'Test in the Piceance Basin, Colorado: Society of Petroleum Engineers paper number 2ikbi, in Society of Potroleum Engineors Rocky Mountain Regional Meetink and low Permoability Renervoirs Symposium, April 15 17, 1991 Denver, CO, p. 611 622.

Narr, W., 1991, Fracture density in the deep subsurface: 'Techniques with application to Point Aruuello oil field: American Association of Petroloum Cioologints Bullotin, v. 76, p. 13300 1323.

Nelson, R.A., 1991, Multi ncale natural fracture development and its effect on reservoir modeling (abstract): American Association of Patroleum (ieologists Bulletin, v. 75, p. 646.

Nelson, K.A., Lenox, L.C.., und Ward, H.l. Ir., 1987, Oriented core: Its uxe, orror, and uncertainty: American Association of Potroleum Cieologists Hulletin, v. 71, 1. 357 367. 


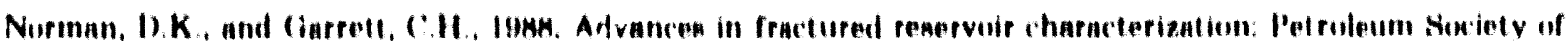

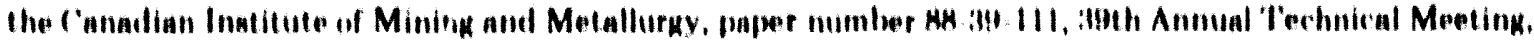

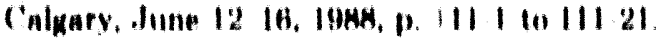

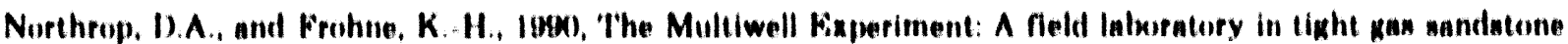
reservoirs: dournal of I'ptroleum 'Technolong, v. 12, p. 772770.

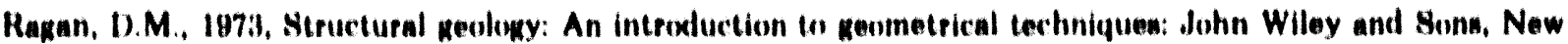
York, 2017 p.

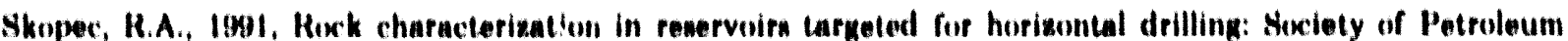

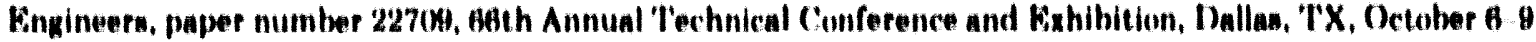
(in prens).

Shopec, R.A., Mann, M.M. Jefferm, I, and (irier, S.P., IOQO, Horizontal core accuisition and orientation for formation ovaluation: Keciety of Jetroleum Knyineern paper number 20418, in Society of Petroleum Engineers Bhth Annual Technical Conference and Exhibition, September 21 26, New Orleann, LA, p. 15.1166.

Skopec, K.A., (chairman), (in prean), Wellnite cure handling preceduren: Work aroup repurt prepared for the American Petroleum Inutitute. Sulcommittoe on Core Analyalin.

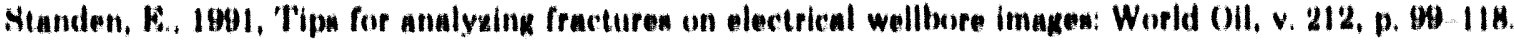

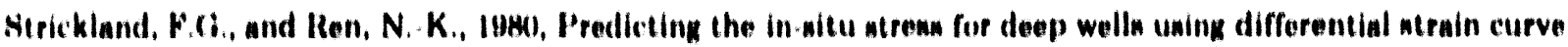

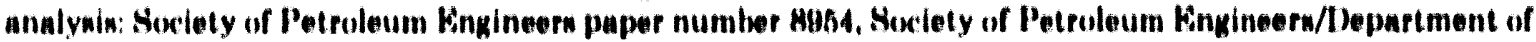

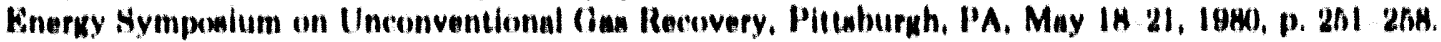

'Teufel, I.W., 1983, Detormination of in situ ut rean from andantic nt rain recovery meanurementa of uriented core:

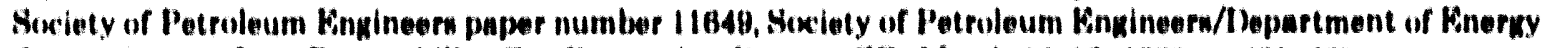

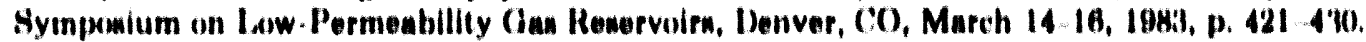

'Teufel, I.W., and Farrell, H.F., 1992, Interrelationahip betweon in witu ntren, natural fracturen, and reservolp permeability, a cane atudy of the Bkofiak Flald: Symponium on Fractured and dointed Koxk Man,

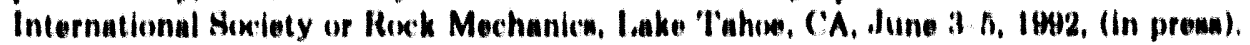

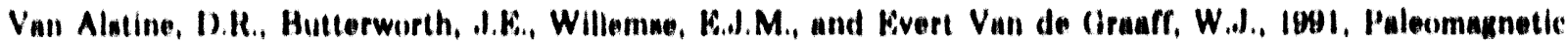

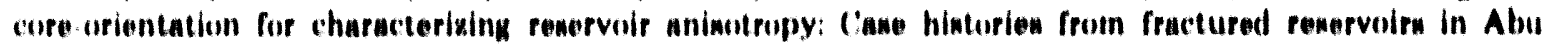

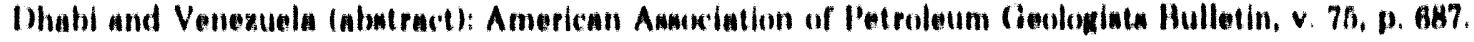

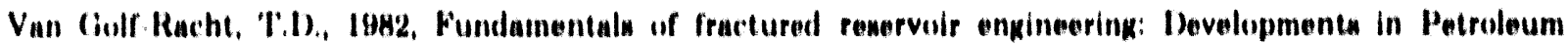
Brience. No. 12, Ginevier, Amuterdam, $26.1 \mathrm{p}$. 


\section{APPENDIX C \\ Viscoelastic Stress History Equations for Basin Stress Modeling}

The viscoelastic solution to the problem is ohtained using the Viscoelastic Correspon. dence Principle. This principle atates that if a solution to an elastic problem is known, then the LaPlace tranaform of the solution to the corresponding vincoelantic problem may be found by replacing the elastic constants ( $\mu$ and $F$ ) by appropriate quotients of operator polynomials, and the actual loads by their Lalalace transforms. Using the Vincoelantic Correspondence Principle, the vincoelantic nolutions can be determined directly from the elantic solutions.

The major problem is development of an appropriate vincoclastic model to describe the behavior of rocks over geologic time. Since little in known about such behavior, we have chosen three requirements.

1. Initial elastic response as if the rock is linear-elantic.

2. An time - $\cdots$, the material approaches a uniform state, that in, all shear stressen will eventually relax out.

3. Keop it an simple an possible. No good data are available to juntify a complex model.

The simplest case which yields acceptable initial and long-term behavior is one in wilich the rock in:

1. Bilastic in dilation

2. Maxwell material in diaturtion

After performing the necessary transformations and inversions, the viscoelastic solution in kiven as

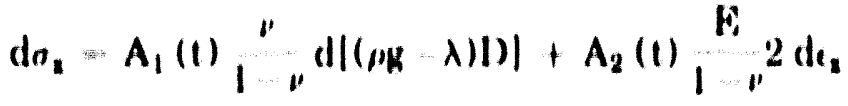

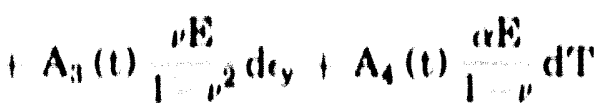

for the $x$ term. ('The corresponding y term is formed by a transposition of $x$ and $y$ subscripts.) 'The $A_{1}$ are the relaxation functions and are given by

$$
\begin{aligned}
& A_{1}(1)=\left(\begin{array}{lll}
11 & (1,2 n) & t / 1 n
\end{array}\right.
\end{aligned}
$$

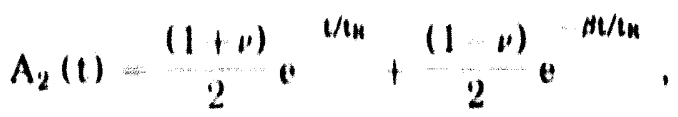

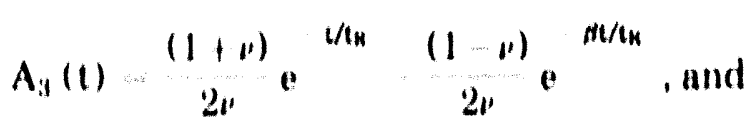

$$
\begin{aligned}
& 1 / 1 \mathrm{H} \\
& A_{1}(1)-\theta
\end{aligned}
$$


where $t_{K}$ is the relaxation time of the rock, and a is given by

$$
\beta=\frac{(1) n)}{(1+n)}
$$

'These equations are identical to the elastic solution if the $\Lambda_{1}$ are all unity.

These resulte can be summed over an arbitrarily large number of time intervals, $t_{1}$ to $t_{2}$. to obtuin

$$
\begin{aligned}
& J \sigma_{1}=\int_{11}^{1 t} A_{1}\left(t-t^{\prime}\right) \frac{d t}{L-1} \frac{d(p g-\lambda) \mid) \mid}{d t^{\prime}} d t^{\prime} \\
& +\int_{t_{1}}^{t_{1}} A_{2}\left(t-t^{\prime}\right) \frac{E}{1 \ldots t^{2}} \frac{d t_{2}}{d t^{\prime}} d t^{\prime} \\
& +\int_{11}^{12} A_{3}\left(t-t^{\prime}\right) \frac{11}{1} \frac{d t}{d t^{2}} \frac{d t^{\prime}}{d t^{\prime}} \\
& +\int_{1_{1}}^{t_{4}} A_{4}\left(t-t^{\prime}\right) \frac{d \mathrm{E} E}{d t^{\prime} T} d t^{\prime}
\end{aligned}
$$

and a similar result for the $y$ direction. While these equations are similar to the clastic solution, the presence of time, $t$, in the $A_{1}$ considerably complicates the calculations and bookkeeping chores. As time advances, each of these intograls must be reevaluated with the new value of $t$ in the reluxation functions. 'This in required because the viscoelastic material has a memory of previous disturbances and will continue to relax from previous disturhances even as it is responding to new ones. Bechuse of this feature of viscoelastic materials, the stresses are "naturally" locked in (or cumulative). 


\section{APPENDIX D}

\section{Techniques for In Situ Stress Measurement: Anelastic Strain Recovery (ASR), and Circumferential Velocity Anisotropy (CVA)}

The orientation of the principal horizontal stresses can often be determined from various types of core analyses. Types of measurements include anelastic strain recovery (ASR; Teufel, 1983; Blanton, 1983, Warpinski and Teufel, 1989), differential strain curve analysis (DSCA; Strickland and Ren, 1980), and circumferential velocity analysis (CVA; Sayers, 1988). DSCA is offered by service companies to the industry and will not be discussed here.

\section{Anelastic Strain Recovery (ASR)}

ASR has considerable appeal because it is a direct measurement of the strain relief process as it is occurring. This strain relaxation occurs because the original in situ stresses at depth have been relieved through drilling. Since this process is likely to be irreversible, ASR provides the only true measurement of this behavior. The appeal of ASR, however, is somewhat negated by the difficulty of the measurement.

ASR is conducted by selecting samples at the drill site, instrumenting them with clip-on displacement gages as quickly as possible, and monitoring the subsequent relaxation of the core for 1-2 days. Three gages, spaced $45^{\circ}$ apart, are placed around the horizontal plane, while one axial gage is optionally placed on the core. The axial gage serves no purpose for fracture azimuth, but it is necessary for estimating stress magnitudes.

The orientation of the maximum stress is the direction of the maximum strain recovery; recovery occurs due to microcracking in response to the unloading of the in situ stresses. More unloading, and therefore more strain recovery, occurs in the direction of the maximum horizonial stress than it does in the direction of the minimum stress. This behavior is shown in Figure D1. The direction of the maximum strain recovery can be quickly computed by using the strain-rosette equations, yielding

$$
\theta=\frac{1}{2} \tan ^{-1}\left(\frac{\epsilon_{45}-\left(\epsilon_{0}+\epsilon_{90}\right)}{\epsilon_{0}-\epsilon_{90}}\right)
$$

The angle, $\theta$, has to be determined by inspection, as it is always less than or equal to $45^{\circ}$, and it is the angle with respect to the largest of the $\epsilon_{0}$ or the $\epsilon_{90} 0$ strains.

There are many complications that can occur with ASR, so it should never be used alone. If the rock is extremely tight, pore pressure may be trapped within the sample and cause contractions in the core as it slowly escapes. Pore pressure contractions are usually larger than the strain recovery, and are due to a volumetric shrinkage of the core as the pore pressure is reduced. Pore pressure effects can be accounted for, but they add another uncertainty to the analysis (Warpinski and Teufel, 1989).

Rock fabric, as due to tectonic cracks, bedding, burrows, and other aligned features, is probably the most serious difficulty in performing these measurements. ASR will often produce a large response to many types of fabric. In using this techniques, it is always important to inspect the core carefully, both before and after monitoring, to ensure that fabric is not affecting the results. Thin sections can also be useful. Employing more than one of these procedures is often a good double check. 
Figure D2 shows the type of strain relaxation that typically occurs on sandstone rocks. This test is on a MWX coastal sandstone at a depth of $6517 \mathrm{ft}$, and yields a maximum recovery of $364 \mu \mathrm{\epsilon}$ on the axial gage and 100-200 $\mu \mathrm{\epsilon}$ on the horizontal gages. Note that data is first obtained about 7 hours after the core was cut. The solid lines are theoretical fits of the data, using an analysis procedure described in Warpinski and Teufel (1989).

Analysis of these results yield:

maximum principal horizontal strain $.237 \mu \epsilon$

minimum principal horizontal strain $101 \mu t$ overburden strain $364 \mu \epsilon$ angle with respect to $0^{\circ}$ gage $-30^{\circ}$ maximum stress angle $\mathrm{N} 87^{\circ} \mathrm{E}$

These results can also be used to estimate the stress magnitudes, as given by Blanton (1983), and Warpinski and Teufel (1989).

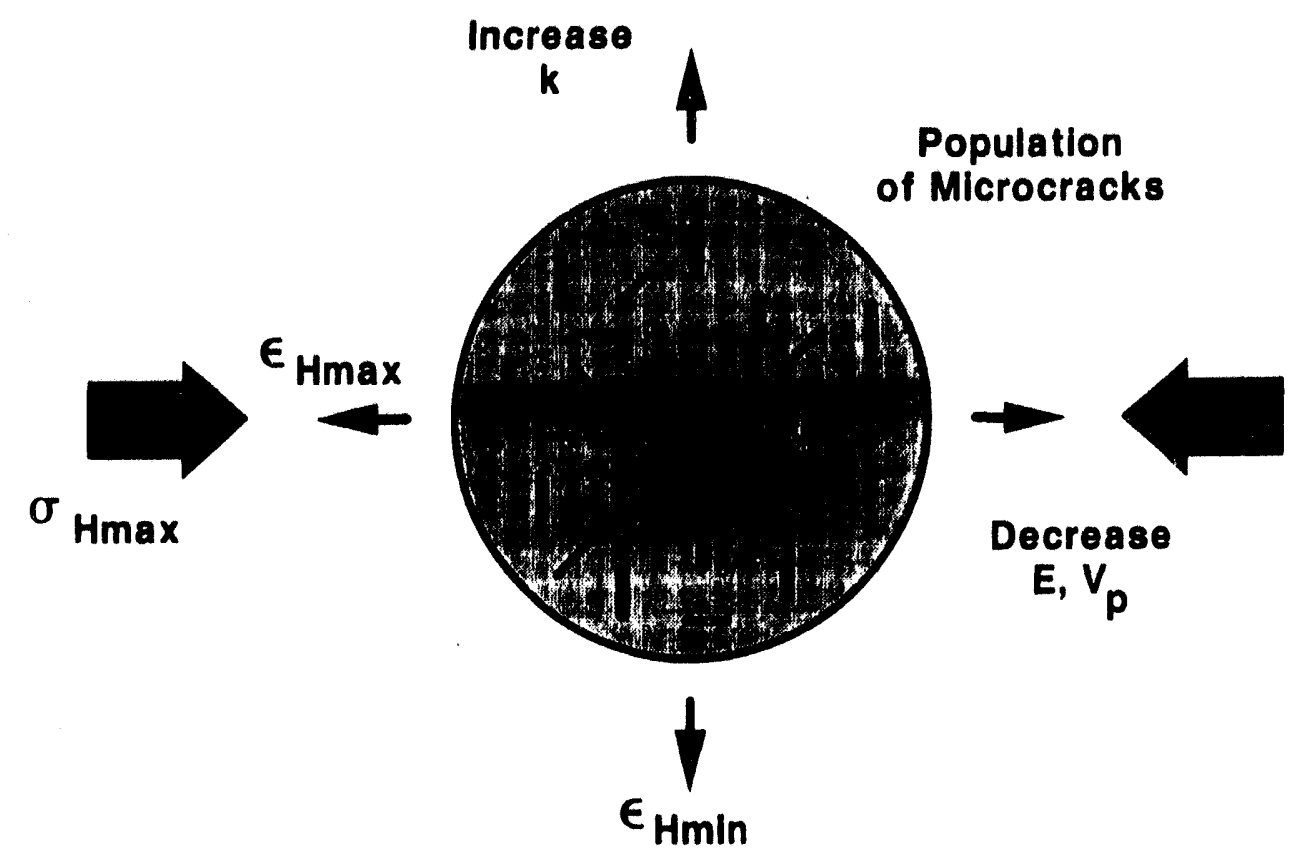

Figure D1. Preferential development of microcracks aligned normal to the maximum in situ stress, during anelastic strain recovery after rock has been cored. 


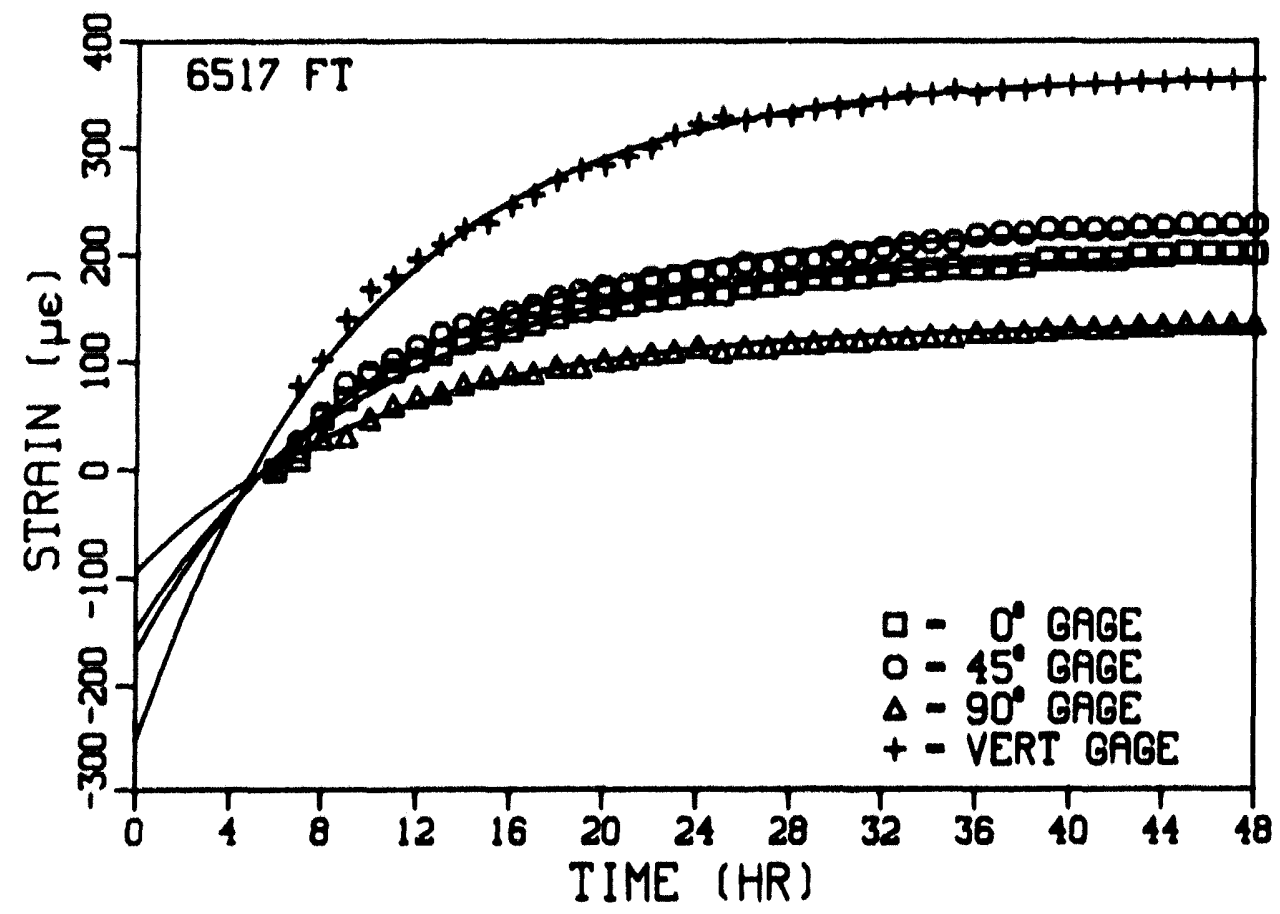

Figure D2. Time-dependent strain profiles for strain gauges with different orientations around a core during anelastic strain recovery.

\section{Circumferential Velocity Anisotropy (CVA)}

The relaxation of a piece of core from its in situ stress state at depth produces microcracks that perturb the acoustic velocity through the core sample. Measurement of the circumferential velocity anisotropy (CVA) of the core then provides information about what orientation has the most open microcracks (slowest velocity), which can be related to the in situ stress orientation, or occasionally to the rock fabric if one exists. The theoretical velocity distribution for a preferentially oriented population of microcracks has been worked out by Sayers (1988), yielding a velocity distribution given by

$$
\mathrm{V}(\theta)=\mathrm{V}_{\mathrm{avg}}+\mathrm{A} \cos (2 \theta+\phi)+\mathrm{B} \cos (4 \theta+\phi)
$$

In this equation, the velocity at any orientation, $\mathrm{V}(\theta)$, is a function of the average velocity through the sample plus a $2 \theta$ and a $4 \theta$ component. The phase angle, $\phi$, is simply the offset angle that makes $\mathrm{V}(\theta)$ a maximum at $2 \theta+\phi=0^{\circ}$ (assuming $\mathrm{B}$ is much smaller than $\mathrm{A}$ ).

Because acoustic waves will be slowed primarily in the direction in which they cross the most cracks, the orientation of the minimum velocity, $2 \theta+\phi=180^{\circ}$, is the direction in which the most cracks are crossed. Since more microcracks will open up against the largest principal stress, the minimum velocity orientation should be aligned with the maximum stress direction. A schematic of this behavior is shown in Figure 1, which shows that many petrophysical properties are affected by the cracks.

While application of this technique is straightforward, there are a number of factors that can cause problems. Some rocks exhibit little or no relaxation so that few microcracks are formed and the velocity anisotropy is small. High porosity rock, where additional microcracks have a minimal effect on velocity through the highly voided rock, can also yield questionable results. Whenever the velocity variations are $2-3 \%$ or less, the inferred stress orientation should be considered unreliable. 
Another major problem for the CVA technique is the prior existence of a rock fabric due to cracks, layering, oriented grains or crystals, or many other factors. Such a fabric can often produce a velocity anisotropy that overwhelms the microcracks velocity anisotropy, thus yielding a fabric orientation rather than a stress orientation. However, fabrics tend to have a different velocity character than microcracks, and this becomes very apparent in fitting the theoretical curve to the data. When the velocity distribution is controlled by relaxation microcracks, the theoretical fit is generally good, and the sinusoidal character of the anisotropy is evident. When the anisotropy is due to fabric, there is generally a poor fit of the theoretical curve, and the velocity data has a blocky structure. This difference provides a qualitative diagnostic for fabric problems.

An occasional problem is the presence of a damaged zone around the core surface, which can often cause significant velocity slowing. It is easiest to run velocity surveys on as-received core, but if the data are not satisfactory, the surface of the core should be ground down about $1 / 8$ in. and the velocity survey rerun. This procedure often improves the quality of the data.

Figure D3 shows and example of the velocity anisotropy obtained from a MWX core sample taken from the coastal zone at $6520 \mathrm{ft}$. This sandstone rock had a $14 \%$ anisotropy with a well-defined minimum at $\mathrm{N} 96^{\circ} \mathrm{E}$, the orientation of the stress field at this depth. Note also that the data are well-fit by the theoretical curve using a least-square regression (the solid line); this good fit assures that the anisotropy is not controlled by fabric.

\section{VELOCITY ANISOTROPY RESULTS}

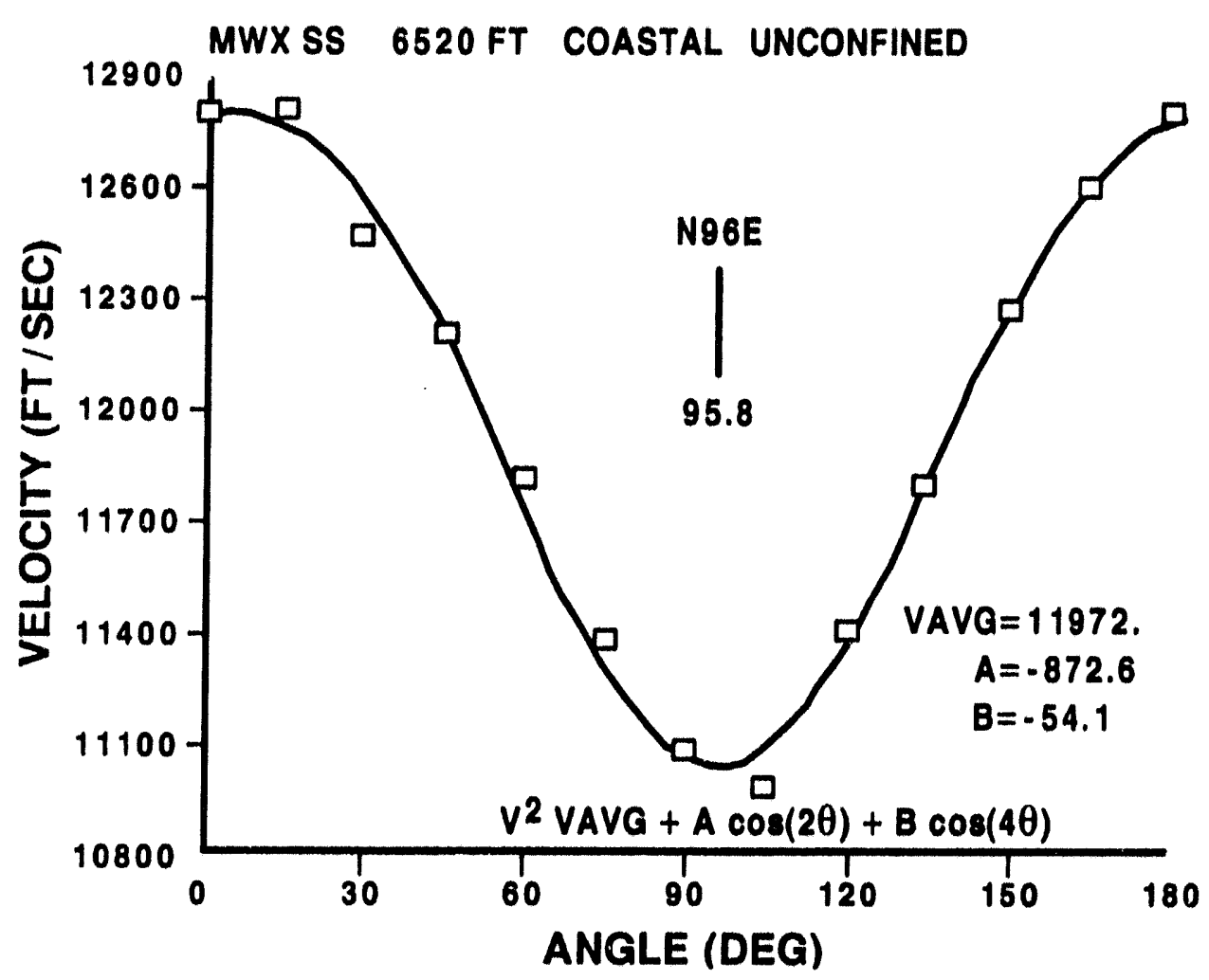

Figure D3. Velocities at different locations around a core, showing differences due to preferentially aligned microcracks. 


\section{References}

Blanton T.L, 1983, The relation between recovery deformation and in situ stress magnitudes: SPE Symposium on Low Permeability, Denver, CO, p. 213-218.

Sayers, C. M., 1988, Stress-induced ultrasonic S-wave velocity anisotropy in fractured rock: Ultrasonics, v. 26, p. $311-317$.

Strickland, F.G. and Ren, N.K., 1980, Predicting the in situ stress state for deep wells using differential strain curve analysis: SPE 8954, SPE Unconventional Gas Recovery Symposium, Pittsburgh, PA, p. 251-258.

Teufel, L. W., 1983, Determination of the principal horizontal stress directions from anelastic strain recovery measurements of oriented core: application to the Cotton Valley Formation, East Texas: Proc., ASME Symposium on Geomechanics, Houston, TX, June 20-22, 1983.

Warpinski, N.R., and Teufel, L.W, 1989, A viscoelastic constitutive model for determining in situ stress magnitudes from anelastic strain recovery of core: SPE Production Engineering, v. 4, p. 272-280. 


\section{APPENDIX E \\ Computer Codes for Calculating the Effects of Topography on Stress}

Two simple computer codes are given as examples of how topographic effects can be easily estimated. The first code is used for estimating the change in stress orientation due to a mesa and escarpment. The second code is a general 3-D code for calculating the additional stress imparted by any type of topographic high, although the example given is for a ridge of finite width and length.

\section{Mesa Topographic Calculations}

The effect of a mesa can be evaluated using the equations described in the text. In this code, the geometric input parameters are the height of the mesa, its width, the width of the escarpment, the distance from the edge of the escarpment to the well, and the depth of interest in the well. From these data, the induced stresses at the point of interest (assuming a rock weight gradient of $1.0 \mathrm{psi} / \mathrm{ft}$ ) are calculated. Next, the far-field in situ stress magnitudes and their orientation relative to the escarpment are input. The two sets of stresses are summed appropriately, and a new principal stress orientation is determined. The following pages contain a listing of the FORTRAN source code for the program.

COMPUTER PRINT OUTS FOLLOW THIS SECTION! 


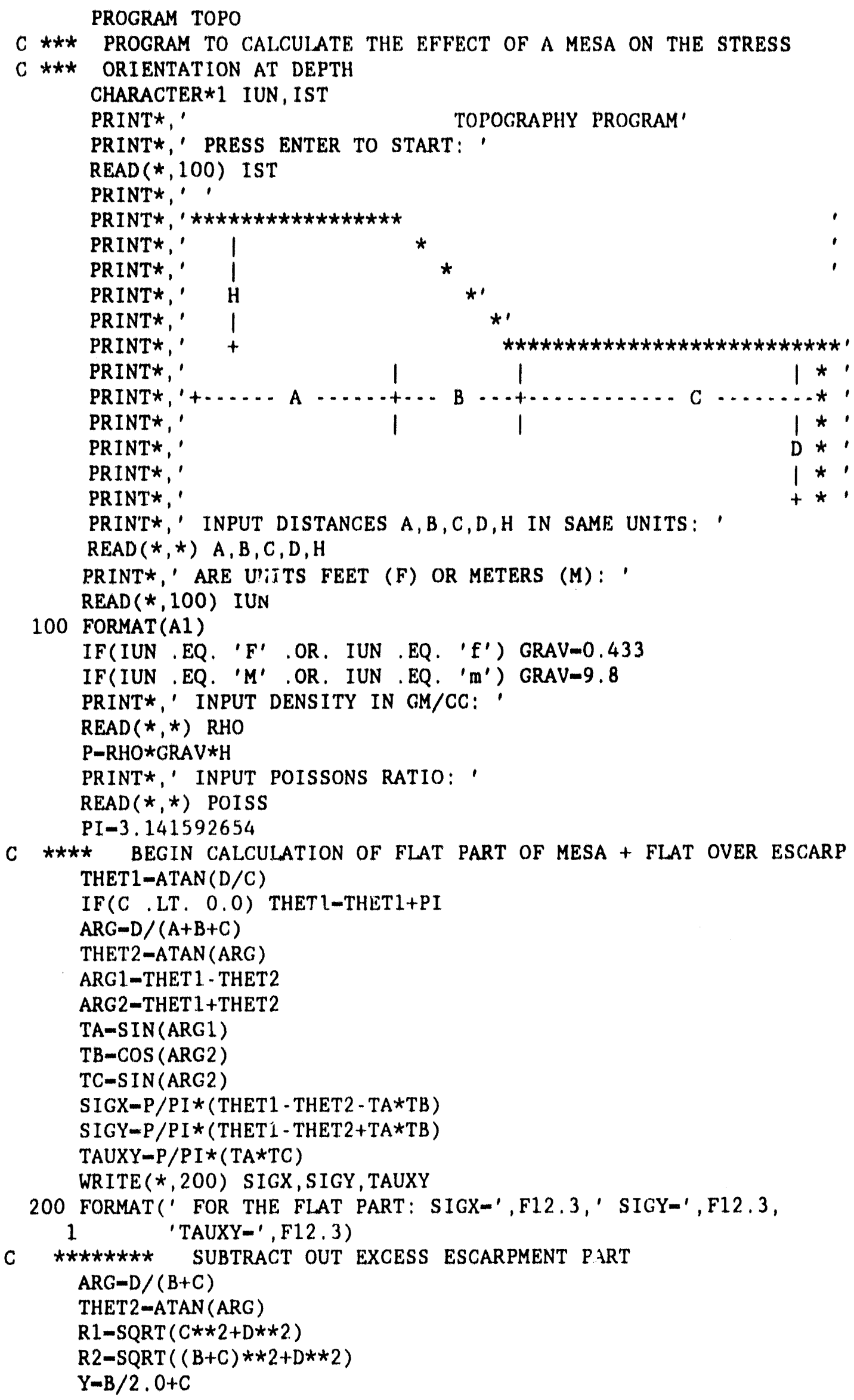


TA-THET1 - THET2

$\mathrm{TB}=1+\mathrm{Y} / \mathrm{B} * 2.0$

ARG $-2.0 *$ THET 1

$\operatorname{SIGX}=\mathrm{SIGX}-0.5 * \mathrm{P} / \mathrm{PI} *(\mathrm{~TB} * \mathrm{TA}-\mathrm{SIN}(\mathrm{ARG}))$

SIGY-SIGY $-0.5 * P / P I *(T B * T A+S I N(A R G)-D / B * 2.0 * A L O G((R 2 / R 1) * * 2))$

TAUXY-TAUXY $-0.5 * P / P I *(1.0-D / B * 2.0 * T A-\operatorname{COS}(A R G))$

SIGZ-POISS* (SIGX+SIGY)

WRITE $(*, 201)$ SIGX, SIGY, TAUXY, SIGZ

201 FORMAT (' ALL PARTS: SIGX-', F12.3,' SIGY-', F12.3/

1 'TAUXY-',F12.3,' SIGZ-',F12.3)

C

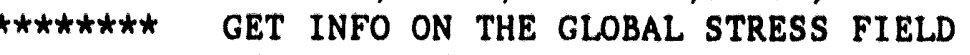

PRINT*,' INPUT THE MAGNITUDES OF THE TWO HORIZONTAL STRESSES '

PRINT*,' SMAX (S1) THEN SMIN (S2): '

$\operatorname{READ}(*, *)$ S1, S2

PRINT*,

PRINT*,

PRINT*,'

PRINT*,

PRINT*,

PRINT*,'

PRINT*,'

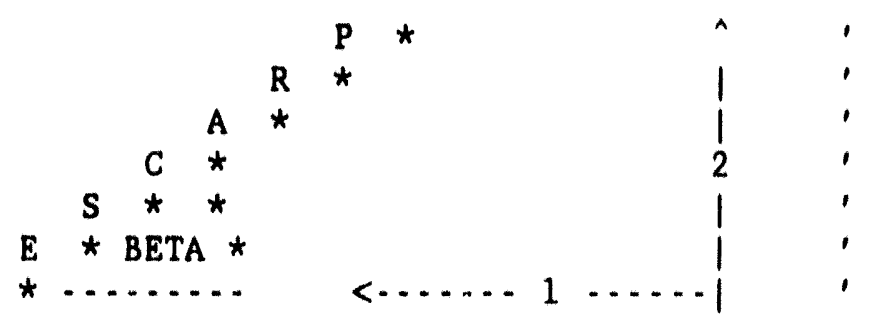

PRINT* ' INPUT ANGLE BETA BETWEEN SMAX \& ESCARPMENT AZIMUTH:'

PRINT*' INPUT - 100 FOR RANGE OF BETA (0-90 BY 5 DEG): '

$\operatorname{READ}(*, *)$ BETA

IF (BETA, GT, -99) THEN

BETA-BETA $/ 180.0 \star P I$

$\mathrm{N}-1$

DBETA $=0.0$

ELSE

BETA -0.0

DBETA-5. 0/180, 0*PI

$\mathrm{N}-19$

ENDIF

C

$\star \star \star \star \star \star * \star$ CALCULATE PERTURBATION ON GLOBAL STRESSES

DO $50 \mathrm{I}=1, \mathrm{~N}$

BETAD-BETA $* 180.0 /$ PI

WRITE $(*, 205)$ BETAD

205 FORMAT(' BETA-', F8.2)

$\operatorname{SIP}-S 1+\operatorname{SIGZ} * \operatorname{COS}(B E T A) * \star 2+\operatorname{SIGY} * \operatorname{SIN}(B E T A) * * 2$

S2P-S $2+\operatorname{SIGZ} * \operatorname{SIN}(B E T A) * * 2+\operatorname{SIGY} * \operatorname{COS}(B E T A) * * 2$

ARG -2 . 0*BETA

TAU12P $-0,5 *($ SIGY - SIGZ) *SIN (ARG)

C

$\star \star \star \star \star \star \star \star *$ CALCULATE NEW PRINCIPAL STRESS ORIENTATION

ARG-2 . 0*TAU12P/(S1P-S2P)

ALPHA $0.5 *$ ATAN (ARG)

ALPHA-ALPHA* $180.0 /$ PI

IF(S2P .GT. S1P) ALPHA-ALPHA +90.0

WRITE $(*, 202)$ S1P, S2P, TAU12P, ALPHA

50 BETA-BETA+DBETA

202 FORMAT (' NEW STRESSES: S1-',F12.3,' S2-',F12.3,' TAU-',F12.3/

1

'ANGLE FROM OLD STRESS DIRECTION=', F8.2)

PRINT*,' PRESS ENTER TO END: '

$\operatorname{READ}(*, 100)$ IST

STOP

END 


\section{General 3-D Code for Stress Magnitude Calculations}

A general code for any 3-D topographic high can be easily assembled if the topographic feature can be simply represented by a surface or several pieces of surfaces. In this case, equations given by Jaeger and Cook (1976) can be directly applied. Given the geometry shown in Figure E1, where a load is applied at point $P$ and the stress is calculated at point $Q$, the equations for the stresses are given by:

$$
\begin{aligned}
& \sigma_{\mathbf{x}}=\frac{1}{2 \pi} \iint\left[\frac{3(x-\xi)^{2} z}{\rho^{6}}+\frac{G\left[(y-\eta)^{2}+z^{2}\right]}{(\lambda+G) \rho^{3}(z+\rho)}-\frac{G z}{(\lambda+G) \rho^{3}}\right. \\
& \left.-\frac{G(x-\xi)^{2}}{(\lambda+G) \rho^{2}(z+\rho)^{2}}\right] p(\xi, \eta) d \xi d \eta \\
& \sigma_{y}=\frac{1}{2 \pi} \iint\left[\frac{3(y-\eta)^{2} z}{\rho^{6}}+\frac{G\left[(x-\xi)^{2}+z^{2}\right]}{(\lambda+G) \rho^{3}(z+\rho)}-\frac{G z}{(\lambda+G) \rho^{3}}\right. \\
& \left.-\frac{G(y-\eta)^{2}}{(\lambda+G) \rho^{2}(z+\rho)^{2}}\right] p(\xi, \eta) d \xi d \eta \\
& \sigma_{z}=\frac{3 z^{3}}{2 \pi} \iint \rho^{-6} p(\xi, \eta) d \xi d \eta \\
& \tau_{\mathrm{yz}}=\frac{3 z^{2}}{2 \pi} \iint(y-\eta) \rho^{-B} p(\xi, \eta) \mathrm{d} \xi \mathrm{d} \eta \\
& \tau_{z x}=\frac{3 z^{2}}{2 \pi} \iint(x-\xi) \rho^{-6} p(\xi, \eta) d \xi d \eta \\
& \tau_{z y}=\frac{1}{2 \pi} \iint\left[\frac{[3 z(x-\xi)(y-\eta)}{\rho^{6}}-\frac{G(x-\xi)(y-\eta)(z+2 \rho)}{(\lambda+G) \rho^{3}(z+\rho)^{2}}\right] p(\xi, \eta) d \xi d \eta
\end{aligned}
$$

with $\rho=\left[(x-\xi)^{2}+(y-\eta)^{2}+z^{2}\right]^{1 / 2}$

The double integration is not difficult if $p(\xi, \eta)$ can be defined. In this example code, a subroutine is called to provide $p(\xi, \eta)$ at any point in a normalized form (i.e., the height of the topographic feature is divided by the maximum height). Because a subroutine provides the load data, the only input parameters needed for the main program are Poisson's ratio, the maximum height, the density of the rocks, and the depth of the calculation. This program calculates the all six stresses along any line of constant $x$ or constant $y$ values. The following pages are a listing of the FORTRAN source code for this example. 


\section{3-D TOPOGRAPHY GEOMETRY}

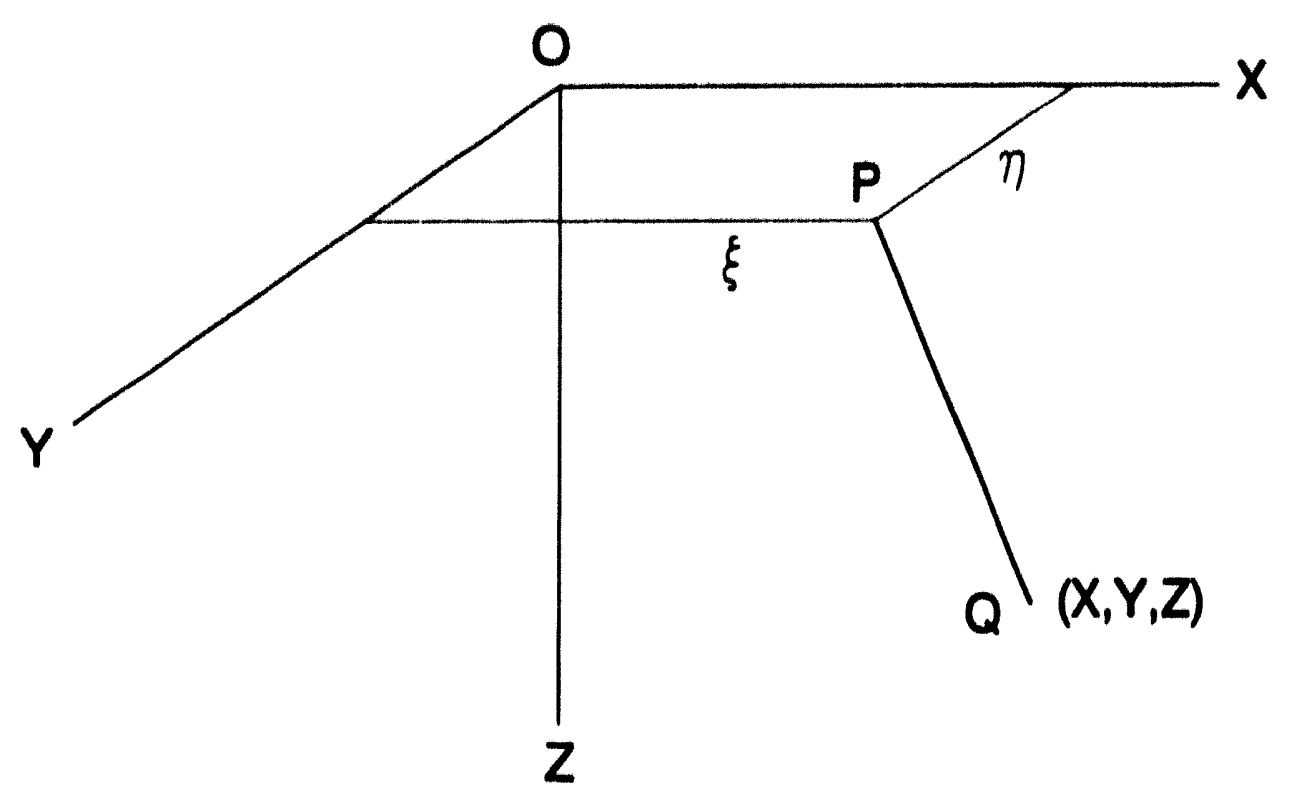

Figure E1. Three-dimensional topography geometry. 
PROGRAM TOPO3D

C PROGRAM TO CALCUIATE THE EFFECT OF TOPOGRAPHY ON THE STRESS

C FIELD AT DEPTH

$\mathrm{C}$

C

INPUT DATA FOR MAIN PROGRAM INCLUDE:

POISSON'S RATIO

MAXIMUM HEIGHT OF TOPOGRAPHY

DENSITY OF ROCKS IN THE TOPOGRAPHIC HIGH

DEPTH WHERE STRESSES ARE TO BE CALCULATED

INPUT DATA ON THE RIDGE GEOMETRY ARE HANDLED IN SUBROUTINE PLOAD. THE CURRENT PLOAD IS AN EXAMPLE FOR A RIDGE

RESULTS ARE WRITTEN TO AN OUTPUT FILE OF OPERATORS CHOICE

CALCULATIONS ARE PERFORMED AT THE SPECIFIED DEPTH, $z$, ALONG A LINE FOR WHICH EITHER $X$ OR Y ARE CONSTANT

C

$\mathrm{C}$

CHARACTER 1 IXY

CHARACTER $* 20$ FILEOUT

DIMENSION FA $(6,3), \operatorname{FB}(6,3), \operatorname{SUMU}(6), \operatorname{SUMV}(6)$

PRINT*,' INPUT POISSONS RATIO:

$\operatorname{READ}(*, *)$ POISS

POI $-1,0-2,0 *$ POISS

PRINT*,' INPUT MAXIMUM heIGHT (ABOVE sURFACE) OF TOPO: '

$\operatorname{READ}(*, *) H$

PRINT*,' INPUT DENSITY OF ROCKS (GM/CC):

$\operatorname{READ}(*, *)$ DENS

PFAC $-0,433 * D E N S * H$

PRINT*,' INPUT DEPTH FOR CALCULATION: '

$\operatorname{READ}(*, *) 2$

PI -3.141592654

PRINT*,' INPUT A PATH AND NAME FOR THE OUTPUT FILE: '

READ ( $*, 101)$ FILEOU'T

101 FORMAT (A20)

$\operatorname{OPEN}(8, F I L E-F I L E O U T)$

C $\star \star \star$ U-ZETA-X

C $\star \star \star *$ V-ETA-Y

C $* * *$ CALL PLOAD TO GET MAX AND MIN VALUES FOR INTEGRATION

CALL PLOAD $(0,0,0,0$, UMAX, UMIN, VMAX, VMIN $, 0.0,0)$

WRITE $(*, 200)$ UMIN, UMAX, VMIN, VMAX

WRITE $(8,200)$ UMIN, UMAX, VMIN, VMAX

200 FORMAT(' ZETA RANGE: ', 2F12.2,' ETA RANGE: ',2F12.2)

PRINT*, ' YOU CAN CALCULATE STRESS ALONG $X$ OR Y LINE'

PRINT*,' WHICH ONE IS CONSTANT ( $X$ OR $Y$ ) :

$\operatorname{READ}(*, 100)$ IXY

100 FORMAT (A1)

$C * \star *$ SET UP MIN AND MAX VALUES FOR CALCULATION \& NUMBER OF STEPS

IF (IXY .EQ. ' $X$ ' .OR, IXY .EQ. ' $X$ ') THEN

$C \star \star \star \star$ FOR LINES OF CONSTAN'T $X$

PRINT*,' INPUT $X$ VALUE: '

$\operatorname{READ}(*, *) X$

PRINT*,' INPUT MIN \& MAX Y VALUES AND NUMBER OF STEPS'

PRINT*,' FOR ONE POINT, NUMBER OF STEPS - $0: '$

$\operatorname{READ}(*, *)$ YMIN , YMAX, N 


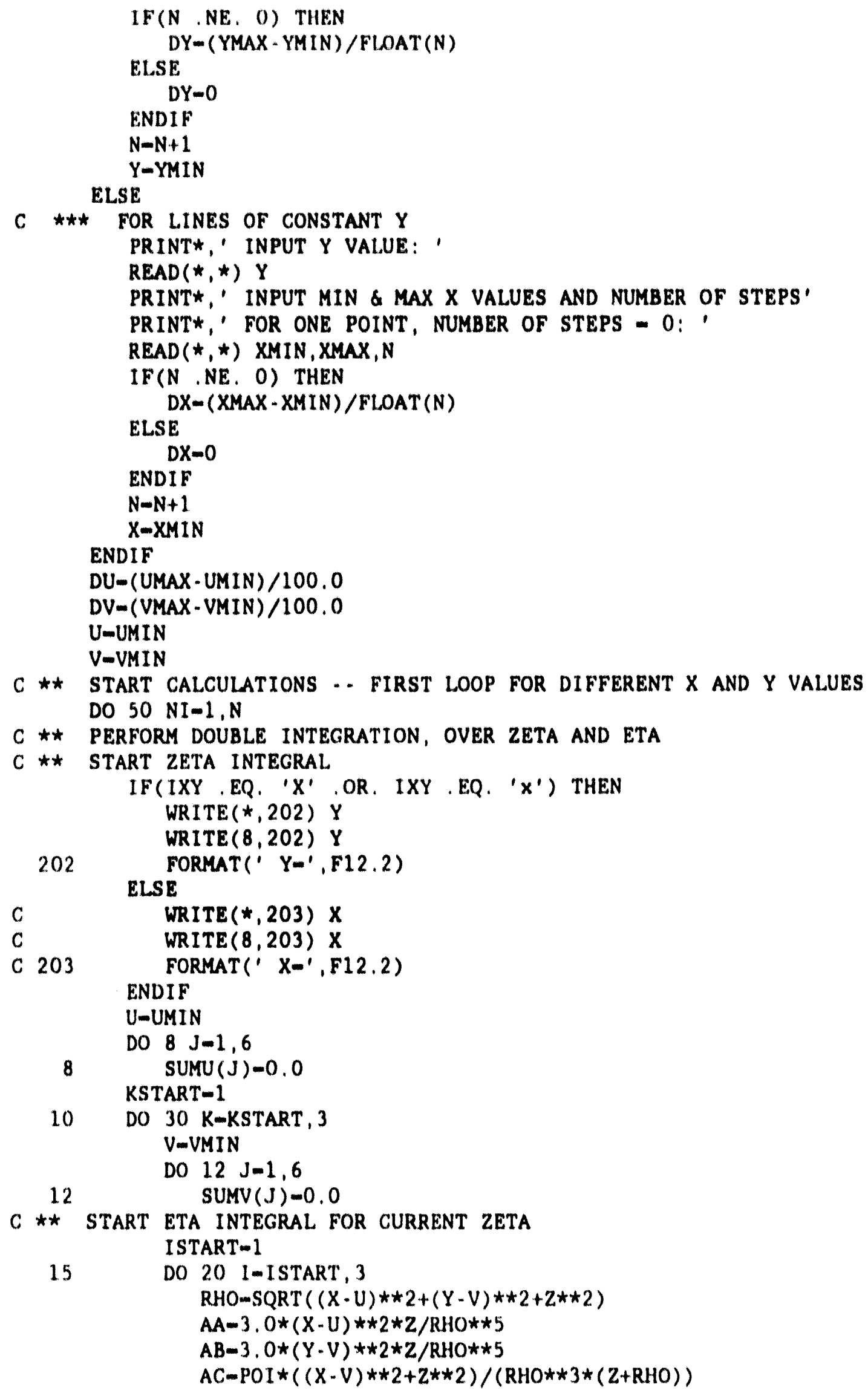




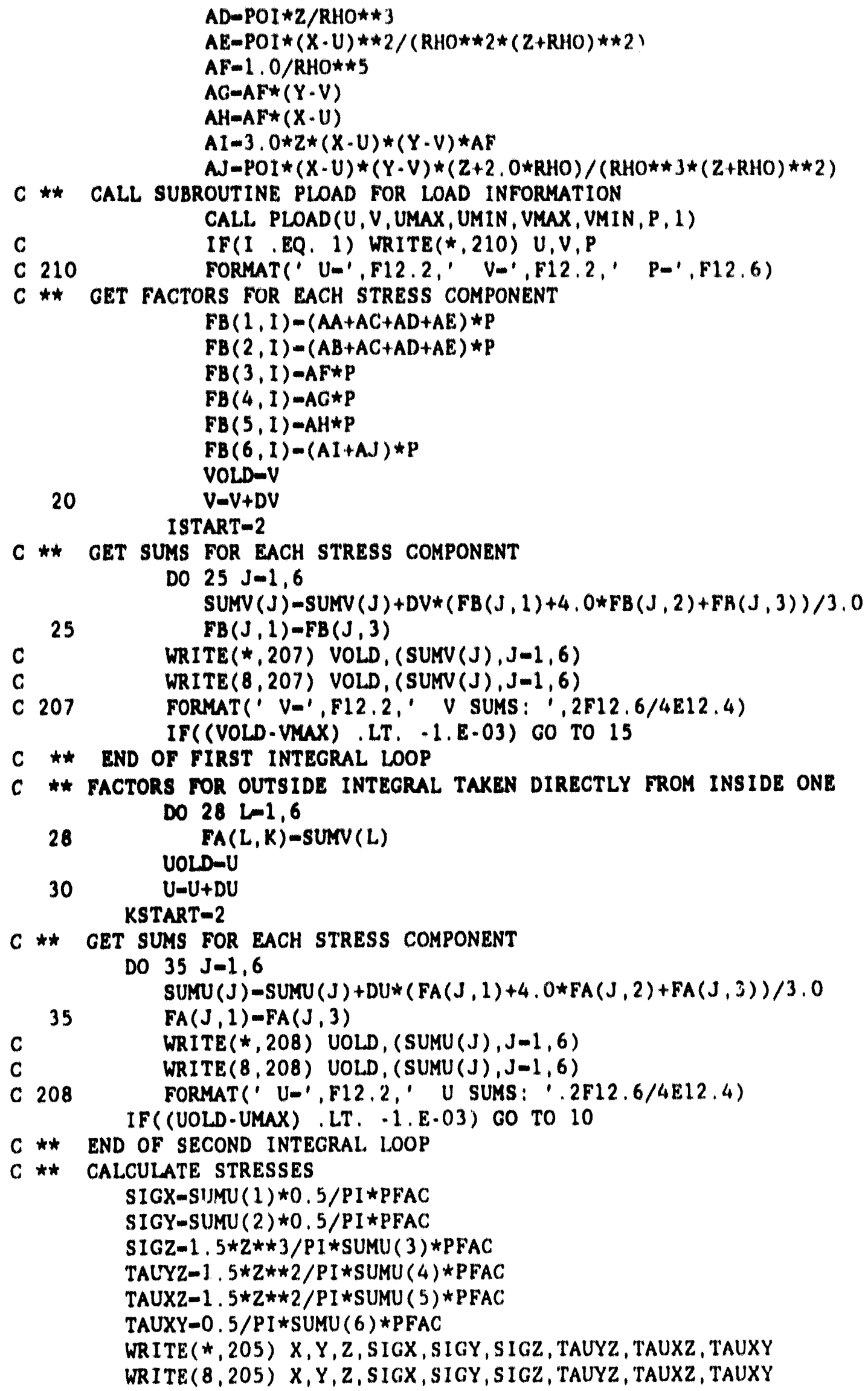




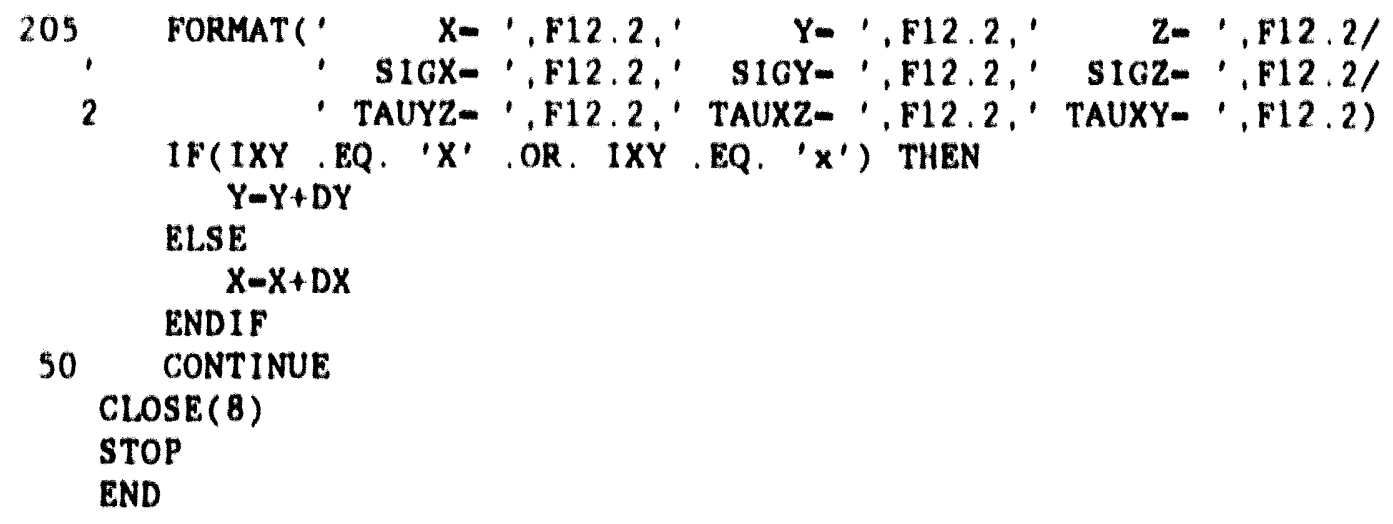




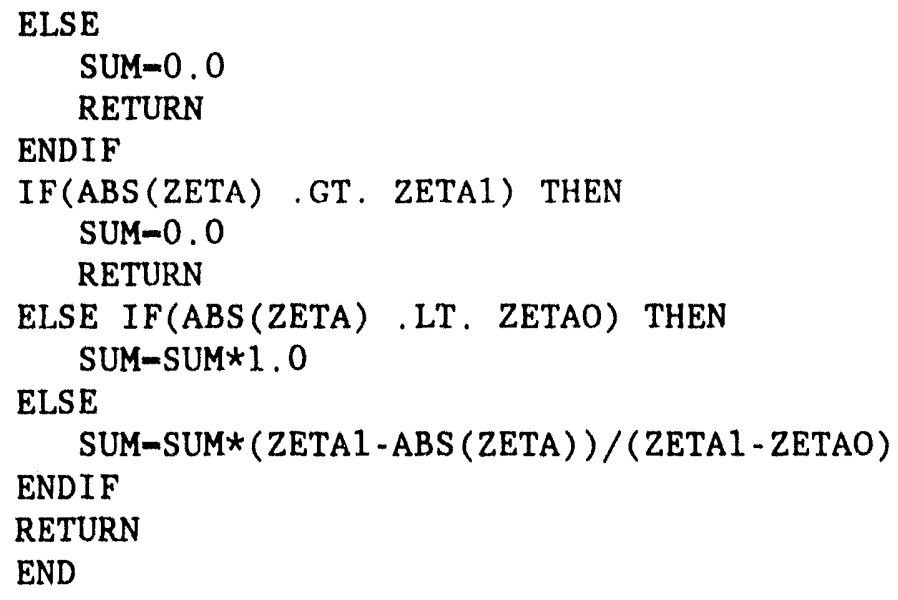




\section{References}

Jaeger, J.C. and Cook, N.G.W, 1976, Fundamentals of Rock Mechanics, Halsted Press, New York. 


\section{APPENDIX F}

\section{Computer Code for Stress-History Calculations}

A computer code, which was originally developed to calculate the stress history of the Multiwell site, has been modified for general use in calculating the stress history at any site. This model assumes that the rock is viscoelastic, although large relaxation times result in an elastic calculation, and that the stresses are controlled by the weight of the overburden, the pore pressure, the temperature, the tectonic strains in both horizontal directions, and the properties of the rocks, which are functions of time. The difficulty in running this model lies primarily in determining the input parameters with sufficient accuracy.

The equations governing the response of the rock are first developed in the text in elastic form and are given in Appendix $\mathrm{C}$ in viscoelastic form. The primary input parameters are the material and formation characteristics at each time step. These include:

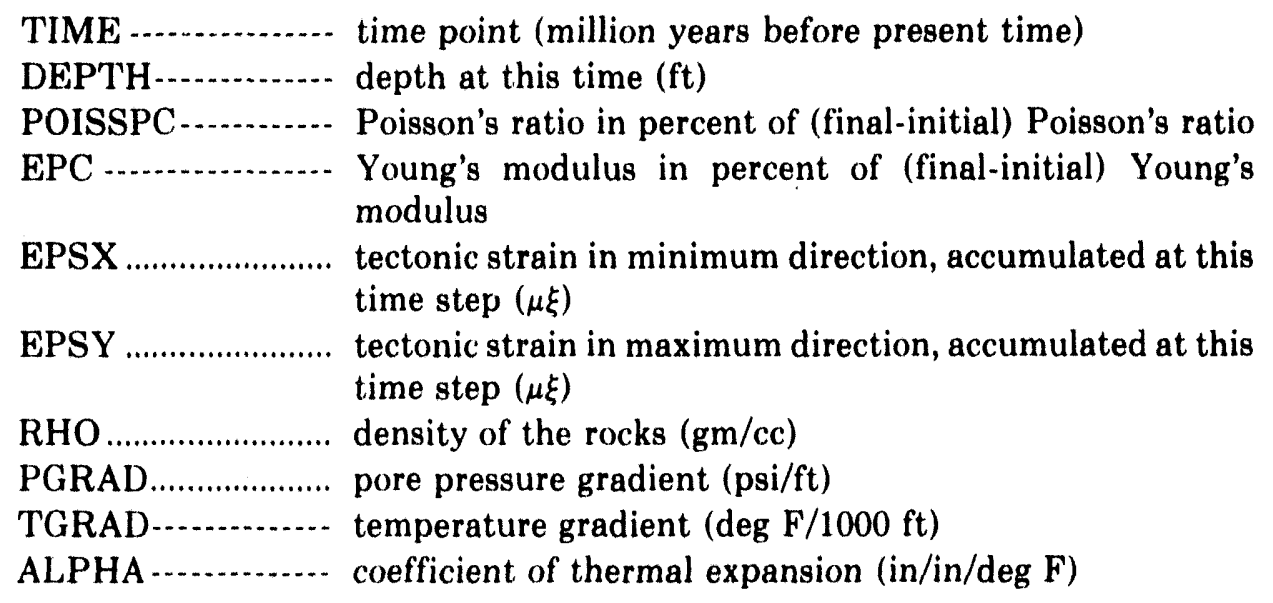

Other input parameters include:

Number of time steps

The present Poisson's ratio and Young's modulus (psi)

The initial Poisson's ratio and Young's modulus (psi)

The rock relaxation time (million years)

The number of integration steps (usually 4 is sufficient)

The time dependent inputs for Poisson's ratio and Young's modulus were set up as percentages of the (final-initial) values because the initial value is not well-constrained. This way, initial values and the subsequent lithification rates could be easily changed for parametric studies without changing the entire input file at each time step. The strain input is set up so that the strains are cumulative. If the calculation is elastic (large relaxation time) with constant properties, then the total tectonic strain at any time is the sum of all the previous strains. If a large compressive strain (positive strain) has occurred for some period, then relaxation of this compressive strain is accomplished with an extensional strain (negative strain) at the next time steps. Example input data sets for the three cases run in this study are given in Tables F1, F2, and F3. 


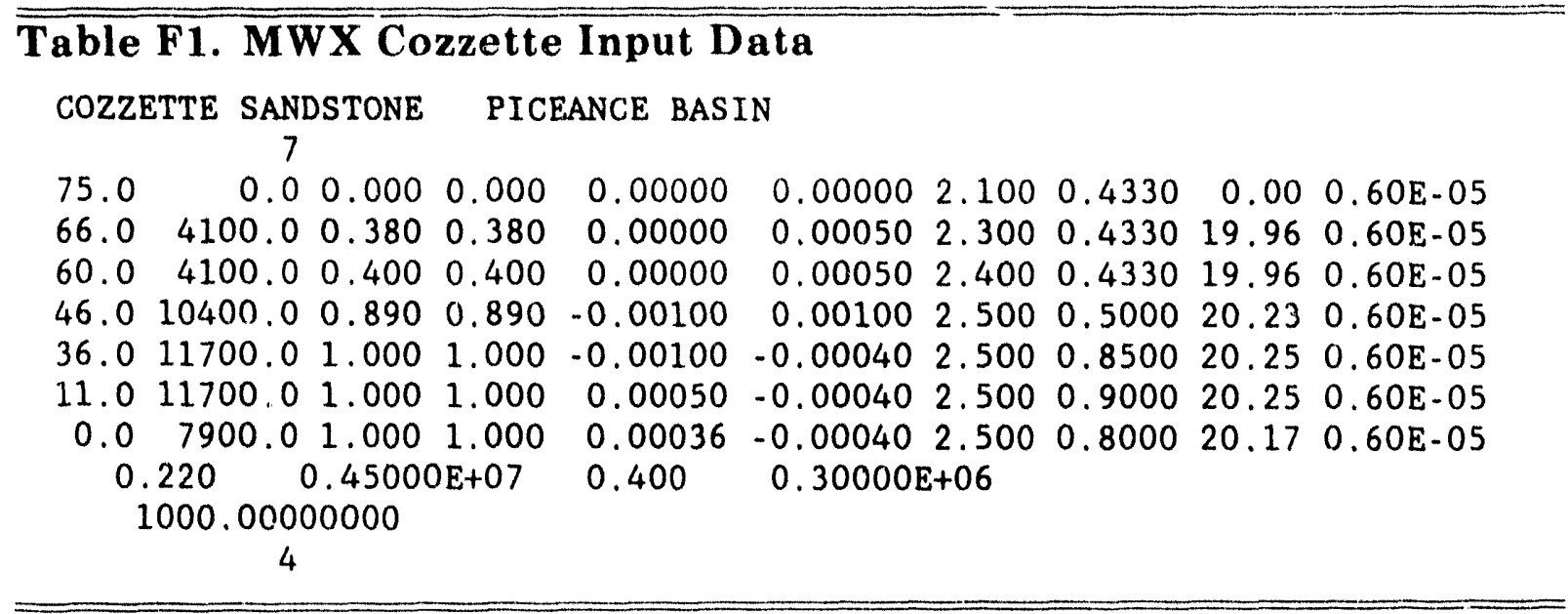

\section{Table F2. Ralston Federal 31 Cozzette Input Data}

RALSTON FEDERAL 31

$\begin{array}{rrrllllllll}74.0 & 0.0 & 0.000 & 0.000 & 0.00000 & 0.00000 & 2.100 & 0.4330 & 0.00 & 0.60 \mathrm{E}-05 \\ 66.0 & 4000.0 & 0.500 & 0.500 & 0.00000 & 0.00050 & 2.300 & 0.4330 & 24.00 & 0.60 \mathrm{E}-05 \\ 60.0 & 4000.0 & 0.550 & 0.550 & 0.00000 & 0.00050 & 2.400 & 0.4330 & 24.00 & 0.60 \mathrm{E}-05 \\ 36.0 & 8500.0 & 1.000 & 1.000 & -0.00100 & 0.00100 & 2.500 & 0.6000 & 24.00 & 0.60 \mathrm{E}-05 \\ 11.0 & 8500.0 & 1.000 & 1.000 & -0.00050 & -0.00040 & 2.500 & 0.7000 & 24.00 & 0.60 \mathrm{E}-05 \\ 0.0 & 6370.0 & 1.000 & 1.000 & 0.00030 & -0.00040 & 2.500 & 0.6500 & 24.00 & 0.60 \mathrm{E}-05 \\ 0.220 & 0.45000 \mathrm{E}+07 & 0.400 & 0.30000 \mathrm{E}+06 & & & & 0.05 \\ 1000.00000000 & & & \end{array}$

4

\section{Table F3. Apache 1-C Rushmore Cozzette Input Data}

APACHE 1-C US RUSHMORE

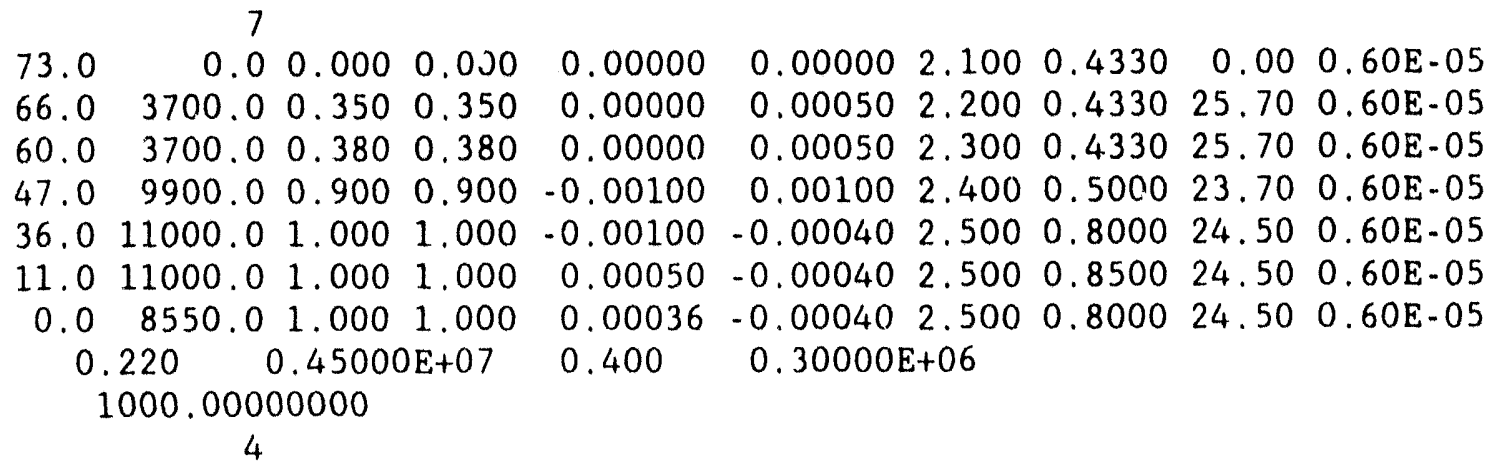


This program was written, compiled, and linked using Ryan-McFarland FORTRAN and the PLOT88 software library for graphics. The main program contains the evaluation of the integrals through all time steps. Subroutine INPUT is used to enter the data, either by hand or by file. Subroutine TABLE writes the data in a tabular form. Subroutine SPLOT is a plotting routine that can produce the following output as a function of time:

Total stresses (SHMAX, SHMIN, SV, P)

Effective stresses (EFFSHMAX, EFFSHMIN, EFFSV)

Stress components (S1 (gravity), S2 (thermal), S3X (x tectonic), S3Y (y tectonic))

Strains (EPSX, EPSY)

Temperature (T)

Depth (D)

Subroutine FAIL calculates the failure behavior of the rocks and compares this behavior to actual failure data input by the user. Mohr-Coulomb failure data are used for this routine, and an example of input failure data for the Cozzette case is given below.

5

$\begin{array}{ll}-2320.00 & 0.00 \\ 11237.50 & 11165.00 \\ 17980.00 & 16457.50 \\ 22910.00 & 20010.00 \\ 29145.00 & 24795.00\end{array}$

The first input is the number of data points, followed by any points on the Mohr-Coulomb envelope, with the first point being mean effective stress and the second point being maximum shear stress. There is also an option for a reduced strength envelope. Most failure data are obtained on dry samples at strain rates of $1 \times 10^{-5}$. Under in situ geologic conditions, where water is present and strain rates are several orders of magnitude lower, the failure envelope can be expected to be $20-50 \%$ lower, and this can be accounted for using a reduction factor of $0.8-0.5$. Failure results are also plotted in subroutine FAIL. A listing of the FORTRAN source code and example output for the Cozzette case are given in the following pages.

A sample output for the Cozzette sandstone is presented. These results were obtained using the input from Tables F1, F2, and F3. The accompanying plots (Figures F1-F7), were produced during the running of the output example. They show all the data that can be plotted using this program. 


\section{Program}

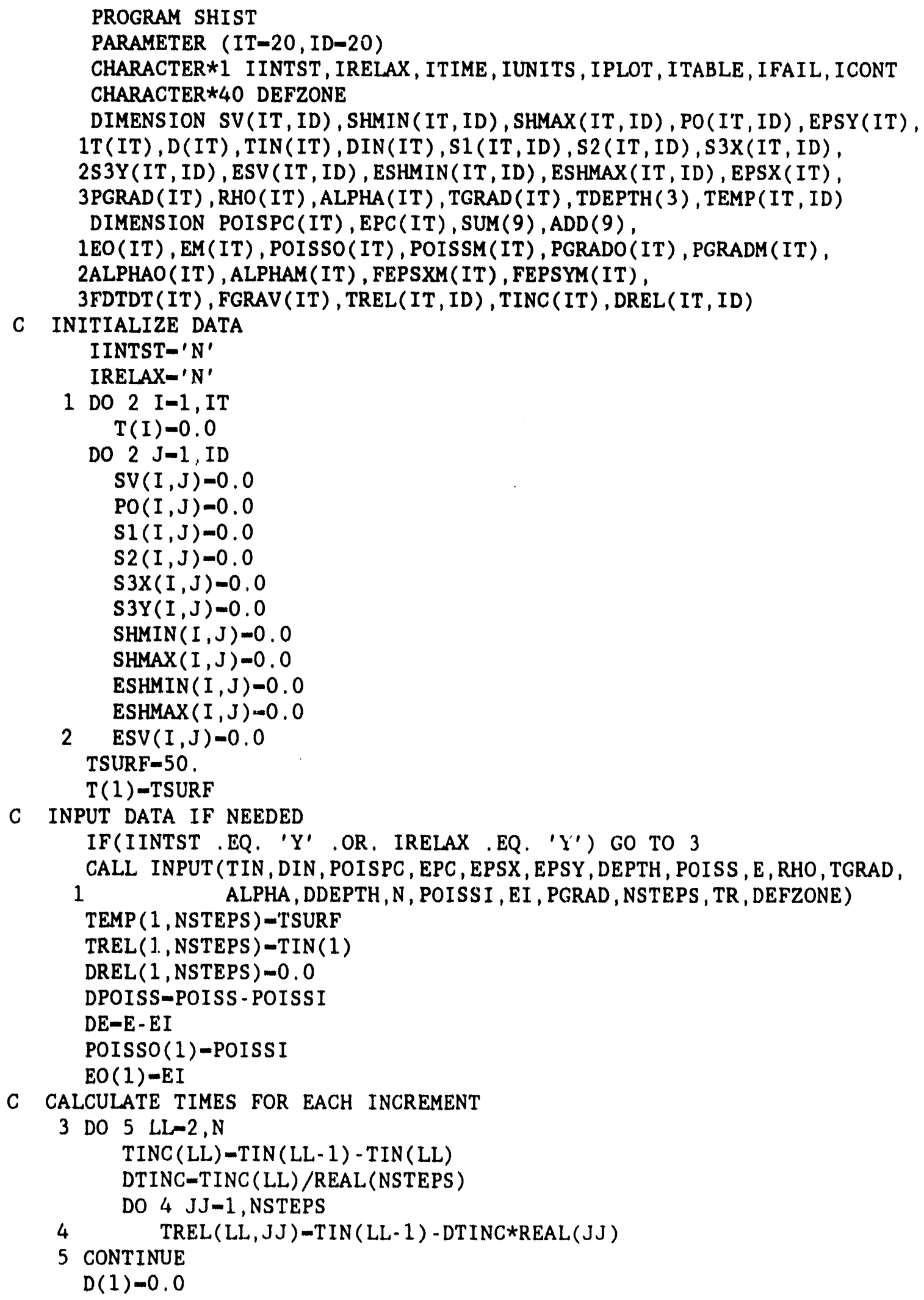


C START THE CALCULATIONS; DO LOOP ON LARGE TIME INTERVALS

DO $50 \mathrm{~L}-2, \mathrm{~N}$

PRINT 100,TIN(L), EPSX(L), EPSY(L), POISPC(L), EPC(L)

$\operatorname{WRITE}(10,100) \operatorname{TIN}(L), \operatorname{EPSX}(L), \operatorname{EPSY}(L), \operatorname{POISPC}(L), \operatorname{EPC}(L)$

PRINT 202, RHO (L), TGRAD (L), ALPHA (L) , PGRAD (L)

WRITE $(10,202) \operatorname{RHO}(L), \operatorname{TGRAD}(L), \operatorname{ALPHA}(L), \operatorname{PGRAD}(L)$

$\operatorname{DDELTA}-\mathrm{DIN}(\mathrm{L})-\mathrm{DIN}(\mathrm{L}-1)$

$D(L)-D(L-1)+D D E L T A$

C DETERMINE SLOPE AND INTERCEPTS FOR THE PROPERTIES

POISSO (L) - POISPC $(L-1) *$ DPOISS+POISS I

$E O(L)-E P C(L-1) * D E+E I$

POISSM (L) $-(\operatorname{POISPC}(L)-\operatorname{POISPC}(L-1)) *$ DPOISS/TINC (L)

$\operatorname{EM}(L)-(\operatorname{EPC}(L)-\operatorname{EPC}(L-1)) * D E / \operatorname{TINC}(L)$

PGRADO (L) -PGRAD (L- 1$)$

$\operatorname{PGRADM}(\mathrm{L})-(\operatorname{PGRAD}(\mathrm{L})-\operatorname{PGRAD}(\mathrm{L}-1)) / \operatorname{TINC}(\mathrm{L})$

ALPHAO (L) -ALPHA (L-1)

$\operatorname{ALPHAM}(L)=(\operatorname{ALPHA}(L)-\operatorname{ALPHA}(L-1)) / \operatorname{TINC}(L)$

C DETERMINE THE FORCING LOADS AND STRAINS FOR THIS TIME STEP

$\operatorname{FEPSXM}(L)-\operatorname{EPSX}(L) / \operatorname{TINC}(L)$

$\operatorname{FEPSYM}(L)-\operatorname{EPSY}(L) / \operatorname{TINC}(L)$

$\mathrm{T}(\mathrm{L})-\mathrm{TSURF}+\mathrm{D}(\mathrm{L}) \star \mathrm{TGRAD}(\mathrm{L}) / 1000$.

$\operatorname{FDTDT}(\mathrm{L})-(\mathrm{T}(\mathrm{L})-\mathrm{T}(\mathrm{L}-1)) / \mathrm{TINC}(\mathrm{L})$

$\operatorname{FGRAV}(L)=(((0.433 * \operatorname{RHO}(\mathrm{L})-\operatorname{PGRAD}(\mathrm{L})) * \mathrm{D}(\mathrm{L}))-((0.433 *$

1 RHO (L-1) - PGRAD (L- I)) *D(L-1)))/TINC (L)

C START THE INTEGRATION

C REMEMBER, EACH INTEGRAL MUST BE CARRIED THROUGH ALL TIME

C THE FIRST LOOP IS FOR EACH OF THE INCREMENTAL TIMES THAT THE

C RELAXATION FUNCTION IS TO BE EVALUATED

DZ1-DDELTA/REAL(NSTEPS)

DO 35 MTIME-1, NSTEPS

TIME-TREL(L, MTIME)

C PRINT 504, L, MTIME, TIME

C WRITE $(10,504)$ L, MTIME, TIME

C 504 FORMAT(' L-', I2,' MTIME-' , I2,' TIME-' , F12.4)

C THE 2ND LOOP IS FOR EACH STEP IN HISTORY WHERE A FORCING FUNC. OCCURS DO $30 \mathrm{MFF}-2, \mathrm{~L}$

C PRINT 503, MFF, FGRAV(MFF), FDTR (MFF), FEPSXM(MFF), FEPSYM(MFF)

C WRITE $(10,503)$ MFF, FGRA: (MFF), FDTDT (MFF), FEPSXM (MFF), FEPSYM (MFF)

C 503 FORMAT(' MFF-', I2,' FG-', E12.4,' FDT=',E12.4,' FEPSX-', E12.4,

C 1' FEPSY-', E12, 4)

C NEED THE INCREMENTAL TIME STEP FOR EACH LARGE TIME PERIOD

C REMEMBER, EACH LARGE TIME PERIOD IS DIIFERENT SIZE, SO THE

C INCREMENTAL TIME STEPS ARE IRREGULAR ALSO

DZ-TINC (MFF) /(REAL (NSTEPS) *2.0)

$\mathrm{Z}=0.0$

C PRINT 502, MFF, TINC(MFF), DZ

C WRITE $(10,502) M F F, T I N C$ (MFF), DZ

C 502 FORMAT(' MFF-', I2,' TINC-',F12.4,' DZ-',F12.6) 
C START THE SUMMATION FOR EACH INCREMENTAL TIME STEP

C THE 3RD LOOP CALCULATES INCREMENTAL STRESS FOR EACH INCREMENTAL TIME DO 20 I-1, NSTEPS

IF (MFF .EQ. L .AND, I .GT. MTIME) GO TO 20

C PRINT $501, \mathrm{I}, \mathrm{Z}$

C $\operatorname{WRITE}(10,501) \mathrm{I}, \mathrm{Z}$

C 501 FORMAT (' I-', I2,' Z-', F12,4) DO $8 \mathrm{JJ}-1,6$

$8 \operatorname{SUM}(J J)=0.0$

C EVALUATE PROPERTIES AT THREE POINTS(ENDS AND MIDDLE) DO $15 \mathrm{~J}-1,3$ POISSF-POISSO (MFF) +POISSM (MFF) *Z $E F-E O(M F F)+E M(M F F) * Z$ ALPHAF-ALPHAO (MFF) +ALPHAM (MFF) $* Z$

C CALCULATE THE DELTA TIME OVER WHICH RELAXATION OCCURS

C REMEMBER, TIME INCREASES AS WE GO BACK IN HISTORY TINTEG-TIN (MFF - 1) - Z RELAXT-TINTEG - TIME

C EVALUATE THE RELAXATION FUNCTION AT THIS TIME C1-1.0-POISSF C2-1.0+POISSF C3-1.0-2.0*POISSF $\mathrm{C} 4-3.0 * \mathrm{C} 1 / \mathrm{C} 2$ C5-EXP (-RELAXT/TR $)$ C6-EXP ( - C4*RELAXT/TR $)$

$\mathrm{A} 1-\mathrm{C} 1 / \mathrm{POISSF}-\mathrm{C} 3 /$ POISSF $* \mathrm{C} 5$

$\mathrm{A} 2-\mathrm{C} 2 / 2.0 * \mathrm{C} 5+\mathrm{C} 1 / 2.0 * \mathrm{C} 6$

A $3-0.5 * \mathrm{C} 2 /$ POISSF $*$ C $5-0.5 * \mathrm{C} 1 /$ POISSF $*$ C 6

$\mathrm{A} 4-\mathrm{C} 5$

C PRINT 500, J, TIME, TINTEG, RELAXT, A1, A2, A3, A4, A5, A6

C WRITE $(10,500) \mathrm{J}$, TIME, TINTEG, RELAXT, A1 , A2, A3, A4, A5, A6

C 500 FORMAT(' J-', I2,' TIME-',F12.4,' TINTG-',F12.4,' RELXT-', F12.4

C $1,{ }^{\prime}$ THE A''S ARE', /6E12.4)

C CALCULATE TOTAL CONTRIBUTION TO INTEGRAL (RELAX, + PROP + FOR FUN) $A D D(1)-P O I S S F /(1.0-$ POISSF $) *$ FGRAV (MFF) *AI $A D D(2)-A L P H A F * E F /(1.0-P O I S S F) * F D T D T(M F F) * A 4$

$A D D(3)-E F /(1.0-P O I S S F \star * 2) \star F E P S X M(M F F) \star A 2$ $A D D(4)-E F /(1.0-P O I S S F * * 2) * F E P S Y M(M F F) * A 2$ $A D D(5)-P O I S S F * A D D(3) \star A 3 / A 2$ $A D D(6)-P O I S S F A D D(4) \star A 3 / A 2$

C PRINT 505, (ADD(IJK), IJK-1,6)

C $\operatorname{WRITE}(10,505)(\operatorname{ADD}(\mathrm{IJK}), \mathrm{IJK}-1,6)$

C 505 FORMAT('ADD(I)-', 6E12.4)

FAC- 1.0

IF (J .EQ. 2) $\mathrm{FAC}-4.0$

C ADD THIS CONTRIBUTION TO THE RUNNING SUM ( 3 POINTS FOR EACH SUM) DO $12 K=1,6$

$12 \operatorname{SUM}(K)-\operatorname{SUM}(K)+A D D(K) * F A C$

15 IF (J . LT. 3) Z Z Z Z DZ 
C NOW CALCULATE THE STRESS COMPONENTS FOR THIS INCREMENT

$S 1$ ( L, MTIME) $-S 1$ (L, MTIME) +DZ/3.0*SUM(1)

S2 (L, MT IME) $-S 2(L, M T I M E)+D Z / 3.0 * \operatorname{SUM}(2)$

S $3 X(L, M T I M E)-S 3 X(L, M T I M E)+D Z / 3.0 *(\operatorname{SUM}(3)+\operatorname{SUM}(6))$

S3Y (L, MTIME) -S 3Y (L, MTIME) +DZ/3.0*(SUM(4)+SUM(5))

C PRINT 506,S1 (L, MTIME), S2 (L, MTIME), S3X (L, MTIME), S3Y (L, MTIME)

C WRITE(10,506)S1(L, MTIME), S2(L,MTIME), S3X(L, MTIME), S 3Y (L, MTIME)

C 506 FORMAT(' S1-',E12.4,' S2-',E12.4,' S3X-',E12.4,' S3Y-',E12.4)

20 CONTINUE

C END OF THE THIRD LOOP

C END OF THE SECOND LOOP

30 CONTINUE

C CALCULATE OVERBURDEN STRESS, PORE PRESSURE AND TEMPERATURE

DREL (L, MTIME) $=D(L-1)+D Z 1 * R E A L$ (MTIME)

$\operatorname{SV}(L, M T I M E)-R H O(L) * 0.433 * \operatorname{DREL}(L, M T I M E)$

PO (L, MTIME) $-($ PGRADO (L) +PGRADM (L) * (TIN (L-1) - TREL (L, MTIME))) *

IDREL (L, MTIME)

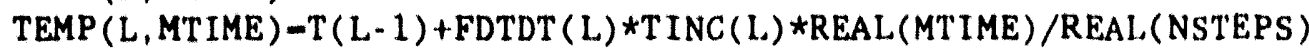

C CALCULATE THE HORIZONTAL STRESSES

SHMIN (L, MTIME) -S1 (L, MTIME) +S2 (L, MTIME) +S3X (L, MTIME) + PO (L, MTIME)

SHMAX (L, MTIME) -S1 (L, MTIME) +S2 (L, MTIME) +S3Y (L, MT IME) + PO (L, MTIME)

C CALCULATE THE EFFECTIVE STRESSES

ESV (L, MTIME) -SV (L, MTIME) - PO (L, MTIME)

$\operatorname{ESHMIN}(L, M T I M E)-S H M I N(L, M T I M E)-P O(L, M T J M E)$

ESHMAX (L, MT IME)-SHMAX (L, MT IME) - PO(L, MT IME)

PRINT 201,DREL(L,MTIME), SV (L,MTIME), S1 (L, MTIME), S2 (L,MTIME), S3X (L

1, MT IME) , S3Y (L, MTIME), SHMIN (L, MT IME), SHMAX (L, MTIME), PO(L, MTIME),

2 TEMP(L, MTIME), ESV (L, MTIME), ESHMIN(L, MTIME), ESHMAX (L, MTIME)

WRITE $(10,201)$ DREL(L,MTIME), SV (L,MTIME), S1 (L, MTIME) , S2 (L, MTIME),

1

2

3

S3X (L, MTIME), S3Y (L, MT IME), SHMIN (L, MT IME),

SHMAX (L, MTIME), PO (L, MTIME), TEMP (L, MTIME),

$\operatorname{ESV}(L, M T I M E), \operatorname{ESHMIN}(L, M T I M E), \operatorname{ESHMAX}(L, M T I M E)$

C END OF FIRST LOOP

35 CONTINUE

50 CONTINUE

C PREPARE FOR OUTPUT

I PU -1

PRINT*,' DO YOU WANT OUTPUT IN SI(S) OR CONV(C) UNITS: '

READ 111, IUNITS

IF(IUNITS .EQ. 'S') THEN

$A=0.0068948$

I PU-2

DO $55 \mathrm{~J}=1, \mathrm{~N}$

DO $55 \mathrm{~K}-1$, NSTEPS

$\operatorname{SV}(J, K)-S V(J, K) \star A$

$\mathrm{PO}(J, K)=\mathrm{PO}(J, K) * A$

$S 1(J, K)-S 1(J, K) \star A$

$S 2(J, K)-S 2(J, K) * A$

$S 3 X(J, K)-S 3 X(J, K) \star A$

$\operatorname{S3Y}(J, K)-S 3 Y(J, K) \star A$

$\operatorname{SHMIN}(J, K)-\operatorname{SHMIN}(J, K) * A$

$\operatorname{SHMAX}(J, K)-\operatorname{SHMAX}(J, K) \star A$ 


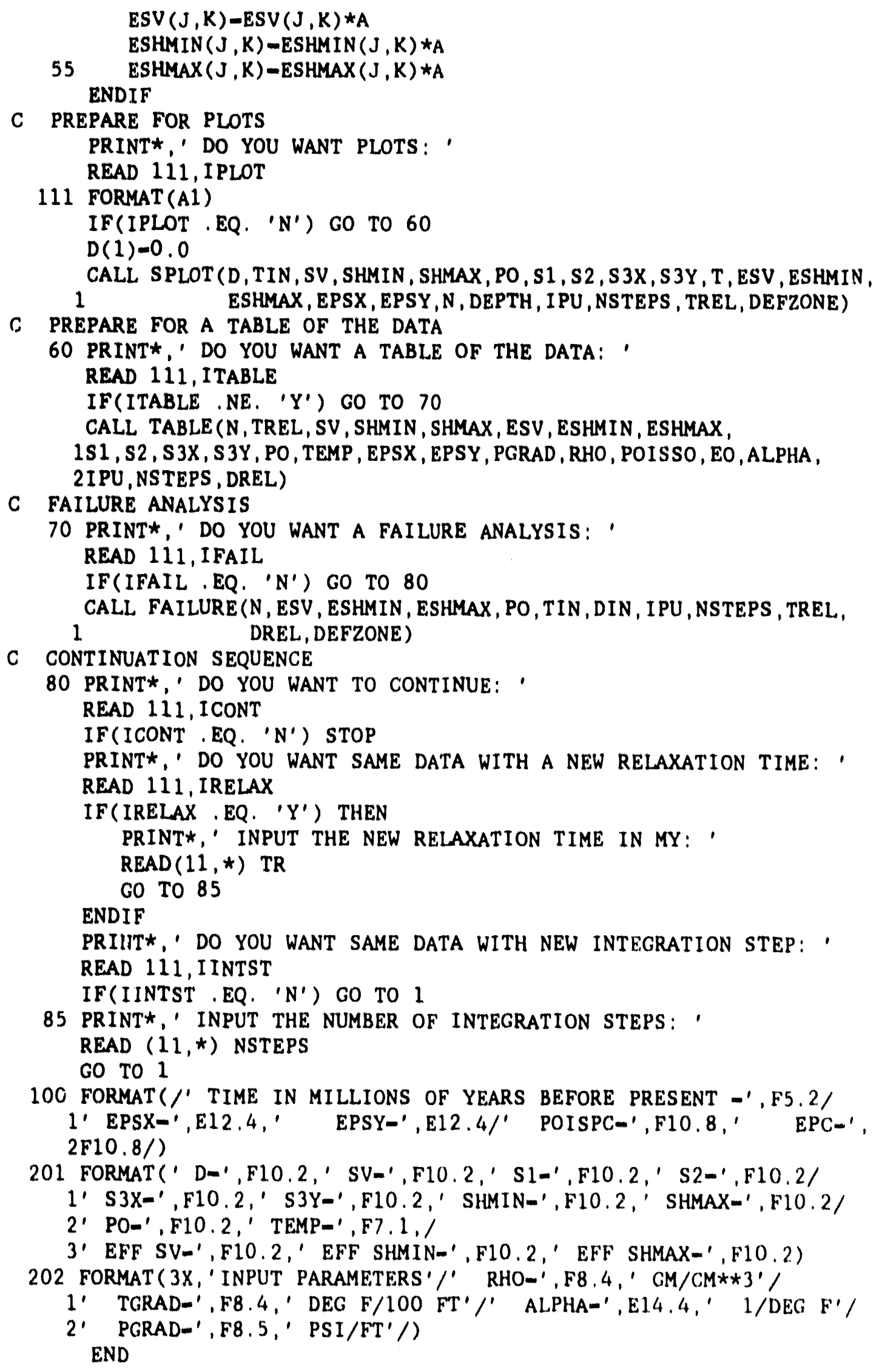


SUBROUTINE INPUT (TIN , DIN, POISSPC, EPC, EPSX, EPSY, DEPTH, POISS, E, 1

2

CHARALTER $* 1$ IFH, IWR

RHO, TGRAD, ALPHA, DDEPTH, N, POISS I , EI , PGRAD, NSTEPS, TR, DEFZONE)

CHARACTER $* 20$ FILEIN, FILEOUT

CHARACTER $* 40$ DEFZONE

PARAMETER (IT-20)

DIMENSION TIN(IT), DIN(IT), POISSPC(IT), EPC(IT), EPSX(IT), EPSY

1 (IT) , PGRAD (IT), TGRAD (IT) , ALPHA (IT) , RHO(IT)

C

C

C

C

C

C

C

C

C

C

C

C

C

C

C

C
POISSPC ...... POISSONS RATIO - 8 INCREASE FROM INITIAL TO PRESENT DAY VALUE

EPC $\ldots . . . . .$. YOUNGS MODULUS $-\&$ INCREASE FROM INITIAL TO PRESENT DAY VALUE

EPSX ......... TECTONIC STRAIN IN MIN DIRECTION - MICROSTRAIN

EPSY ......... TECTONIC STRAIN IN MAX DIRECTION - MICROSTRAIN

RHO .......... DENSITY - . GM/CC

PGRAD ........ PORE PRESSURE GRADIENT - PSI/FT

TGRAD ........ TEMPERATURE GRADIENT +. DEG F/1000 FT

ALPHA $\cdots . . . .$. COEFFICIENT OF LINEAR THERMAL EXPANSION

INPUT FILE

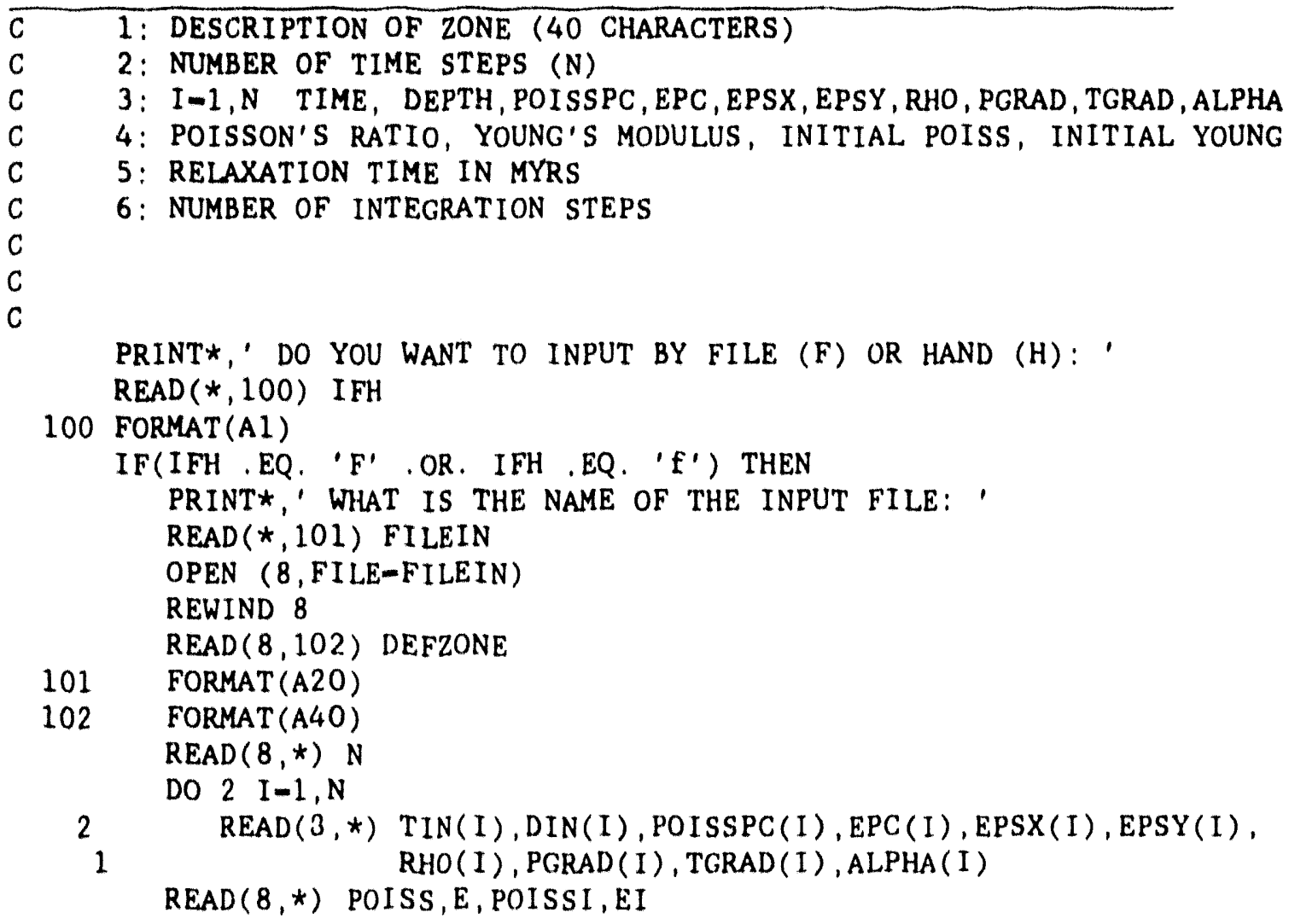




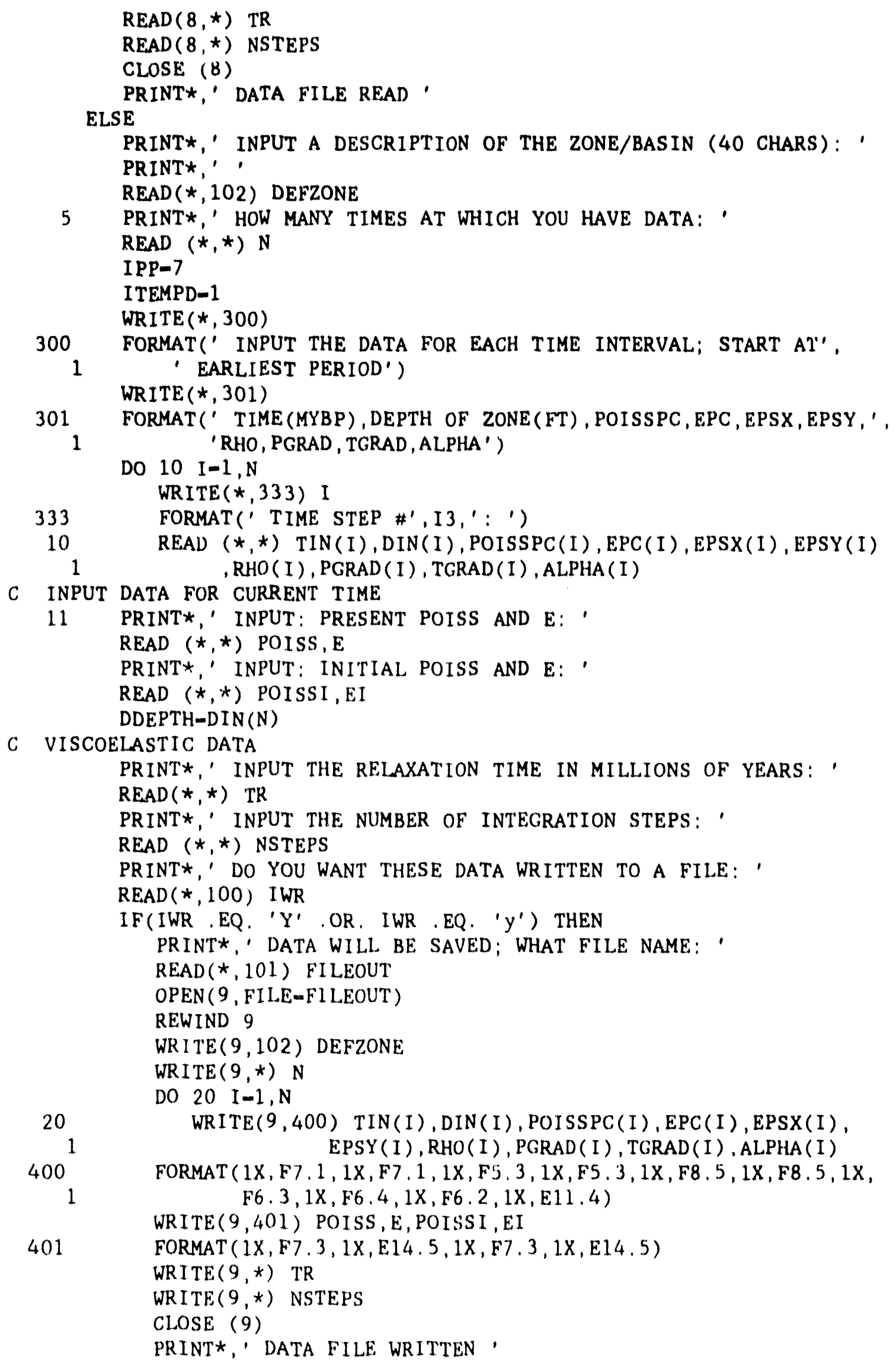




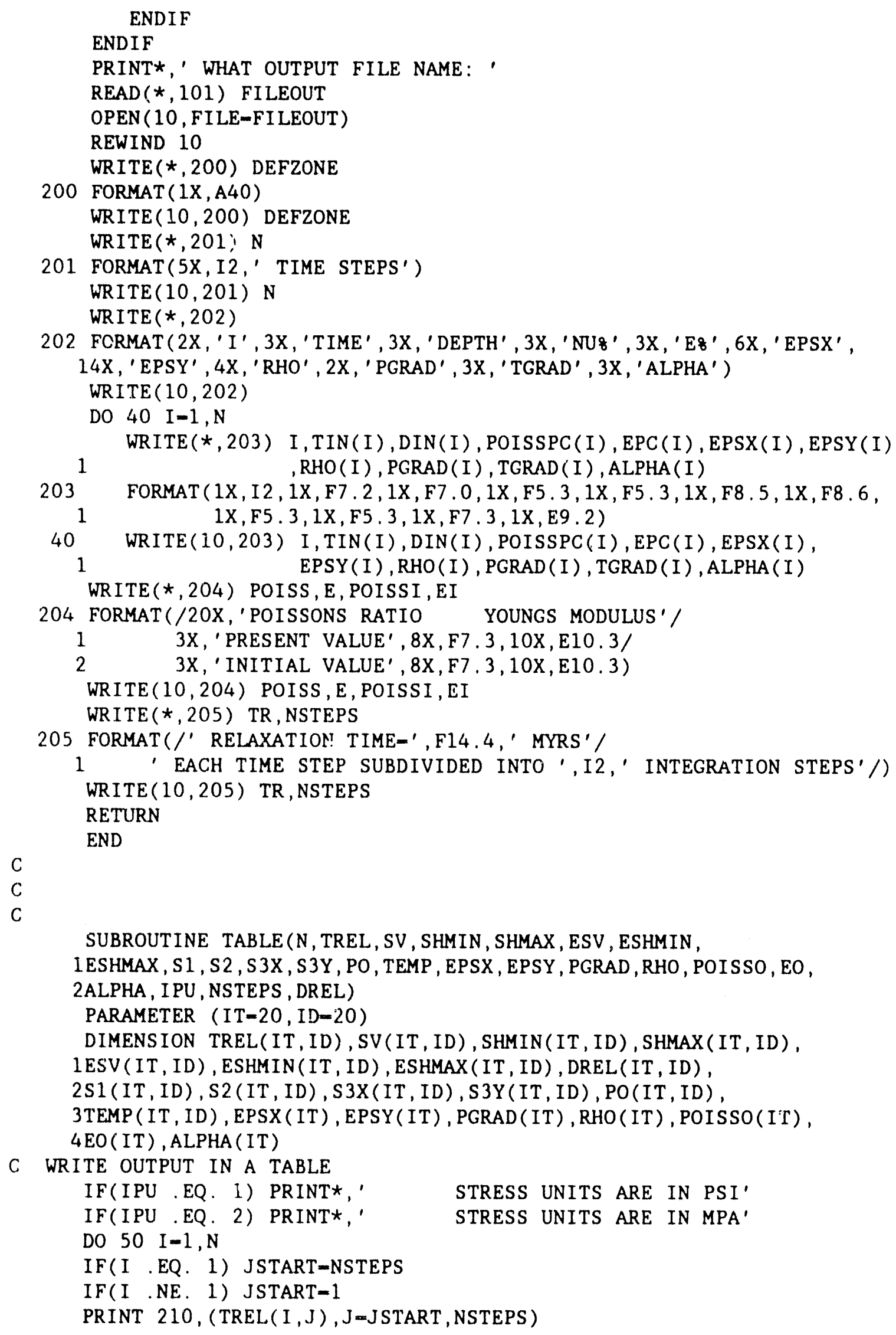


PRINT 211, (DREL ( $I, J), J=J S T A R T$, NSTEPS)

PRINT 212, (SV(I,J),J-JSTART, NSTEPS)

PRINT 213, (SHMIN (I, J), J-J START, NSTEPS)

PRINT 214, (SHMAX (I,J), J-J START, NSTEPS)

PRINT 215, (ESV (I,J), J-JSTART, NSTEPS)

PRINT 216, (ESHMIN $(I, J), J-J S T A R T, N S T E P S)$

PRINT 217, (ESHMAX ( $I, J), J=J S T A R T$, NSTEPS)

PRINT 218, ( $11(\mathrm{I}, \mathrm{J}), \mathrm{J}$-JSTART, NSTEPS)

PRINT 219, (S2 $(I, J), J-J S T A R T$, NSTEPS)

PRINT 220, (S3X(I,J), J-JSTART, NSTEPS)

PRINT 221, ( $33 Y(I, J)$, J-JSTART, NSTEPS)

PRINT 222, (PO (I,J), J-JSTART, NSTEPS)

PRINT 223, (TEMP (I , J ), J-JSTART, NSTEPS)

PRINT 224, EPSX(I)

PRINT 225, EPSY(I)

PRINT 226, PGRAD(I)

PRINT 227, RHO(I)

PRINT 228, POISSO(I)

PRINT 229,EO(I)

PRINT 230,ALPHA(I)

WRITE $(10,210)$ (TREL ( I, J ), J-JSTART, NSTEPS)

WRITE $(10,211)$ (DREL $(I, J), J$-JSTART, NSTEPS)

WRITE $(10,212)$ (SV(I,J), J-JSTART, NSTEPS)

WRITE $(10,213)$ (SHMIN (I,J), J-JSTART, NSTEPS)

WRITE $(10,214)$ (SHMAX (I,J), J-JSTART, NSTEPS)

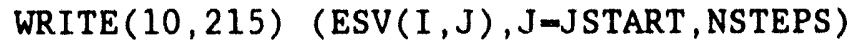

WRITE $(10,216)$ (ESHMIN $(I, J), J-J \operatorname{START}, \operatorname{NSTEPS})$

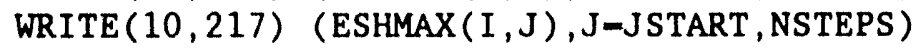

WRITE $(10,218)$ (S1 (I,J), J-JSTART, NSTEPS)

WRITE $(10,219)$ (S2 (I, J ), J-JSTART, NSTEPS)

WRITE $(10,220) \quad(S 3 X(I, J), J$-JSTART, NSTEPS $)$

WRITE $(10,221) \quad$ (S3Y (I , J ), J=JSTART, NSTEPS)

WRITE $(10,222)$ (PO $(I, J), J-J S T A R T$, NSTEPS )

WRITE $(10,223)$ (TEMP (I,J),J-JSTART, NSTEPS)

WRITE $(10,224) \operatorname{EPSX}(I)$

$\operatorname{WRITE}(10,225) \quad \operatorname{EPSY}(I)$

WRITE $(10,226)$ PGRAD (I)

WRITE $(10,227)$ RHO(I)

WRITE $(10,228)$ POISSO(I)

$\operatorname{WRITE}(10,229) \quad \mathrm{EO}(\mathrm{I})$

WRITE $(10,230)$ ALPHA(I)

49 PRINT 231

50 CONTINUE

210 FORMAT $(/$, TIME (MY) $=\prime, 6 \mathrm{X}, 7(1 \mathrm{X}, \mathrm{F} 5.1,2 \mathrm{X}) /$ )

211 FORMAT (' DEPTH (FT) $=^{\prime}, 5 \mathrm{X}, 7 \mathrm{~F} 8,1$ )

212 FORMAT(' SV=' , 13X, 7F8.1)

213 FORMAT (' SHMIN-', 10X, 7F8.1)

214 FORMAT (' SHMAX =', 10X,7F8.1)

215 FORMAT(' EFF SV=',9X,7F8.1)

216 FORMAT (' EFF SHMIN-' , 6X,7F8.1)

217 FORMAT(' EFF SHMAX=' $, 6 \mathrm{X}, 7 \mathrm{~F} 8.1$ )

218 FORMAT(' S1-GRAV-' , 8X, 7F8.1)

219 FORMAT(' S2-TEMP-' , 8X, 7F8,1) 


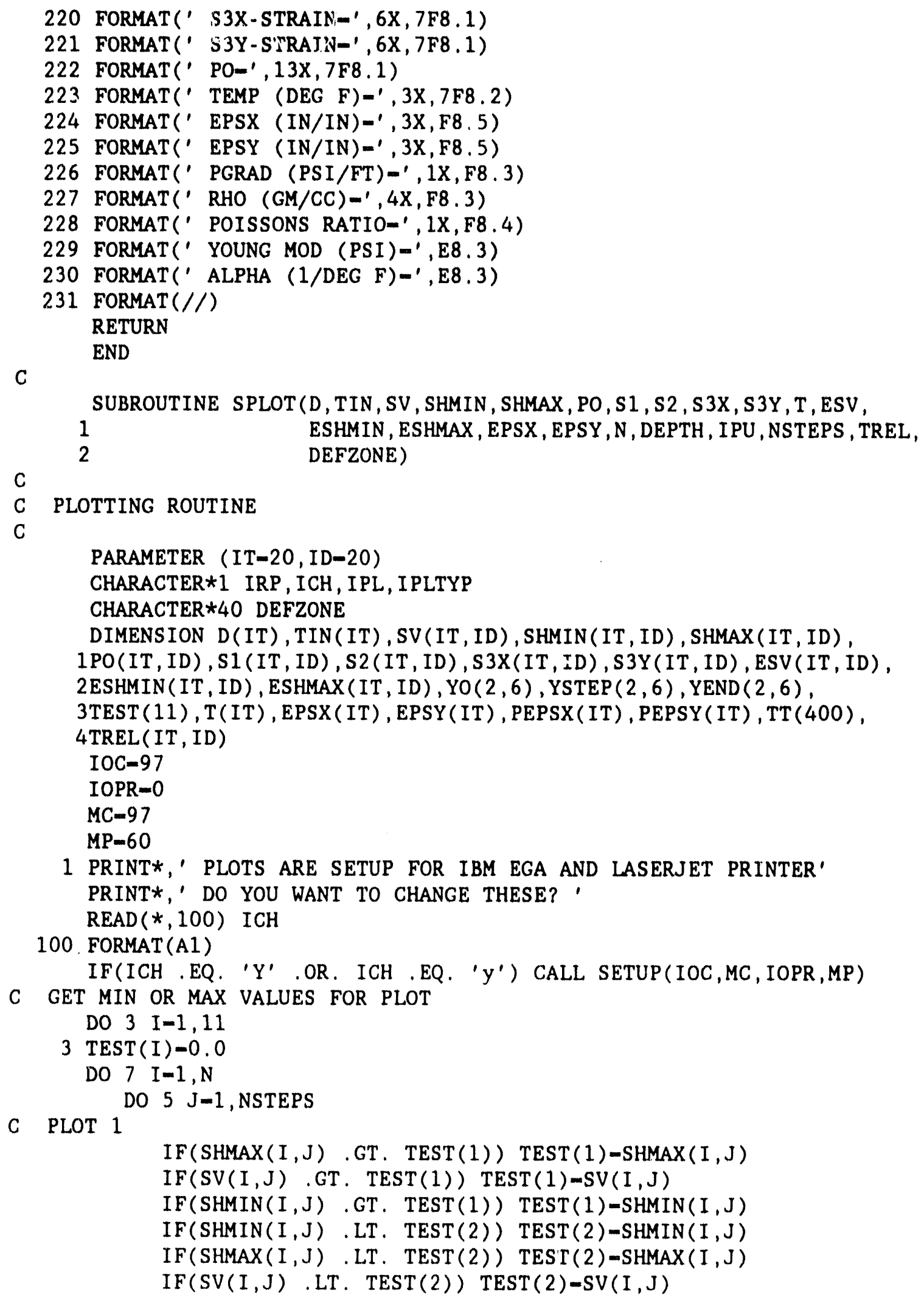


C PLOT 2

$\operatorname{IF}(\operatorname{PO}(I, J), \operatorname{LT} . \operatorname{TEST}(2)) \operatorname{TEST}(2)-P O(I, J)$

$$
\begin{aligned}
& \text { IF (ESHMAX (I,J) .GT. TEST(3)) TEST(3)-ESHMAX (I,J) } \\
& \operatorname{IF}(\operatorname{ESHMIN}(I, J), G T \cdot \operatorname{TEST}(3)) \operatorname{TEST}(3)-\operatorname{ESHMIN}(I, J) \\
& \operatorname{IF}(\operatorname{ESV}(1, J), G T, \operatorname{TEST}(3)) \operatorname{TEST}(3)-\operatorname{ESV}(I, J) \\
& \operatorname{IF}(\operatorname{ESV}(I, J) \quad . L T \cdot \operatorname{TEST}(4)) \operatorname{TEST}(4)-\operatorname{ESV}(I, J) \\
& \operatorname{IF}(\operatorname{EShMIN}(I, J), L T \cdot \operatorname{TEST}(4)) \operatorname{TEST}(4)-\operatorname{EShMIN}(I, J) \\
& \operatorname{IF}(\operatorname{EShMax}(I, J) \quad . L T \cdot \operatorname{TEST}(4)) \operatorname{TEST}(4)-\operatorname{EShMaX}(I, J)
\end{aligned}
$$

C PLOT 3

$$
\begin{aligned}
& \operatorname{IF}(\operatorname{S3Y}(I, J) \text {,GT. TEST(5)) } \operatorname{TEST}(5)-\operatorname{S} 3 Y(I, J) \\
& \operatorname{IF}(S 2(I, J) \text {,GT. TEST(5)) } \operatorname{TEST}(5)-S 2(I, J) \\
& \operatorname{IF}(S 1(I, J), G T . \operatorname{TEST}(5)) \operatorname{TEST}(5)-S 1(I, J) \\
& \operatorname{IF}(\operatorname{S} 3 X(I, J) \text {,GT. TEST(5)) TEST(5)-S } 3 X(I, J) \\
& \operatorname{IF}(\operatorname{S} 3 X(I, J) \text {.LT. } \operatorname{TEST}(6)) \operatorname{TEST}(6)-S 3 X(I, J) \\
& \operatorname{IF}(\operatorname{S} 3 Y(I, J) \text {. LT. } \operatorname{TEST}(6)) \operatorname{TEST}(6)-\operatorname{S} 3 Y(I, J) \\
& \operatorname{IF}(S 2(I, J) \text {. LT. } \operatorname{TEST}(6)) \operatorname{TEST}(6)-S 2(I, J) \\
& \operatorname{IF}(\operatorname{SI}(I, J) \text {.LT. } \operatorname{TEST}(6)) \operatorname{TEST}(6)-\mathrm{S} 1(I, J)
\end{aligned}
$$

C PLOT 6

$$
\begin{aligned}
& \operatorname{PEPSX}(I)-\operatorname{EPSX}(I) \star 1 . E+06 \\
& \operatorname{PEPSY}(I)-\operatorname{EPSY}(I) \star 1 . E+06
\end{aligned}
$$$$
\text { IF(PEPSY(I) .GT, TEST(7)) TEST(7)-PEPSY(I) }
$$

5 IF(PEPSX(I) .LT. TEST(8)) TEST(8)-PEPSX(I)

C PLOT 4

C PLOT 5

$$
\text { IF(T(I) .GT. TEST(9)) TEST(9)-T(I) }
$$

$$
\operatorname{IF}(D(I) \text {. GT. TEST(10)) TEST(10) }-D(I)
$$

C $X$ AXIS (TIME)

7 IF(TIN(1) .GT. TEST(11)) TEST(11)-TIN(I)

KDEPTH-INT (DEPTH)

WRITE $(*, 201)$ TEST (11)

201 FORMAT(' START TIME IS ',F12.3,' YRS BEFORE PRESENT'/

1 INPUT: START TIME, TSTEP AND TEND (E.G. 75,5,0): ')

$\operatorname{READ}(*, *)$ TO, TSTEP, TMAX

TSTEP- - TSTEP

C IPLTYP DESCRIBES TYPE OF PLOT

DO $80 \mathrm{~J}-1,6$

$I D E V=I O C$

JDEV-MC

IPL ' ' N'

IF (J.EQ.1) PRINT*,' DO YOU WANT TO PLOT TOTAL STRESS: '

IF (J.EQ.2) PRINT*,' DO YOU WANT TO PLOT EFF. STRESS:

IF (J.EQ. 3) PRINT*,' DO YOU WANT TO PLOT STRESS COMP.: '

IF (J.EQ.4) PRINT*,' DO YOU WANT TO PLOT TEMPERATURE:

IE (J.EQ.5) PRINT*,' DO YOU WANT TO PLOT DEPTH:

IF (J.EQ.6) PRINT*,' DO YOU WANT TO PLOT STRAINS:

READ 100, IPLTYP

IF (IPLTYP .EQ. ' $N$ ') GO TO 80

C SETUP FOR THE CORRECT PLOT

IF (J .EQ . 1) THEN

IAXEP $=1$

IAXEN-2

TEST (IAXEN) -0.0

ELSE IF(J .EQ, 2) THEN

IAXEP-3

IAXEN -4 


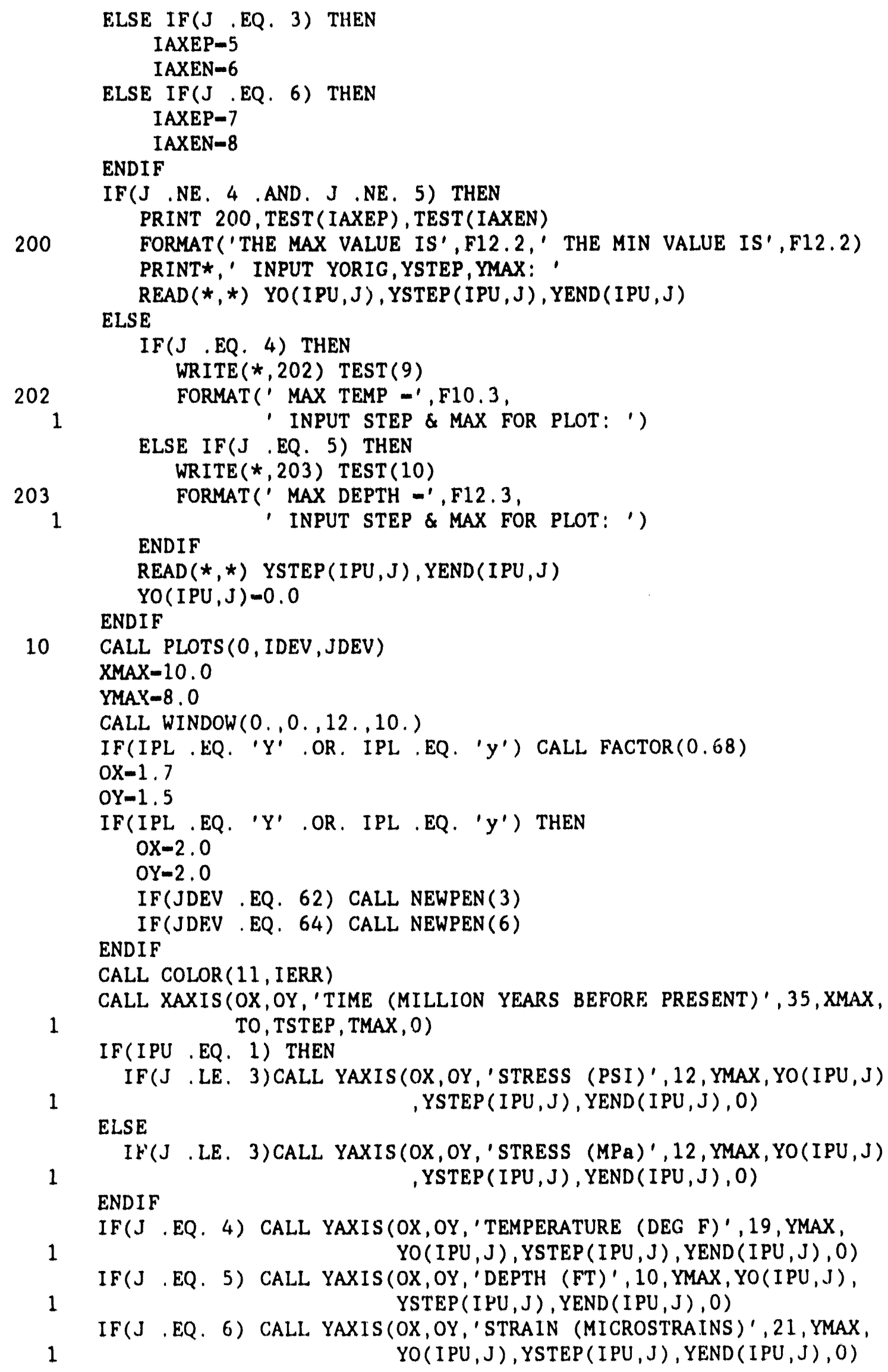




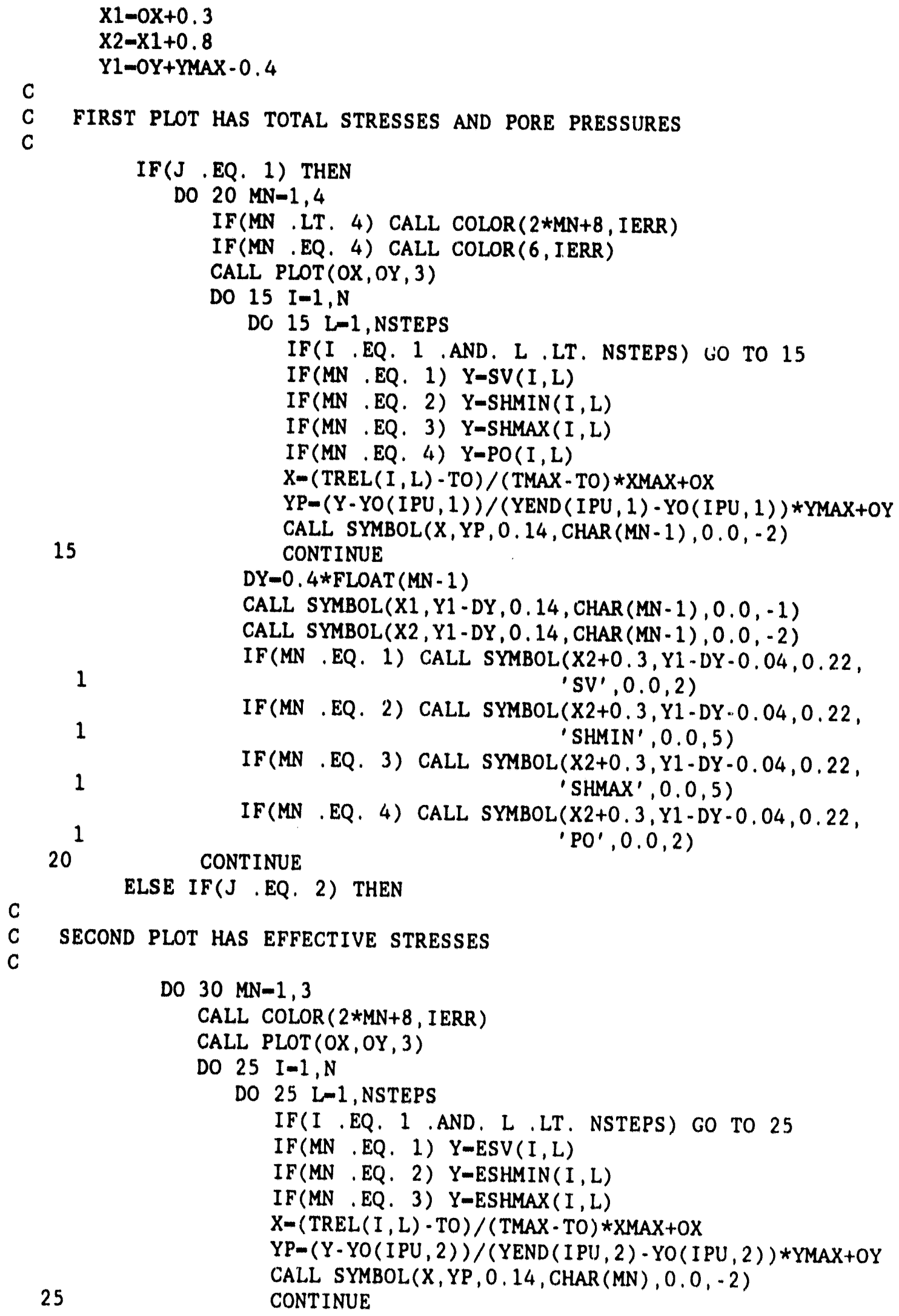




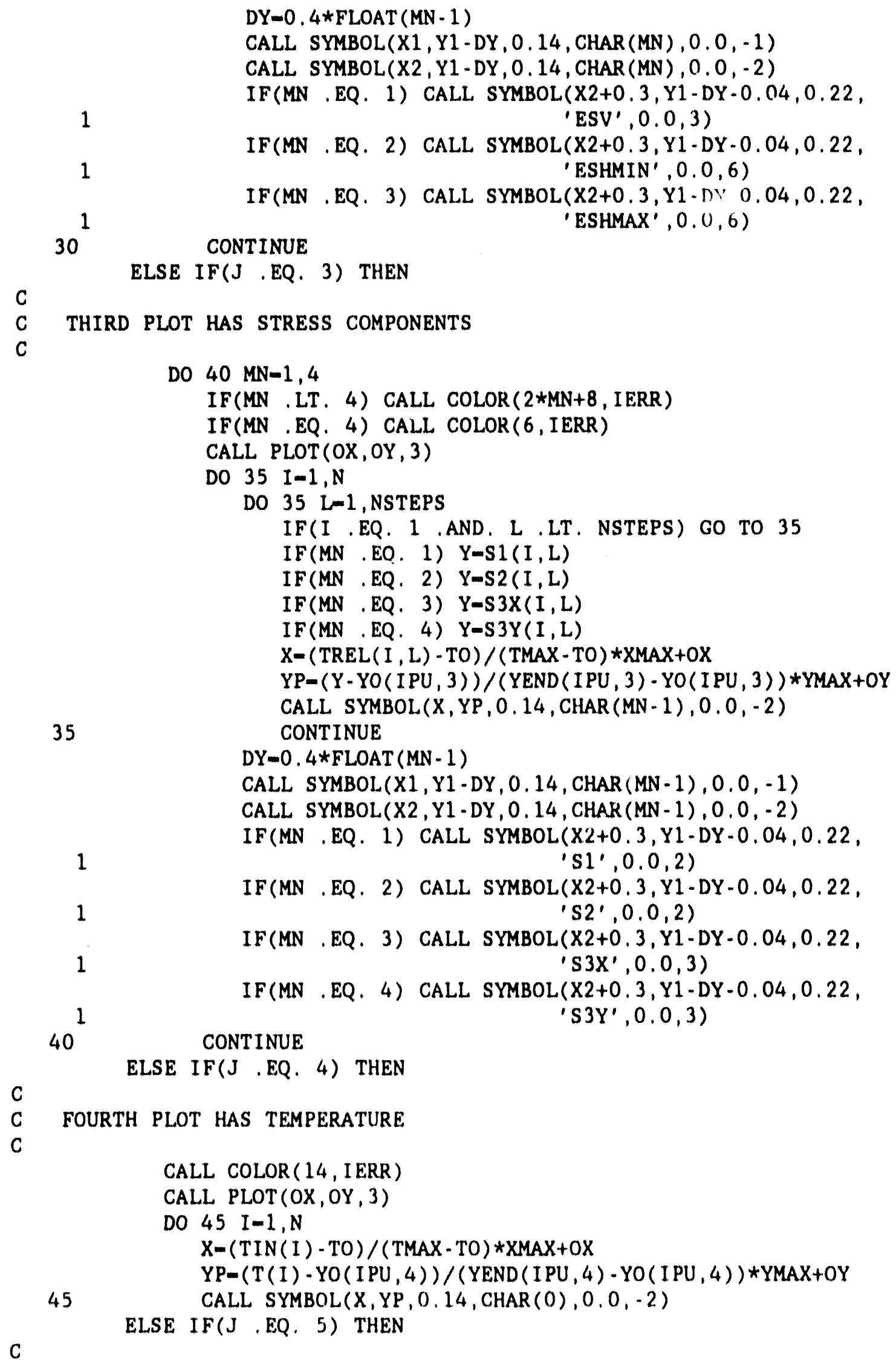




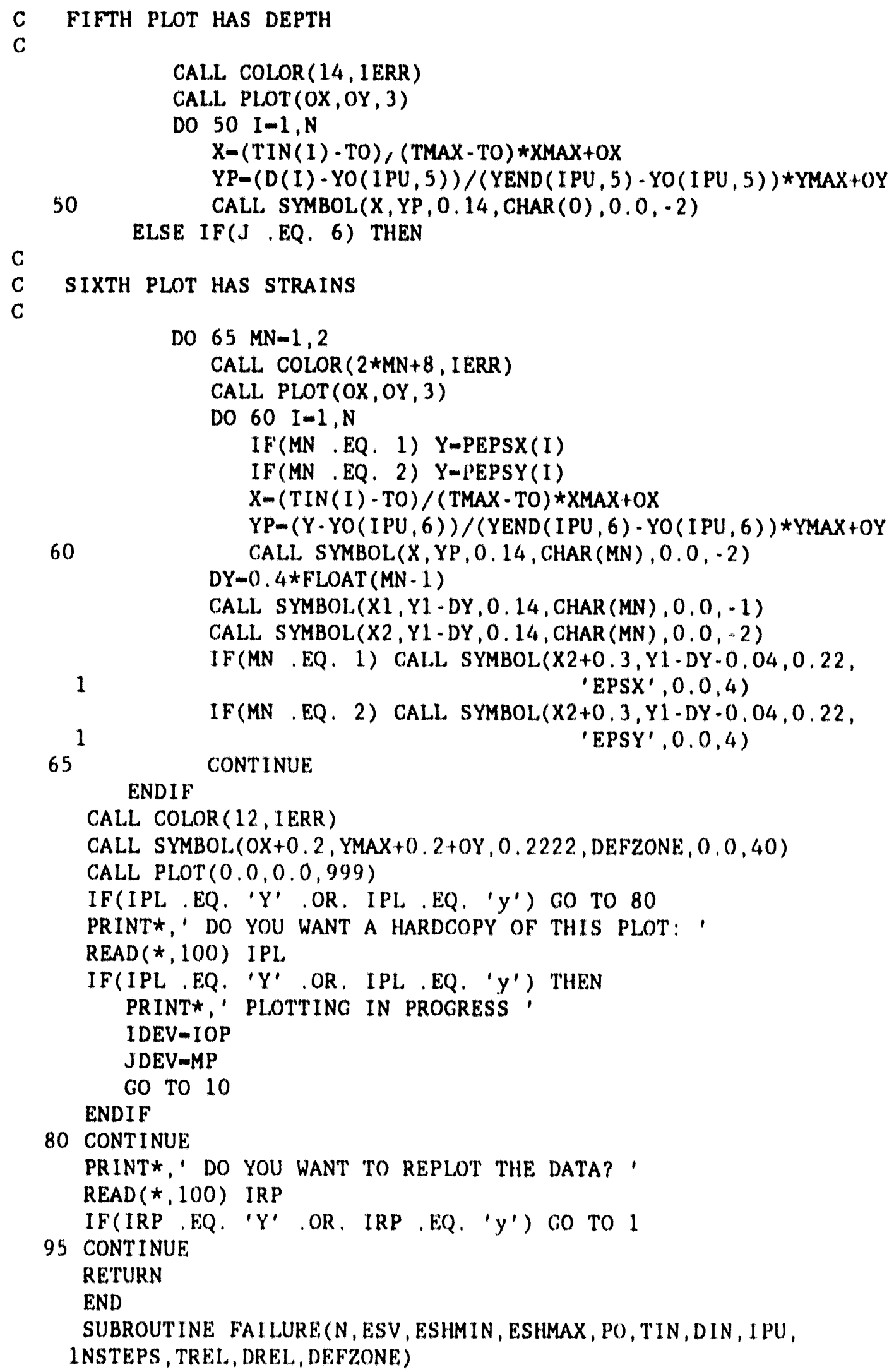




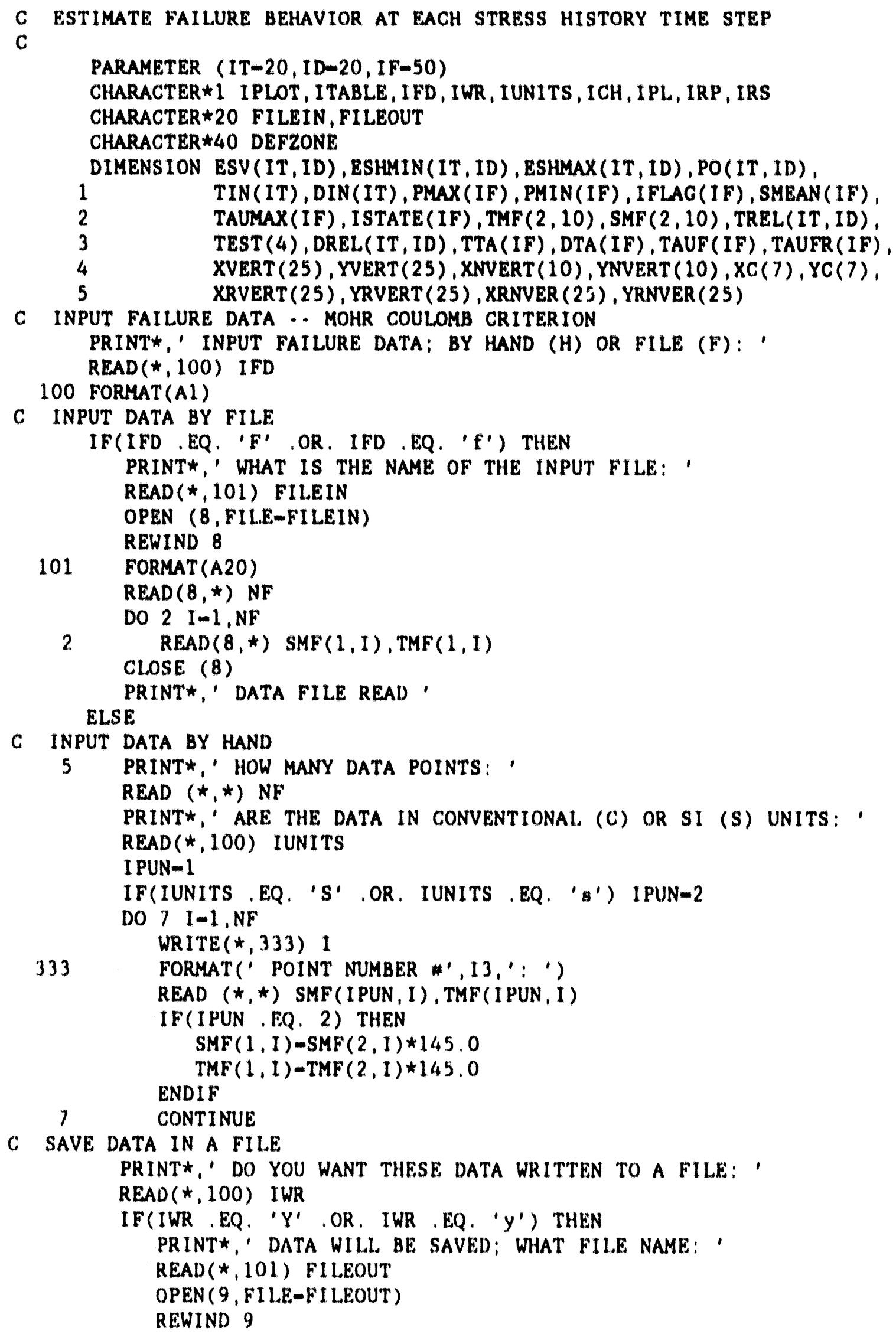




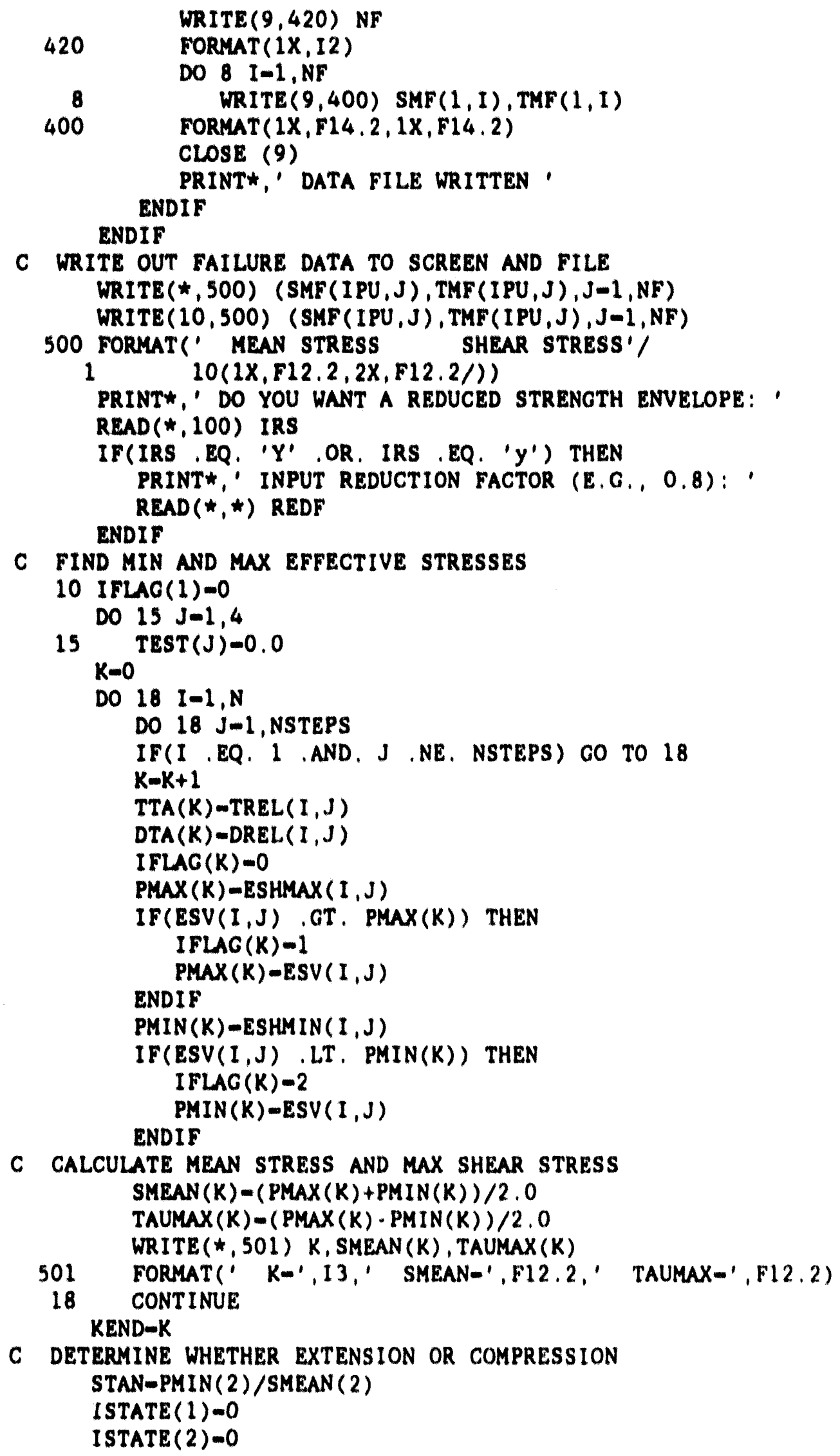




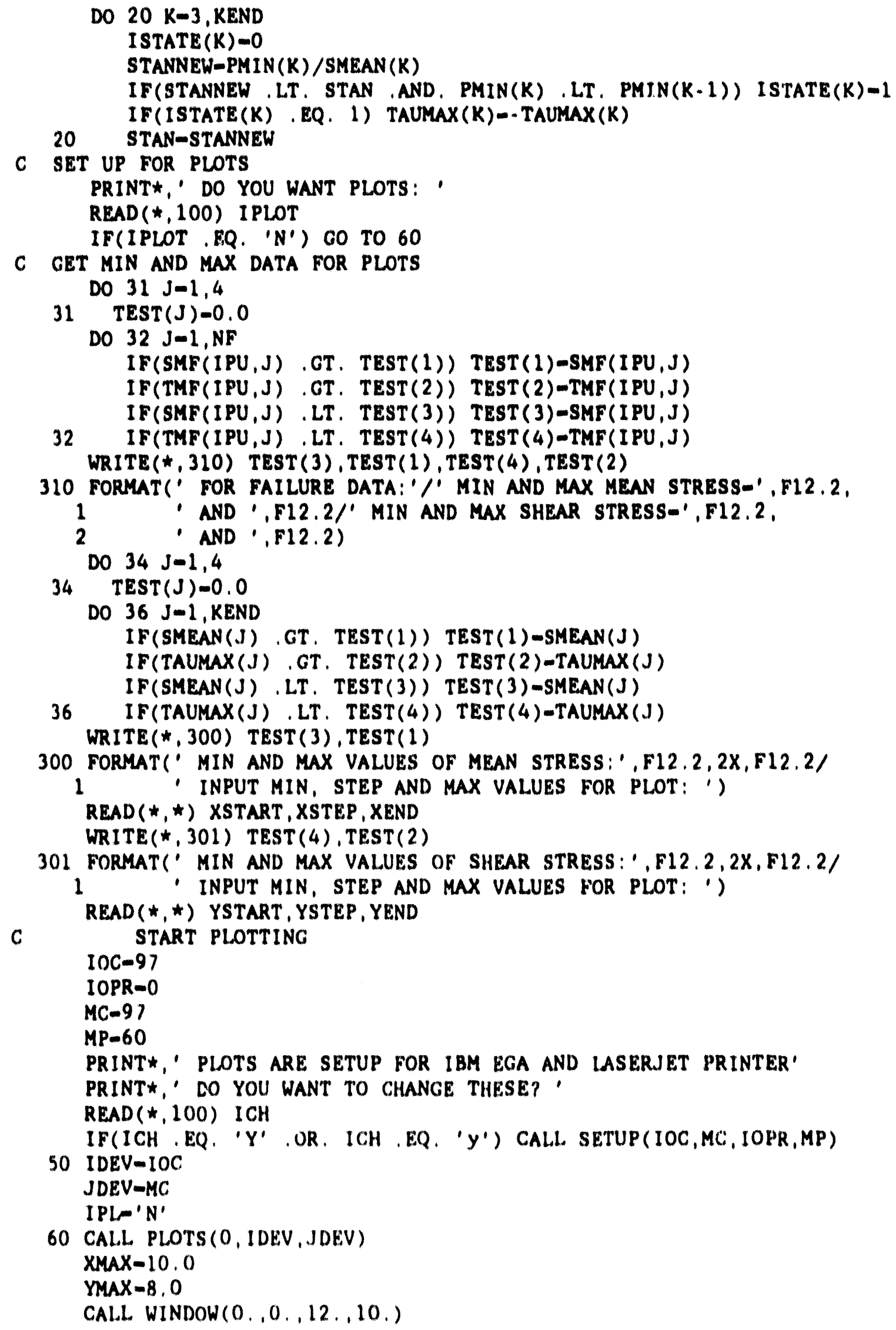


IF(IPL ,EQ. ' $Y$ ' ,OR, IPL. EQ. ' $y$ ') CALL $\operatorname{FACTOR}(0,68)$

$0 X-1.7$

OY -1.5

IF(IPL ,EQ. 'Y' ,OR, IPL .EQ. ' $y$ ') THEN

$0 \mathrm{X}-2.0$

$O Y-2.0$

IF(JDEV .EQ. 62) CALL NEWPEN (2)

ENDIF

IF(JDEV , EQ. 64) CALL NEWPEN(4)

CALL COLOR (11, IERR)

IF(IPU .EQ. 1) THEN

CALL XAXIS(OX,OY, 'MEAN EFFECTIVE STRESS (PSI)', 27, XMAX,XSTART, 1 XSTEP, XEND, 0)

CALL YAXIS(OX,OY, 'MAXIMUM SHEAR STRESS (PSI)', 26, YMAX, YSTART,

1

ELSE YSTEP, YEND, 0)

CALL XAXIS (OX,OY, 'MEAN EFFECTIVE STRESS (MPa)', 27, XMAX,XSTART,

1 XSTEP, XEND, O)

CALL YAXIS (OX,OY, 'MAXIMUM SHEAR S'TRESS (MPa)',26, YMAX, YSTAR'T,

1 YSTEP, YEND , 0)

ENDIF

$x 1-0 x+0.3$

$X 2-X 1+0.8$

$Y 1-O Y+Y M A X \cdot 0.4$

C PLOT THE CALCULATED MEAN STRESS VS SHEAR STRESS DATA

CALL COLOR (10,1ERR)

IST -1

DO $65 \mathrm{~K}-1, \mathrm{KEND}$

IF( 1 . EQ. 1 . AND, L . LT. NSTEPS) GO TO 65

$X-(\operatorname{SMEAN}(K) \cdot X S T A R T) /(X E N D-X S T A R T) * X M A X+O X$

YP- $($ TAUMAX $(K)$ - YSTART $) /(Y E N D-Y S T A R T) * Y M A X+O Y$

IF(K . GT 2 . AND. ISTATE(K) . NE. ISTATE $(K-1))$ THEN

C CHANGE FROM COMPRESSION TO EXTENSION - DRAW CURVED LINE

$X C(1)=X O L D$

$Y C(1)-Y$ YOL.D

DIS-SQRT $((X \cdot X O L D) \star \star 2+(Y P \cdot Y P O L D) * \star 2)$

RADIUS-DIS $/ 1.5$

IF(ISTATE (K) , EQ, I AND, ISTATE $(K-1), E Q, 0)$ THEN CS IGN-1,0

ELSE IF(ISTATE(K) , EQ, 0 .AND, ISTATE(K-1) , EQ. 1) THEN CSIGN- $-1,0$

ENDIF

AM- - $(X-X O L D) /(Y P \cdot Y P O L D)$

$B-(Y P+Y P O L D) / 2.0+0.5 *(X * \star 2 \cdot X O L D * \star 2) /(Y P \cdot Y P O L D)$

$A A-Y P-B$

$A B-1.0+A M \star \star 2$

$X M-(X+A M * A A-C S I G N * \operatorname{SQRT}((X+A A * A M) * \star 2$

1

$-A B \star(X \star \star 2+A A \star \star 2 \cdot R A D I U S \star \star 2))) / A B$

$Y M-A M * X M+B$

THET-ASIN (0,5*DIS/RADIUS)

IF (YP . LT. TPOLD) THET - THET

DTHET-THET $/ 3.0$

ALPHA-ATAN (AM) - THET 


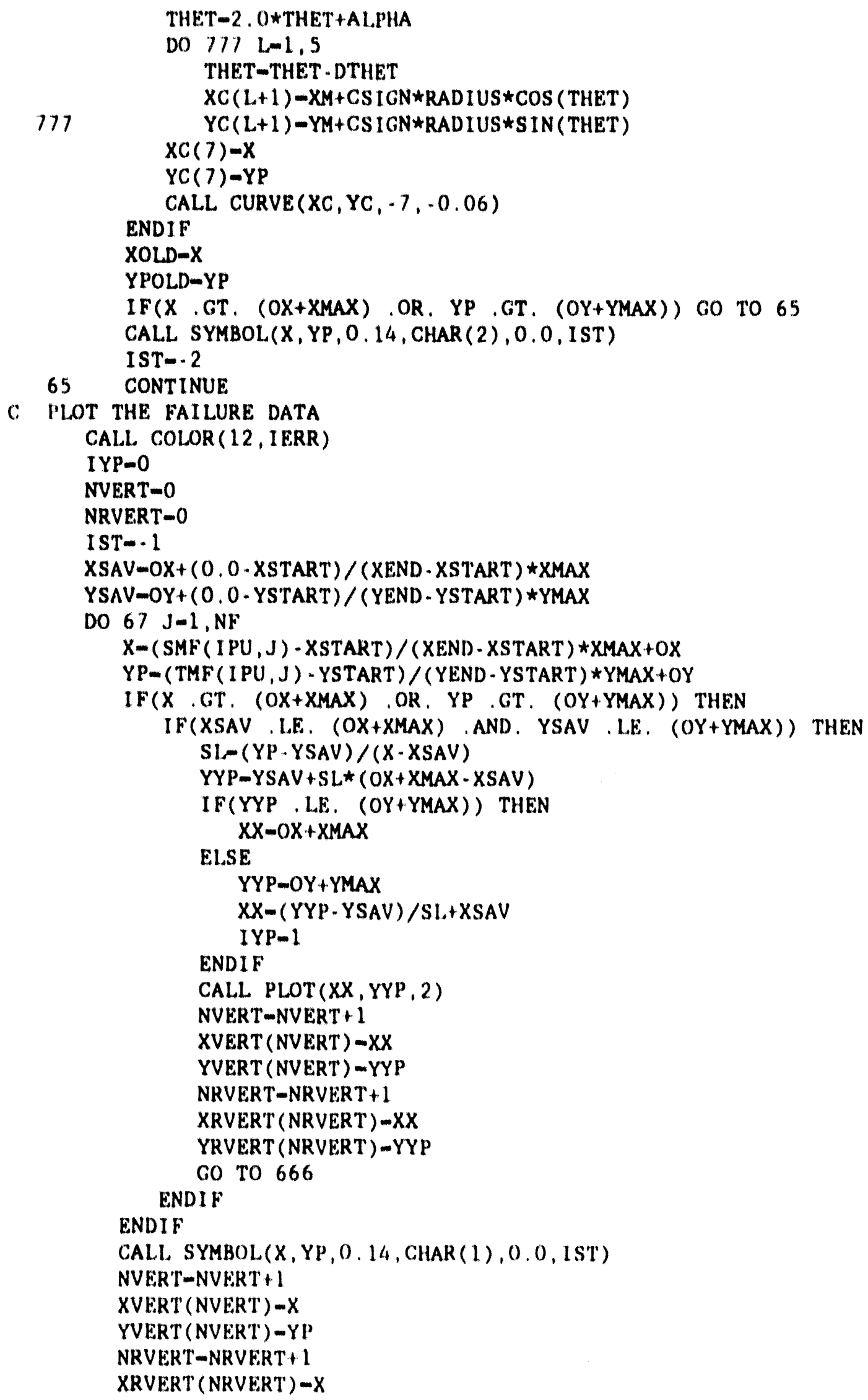




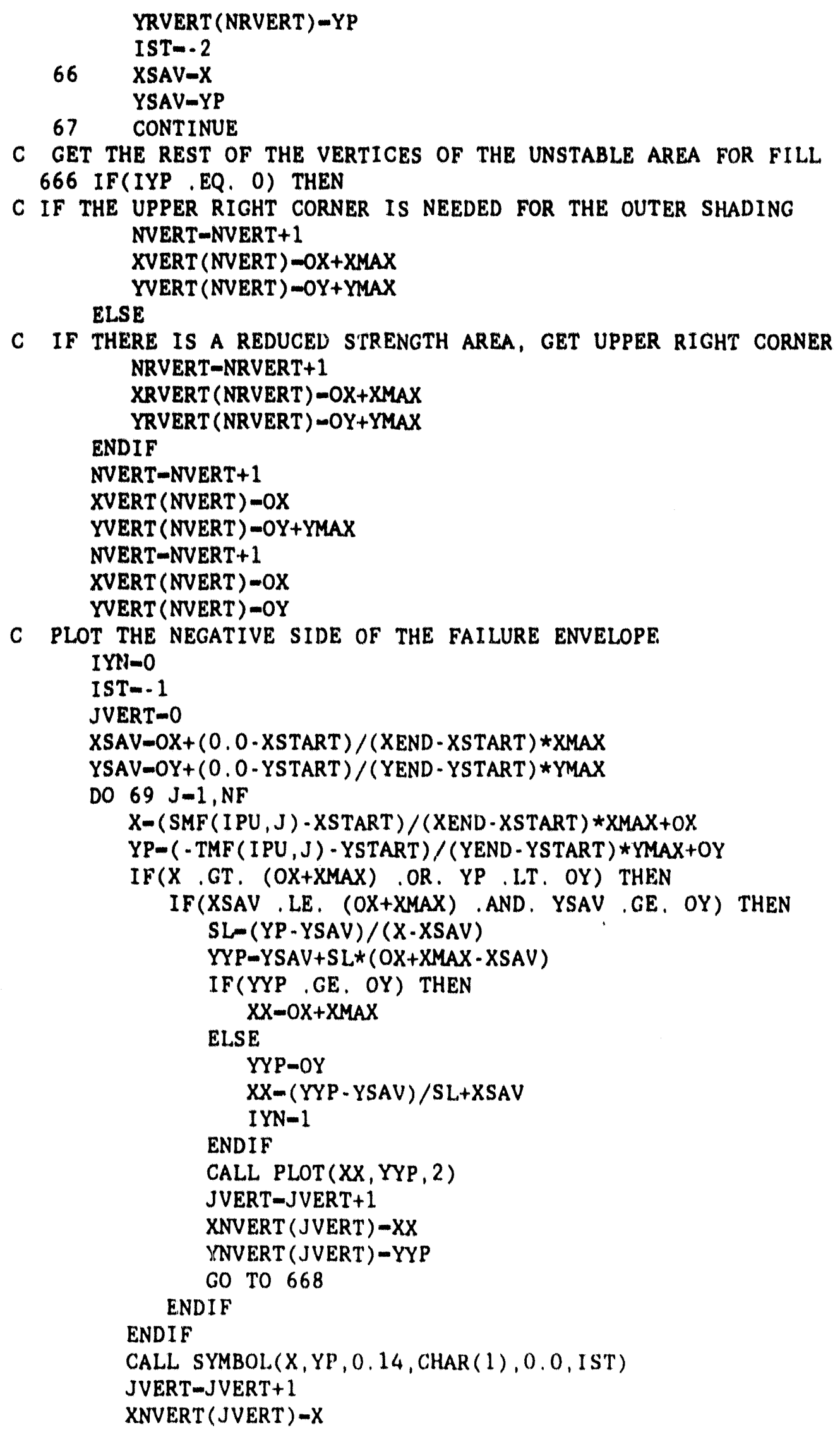

C IF THERE IS A REDUCED STRENGTH AREA, GET UPPER RIGHT CORNER NRVERT-NRVERT +1 


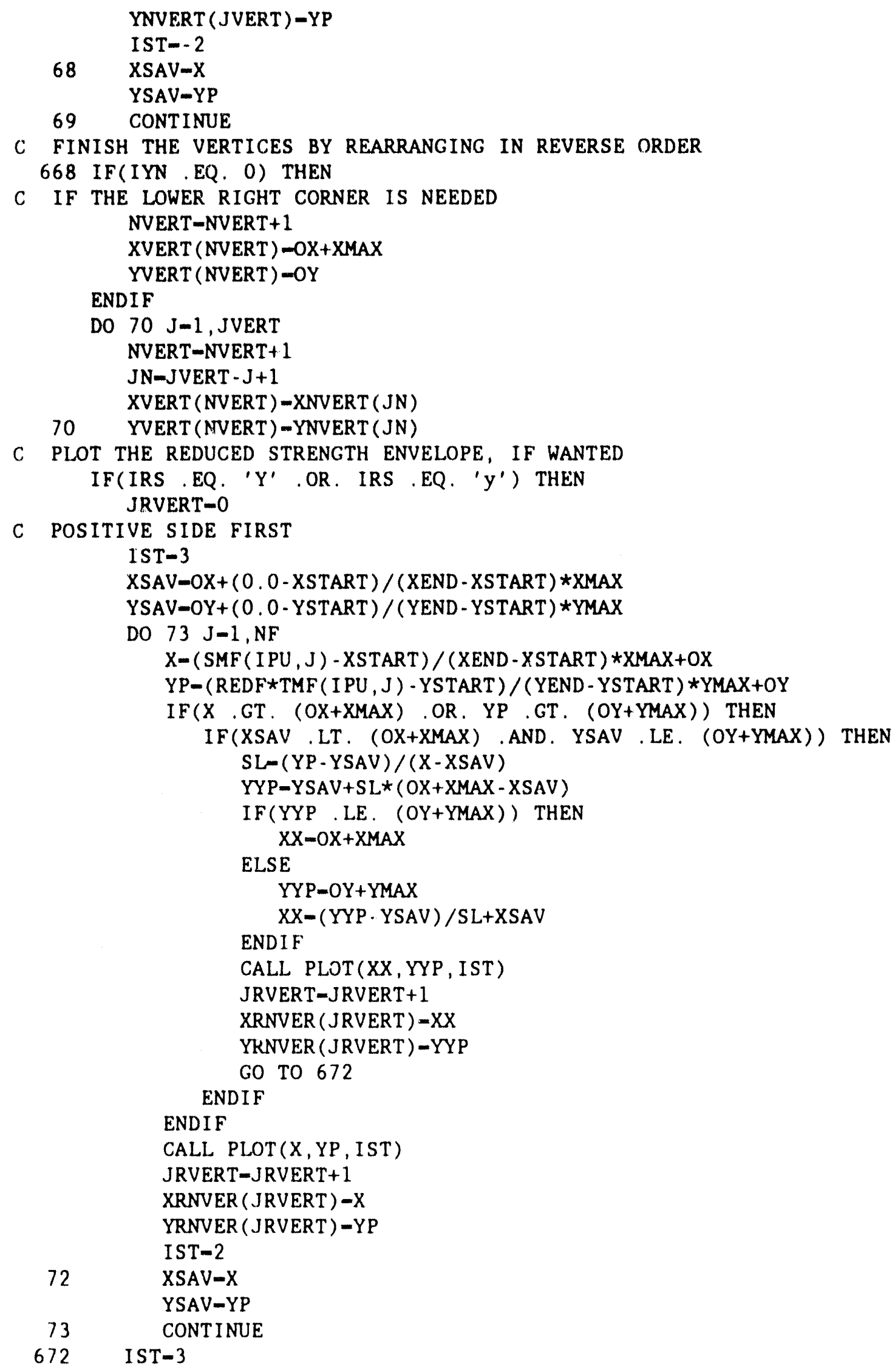


C FILL THE POSITIVE SIDE OF THE REDUCED STRENGTH FAILURE ZONE

DO $74 \mathrm{~J}-1$, JRVERT

NRVERT-NRVERT +1

JN-JRVERT - J +1

XRVERT (NRVERT) -XRNVER (JN)

74 YRVERT (NRVERT) -YRNVER (JN)

CALL NEWPEN(1)

CALL STFILL(6)

CALL FILL(XRVERT, YRVERT, NRVERT)

IF(JDEV .EQ. 62) CALL NEWPEN (2)

IF (JDEV . EQ. 64) CALL NEWPEN(4)

C PLOT THE NEGATIVE SIDE OF THE REDUCED STRENGTH FAILURE ENVELOPE NRVERT -0

$X S A V=0 X+(0.0-X S T A R T) /(X E N D-X S T A R T) * X M A X$

YSAV $-0 Y+(0.0-Y S T A R T) /($ YEND - YSTART $) *$ YMAX

DO $78 \mathrm{~J}=1, \mathrm{NF}$

$X-($ SMF (IPU , J) $-X S T A R T) /(X E N D-X S T A R T) * X M A X+O X$

$Y P-(-R E D F * T M F(I P U, J)-Y S T A R T) /(Y E N D-Y S T A R T) * Y M A X+O Y$

IF $(X$. GT . (OX +XMAX) .OR. YP . LT . OY) THEN

IF (XSAV , LT . (OX+XMAX) .AND. YSAV , GE, OY) THEN

$S L-(Y P-Y S A V) /(X-X S A V)$

$Y Y P=Y S A V+S L *(O X+X M A X-X S A V)$

IF (YYP . LE. (OY+YMAX)) THEN $X X-O X+X M A X$

ELSE

$Y Y P=O Y+Y M A X$

$X X=(Y Y P-Y S A V) / S L+X S A V$

ENDIF

CALL PLOT (XX, YYP, IST)

NRVERT-NRVERT +1

XRVERT (NRVERT) $-X X$

YRVERT (NRVERT) - YYP

GO TO 677

ENDIF

ENDIF

CALL PLOT (X, YP, IST)

NRVERT-NRVERT +1

XRVERT (NRVERT) $=X$

YRVERT $($ NRVERT) $=$ YP

77 XSAV $-\mathrm{X}$

$X S A V-X$

78 CONTINUE

677 CONTINUE

ENDIF

C FILL UNSTABLE AREA

CALL $\operatorname{COLOR}(14$, IERR $)$

CALL NEWPEN (1)

CALL STFILL( 3 )

CALL FILL(XVERT, YVERT, NVERT)

IF (JDEV .EQ. 62) CALL NEWPEN (2)

IF (JDEV . EO. 64) CALL NEWPEN(4) 
C FILL THE NEGATIVE SIDE OF THE REDUCED STRENGTH FAILURE ZONE IF (IRS .EQ. ' $Y$ ' ,OR. IRS .EQ. ' $y$ ') THEN IF (IYN .EQ. 1) THEN NRVERT-NRVERT +1 XRVERT (NRVERT) $-O X+X M A X$ YRVERT (NRVERT) -OY

ENDIF

DO $79 \mathrm{~J}-1$, JVERT

NRVERT-NRVERT +1

JN-JVERT $-\mathrm{J}+1$

79

XRVERT (NRVERT) -XNVERT (JN)

YRVERT (NRVERT)-YNVERT (JN)

CALL COLOR(12, IERR)

CALL NEWPEN (1)

CALL STFILL(6)

CALL FILL(XRVERT, YRVERT, NRVERT)

IF(JDEV .EQ. 62) CALL NEWPEN(2)

ENDIF

IF(JDEV .EQ. 64) CALL NEWPEN(4)

C WRITE LABEL ON PLOT

CALL COLOR (14, IERR)

CALL SYMBOL $(O X+0.2$, YMAX+0.2+OY, 0.2222 , DEFZONE , 0.0,40)

CALL PLOT $(0.0,0.0,999)$

IF(IPL .EQ. 'Y' .OR. IPL .EQ. ' $y$ ') GO TO 80

PRINT*,' DO YOU WANT A HARDCOPY OF THIS PLOT:

$\operatorname{READ}(*, 100)$ IPL

IF (IPL .EQ. ' $Y$ ' .OR, IPL .EQ. ' $y$ ') THEN

PRINT*,' PLOTTING IN PROGRESS '

IDEV-IOP

JDEV-MP

ENDIF

GO TO 60

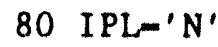

PRINT*,' DO YOU WANT TO REPLOT THE DATA? '

$\operatorname{READ}(*, 100)$ IRP

IF(IRP .EQ. 'Y' ,OR. IRP .EQ. ' $y$ ') GO TO 50

85 PRINT*, 'DO YOU WANT A FAILURE TABLE: '

READ 100, ITABLE

IF(ITABLE. EQ. ' $N$ ') GO TO 90

IF(IPU .EQ. 1) PRINT*,' UNITS ARE PSI'

IF(IPU .EQ. 2) PRINT*,' UNITS ARE MPA'

DO $87 \mathrm{~J}=1$, KEND

DO $86 \mathrm{~K}-2, \mathrm{NF}$

IF $(\operatorname{SMF}(I P U, K)$,GT. SMEAN $(J))$ THEN

1

SLOPE- (TMF (IPU, K) -TMF (IPU, K- I))/(SMF (IPU, K)

$-\operatorname{SMF}(I P U, K-1))$

$\operatorname{TAUF}(J)-\operatorname{TMF}(I \mathrm{PU}, K-1)+\operatorname{SLOPE} *(\operatorname{SMEAN}(J)-\operatorname{SMF}(I P U, K-1))$

$\operatorname{TAUFR}(J)-\operatorname{TAUF}(J) \star R E D F$ ENDIF

86 CONTINUE

87 CONTINUE

PRINT 200

$\operatorname{WRITE}(10,200)$ 
DO $88 \mathrm{~J}-1$, KEND

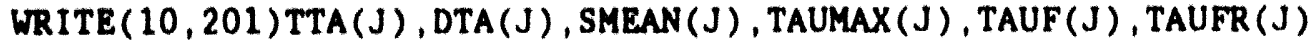

$88 \operatorname{PRINT} 201, \operatorname{TTA}(J), \operatorname{DTA}(J), \operatorname{SMEAN}(J), \operatorname{TAUMAX}(J), \operatorname{TAUF}(\mathrm{J}), \operatorname{TAUFR}(J)$

90 CONTINUE

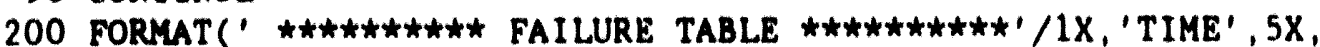

1'DEPTH', 3X, 'MEAN STRESS', 3X, 'MAX SHEAR', 3X, 'FAIL STRESS', 3X, 2'RED. FAIL STRESS')

201 FORMAT (1X, F5 .1, 2X, F8, 1, 4X, F8, 1, 4X, F8, 1, 6X, F8, 1, 9X, F8, 1)

RETURN

END 


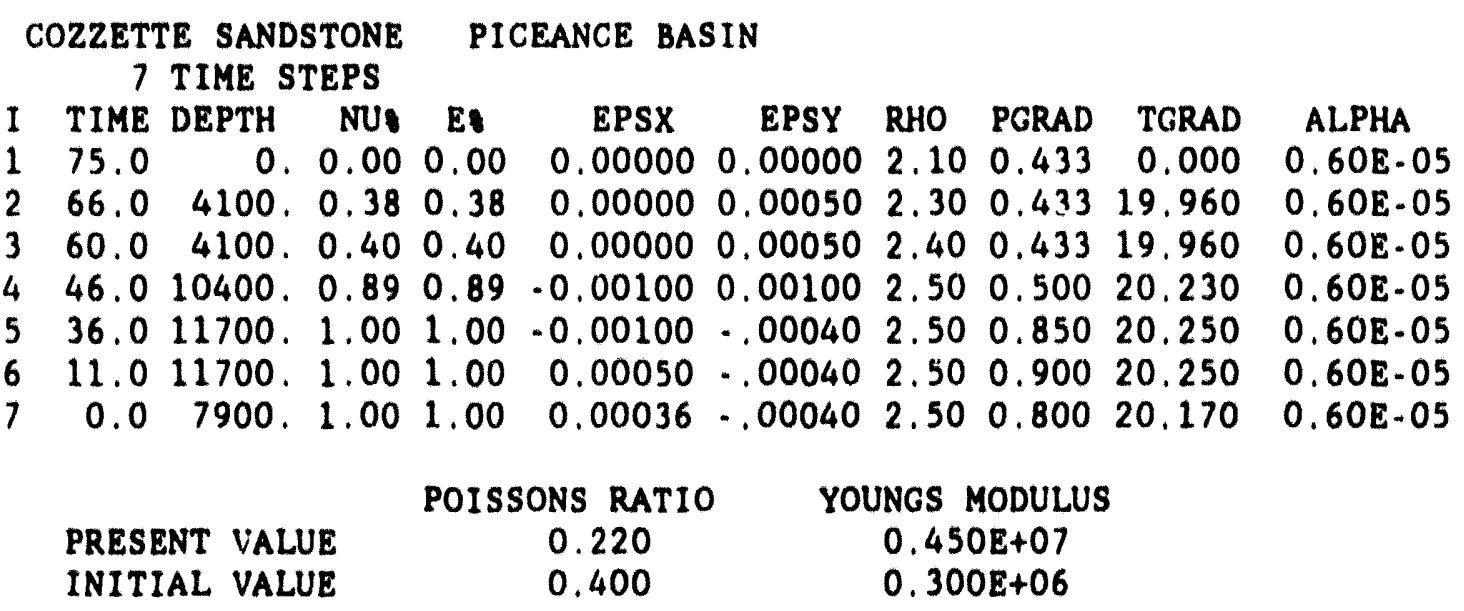

RELAXATION TIME- $\quad 1000.0000$ MYRS

EACH TIME STEP SUBDIVIDED INTO 4 INTEGRATION STEPS

TIME IN MILLIONS OF YEARS BEFORE PRESENT -66.00
EPSX- $0.0000 E+00 \quad$ EPSY- $0.5000 \mathrm{E} \cdot 03$
POISPC $-0.38000000 \quad$ EPC $=0.38000000$

INPUT PARAMETERS

RHO- $2.3000 \mathrm{GM} / \mathrm{CM} * * 3$

TGRAD- 19.9600 DEG F/100 FT

ALPHA- $0.6000 \mathrm{E}-05$ 1/DEG F

PGRAD $=0.43300$ PSI $/$ FT

D- $1025.00 \mathrm{sV}=1020.80 \mathrm{~s} 1-\quad 371.43 \mathrm{~s} 2=100.48$

S3X- 28.73 S3Y- 73.58 SHMIN- 944.46 SHMAX- 989.31

PO- $\quad 443.83$ TEMP- 70.5

EFF SV= $\quad 576.97$ EFF SHMIN- 500.63 EFF SHMAX- $\quad 545.49$

D- 2050.00 SV- 2041.59 S1- 717.43 S2- 276.19

S3X- $\quad 77.44$ S3Y- 203.80 SHMIN- 1958.70 SHMAX- 2085.06

PO- $\quad 887.65$ TEMP- $\quad 90.9$

EFF SV- 1153.94 EFF SHMIN- 1071.05 EFF SHMAX- 1197.41

D- $\quad 3075.00 \mathrm{SV}=3062.39 \mathrm{~S} 1-\quad 1039.43 \mathrm{~S} 2-\quad 522.95$

S3X- $\quad 143.59$ S3Y- 388.93 SHMIN- 3037.44 SHMAX- 3282.78

PO- 1331.47 TEMP- 111.4

EFF SV- 1730.92 EFF SIMIN- 1705.97 EFF SHMAX- 1951.31

D- $4100.00 \mathrm{SV}=4083.19 \mathrm{~S} 1-1338.77 \mathrm{~S} 2=836.89$

S3X- $\quad 224.80$ S3Y- $\quad 627.40$ SHMIN- 4175.76 SHMAX- 4578.37

PO- $\quad 1775.30$ TEMP- 131.8

EFF SV- 2307.89 EFF SHMIN- 2400.46 EFF SHMAX- 2803.07

TIME IN MILLIONS OF YEATS BEFORE PRESENT $=60.00$

EPSX- $0.0000 E+00$ EPSY $-0.5000 E-03$

POISPC $-0.40000001 \quad$ EPC -0.40000001 
INPUT PARAMETERS

RHO- $2.4000 \mathrm{GM} / \mathrm{CM} * * 3$

TGRAD- 19.9600 DEG F/100 FT

ALPHA- $\quad 0.6000 \mathrm{E}-05$ 1/DEG F

PGRAD -0.43300 PSI/FT

D- 4100.00 SV- 4260.72 S1- 1362.22 S2- 835.64

S3X- $\quad 313.19$ S3Y $=893.77$ SHMIN- 4286.35 SHMAX- 4866.92

PO- 1775.30 TEMP- 131.8

EFF SV- 2485.42 EFF SHMIN- 2511.05 EFF SHMAX- 3091.62

D- $\quad 4100.00 \mathrm{sV}-4260.72 \mathrm{~s} 1-\quad 1385.60 \mathrm{~s} 2-\quad 834.38$

S3X- $\quad 402.20$ S3Y- 1162.43 SHMIN- 4397.48 SHMAX- 5157.71

PO- 1775.30 TEMP- 131.8

EFF SV- 2485.42 EFF SHMIN- 2622.18 EFF SHMAX- 3382.41

D- 4100.00 SV- 4260.72 S1- 1408.93 s2- 833.13

S3X- $\quad 491.80$ S3Y- 1433.38 SHMIN- 4509.17 SHMAX- 5450.74

PO- $\quad 1775.30$ TEMP- 131.8

EFF SV- 2485.42 EFF SHMIN- 2733.87 EFF SHMAX- 3675.44

D- $4100.00 \mathrm{SV}=\quad 4260.72 \mathrm{~S} 1-\quad 1432.20 \mathrm{S2}-\quad 831.89$

S3X- $\quad 582.00$ S3Y- 1706.61 SHMIN- 4621.39 SHMAX- 5746.00 PO- 1775.30 TEMP- 131.8

EFF SV- 2485.42 EFF SHMIN- 2846.09 EFF SHMAX- 3970.70

TIME IN MILLIONS OF YEARS BEFORE PRESENT -46.00

EPSX - $-0.1000 \mathrm{E}-02$ EPSY - 0.1000E-02

POISPC $-0.88999999 \quad$ EPC -0.88999999

INPUT PARAMETERS

RHO- $2.5000 \mathrm{GM} / \mathrm{CM} * \star 3$

TGRAD- 20.2300 DEG F/100 FT

ALPHA- $\quad 0.6000 E-05$ 1/DEG F

PGRAD- 0.50000 PSI/FT

D- $\quad 5675.00 \mathrm{SV}-\quad 6143.19 \mathrm{S1}-1851.31 \mathrm{S2}-\quad 1459.20$

S3X- $\quad 157.17$ S3Y- 2123.45 SHMIN- 6020.01. SHMAX- 7986.29

PO- 2552.33 TEMP- 164.0

EFF SV- $\quad 3590.86$ EFF SHMIN- 3467.68 EFF SHMAX- 5433.96

D- 7250.00 SV- 7848.12 S1- 2231.23 S2- 2205.11

S3X- $\quad-371.58$ S3Y- 2644.23 SHMIN- 7446.89 SHMAX- 10462.70

PO- 3382.12 TEMP- 196.1

EFF SV- 4466.00 EFF SHMIN- 4064.76 EFF SHMAX- 7080.57

D- $\quad 8825.00 \mathrm{SV}=9553.06 \mathrm{~s} 1-\quad 2574.60 \mathrm{~s} 2-\quad 3061.85$

S3X- .1007 .18 S3Y- 3271.89 SHMIN- 8893.96 SHMAX- 13173.03

PO- 4264.68 TEMP. 228.3

EFF SV- 5288.38 EFF SHMIN- 4629.28 EFF SHMAX- 8908.35

D- $10400.00 \mathrm{SV}-11258.00 \mathrm{S1}-2883.79 \mathrm{~s} 2 \mathrm{-} \quad 4022.38$

S3X- -1752.69 S3Y- 4009.49 SHMIN= 10353.48 SHMAX- 16115.66

PO- $\quad 5200.00$ TEMP- 260.4

EFF SU- $\quad 6058.00$ EFF SHMIN- 5153.48 EFF SHMAX- 10915.66 
TIME IN MILLIONS OF YEARS BEFORE PRESENT -36.00

EPSX- $-0.1000 \mathrm{E}-02$
EPISPC- $1.00000000 \quad$ EPC -1.00000000

INPUT PARAMETERS

RHO- $2.5000 \mathrm{GM} / \mathrm{CM} \star \star 3$

TGRAD- 20.2500 DEG F/100 FT

ALPHA- $\quad 0.6000 \mathrm{E}-0.5$ 1/DEG F

PGRAD 0.85000 PSI/FT

D- 10725.00 SV- 11609.81 s1- 2631.34 S2- 4225.80

S $3 X-\quad-2929.92$ S3Y- 3303.86 SHMIN- 10228.16 SHMAX- 16461.94

PO- 6300.94 TEMP- 267.0

EFF SV- 5308.87 EFF SHMIN- 3927.22 EFF SHMAX- 10161.00

D- $11050.00 \mathrm{sV}-11961.62 \mathrm{s1}-2384.48 \mathrm{~s} 2-4433.32$

S3X- -4131.96 S3Y- 2587.25 SHMIN- 10144.59 SHMAX- 16863.80

PO- 7458.75 TEMP- 273.7

EFF SV- 4502.87 EFF SHMIN- 2685.84 EFF SHMAX- 9405.05

D- 11375.00 sV- 12313.44 s1- 2143.12 s2= 4644.86

S3X- -5358.52 S3Y- 1859.98 SHMIN- 10102.90 SHMAX- 17321.39

PO- 8673.44 TEMP- 280.3

EFF SV- 3640.00 EFF SHMIN- 1429.46 EFF SHMAX- 8647.96

D- 11700.00 SV- 12665.25 S1- 1907.14 S2- 4860.37

S3X- -6609.31 S3Y- 1122.36 SHMIN- 10103.19 SHMAX- 17834.86

PO- 9945.00 TEMP- 286.9

EFF SV- 2120.25 EFF SHMIN- 158.19 EFF SHMAX- 7889.86

TIME IN MILLIONS OF YEARS BEFORE PRESENT -11.00

EPSX- $0.5000 \mathrm{E}-03$ EPSY- $-0.4000 \mathrm{E}-03$

POISPC- $1.00000000 \quad$ EPC -1.00000000

INPUT PARAMETERS

RHO- $2.5000 \mathrm{GM} / \mathrm{CM} \star * 3$

TGRAD- 20.2500 DEG F/100 FT

ALPHA- $0.6000 E-05$ 1/DEG F

PGRAD- 0.90000 PSI $/$ FT

D- $11700.00 \mathrm{SV}=12665.25 \mathrm{~S} 1-1870.62 \mathrm{~S} 2-4830.08$

S3X- -6066.65 S3Y- 757.66 SHMIN- 10725.31 SHMAX- 17549.62

PO- 10091.25 TEMP- 286.9

EFF SV- 2574.00 EFF SHMIN- 634.06 EFF SHMAX- 7458.37

D- $11700.00 \mathrm{SV}-12665.25 \mathrm{~S} 1-1833.43 \mathrm{~S} 2=4799.99$

S3X- -5529.89 S3Y- 397.76 SHMIN- 11341.02 SHMAX- 17268.68

PO- 10237.50 TEMP- 286.9

EFF SV- 2427.75 EFF SHMIN- 1103.52 EFF SHMAX- 7031.18

D- 11700.00 SV- 12665.25 S1- 1795.55 s2- 4770.08

S3X- -4998.98 S3Y- 42.61 SHMIN- 11950.40 SHMAX- 16992.00

PO- 10383.75 TEMP- 286.9

EFF SV- 2281.50 EFF SHMIN- 1566.65 EFF SHMAX- 6608.25

D- 11700.00 SV- 12665.25 S1- 1757.00 S2- 4740.36

S3X- .4473 .85 S3Y- -307.86 SHMIN- 12553.51 SHMAX- 16719.51

PO- 10530.00 TEMP- 286.9

EFF SV- 2135.25 EFF SHMIN- 2023.51 EFF SHMAX- 6189.51 


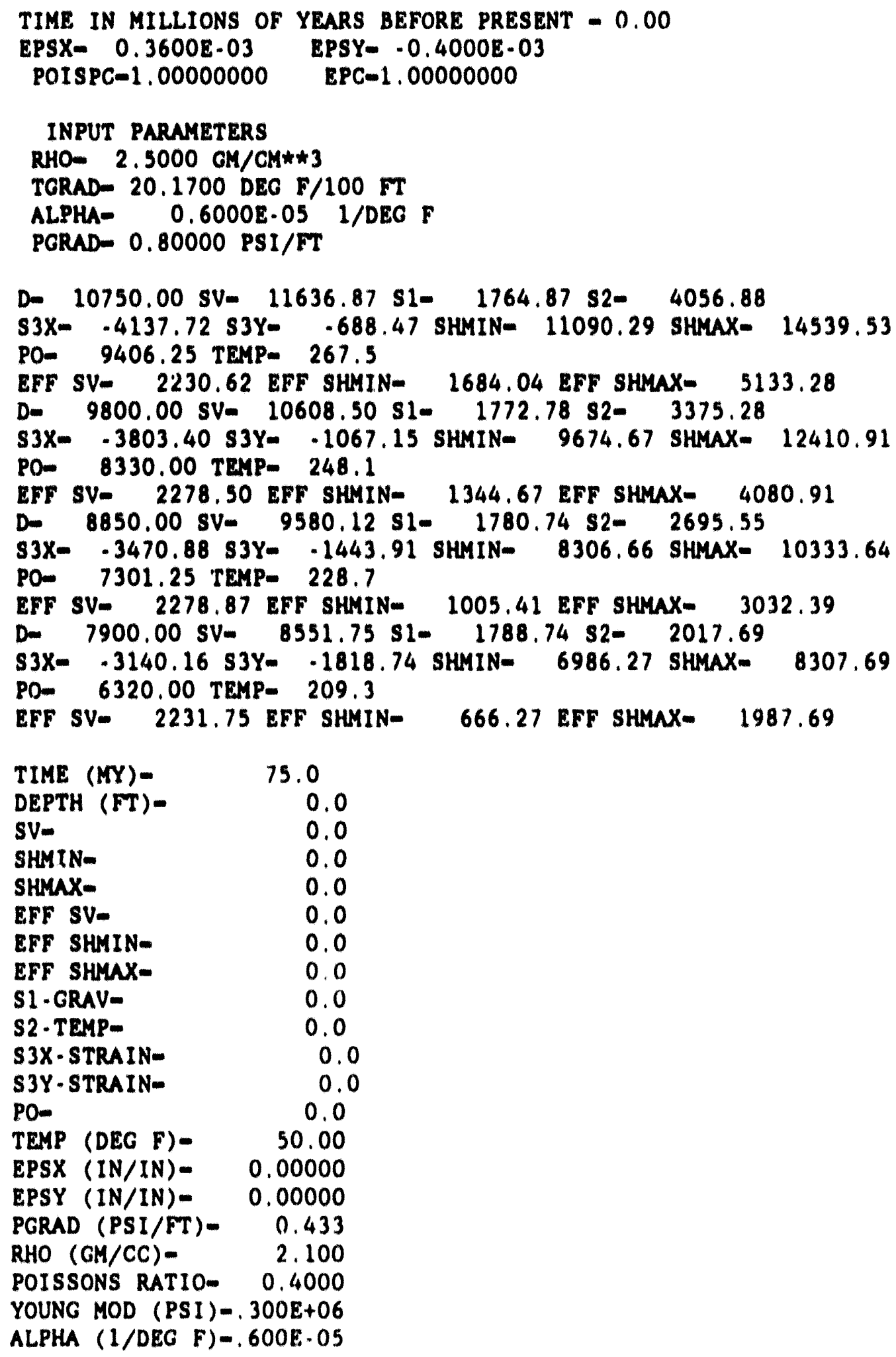




\begin{tabular}{|c|c|c|c|c|}
\hline $\begin{array}{l}\text { TIME (MY)- } \\
\text { DEPTH (FT)- } \\
\text { SV- } \\
\text { SHMIN- } \\
\text { SHMAX- } \\
\text { EFF SV- } \\
\text { EFF SHMIN- } \\
\text { EFF SHMAX- } \\
\text { S1-CRAV- } \\
\text { S2-TEMP- } \\
\text { S3X-STRAIN- } \\
\text { S3Y-STRAIN- } \\
\text { PO- } \\
\text { TEMP (DEG F)- } \\
\text { EPSX (IN/IN)- } \\
\text { EPSY (IN/IN)- } \\
\text { PGRAD (PSI/FT)- } \\
\text { RHO (GM/CC)- } \\
\text { POISSONS RATIO- } \\
\text { YOUNG MOD (PSI)- } \\
\text { ALPHA (1/DEG F)- }\end{array}$ & $\begin{array}{c}72.7 \\
1025.0 \\
1020.8 \\
944.5 \\
989.3 \\
577.0 \\
500.6 \\
545.5 \\
371.4 \\
100.5 \\
28.7 \\
73.6 \\
443.8 \\
70.46 \\
0.00000 \\
0.00050 \\
0.433 \\
2.300 \\
0.4000 \\
300 \mathrm{E}+06 \\
.600 \mathrm{E} .05\end{array}$ & $\begin{array}{l}70.5 \\
2050.0 \\
2041.6 \\
1958.7 \\
2085.1 \\
1153.9 \\
1071.1 \\
1197.4 \\
717.4 \\
276.2 \\
77.4 \\
203.8 \\
887.7 \\
90.92\end{array}$ & $\begin{array}{c}68.2 \\
3075.0 \\
3062.4 \\
3037.4 \\
3282.8 \\
1730.9 \\
1706.0 \\
1951.3 \\
1039.4 \\
522.9 \\
143.6 \\
388.9 \\
1331.5 \\
111.38\end{array}$ & $\begin{array}{l}66.0 \\
4100.0 \\
4083.2 \\
4175.8 \\
4578.4 \\
2307.9 \\
2400.5 \\
2803.1 \\
1338.8 \\
836.9 \\
224.8 \\
627.4 \\
1775.3 \\
131.84\end{array}$ \\
\hline $\begin{array}{l}\text { TIME (MY)- } \\
\text { DEPTH (FT)- } \\
\text { SV- } \\
\text { SHMIN- } \\
\text { SHMAX- } \\
\text { EFF SV- } \\
\text { EFF SHMIN- } \\
\text { EFF SHMAX- } \\
\text { SI-GRAV- } \\
\text { S2-TEMP- } \\
\text { S3X-STRAIN- } \\
\text { S3Y-STRAIN- } \\
\text { PO- } \\
\text { TEMP (DEG F)- } \\
\text { EPSX (IN/IN)- } \\
\text { EPSY (IN/IN)- } \\
\text { PGRAD (PSI/FT)- } \\
\text { RHO (GM/CC)- } \\
\text { POISSONS RATIO- } \\
\text { YOUNG MOD (PSI)- } \\
\text { ALPHA (I/DEG F)- }\end{array}$ & $\begin{array}{c}64.5 \\
4100.0 \\
4260.7 \\
4286.3 \\
4866.9 \\
2485.4 \\
2511.0 \\
3091.6 \\
1362.2 \\
835.6 \\
313.2 \\
893.8 \\
1775.3 \\
131.84 \\
0.00000 \\
0.00050 \\
0.433 \\
2.400 \\
0.3316 \\
190 \mathrm{E}+07 \\
600 \mathrm{E} \cdot 05\end{array}$ & $\begin{array}{c}63.0 \\
4100.0 \\
4260.7 \\
4397.5 \\
5157.7 \\
2485.4 \\
2622.2 \\
3382.4 \\
1385.6 \\
834.4 \\
402.2 \\
1162.4 \\
1775.3 \\
131.84\end{array}$ & $\begin{array}{l}61.5 \\
4100.0 \\
4260.7 \\
4509.2 \\
5450.7 \\
2485.4 \\
2733.9 \\
3675.4 \\
1408.9 \\
833.1 \\
491.8 \\
1433.4 \\
1775.3 \\
131.84\end{array}$ & $\begin{array}{l}60.0 \\
4100.0 \\
4260.7 \\
4621.4 \\
5746.0 \\
2485.4 \\
2846.1 \\
3970.7 \\
1432.2 \\
831.9 \\
582.0 \\
1706.6 \\
1775.3 \\
131.84\end{array}$ \\
\hline $\begin{array}{l}\text { TIME (MY)- } \\
\text { DEPTH (FT)- } \\
\text { SV- } \\
\text { SHMIN- } \\
\text { SHMAX- } \\
\text { EFF SV- } \\
\text { EFF SHMIN- } \\
\text { EFF SHMAX- }\end{array}$ & $\begin{array}{l}56.5 \\
5675.0 \\
6143.2 \\
6020.0 \\
1986.3 \\
3590.9 \\
3467.7 \\
5434.0\end{array}$ & $\begin{array}{l}53.0 \\
7250.0 \\
7848.1 \\
7446.9 \\
10462.1 \\
4466.0 \\
4064.8 \\
7080.6\end{array}$ & $\begin{array}{r}49.5 \\
8825.0 \\
9553.1 \\
8894.0 \\
13173.0 \\
5288.4 \\
4629.3 \\
8908.3\end{array}$ & $\begin{array}{r}46.0 \\
10400.0 \\
11258.0 \\
10353.5 \\
16115.7 \\
6058.0 \\
5153.5 \\
10915.7\end{array}$ \\
\hline
\end{tabular}




\begin{tabular}{|c|c|c|c|c|}
\hline $\begin{array}{l}\text { S1-GRAV- } \\
\text { S2-TEMP- } \\
\text { S3X-STRAIN- } \\
\text { S3Y-STRAIN- } \\
\text { PO- } \\
\text { TEMP (DEG F)- } \\
\text { EPSX (IN/IN)- } \\
\text { EPSY (IN/IN)- } \\
\text { PGRAD (PSI/FT)- } \\
\text { RHO (GM/CC)- } \\
\text { POISSONS RATIO- } \\
\text { YOUNC MOD (PSI)- } \\
\text { ALPHA (1/DEG F)- }\end{array}$ & $\begin{array}{r}1851.3 \\
1459.2 \\
157.2 \\
2123.5 \\
2552.3 \\
163.98 \\
0.00100 \\
0.00100 \\
0.500 \\
2.500 \\
0.3280 \\
.1988+07 \\
.6008 .05\end{array}$ & $\begin{array}{c}2231.2 \\
2205.1 \\
.371 .6 \\
2644.2 \\
3382.1 \\
196.11\end{array}$ & $\begin{array}{r}2574.6 \\
3061.9 \\
6.1001 .2 \\
2 \quad 3271.9 \\
4264.7 \\
228.25\end{array}$ & $\begin{array}{r}2883.8 \\
4022.4 \\
2.1752 .7 \\
94009.5 \\
5200.0 \\
260.39\end{array}$ \\
\hline $\begin{array}{l}\text { TIME (MY)- } \\
\text { DEPTH (FT)- } \\
\text { SV- } \\
\text { SHMIN- } \\
\text { SHMAX- } \\
\text { EFF SV- } \\
\text { EFF SHMIN- } \\
\text { EFF SHMA- } \\
\text { S1. GRAV- } \\
\text { S2-TEMP- } \\
\text { S3X-STRAIN- } \\
\text { S3Y-STRAIN- } \\
\text { PO- } \\
\text { TEMP (DEC F)- } \\
\text { EPSX (IN/IN)- } \\
\text { EPSY (IN/IN)- } \\
\text { PGRAD (PSI/FT)- } \\
\text { RHO (GM/CC)- } \\
\text { POISSONS RATIO- } \\
\text { YOUNG MOD (PSI)- } \\
\text { ALPHA (I/DEG F)- }\end{array}$ & $\begin{array}{r}43.5 \\
10725.0 \\
11609.8 \\
10228.2 \\
16461.9 \\
5308.9 \\
3921.2 \\
10161.0 \\
2631.3 \\
4225.8 \\
.2929 .9 \\
3303.9 \\
6300.9 \\
261.03 \\
.0 .00100 \\
0.00040 \\
0.850 \\
2.500 \\
0.2398 \\
.4048+07 \\
.6005 .05\end{array}$ & $\begin{array}{c}41.0 \\
11050.0 \\
11961.6 \\
10144.6 \\
16863.8 \\
4502.9 \\
2685.8 \\
9405.1 \\
2384.5 \\
4433.3 \\
9.4132 .0 \\
92587.3 \\
1458.7 \\
213.66\end{array}$ & $\begin{array}{c}38.5 \\
11375.0 \\
12313.4 \\
10102.9 \\
17321.4 \\
3640.0 \\
1429.5 \\
8648.0 \\
2143.1 \\
4644.9 \\
.5358 .5 \\
1860.0 \\
8673.4 \\
280.29\end{array}$ & $\begin{array}{c}36.0 \\
11700.0 \\
12665.2 \\
10103.2 \\
17834.9 \\
2720.2 \\
158.2 \\
7889.9 \\
1907.1 \\
4860.4 \\
5.6609 .3 \\
1122.4 \\
9945.0 \\
286.92\end{array}$ \\
\hline $\begin{array}{l}\text { TIME (MY)- } \\
\text { DEPTH (FT)- } \\
\text { SV- } \\
\text { SHMIN- } \\
\text { SHMAX- } \\
\text { EFF SV- } \\
\text { EFF SHMIN- } \\
\text { EFF SHMAX- } \\
\text { SI-GRAV- } \\
\text { S2-TEMP- } \\
\text { S3X-STRAIN- } \\
\text { S3Y-STRAIN- } \\
\text { PO- } \\
\text { TEMP (DEG F)- } \\
\text { EPSX (IN/IN)- } \\
\text { EPSY (IN/IN)- } \\
\text { PGRAD (PSI/FT)- }\end{array}$ & $\begin{array}{c}29.1 \\
11700.0 \\
12665.2 \\
10725.3 \\
17549.6 \\
2574.0 \\
634.1 \\
7458.4 \\
1870.6 \\
4830.1 \\
.6066 .6 \\
757.7 \\
10091.2 \\
286.92 \\
0.00050 \\
0.00040 \\
0.900\end{array}$ & $\begin{array}{c}23.5 \\
11700.0 \\
12665.2 \\
11341.0 \\
17268.7 \\
2427.7 \\
1103.5 \\
7031.2 \\
1833.4 \\
4800.0 \\
.5529 .9 \\
397.8 \\
10237.5 \\
286.92\end{array}$ & $\begin{array}{c}11.2 \\
11700.01 \\
12665.2 \\
11950.4 \\
16992.0 \\
2281.5 \\
1566.7 \\
6608.2 \\
1795.6 \\
4770.1 \\
.4999 .0 \\
42.6 \\
10383.71 \\
286.92\end{array}$ & $\begin{array}{c}11.0 \\
11700.0 \\
12665.2 \\
12553.5 \\
16719.5 \\
2135.2 \\
2023.5 \\
6189.5 \\
1757.0 \\
4740.4 \\
.4473 .9 \\
=307.9 \\
10530.0 \\
286.92\end{array}$ \\
\hline
\end{tabular}




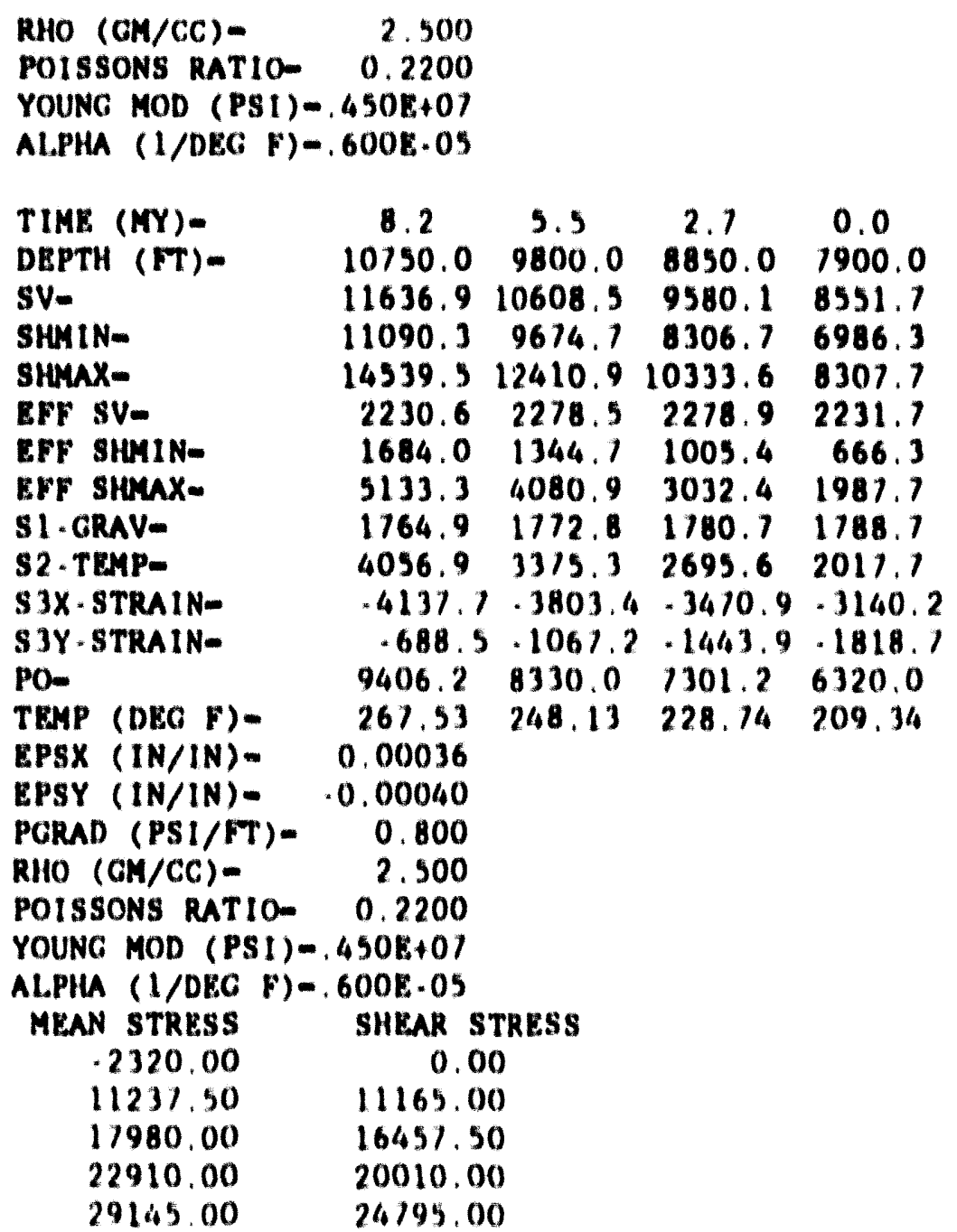

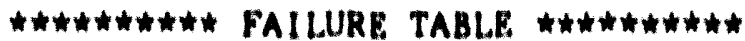

TIME DEPTH MEAN STRESS MAX SIIEAR FAII. STRESS RED. FAII. STRESS

$\begin{array}{rrrr}15.0 & 0.0 & 0.0 & 0.0 \\ 72.1 & 1025.0 & 538.8 & 38.2 \\ 10.5 & 2050.0 & 1134.2 & 63.2 \\ 68.2 & 3075.0 & 1828.6 & 122.7 \\ 66.0 & 4100.0 & 2555.5 & 241.6 \\ 64.5 & 4100.0 & 278 C .5 & 303.1 \\ 63.0 & 4100.0 & 2933.9 & 448.5 \\ 61.5 & 4100.0 & 3080.4 & 595.0 \\ 60.0 & 4100.0 & 3228.1 & 742.6 \\ 56.5 & 5675.0 & 4450.8 & 983.1 \\ 53.0 & 1250.0 & 5572.1 & 1501.9 \\ 49.5 & 8825.0 & 6768.8 & 2139.5 \\ 46.0 & 10400.0 & 8034.6 & 2881.1 \\ 43.5 & 10725.0 & 7044.1 & .3116 .9 \\ 41.0 & 11050.0 & 6045.4 & .3359 .6 \\ 38.5 & 11375.0 & 5038.1 & .3609 .2\end{array}$

$\begin{array}{ll}2421.9 & 1456.7 \\ 2841.4 & 1704.8 \\ 3298.4 & 1919.0 \\ 3831.3 & 2298.8 \\ 4389.1 & 2633.5 \\ 4561.9 & 2740.8 \\ 4679.5 & 2801.1 \\ 4792.0 & 2875.2 \\ 4905.3 & 2943.2 \\ 5843.1 & 3506.2 \\ 6704.6 & 4022.8 \\ 1622.6 & 4573.5 \\ 8594.0 & 5156.4 \\ 7833.9 & 4700.3 \\ 7061.4 & 4240.5 \\ 6294.8 & 3776.9\end{array}$




$\begin{array}{rrrrrr}36.0 & 11700.0 & 4024.0 & .3865 .8 & 5516.1 & 3309.7 \\ 29.7 & 11700.0 & 4046.2 & 3412.2 & 5533.1 & 3319.9 \\ 23.5 & 11700.0 & 4067.4 & 2963.8 & 5549.4 & 3329.6 \\ 17.2 & 11700.0 & 4087.5 & 2520.8 & 5564.8 & 3338.9 \\ 11.0 & 11700.0 & 4106.5 & 2083.0 & 5579.4 & 3347.6 \\ 8.2 & 10750.0 & 3408.7 & 1724.6 & 5043.9 & 3026.3 \\ 3.5 & 9800.0 & 2712.8 & 1368.1 & 4509.8 & 2705.9 \\ 2.7 & 8850.0 & 2018.9 & 1013.5 & 3977.3 & 2386.4 \\ 0.0 & 1900.0 & 1449.0 & .782 .7 & 3539.9 & 2124.0\end{array}$




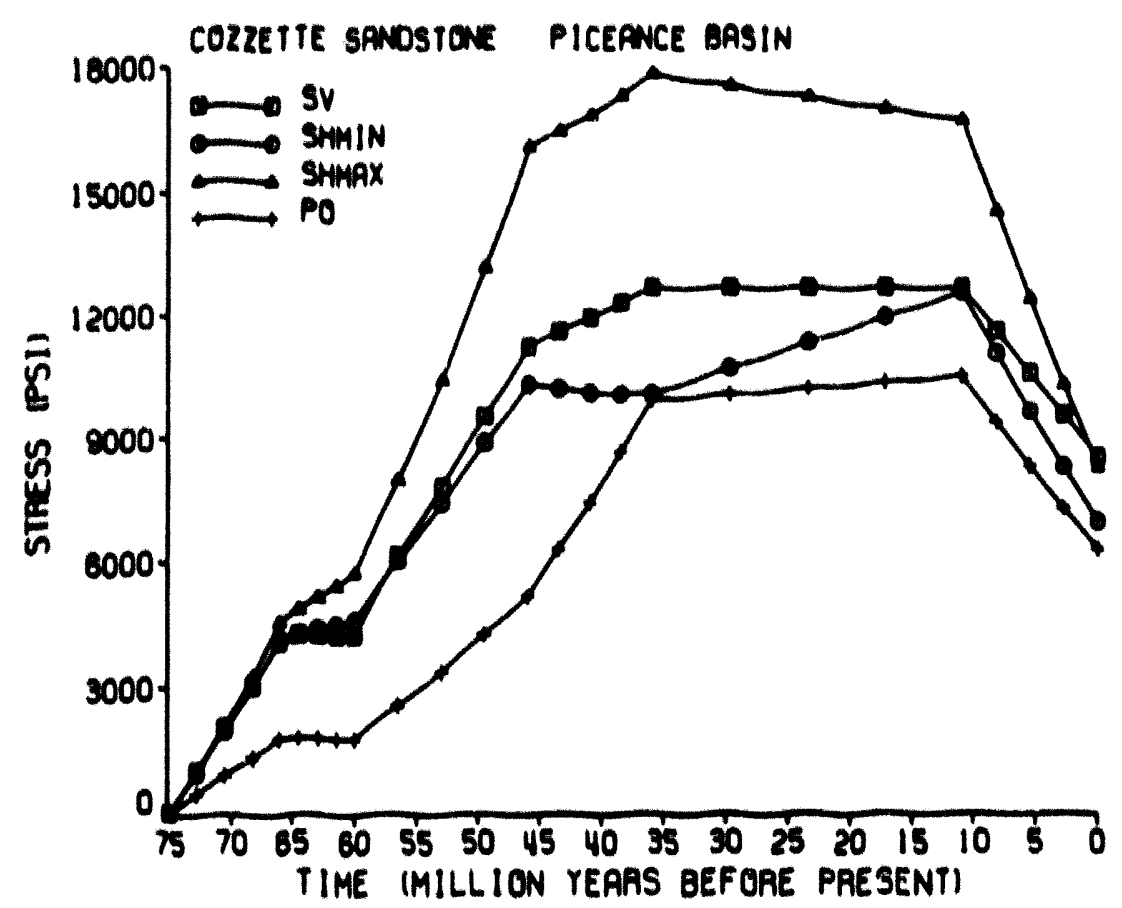

Figure F1. Calculated magnitudes, through time, for the vertical stress (SV), minimum and maximum horizontal stresses (SHMIN and SHMAX), and the pore pressure (PO) for the Cozzotte Sandstone at the MWX site.

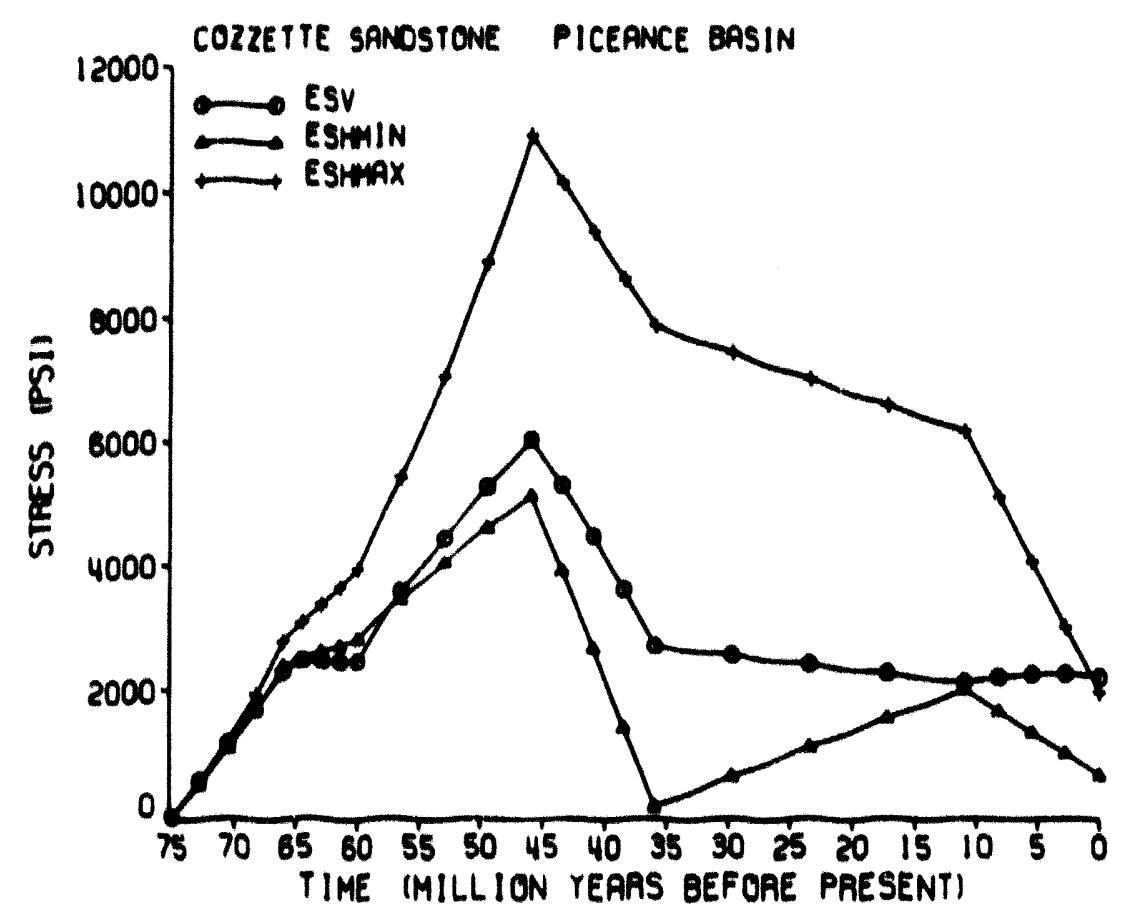

Figure F2. Calculated magnitudes, through time, for the vertical effective stress (FSV), and minimum and maximum effective horizontal stresses (ESHMIN nad ESHMAX). 


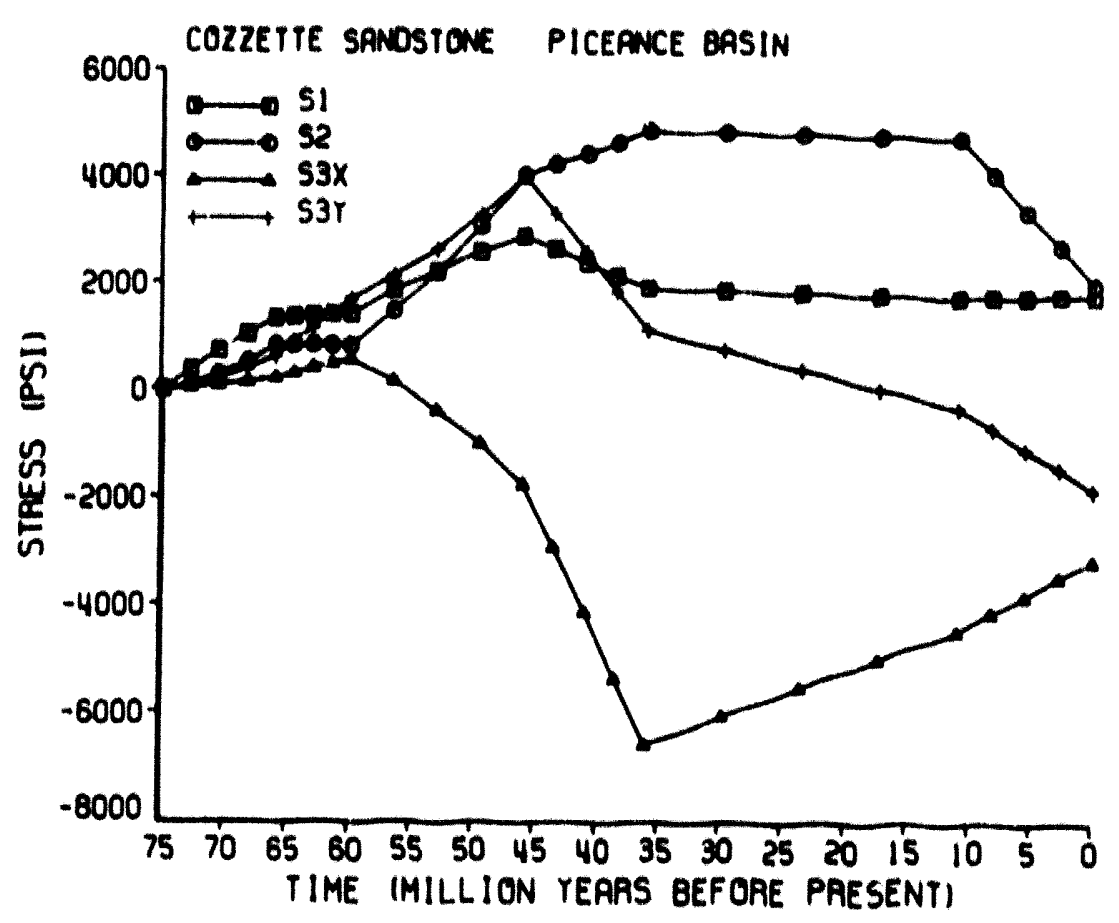

Figure F3. Magnitudes of the different components of the total stress through time: gravity (S1), thermal stress (S2), and the two horizontal tectonic stresses (Si3X and $S_{3} 3 \mathrm{Y}$ ).

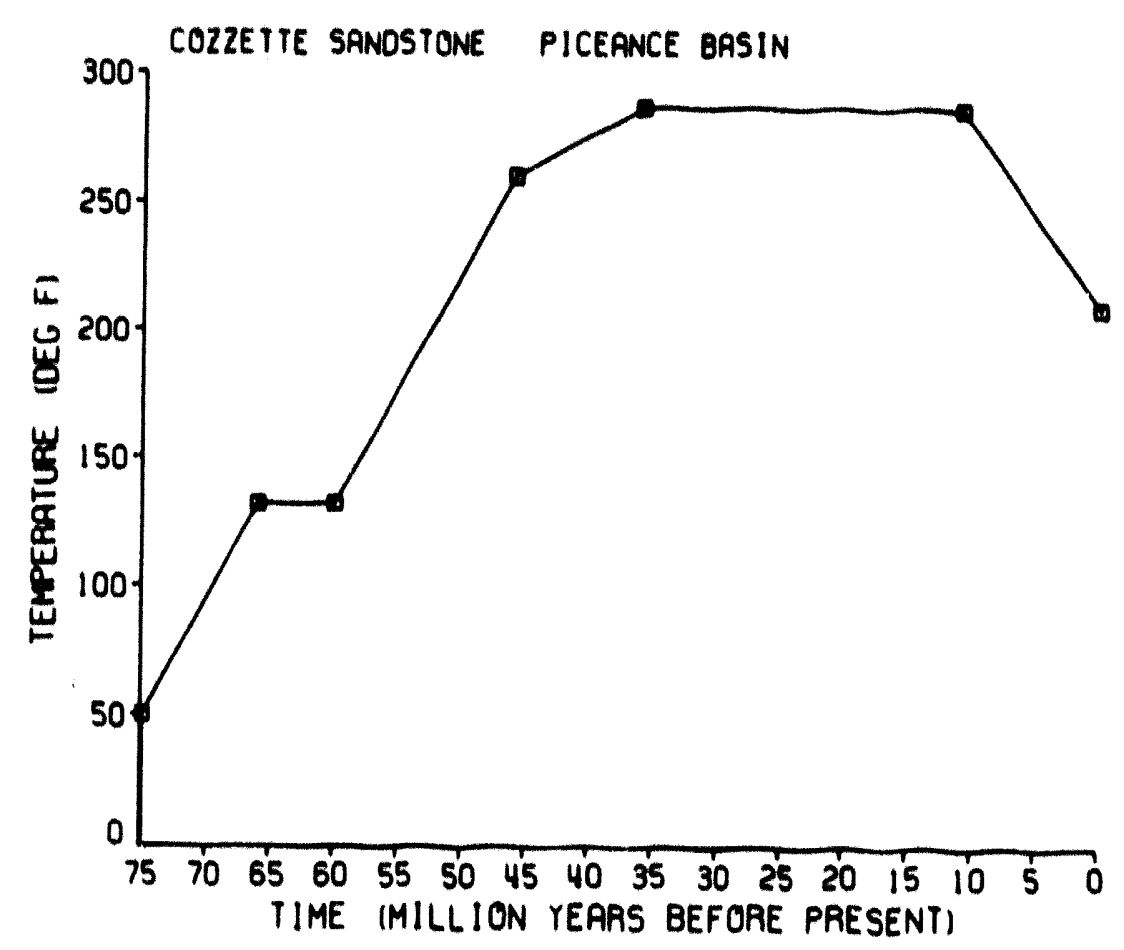

Figure F4. Input values for the temperature through time. 


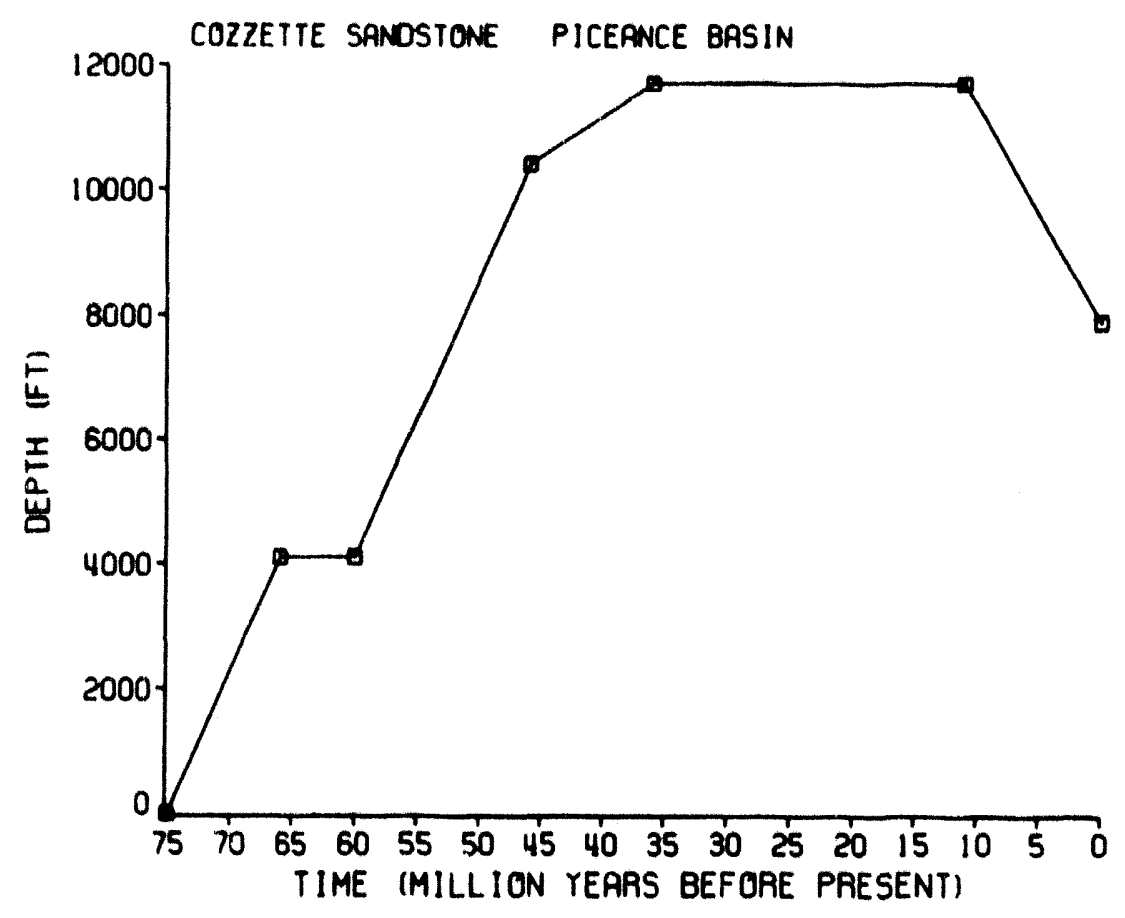

Figure F5. Input values for the depth of burial through time.

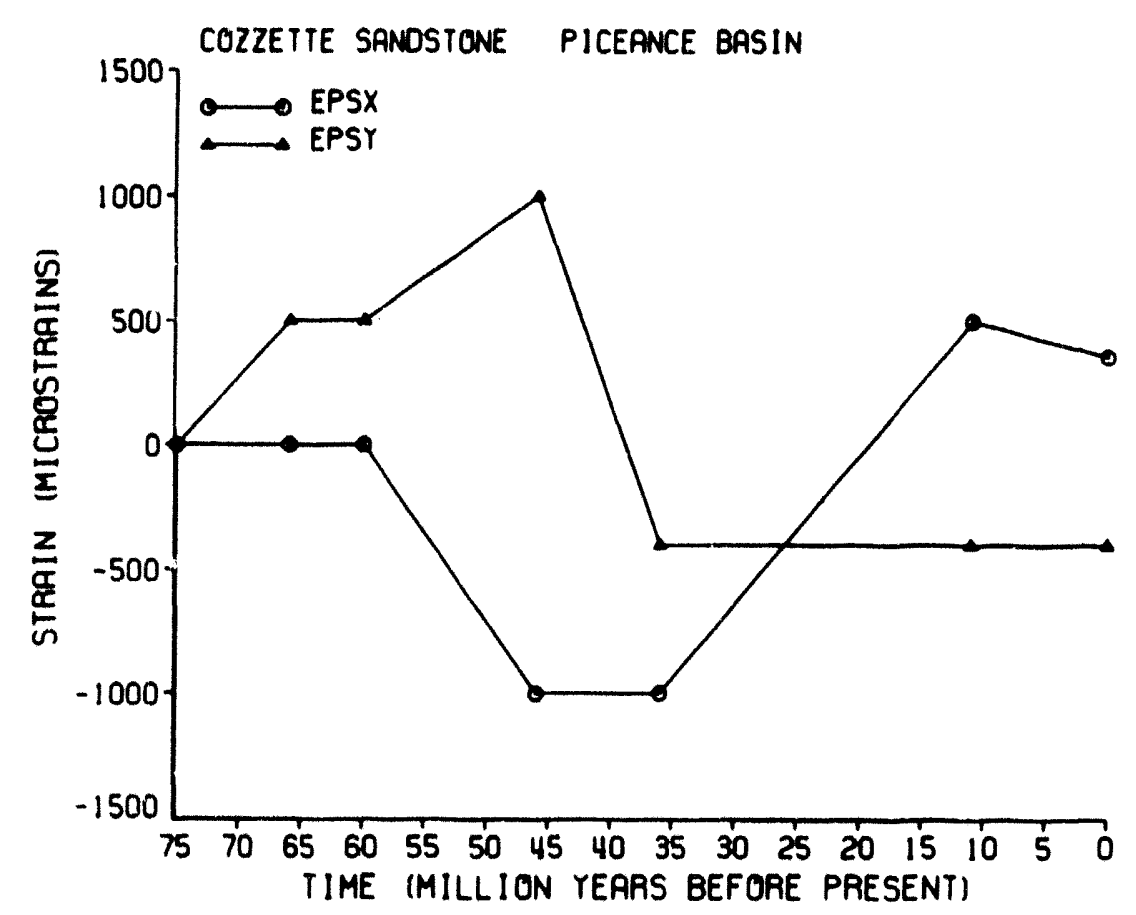

Figure F6. Input parameters for the maximum and minimum tectonic strains (EPSY and EPSX) through time. 


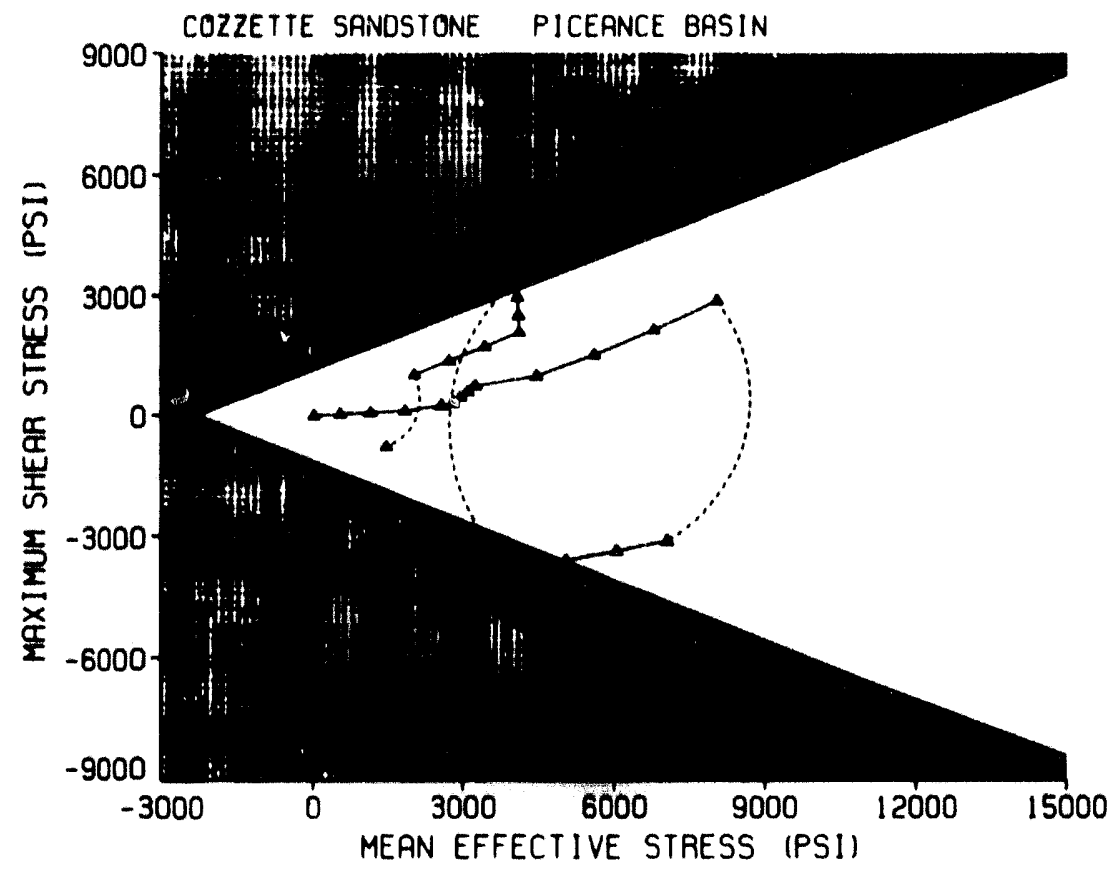

Figure F7. Calculated stress conditions in the Cozzette Sandstone at the MWX site through time, with respect to the limits of laboratory-determined failure (light shading) and the probable failure under true geologic conditions (dark shading) for the rock. The stress condition at the time of deposition 75 million years ago is depicted by the triangle nearest the point of origin of the failure envelope, and the present day stress condition is the triangle at the other end of the circuitous path, just to the lower right of the original triangle. The most likely times of fracturing are the two events depicted by the stresscondition triangles that lie beyond the limits of yielding. (See Warpinski, 1989, for complete details.) 


\section{Reference}

Warpinski, N.R., 1989, Elastic and viscoelastic calculations of stresses in sedimentary basins: SPE Formation Evaluation, v. 4, p. 522-530. 


\section{DIS'TRIBU'TION:}

$7 \quad$ U.S. Department of Energy

Office of Oil and Gas Exploration

and Production

Attn: Donald A. Juckett

H. William Hochheiser

Guido Dehoratiis

George Stosur

Arthur Hartstein

Jim R. White

F.B. Nuckolls

FE-30/Forrestal Building

Washington, D.C. 20585

28

U.S. Department of Energy

Morgantown Energy Technology Center

Attn: Leonard Graham Royal J. Watts (25)

Karl-Heinze Frohne

Charles A. Komar

P() Box 880

Collins Ferry Road

Morgantown, WV 26505

$5 \quad$ U.S. Department of Energy

Bartlesville Project Office

Attn: 'Thomas C. Wesson

Alex B. Crawley

Robert F. Lemmon

Rhonda lindsey

Edith Allison

Bartlesville, OK 74005

1 Neil Hurley

Marathon Oil (o.,

PO Box 269

Littleton, (C) 80160

3) Oryx Energy Co.

Attn: Harold Illich

Howard White

Robert Skopec

PO Box 2880

Dallas, TX

1 Robert B. Hunter

BP Exploration (Alaska)

PO Box 196612

Anchorage, AK 99519-6612
2 Gas Research Institute

Attn: David Hill

Stephen Wolhart

8600 West Bryn Mawr Ave

Chicago, Il. 60631

1 Bruce Cain

Shell Westerns E\&P Inc.

PO Box 567

Houston, TX 77001

$1 \quad$ Wm. W. Peabody

Peabody Ventures

125 Lincoln Ave. $\$ 400$

Santa Fe, NM 87501

1 Stephen H. Leeds

Precision Core Analysis, Inc.

1338 S. Valentia St., Suite 140

Denver, (CO 80231

1 Lee Krystinik

Union Pacific Resources (Co.

PO Box 7

Fort Worth, TX 76101-0007

1 Jay C. Close

Resources Finterprises

360) Wakara Way

Salt lake City, U'T 84lo8

1 Byron Kulander

Wright State Iniversity

Department of Cieology

Dayton, OH 45435

1 Jerry Walker

Sierra Energy (Co.

PO Box 20200

Reno, NV 89520

1 Richard Dayvault

Chem-Nuclear Geotech, Inc.

P() Box 14000

Grand Junction, (CO 815022 
DISTRIBUTION (Continued):

1 Carl Evans

Pennzoil Exploration and Production PO Box 2967

Houston, TX 77252-2967

1 Robbie Gries

1660 Lincoln, Ste 1640

Denver, CO 80203

1 C. Dennis Irwin 220 Cimmaron Way

Boulder, CO 80:303

$4 \quad$ US Geological Survey

Denver Federal Center

Attn: Ben Law, MS 939 Charles SPencer MS 939

Marilyn Grout MS 913

Earl Verbeek MS 913

Denver, CO 80225

1 William Hanson

Amoco Production Co.

PO Box 3092

Houston, TX 77253-5071

1 Stephen Laubach

Bureau of Economic Geology

University Station, Box X

Austin, TX 78713.7508

1 W. Travis Brown

Travis Energy Group

8423 E. Otero Circle

Engleword, CO 80112

1 Ted Campen

Campen Consultants Inc.

7314 Charolais Street

Billings, M'T 59106

1 Donald Dayhuff

Chandler \& Associates, Inc.

770 Lincoln Tower Bldg

1860 Lincoln

Denver, CO 80203
1 W. Jim Eubanks

ARCo international Oil and Gas Co.

PO Box 260888

Plano, TX 75028.0888

1 Robin Hill

CER Corporation

950 Grier Dr

Las Vegas, NV 89119

4 Harvey E. Yates Co.

One Sunwent Centre

Attn: Larry Brooks

Frank Messa

George Yates

A. J. Deans

PO Box 1933

Roswell, NM 88202

1 Jim Peterson

Dept. of Geology

Univ. of Montana

Missoula, M'T 59812

1 Billy Ward, Jr.

1104 E. Dover PI

Broken Arrow, OK 74012

1 Noel Waechter

Waechter and Associates

Lombardi Bldg, Suite 318

1645 Court Place

Denver, CO 80202

1 Jim Minelli

Meridian Oil

5613 D.T.C. Parkway

Englewood, CO 80111

2 Barrett Resources Corp

Attn: Kurt Reinecke

Terry Barrett

112517 th St, Suite 2100

Denver, Co 80202

1 Lee Woodward

Dept of Geology

University of New Mexico

Albuquerque, NM 87131 
DIS'TRIBUTION (Continued):

1 Neil Whitehead

NM Bureau Mines \& Mineral Resources

Socorro, NM 87081

1 Randall Billinggley

Amoco Production Co

PO Box 800

Denver, Co 80201

1 Norman C. Wardlaw

Department of Geology

University of Calgary

2500 University Drive NW

Calgary, Alberta

T2N IN4

CANADA

1 Daniel Clark-Lowes

Scott Pickford plc

256 High Street

Croydon, Surrey

CRO INF

ENGLAND
1 Chris Garrett

Core Laboratories

Wesgeco Houne

PO Box 18, 455 london Road

Isleworth, Middlesex

TW7 5AB

ENGLAND

$\begin{array}{rll}1 & 6100 & \text { R. W. Lynch } \\ 10 & 6112 & \text { D. A. Northrop } \\ 1 & 6114 & \text { M. W. Scott } \\ 5 & 6114 & \text { N. R. Warpinski } \\ 1 & 6117 & \text { W. R. Wawersik } \\ 5 & 6117 & \text { L. W. Toufel } \\ 5 & 6117 & \text { J. C. Lorenz } \\ 1 & 8523-2 & \text { Central Technical Files } \\ 5 & 7141 & \text { Technical Library } \\ 1 & 7151 & \text { Technical Publications } \\ 10 & 7613-2 & \text { Document Processing } \\ & & \text { for DOE/OSTI }\end{array}$



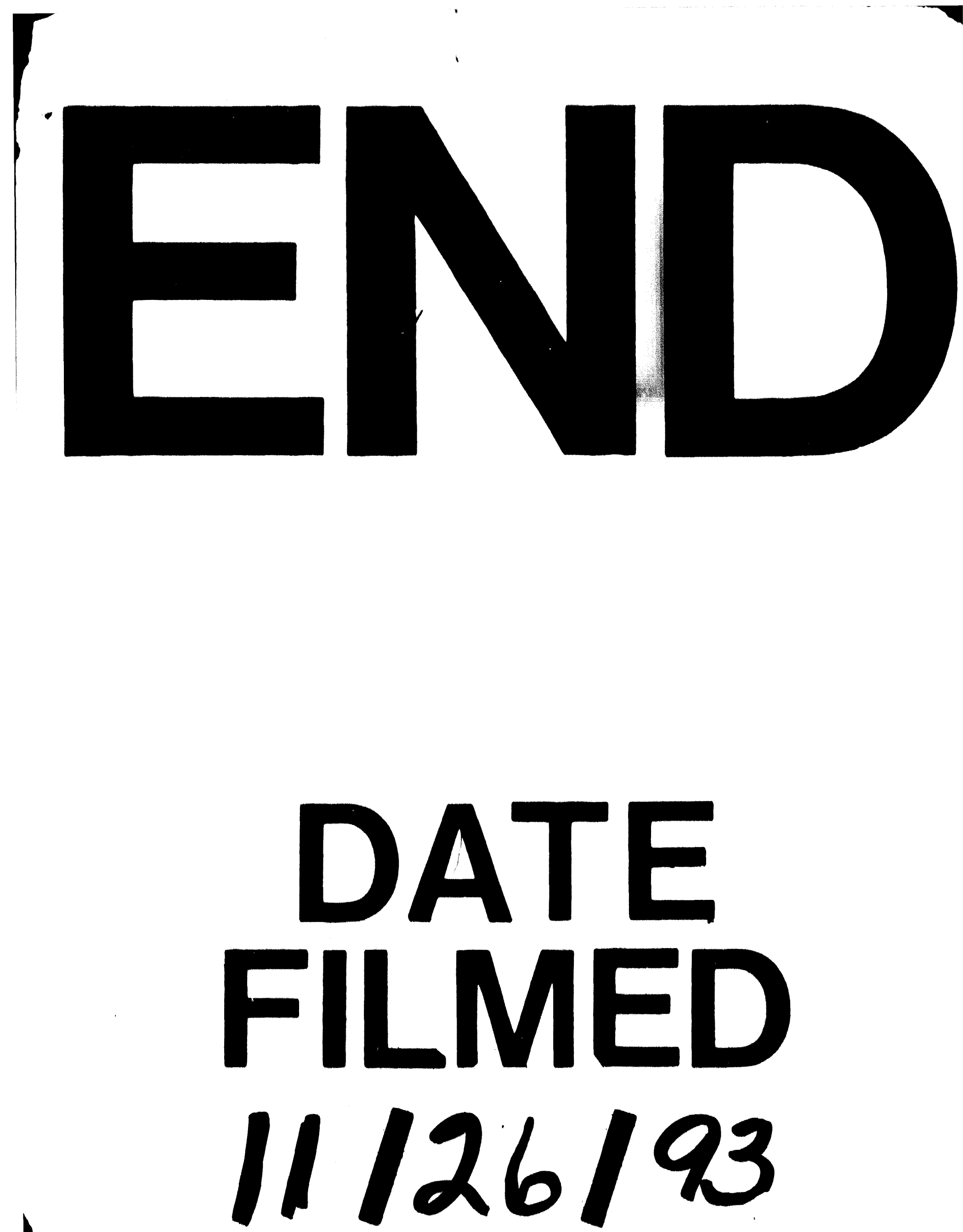
